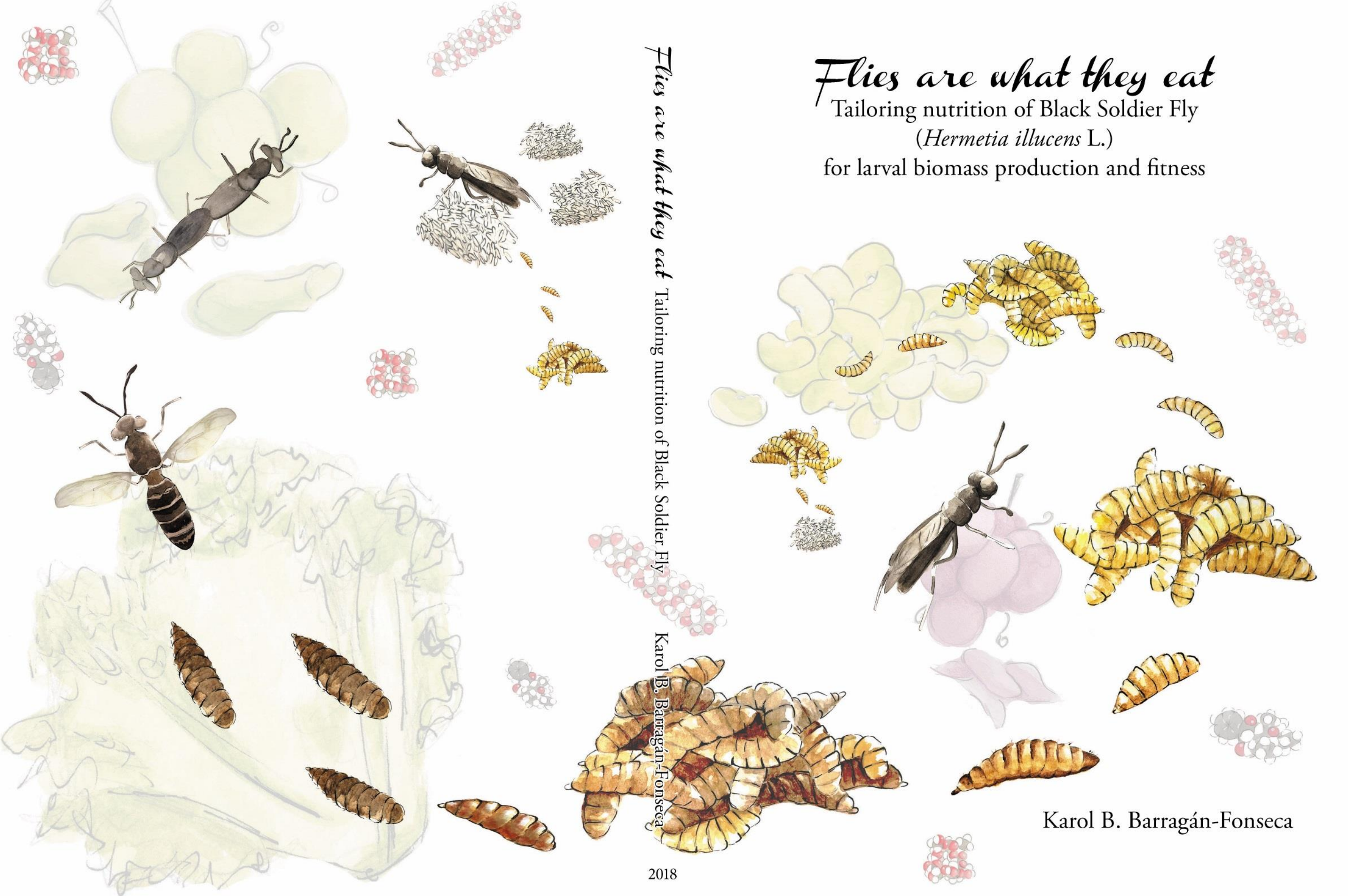




\section{Flies are what they eat Tailoring nutrition of Black Soldier Fly (Hermetia illucens L.) \\ for larval biomass production and fitness}

Karol B. Barragán-Fonseca 


\section{Thesis committee}

\section{Promotors}

Prof. Dr Joop J. A. van Loon

Personal chair at the Laboratory of Entomology

Wageningen University \& Research

Prof. Dr Marcel Dicke

Professor of Entomology

Wageningen University \& Research

\section{Other members}

Prof. Dr W.H. Hendriks, Wageningen University \& Research

Dr H.H.E. van Zanten, Wageningen University \& Research

Dr T. Veldkamp, Wageningen University \& Research

Prof. Dr L.W. Beukeboom, University of Groningen

This research was conducted under the auspices of the C.T. de Wit Graduate School for Production Ecology \& Resource Conservation. 


\title{
Flies are what they eat Tailoring nutrition of Black Soldier Fly (Hermetia illucens L.) for larval biomass production and fitness
}

\author{
Karol B. Barragán-Fonseca
}

\section{Thesis}

submitted in fulfilment of the requirements for the degree of doctor at Wageningen University

by the authority of the Rector Magnificus, Prof. Dr A.P.J. Mol, in the presence of the Thesis Committee appointed by the Academic Board to be defended in public on Monday 25 June 2018 at 11 a.m. in the Aula. 
Karol B. Barragán-Fonseca

Flies are what they eat-Tailoring nutrition of Black Soldier Fly (Hermetia illucens

L.) for larval biomass production and fitness,

160 pages.

$\mathrm{PhD}$ thesis, Wageningen University, Wageningen, the Netherlands (2018)

With references, with summary in English

ISBN: 978-94-6343-293-1

DOI: https://doi.org/10.18174/449739 
To my parents and my larvae: Juli \& Juana 
Abstract 
Black Soldier Fly - BSF; Hermetia illucens L. (Diptera: Stratiomyidae) has been proposed as one of the most suitable insect species to be used as animal feed. Advantages of using BSF that have been identified are their capacity to convert organic waste, to reduce the numbers of certain harmful bacteria and insect pests, to provide potential chemical precursors to produce biodiesel, and to provide high quality protein to be used as feed for a variety of animals. This thesis explores nutritional physiology of BSF and its effect on larval biomass production and fitness. Knowing the physiological mechanisms that BSF employs to deal with different nutrient concentrations, and their impacts on BSF life-history traits and larval body content, may yield valuable insights into the nutritional ecology of BSF. Experiments involving the study of larval densities, total nutrient content, and dietary protein $(\mathrm{P})$ and carbohydrate $(\mathrm{C})$ content and ratio on artificial, semi-artificial and organic residual stream diets were used to unravel their effect on life-history traits, body nutrient content and reproduction of BSF. Results presented in this thesis show that larval density and nutrient content interact at low nutrient content to affect BSF larval performance and body composition, nutrient content overall having a stronger effect. Regarding dietary protein and carbohydrate, I conclude that BSF has post-ingestive mechanisms to deal with imbalanced foods. Carbohydrate-biased P:C ratios positively affect BSF performance, both on the artificial diets and the organic residue stream, P-content being limiting for most of the performance variables. In the experiments throughout this study larval protein content was high and largely independent of dietary protein content, although small differences were found between treatments. However, larval crude fat varied over a wider range depending on dietary macronutrient content, protein content affecting larval crude fat content to a large extent. The data presented in this thesis contribute to our understanding of how nutrition, mainly in terms of protein and carbohydrate content and ratio, affects life-history traits, nutrient body content and reproduction of BSF and how this knowledge can be applied to improve the productive performance and larval body composition in BSF production systems. 



\section{Table of contents}

\section{Chapter 1}

Introduction \& thesis outline

\section{Chapter 2}

Nutritional value of the Black Soldier Fly (Hermetia illucens L.) and its suitability as animal feed - a review

Karol B. Barragan-Fonseca, Marcel Dicke and Joop J. A. van Loon

\section{Chapter 3}

Influence of larval density and dietary nutrient concentration on performance, body protein and fat contents of Black Soldier Fly (Hermetia illucens L.)

Karol B. Barragan-Fonseca, Marcel Dicke \& Joop J. A. van Loon

\section{Chapter 4}

Exploring the effect of dietary protein and carbohydrate on life-history traits and body protein and fat contents of the Black Soldier Fly (Hermetia illucens L.)

Karol B. Barragan-Fonseca, Gerrit Gort, Marcel Dicke \& Joop J. A. van Loon

\section{Chapter 5}

Performance of the Black Soldier Fly, Hermetia illucens L. (Diptera: Stratiomyidae) on vegetable residue-based diets formulated based on protein and carbohydrate contents Karol B. Barragan-Fonseca, Julián Pineda-Mejia, Marcel Dicke \& Joop J. A. van Loon

\section{Chapter 6}

Tipping the balance: effects of protein and carbohydrate contents on life-history traits and larval nutrient content of the Black Soldier Fly (Hermetia illucens L.)

Karol B. Barragan-Fonseca, Gerrit Gort, Marcel Dicke \& Joop J. A. van Loon

\section{Chapter 7}

General Discussion: unravelling BSF nutrition - the way forward

\section{Acknowledgements}

\section{Summary}

\section{Résumé \& publications}

\section{Education statement}





\section{Chapter 1}

\section{Introduction $\&$ thesis outline}

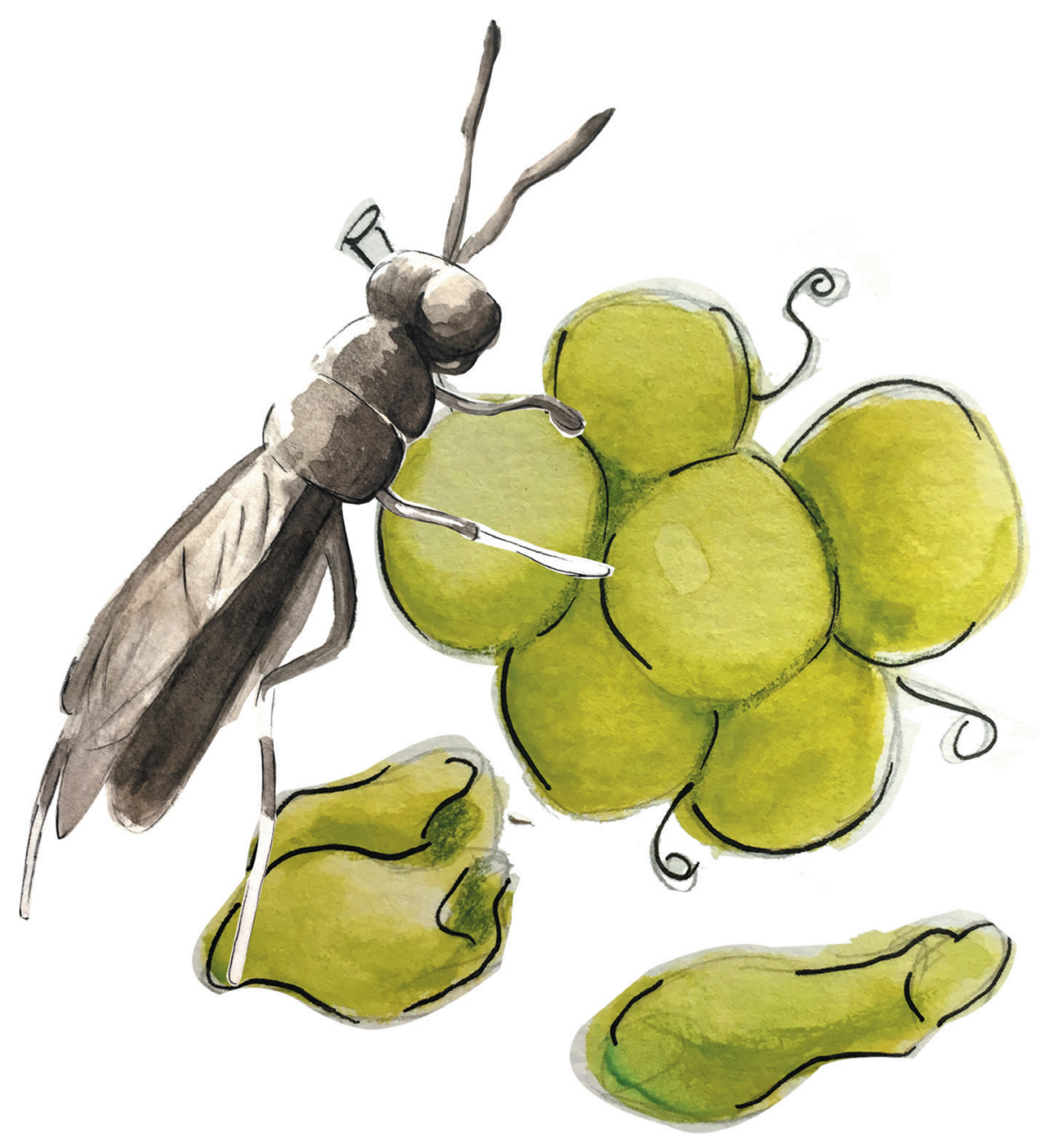



Within the class Insecta a diversity of diets is utilized to acquire nutrients. Approximately $50 \%$ of the 1 million insect species that have been described to date feed on plants, $25 \%$ are carnivorous parasites and predators and among the remaining 25\% are detritivores feeding on decaying organic matter (Gullan \& Cranston, 2010). Insects are poikilothermic organisms that have a variable body temperature that is affected by the temperature of the environment (Gullan \& Cranston, 2010; Oonincx et al., 2010). This is expected to result in both high feed conversion efficiencies and growth rates (van Huis, 2013). Tens of thousands of species in the orders Coleoptera (beetles) and Diptera (flies) are detritivores and fulfil vital roles in nutrient cycling in ecosystems (Dicke, 2017). Over the past decade, interest in mass rearing of a number of detritivorous insect species has steeply increased (Van Huis \& Tomberlin, 2017). The main reason for this interest is that these species can be reared on low-grade bio-waste and convert it into high quality proteins, lipids and other useful products. Examples are Tenebrio molitor (Li et al., 2013), Rhynchophorus spp. (Cerda et al., 2001; Elemo et al., 2011) and Musca domestica (Awoniyi, 2007). These insect species are thereby excellent candidates for low-cost production of animal proteins as a sustainable high quality feedstuff for production animals including poultry, swine and fish (DeFoliart, 1989; Veldkamp et al., 2012).

Traditionally, the mass-rearing of insects focused on the production of beneficial insects, used as biological control agents in crop protection (Van Lenteren, 2003) and on the mass-production of sterile male insects deployed in Sterile Insect Technique (SIT) programs applied in the control of e.g. fruit flies (Enkerlin et al., 2017). Most of the current large insect production businesses focus on predators and parasitoids for biological control (Manzano-Agugliaro et al., 2012). However, insects that can be used as food or feed have excellent potential to be reared under controlled conditions. These animals are called 'minilivestock' (Hardouin, 1995). The challenges facing the 'minilivestock' production sector ask for the development of innovative methods that are suited to the social, environmental and economic needs of regional and local communities.

Over the last decades, scarcity of resources has led to an increase in prices of animal feedstock, which represents $60-70 \%$ of costs of animal production systems (van Huis, 2013). The challenges posed by using insects as feed are many and we have to find species which have favourable characteristics. Black Soldier Fly - BSF; Hermetia illucens L. (Diptera: Stratiomyidae) has been proposed as one of the most suitable insect species to be used as animal feed. Advantages of using BSF that have been identified are their capacity to convert organic waste, to reduce the numbers of certain harmful bacteria and insect pests, to provide potential chemical precursors to produce biodiesel, and to provide high quality protein to be used as feed for a variety of animals, including swine, chickens, and fish (Veldkamp et al., 2012). Accordingly, BSF could be an ideal candidate to provide sustainable high quality and cheap animal-protein-rich feedstuff. 
Most research on the use of BSF as minilivestock has focused on the larval stages and the effect of biotic (Tomberlin et al., 2002; Diener et al., 2009; Parra Paz et al., 2015) and abiotic (Furman et al., 1959; Alvarez, 2012) factors in both tropical and temperate regions. However, scant information is available on how these factors affect the adult stage of BSF, in particular mating success and fitness. Therefore, it is essential to study all fitness-related life-history traits to fully understand the effects of larval food quality on fitness and body composition.

Body composition of the larvae depends on the quality and quantity of ingested food (Nguyen et al., 2015; Oonincx et al., 2015). Larvae fed on different substrates had varying body protein content (ranging from 37.0 to $62.7 \%$ DM) and fat content, which showed more variation (ranging from 6.6 to $39.2 \%$ DM) than protein content (Barragan-Fonseca et al., 2017). This variation suggests that larval dietary nutrient concentration affects larval protein and fat content, and in order to produce insects of a defined quality in terms of both macro- and micronutrients for animal feed, it is important to evaluate how larval nutrient content is regulated and affected by dietary nutrient concentration.

For optimal performance insects need to ingest enough food and to maintain a balanced diet (Prabhu et al., 2008). Insects are able to compensate for an unbalanced diet through both behavioural and physiological mechanisms to obtain an optimal intake of energy and nutrients (Zudaire et al., 1998; Raubenheimer \& Simpson, 2003; Behmer, 2008; Roeder $\&$ Behmer, 2014). Since proteins and carbohydrates are the most important nutrients for insect survival, growth and reproduction (Aguila et al., 2013), the balance between protein and carbohydrate (P:C) provides a fruitful starting point to investigate the regulatory trade-offs in macronutrient intake in insects (Simpson \& Raubenheimer, 1993; Raubenheimer \& Simpson, 1999). Most studies on the optimal balance between proteins and digestible carbohydrates and its effect on insect performance have focused on grasshoppers, cockroaches, aphids, larval Lepidoptera and larval Coleoptera (Simpson et al., 1988; Raubenheimer \& Simpson, 2003; Behmer, 2008; Roeder \& Behmer, 2014).

Nutritional studies on BSF thus far have addressed the effects of diets composed of only partly defined ingredients such as organic waste or industrial by-products on BSF development and adult life-history traits (Barragan-Fonseca et al., 2017). This saprophagous species exploits diverse diets, so larval stages are likely to encounter a wide range of dietary macronutrient ratios. When analyzing food sources on which this species is found in the wild (vegetable waste, manure, etc.), P:C ratios tend to be carbohydrate-biased (1:1.5 - 1:2) and present a wide range of crude protein and digestible carbohydrate contents (40-80\% $\mathrm{DM})$. However, it is unknown how BSF regulates the balance of nutrients ingested and absorbed and how this affects its performance and larval body content. 
Knowing the physiological mechanisms that BSF employs to deal with different nutrient concentrations, and their impacts on BSF life-history traits and larval body content, could yield helpful insights into the nutritional ecology of BSF. This knowledge will allow to increase body mass and/or size of individuals and consequently the continuous production of eggs needed for mass-rearing. This will ensure more dependable yields of BSF-mass rearing and development of economically feasible methods to take advantage of this species as animal feed. Therefore, in this thesis I focus on nutritional physiology of BSF, and address the following main questions: (1) How does larval density and nutrient concentration affect biomass production, larval performance and nutrient body content? (Ch. 3) (2) How do dietary protein and carbohydrate content and ratio affect life-history traits, nutrient body content and reproduction of BSF? (Ch 4 and 6) (3) Can protein and carbohydrate contents and $\mathrm{P}: \mathrm{C}$ ratio be applied to optimize diets composed of different organic residues? (Ch. 5)

Figure 1 summarizes the research undertaken to answer the main research questions.

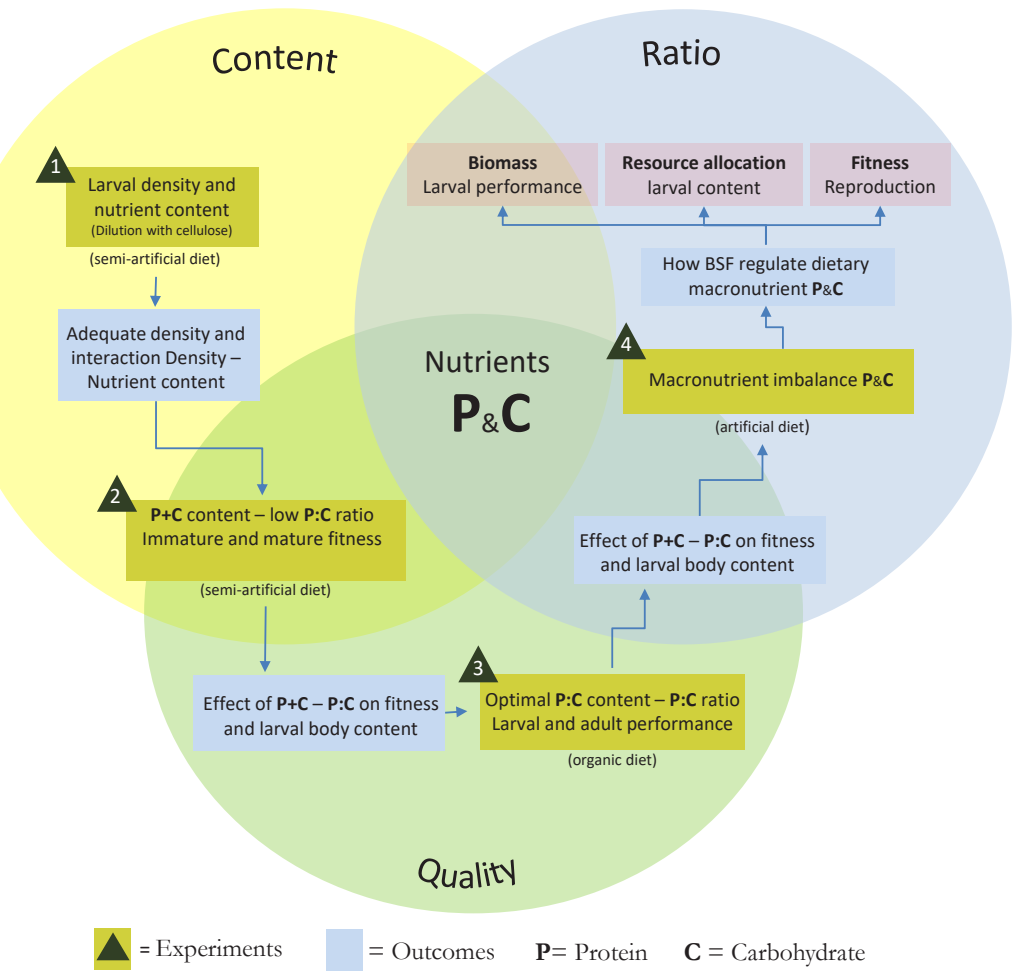

Figure 1. Nutrition of Black Soldier Fly (Hermetia illucens L.): tailoring diet composition for larval biomass production and fitness 


\section{Outline of this thesis}

Chapter 2 provides background information on the nutritional value of BSF larvae, its suitability as animal feed, biotic and abiotic conditions that affect its performance, and identifies which knowledge is required to ensure more dependable yields of BSF-mass rearing and development of economically feasible methods to take advantage of this species as animal feed.

Chapter 3 addresses the effect of dietary nutrient concentration, larval rearing density, and the possible interaction between these two factors on growth characteristics and nutritional content of BSF larvae in terms of crude protein and fat. In this study, BSF larvae were fed with one of three nutrient concentrations, low, intermediate and high, and four rearing densities. Additionally, two feeding regimes were tested and larval yield, larval development time, larval crude protein and crude fat were recorded.

Chapter 4 explores the regulatory trade-offs in macronutrient intake of BSF, and how this affects larval and adult life-history traits of BSF, and larval body content. I investigated the influence of dietary protein $(\mathrm{P})$ and digestible carbohydrate $(\mathrm{C})$ contents and protein to carbohydrate $(\mathrm{P}: \mathrm{C})$ ratio, testing three protein concentrations and three carbohydrate concentrations and their combinations within the range of its natural food sources. In this study, I quantified larval performance, larval body crude protein and fat contents and adult fecundity.

Chapter 5 examines how diets derived from vegetable by-products from the food industry formulated to obtain an average macronutrient content in terms of digestible protein and carbohydrates, and a C-biased carbohydrate ratio influences larval performance of BSF. In this chapter, I also took the ingredients from the best vegetable waste-based diet from the first experiment, and formulated two vegetable waste-based diets differing in total macronutrient content and C-biased carbohydrate ratios, and evaluated their effects on life-history traits of BSF and larval body content in terms of crude protein and fat.

Chapter 6 addresses the question whether and how widely varying macronutrient contents and ratios affect both larval performance and body nutrient composition and adult life history traits of BSF. This chapter not only addresses how larval and adult stages of BSF respond to a broad range of $\mathrm{P}: \mathrm{C}$ ratios at different nutrient concentrations, but also presents useful findings in guiding the formulation of diets in mass-rearing of BSF as minilivestock aimed at obtaining high yields of larval biomass of desired body composition.

In Chapter 7, the findings of this thesis are integrated. I discuss how nutrition influences the larval and adult performance of BSF and how this knowledge can be applied 
to improve the productive performance and larval body composition in BSF production systems. I also emphasize that to ensure stable yields and high larval nutritional quality of BSF-mass rearing a better understanding is required of the complex interactions between quality and quantity of dietary nutrients.

\section{References}

Aguila JR, Hoshizaki DK, Gibbs AG (2013) Contribution of larval nutrition to adult reproduction in Drosophila melanogaster. Journal of Experimental Biology, 216, 399-406.

Alvarez L (2012) The role of black soldier fly, Hermetia illucens (L.) (Diptera: Stratiomyidae) in sustainable waste management in northern climates. Electronic Theses and Dissertations. University of Windsor, Ontario, Canada.

Awoniyi T (2007) Health, nutritional and consumers' acceptability assurance of maggot meal inclusion in livestock diet: a review. International Journal of Tropical Medicine, 2, 52-56.

Barragan-Fonseca KB, Dicke M, Van Loon JJA (2017) Nutritional value of the black soldier fly (Hermetia illucens L.) and its suitability as animal feed - a review. Journal of Insects as Food and Feed, 3, $105-120$.

Behmer ST (2008) Insect herbivore nutrient regulation. Annual Review of Entomology, 54, 165-187.

Cerda H, Martinez R, Briceno N, Pizzoferrato L, Manzi P, Ponzetta MT, et al. (2001) Palm worm: (Rhynchophorous palmarum) traditional food in Amazonas, Venezuela - nutritional composition, small scale production and tourist palatibility. Ecology of Food and Nutrition, 40, 13-32.

Defoliart GR (1989) The human use of insects as food and as animal feed. Bulletin of the Entomological Society of America, 35, 22-35.

Dicke M (2017) Ecosystem services of insects. In: van Huis, A. \& Tomberlin, J (eds) Insects as food and feed - From production to consumption. Pp61-76. Wageningen Academic Publishers, The Netherlands.

Diener S, Zurbrügg C, Tockner K (2009) Conversion of organic material by black soldier fly larvae: establishing optimal feeding rates. Waste Management \& Research, 27, 603-610.

Elemo BO, Elemo GN, Makinde M, Erukainure OL (2011) Chemical evaluation of African palm weevil, Rhychophorus phoenicis, larvae as a food source. Journal of Insect Science, 11, 1-6.

Furman DP, Young RD, Catts PE (1959) Hermetia illucens (Linnaeus) as a factor in the natural control of Musca domestica Linnaeus. Journal of Economic Entomology, 52, 917-921.

Gullan PJ, Cranston PS (2010) The Insects: an outline of entomology, Wiley-Blackwell.

Hardouin J (1995) Minilivestock - from gathering to controlled production. Biodiversity and Conservation, 4, 220-232.

Li L, Zhao Z, Liu H (2013) Feasibility of feeding yellow mealworm (Tenebrio molitor L.) in bioregenerative life support systems as a source of animal protein for humans. Acta Astronautica, 92, 103-109.

Manzano-Agugliaro F, Sanchez-Muros M, Barroso F, Martínez-Sánchez A, Rojo S, Pérez-Bañón C (2012) Insects for biodiesel production. Renewable and Sustainable Energy Reviews, 16, 3744-3753.

Nguyen TT, Tomberlin JK, Vanlaerhoven S (2015) Ability of black soldier fly (Diptera: Stratiomyidae) larvae to recycle food waste. Environmental Entomology, 44, 406-410.

Oonincx D, Van Huis A, Van Loon JJA (2015) Nutrient utilisation by black soldier flies fed with chicken, pig, or cow manure. Journal of Insects as Food and Feed, 1, 131-139.

Oonincx DGAB, Van Itterbeeck J, Heetkamp MJW, Van Den Brand H, Van Loon JJA, Van Huis A (2010) An exploration on greenhouse gas and ammonia production by insect species suitable for animal or human consumption. PloS ONE, 5, e14445.

Parra Paz AS, Carrejo NS, Gómez Rodríguez CH (2015) Effects of larval density and feeding rates on the bioconversion of vegetable waste using black soldier fly larvae Hermetia illucens (L.), (Diptera: Stratiomyidae). Waste and Biomass Valorization, 6, 1059-1065.

Prabhu V, Perez-Staples D, Taylor P (2008) Protein: carbohydrate ratios promoting sexual activity and longevity of male Queensland fruit flies. Journal of Applied Entomology, 132, 575-582. 
Raubenheimer D, Simpson SJ (1999) Integrating nutrition: A geometrical approach. Entomologia Experimentalis et Applicata, 91, 67-82.

Raubenheimer D, Simpson SJ (2003) Nutrient balancing in grasshoppers: Behavioural and physiological correlates of dietary breadth. The journal of Experimental Biology, 206, 1669-1681.

Roeder KA, Behmer ST (2014) Lifetime consequences of food protein-carbohydrate content for an insect herbivore. Functional Ecology, 28, 1135-1143.

Simpson S, Raubenheimer D (1993) A multi-level analysis of feeding behaviour: the geometry of nutritional decisions. Philosophical Transactions of The Royal Society of London: Biological Sciences, 342, 381-402.

Simpson SJ, Simmonds MSJ, Blaney WM (1988) A comparison of dietary selection behaviour in larval Locusta migratoria and Spodoptera littoralis. Physiological Entomology, 13, 225-238.

Tomberlin JK, Sheppard DC, Joyce JA (2002) Selected life-history traits of black soldier flies (Diptera: Stratiomyidae) reared on three artificial diets. Annals of the Entomological Society of America 95, 379-386.

Van Huis A (2013) Potential of insects as food and feed in assuring food security. Annual Review of Entomology, 58, 563-583.

Van Huis A, Tomberlin JK (2017) Insects as food and feed - From production to consumption, Wageningen Academic Publishers, The Netherlands.

Van Lenteren JC (2003) Quality control and production of biological control agents: theory and testing procedures, CABI Publ. , Wallingford, UK.

Veldkamp T, Van Duinkerken G, Van Huis A, Lakemond CMM, Ottevanger E, Van Boekel MAJS (2012) Insects as a sustainable feed ingredient in pig and poultry diets - a feasibility study, Wageningen UR Livestock Research, Report 638, The Netherlands.

Zudaire E, Simpson SJ, Montuenga LM (1998) Effects of food nutrient content, insect age and stage in the feeding cycle on the FMRFamide immunoreactivity of diffuse endocrine cells in the locust gut. Journal of Experimental Biology, 201, 2971-2979. 


\section{Chapter 2}

Nutritional value of the Black Soldier Fly (Hermetia illucens L.) and its suitability as animal feed - a review

Karol B. Barragan-Fonseca, Marcel Dicke and Joop J. A. van Loon

Published in Journal of Insects as Food and Feed, 2017; 3(2): 105-120

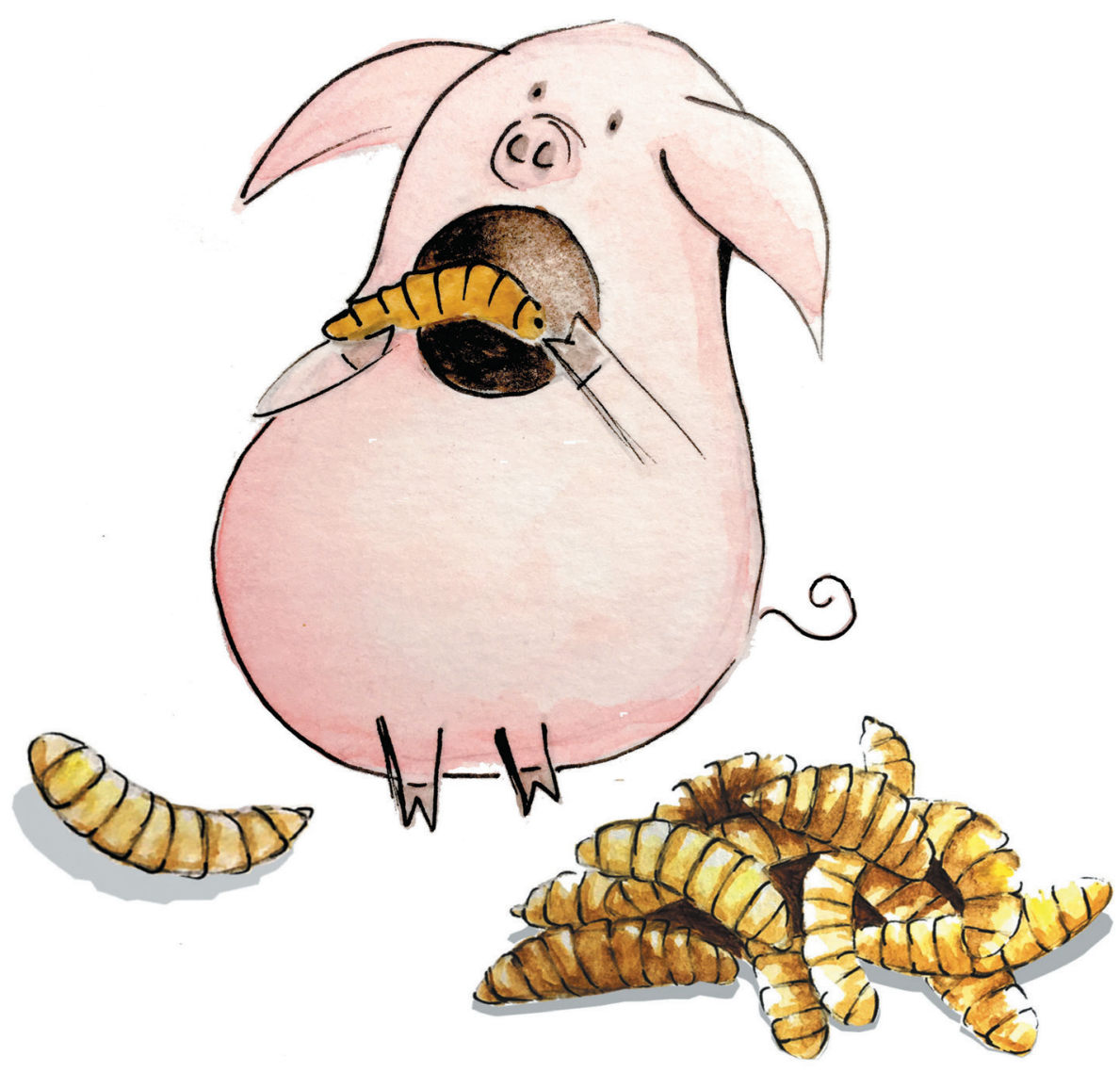




\begin{abstract}
The Black Soldier Fly [BSF; Hermetia illucens L. (Diptera: Stratiomyidae)] has been studied for its capability to convert organic waste to high quality protein, control certain harmful bacteria and insect pests, provide potential chemical precursors to produce biodiesel and for its use as feed for a variety of animals. Nutritional value of BSF larvae is discussed, as well as the effect of biotic and abiotic factors on both larval body composition and performance. Although BSF larvae contain high protein levels (from 37 to 63\% DM), and other macro- and micronutrients important for animal feed, the available studies on including BSF larvae in feed rations for poultry, pigs and fish suggest that it could only partially replace traditional feedstuff, because high or complete replacement resulted in reduced performance. This is due to factors such as high fat content (from 7 to 39\% DM), ash (from 9 to 28\% DM), and consequences of processing. Therefore, further studies are needed on nutrient composition, digestibility and availability for target species and on improved methods to process larvae, among other aspects. Additionally, it is clear that factors including quantity and quality of food, temperature, substrate moisture and/or larval crowding can affect BSF performance. However, the biology of BSF, in particular of the adult stage, has not been studied in detail. This review provides background information on the nutritional value of BSF larvae, its suitability as animal feed, biotic and abiotic conditions that affect its performance, and identifies which knowledge is required to ensure more dependable yields of BSF-mass rearing and development of economically feasible methods to take advantage of this species as animal feed.
\end{abstract}

Key words Black Soldier fly, Hermetia illucens, animal feed, nutritional value. 


\section{Introduction}

The demand for animal-derived protein sources will increase due to the combined effects of the growing human population and rising living standards in developing countries (FAO, 2009). Scarcity of resources has increased prices of animal feedstock during the last years, which represents $60-70 \%$ of production costs of animal production systems and results in competition between human food and animal feed. For instance, use of ingredients like fishmeal, fish oil, soybean meal and grains is on the rise in both human food and animal feed (van Huis, 2013). Insects are proteinaceous (Bosch et al., 2014) and have high feed conversion efficiencies and growth rates (van Huis, 2013), making them a high quality and potentially profitable feedstuff for production animals (Veldkamp et al., 2012, DeFoliart, 1989).

The animal production industry is faced with the challenge to develop innovative methods that are suited to meet future social, environmental and economic needs. Insects that can be sustainably reared on organic side streams could offer a suitable alternative animal protein source (Smetana et al., 2016). There are various species of Coleoptera and Diptera that can be reared on low-grade bio-waste and convert it into high quality proteins. Examples are the beetles Tenebrio molitor Linnaeus, 1758 (Coleoptera: Tenebrionidae) (Li et al., 2013) and Rhynchophorus spp. Herbst, 1795 (Coleoptera: Curculionidae) (Cerda et al., 2001; Elemo et al., 2011), and the flies Musca domestica Linnaeus, 1758 (Diptera: Muscidae) (Calvert et al., 1969; Awomyi, 2007) and Hermetia illucens Linnaeus, 1758 (Diptera: Stratiomyidae) (Newton et al., 2005).

The Black Soldier Fly - BSF (Hermetia illucens) is native to the Americas and is widespread from Argentina to central USA, throughout tropical and temperate regions (Sheppard $e t$ al., 1994). Transported by humans, BSF has established in Australia, India, Africa and Europe (Martínez-Sánchez et al., 2011; Gujarathi \& Pejaver, 2013), because BSF can tolerate a broad range of environmental conditions (light, temperature, humidity).

For use as animal feed, BSF has several major advantages over other insect species. The species is polyphagous and its gut extracts have high amylase, lipase and protease activities (Kim et al., 2011). Thus, it is employed in sustainable recycling of animal waste (Sheppard et al., 1994; Nguyen et al., 2013), faeces (Diener et al., 2009; Lalander et al., 2013), and other type of organic waste (Rachmawati et al., 2010; Diener et al., 2011; Green \& Popa, 2012; Gujarathi \& Pejaver, 2013; Kalová \& Borkovcová, 2013; Nguyen et al., 2013), turning bio-waste into a high quality nutrient source for animal feed (Veldkamp et al., 2012). As a result, BSF has been used as feed for a variety of animals, including swine, poultry, and fish, and is being explored as an important ingredient for pet food. 
Moreover, BSF is not a pest, so its rearing requires no specific precautionary measures and it reduces the presence of harmful bacteria (Liu et al., 2008) in contrast to other dipteran species such as the house fly $M$. domestica. The list of "services" that have been developed includes the conversion of liquid manure and other domestic and agro-industrial waste types into a source of animal proteins (Caruso et al., 2014). Because of the valuable nutrient content of the BSF larvae, they can be employed as the basis of a highly promising technology to sustain a circular economy, which is the concept of an economy that is producing no waste and reducing consumption of raw materials and energy by improving their utilization, based on the interrelationships between the environment and economics. This concept will contribute to remediating the expected future scarcity of sufficient, nutritious and healthy food.

The present review aims to summarise the published information on the nutritional value of BSF larvae as animal feed. The review also discusses the biological aspects important to develop a BSF production system, as 'minilivestock' (Hardouin, 1995), and identifies knowledge gaps that require future research on this species.

\section{Nutritional value of BSF larvae}

\section{Body composition}

Body composition of BSF larvae varies among substrates not only in protein content (ranging from 37 to $63 \% \mathrm{DM}$ ) but also fat content, which has the most variation (ranging from 7 to 39\% DM). Although BSF larvae on average contain both a high protein and fat content (Zheng et al., 2012), body composition of the larvae depends on the quality and quantity of food ingested (Nguyen et al., 2015). For instance, larvae fed swine manure have higher protein content than those fed cow manure (St-Hilaire et al., 2007b), and diets based on spent grains result in higher protein content (Oonincx et al., 2015b). The same applies for crude fat. Fat content accounted for about $30 \%$ of the BSF larval biomass fed on manures, but chicken manure supported maximal larval growth and crude fat content (Li et al., 2011a) (Table 1). Nguyen et al. (2015) found that larvae fed fish and liver contained more protein and fat than those fed chicken feed. Large variation in body composition can also exist throughout the course of larval development itself. For example, crude protein content decreases with increasing age, the highest percentage was reported for larvae of 5 days old (61\%), while it was less in $15(44 \%)$ and $20(42 \%)$ days old larvae (Rachmawati et al., 2010). 
Table 1. Content of crude protein (CP) and crude fat (CF) of BSF larvae reared on different substrates

\begin{tabular}{|c|c|c|c|c|c|}
\hline Substrate & $\% \mathrm{CP}^{1}$ & n & $\% \mathrm{CF}^{1}$ & $\mathbf{n}$ & References \\
\hline Cattle manure & 42.1 & 1 & $34.8 ; 29.9$ & 2 & Newton et al. (1977); Li et al. (2011a) \\
\hline Chicken manure & $40.1 \pm 2.5$ & 3 & $27.9 \pm 8.3$ & 3 & $\begin{array}{l}\text { Sheppard et al. (1994); Arango Gutiérrez et al. } \\
\text { (2004); Li et al. (2011a) }\end{array}$ \\
\hline Swine manure & $43.6 ; 43.2$ & 2 & $26.4 \pm 7.6$ & 4 & $\begin{array}{l}\text { Newton et al. (2005b); St-Hilaire et al. (2007b); } \\
\text { (Li et al., 2011a, Manzano-Agugliaro et al., 2012) }\end{array}$ \\
\hline Palm kernel meal & $42.1 ; 45.8$ & 2 & 27.5 & 1 & Rachmawati et al. (2010) \\
\hline Restaurant waste & - & & 39.2 & 1 & Zheng et al. (2012) \\
\hline Chicken feed & $47.9 \pm 7.1$ & 3 & $14.6 \pm 4.4$ & 3 & $\begin{array}{l}\text { Bosch et al. (2014); Nguyen et al. (2015); Oonincx } \\
\text { et al. (2015a) }\end{array}$ \\
\hline By-products ${ }^{2}$ & $41.7 \pm 3.8$ & 4 & - & & Oonincx et al. (2015a) \\
\hline Liver & 62.7 & 1 & 25.1 & 1 & Nguyen et al. $(2015)^{3}$ \\
\hline Fruits and vegetables & 38.5 & 1 & 6.63 & 1 & Nguyen et al. $(2015)^{3}$ \\
\hline Fish & 57.9 & 1 & 34.6 & 1 & Nguyen et al. $(2015)^{3}$ \\
\hline
\end{tabular}

${ }^{1}$ All values expressed on a dry matter basis. Values are mean \pm standard deviation; ( $\mathrm{n}$ ) gives the number of replicates. If $\mathrm{n}=2$, individual values are stated, separated by a semicolon.

${ }^{2}$ Beet molasses, potato steam peelings, spent grains and beer yeast, bread and cookie remains.

${ }^{3}$ Original values on a fresh matter basis have been converted to dry matter basis using the water content reported.

Dry matter content of fresh larvae is between 20\% and 44\% (Nguyen et al., 2015; Oonincx et al., 2015a), and depends on both diet and larval stage (Rachmawati et al., 2010), because DM is higher in the later instars.

\section{Amino acid content}

Amino acid content of dried BSF larvae does not differ much between studies (Table 2), it appears that contents of some amino acids change in relation to larval diet, amino acid content showing a tendency to be slightly higher in larvae fed cattle manure (St-Hilaire et al., 2007b), than in larvae fed either swine manure (Newton et al., 2005) or chicken manure (Arango Gutiérrez, 2005). The amino acid profile shows that BSF larval protein is particularly rich in lysine (6-8\% of protein content) (Sheppard et al., 2008), and compares favorably with published values for animal feed (Newton et al., 1977). For example, essential amino acid levels in larvae produced on swine manure are similar to soybean meal in lysine, leucine, phenylalanine, and threonine (Newton et al., 2005). When comparing BSF larvae and soy meal values (based on $\mathrm{g} / 16 \mathrm{~g} \mathrm{~N}$ ), larvae contain higher contents of alanine, methionine, histidine, and tryptophan, and a lower content of arginine than soybean meal. 
Table 2. Amino acid content (\%DM and g/16 g Nitrogen*) of BSF larvae fed swine, cattle or chicken manure and soy meal

\begin{tabular}{|c|c|c|c|c|c|c|}
\hline Amino acid & Swine & Swine & Cattle & Chicken & BSF larvae* & Soy meal* \\
\hline Alanine & 3.02 & 2.55 & 3.7 & 2.3 & 7.7 & 4.48 \\
\hline Arginine & 2.65 & 1.77 & 2.2 & 2.12 & 5.6 & 7.48 \\
\hline Aspartic acid & 3.72 & 3.04 & 4.6 & 1.36 & 11.0 & 12.1 \\
\hline Cystine & - & 0.31 & 0.1 & 0.32 & 0.1 & 1.2 \\
\hline Glycine & 2.28 & 2.07 & 2.9 & 2.31 & - & 4.25 \\
\hline Glutamic acid & 3.78 & 3.99 & 3.8 & 2.75 & 10.9 & 19.3 \\
\hline Histidine & 1.18 & 0.96 & 1.9 & 1.16 & 3.0 & 2.53 \\
\hline Isoleucine & 2.03 & 1.51 & 2.00 & 1.55 & 5.1 & 5.04 \\
\hline Leucine & 3.1 & 2.61 & 3.5 & 2.6 & 7.9 & 8.04 \\
\hline Lysine & 2.62 & 2.21 & 3.4 & 2.14 & 6.6 & 6.39 \\
\hline Methionine & 0.74 & 0.83 & 0.9 & 0.78 & 2.1 & 1.17 \\
\hline Phenylalanine & 2.00 & 1.49 & 2.2 & 1.53 & 5.2 & 5.05 \\
\hline Proline & 2.39 & 2.12 & 3.3 & 2.27 & 6.6 & 5.51 \\
\hline Serine & 1.68 & 1.47 & 0.1 & 2.8 & 3.1 & 4.85 \\
\hline Threonine & 1.78 & 1.41 & 0.6 & 1.87 & 3.7 & 3.93 \\
\hline Tryptophan & - & 0.59 & 0.2 & 0.63 & 0.5 & - \\
\hline Tyrosine & 3.08 & 2.38 & 2.5 & 2.62 & 6.9 & 3.64 \\
\hline
\end{tabular}

Data from Newton et al. (1977); Arango Gutiérrez (2005); Newton et al. (2005b); Makkar et al. (2014).

\section{Fatty acid content}

BSF larvae and prepupae have been found to contain $58-72 \%$ saturated fatty acids (SAFA) and 19 - 40\% mono- and poly-unsaturated fatty acids (MUFA and PUFA) of total fat content (Makkar et al., 2014; Surendra et al., 2016), containing high levels of lauric, palmitic and oleic acid (Surendra et al., 2016). It seems that the fatty acid (FA) profile of larvae and prepupae depends on the FA composition of the diet (Table 3). For instance, BSF prepupae may incorporate some $\omega$-3 FA, like $\bigotimes$-linolenic acid or eicosapentaenoic acid, when these occur in their diet (Sealey et al., 2011). Oonincx et al. (2015a) found that higher dietary fat content resulted in a larger proportion of FA being metabolized to lauric acid, suggesting limited possibilities to adapt the FA profile of BSF larvae. Although diet has been suggested to exert strong influences on FA profiles, development and enzymology of fatty acid biosynthesis should also be taken into account to explain overall FA composition (Stanley-Samuelson et al., 1988). 
Table 3. Fatty acid content (\% of total fatty acids) of BSF larvae fed different substrates

\begin{tabular}{|c|c|c|c|c|c|c|c|}
\hline Fatty acid & $\begin{array}{c}\text { Cattle } \\
\text { manure } \\
(\mathrm{CM}) \\
\mathbf{n}=\mathbf{3}\end{array}$ & $\begin{array}{c}\text { Chicken } \\
\text { feed } \\
n=2\end{array}$ & $\begin{array}{c}\begin{array}{c}\text { CM+Fish } \\
\text { offal }\end{array} \\
n=2\end{array}$ & $\begin{array}{c}\text { By- } \\
\text { products } \\
\text { (High fat) } \\
n=2\end{array}$ & $\begin{array}{c}\text { By- } \\
\text { products } \\
\text { (Low fat) } \\
n=2\end{array}$ & $\begin{array}{c}\begin{array}{c}\text { Swine } \\
\text { manure }\end{array} \\
n=1\end{array}$ & $\begin{array}{c}\text { Restaurant } \\
\text { waste } \\
\text { n }=1\end{array}$ \\
\hline Capric acid & 3.1 & 0.9 & - & $0.7 ; 0.8$ & $0.3 ; 1.2$ & - & 1.8 \\
\hline Lauric acid & $26.7 \pm 7.8$ & $47 ; 46.6$ & $34.1 ; 37.1$ & $28.9 ; 38.4$ & $48.4 ; 50.7$ & 49.3 & 23.4 \\
\hline Myristic acid & $3.9 \pm 1.6$ & $6.5 ; 9.2$ & $6.3 ; 6.5$ & $7.4 ; 7.8$ & $9.9 ; 9.5$ & 6.8 & - \\
\hline Palmitic acid & $16.9 \pm 2.6$ & $15 ; 12.7$ & $14.3 ; 17.3$ & $14.4 ; 17$ & $11.6 ; 11.8$ & 10.5 & 18.2 \\
\hline Palmitoleic acid & $5.1 \pm 1.8$ & 3.4 & 7.6 & $2.9 ; 3.4$ & $4.7 ; 6.6$ & 3.5 & 9.4 \\
\hline Stearic acid & $5.3 \pm 1.5$ & $2.2 ; 2.1$ & $2 ; 2.4$ & $2.4 ; 2.8$ & $1.8 ; 2$ & 2.8 & 5.1 \\
\hline Oleic acid & $26.1 \pm 5.2$ & $10.2 ; 14$ & $16.5 ; 18.8$ & $15.9 ; 18.1$ & $10.3 ; 10.8$ & 11.8 & 27.1 \\
\hline Linolenic acid & $4.5 \pm 2.4$ & 9.4 & $3.9 ; 5.9$ & $8.3 ; 17.1$ & $3.6 ; 6$ & 3.7 & 7.5 \\
\hline$\alpha$-Linolenic acid & 0.2 & $0.6 ; 0.8$ & $0.5 ; 0.7$ & $0.8 ; 1.5$ & $0.6 ; 1$ & 0.1 & - \\
\hline Stearidonic acid & - & - & 0.5 & - & - & - & - \\
\hline Arachidonic acid & 0.04 & 0.1 & 0.2 & $0.1 ; 0.2$ & $0.1 ; 0.6$ & - & - \\
\hline Eicosapenta-enoic acid & $0.07 \pm 0.1$ & - & $1.8 ; 3.5$ & - & - & - & - \\
\hline Docosapenta-enoic acid & 0.01 & 0.1 & $0.1 ; 0.4$ & - & - & - & - \\
\hline Docosahexa-enoic acid & 0.06 & 0.1 & $0.4 ; 1.7$ & - & - & - & - \\
\hline
\end{tabular}

Data taken from St-Hilaire et al. (2007a); Li et al. (2011a); Sealey et al. (2011); Kroeckel et al. (2012); Zheng et al. (2012); Oonincx et al. (2015a). Values are mean \pm standard deviation. $\mathrm{n}$ gives the number of replicates. If $\mathrm{n}=2$, individual values are stated, separated by a semicolon.

\section{Mineral content}

BSF larvae contain higher mineral concentrations compared to other insects used in managed feeding programs (Dierenfeld \& King, 2008). Manganese (Mn), iron (Fe), zinc ( $\mathrm{Zn}$ ), copper $(\mathrm{Cu})$, phosphorus $(\mathrm{P})$ and calcium $(\mathrm{Ca})$ are found in high concentrations, with the highest Ca:P ratio reported being 8.4 (Makkar et al., 2014). Sodium (Na) occurs in a lower concentration compared to the levels in other insects (Dierenfeld \& King, 2008). Newton et al. (2005) found differences in mineral contents in BSF larvae reared on poultry or swine manure, possibly reflecting differences in mineral concentrations or availability between the two manure types (Table 4). For instance, P content was significantly higher in BSF reared on poultry manure. Ash content is relatively high and ranges between 9 and 28\% DM (Makkar et al., 2014). All authors report a high Ca content in BSF larvae, which might be partly explained by the fact that the epidermis of BSF secretes a deposit of calcium carbonate $\left(\mathrm{CaCO}_{3}\right)$ which may account for the high $\mathrm{Ca}$ and ash content (Johannsen (1922) in Newton et al. (1977)). Conversely, newly emerged adults contain very little Ca $(0.03 \%)$ since Ca occurs concentrated in the shed pupal cuticle (Finke, 2013). 
Table 4. Mineral content (\%DM) of BSF larvae fed different substrates

\begin{tabular}{ccccc}
\hline Mineral & $\begin{array}{c}\text { Poultry } \\
\text { manure }\end{array}$ & $\begin{array}{c}\text { Swine } \\
\text { manure }\end{array}$ & Chicken feed & Unknown \\
\hline Calcium & $5 ; 7.8$ & 5.36 & 3.14 & 2.41 \\
Phosphorus & $0.7 ; 1.5$ & 0.88 & 1.28 & 0.91 \\
Magnesium & $0.37 ; 0.39$ & 0.44 & 0.79 & 0.45 \\
Sodium & 0.15 & 0.13 & 0.27 & 0.23 \\
Potassium & $0.6 ; 0.7$ & 1.16 & 1.96 & 1.17 \\
Iron & $0.01 ; 0.14$ & 0.08 & 0.04 & 0.02 \\
Zinc & $0.01 ; 0.013$ & 0.03 & 0.02 & 0.01 \\
Copper & 0.001 & 0.003 & 0.002 & 0.001 \\
Manganese & $0.02 ; 0.06$ & 0.03 & 0.04 & 0.02 \\
\hline
\end{tabular}

Data taken from Arango Gutiérrez (2005); Newton et al. (2005b); Dierenfeld \& King (2008); Finke (2013). If $\mathrm{n}=2$, individual values are stated, separated by a semicolon.

\section{Suitability as animal feed}

The following section will give a brief overview of studies that investigated BSF as animal feed.

\section{BSF as pigfeed}

BSF larval meal is a suitable ingredient in pig diets, because of its high contents of amino acids and calcium, and its good palatability. However, its relative deficiency in methionine and cystine requires the inclusion of those amino acids in balanced diets (Makkar et al., 2014). Moreover, due to the high ash and crude fat content, BSF larvae should better be mixed with other proteinaceous ingredients (Newton et al., 1977). Apparent digestibilities of dry matter and nitrogen tended to be better for the pigs fed soybean meal than BSF larval meal (85.3\% and $77.2 \%$ vs $77.5 \%$ and $76 \%)$. In addition, weaned pigs did not perform well when fed on BSF larval meal, suggesting that additional refinement (cuticle removal and rendering) may be necessary to improve the performance of early weaned pigs (Newton et al., 2005).

\section{BSF as poultry feed}

To the best of our knowledge there are few studies available on this topic. BSF larvae and prepupae, grown on swine manure or kitchen waste, have been used satisfactorily as a feed additive for young chicks (Hale, 1973). Partial replacement of soymeal (10-20\%) for broilers showed a production performance, feed efficiency, mortality and carcass traits similar to those fed on commercial diets (Cullere et al., 2016). The partial (50\%) or full replacement of soybean cake by partly defatted BSF larval meal in a diet for layers did not affect their laying performance, nor feed efficiency, if compared to organic standard diets for layers (Maurer et al., 2016).

The high apparent metabolizable energy and the amino acid apparent ileal digestibility coefficients of BSF larval meal, also make it a valuable ingredient for use in the formulation 
of broiler feeds (De Marco et al., 2015). Additionally, Arango Gutiérrez (2005)suggested BSF larvae have a suitable mineral content for the nutrition of poultry, according to broiler mineral requirements, cited by the National Research Council (NRC, 1994).

\section{BSF as fish feed}

Protein replacement in fish diets has been investigated using the meals obtained from both larvae and prepupae of BSF for the following fish species: Channel catfish (Ictalurus punctatus) (Zhang et al., 2014a; Zhang et al., 2014b), Blue tilapia (Oreochromis aureus) (Bondari \& Sheppard, 1987), Hybrid tilapia (Nile tilapia, Oreochromis niloticus crossed with Sabaki tilapia, Oreochromis spilurus) (Furrer, 2011), Rainbow trout (Oncorhynchus mykiss) (Sealey et al., 2011), Atlantic salmon (Salmo salar) (Lock et al., 2015), Turbot (Psetta maxima) (Kroeckel et al., 2012), and Yellow catfish (Tachysurus fulvidraco) (Zhang et al., 2014a).

Most of these studies showed that only low inclusion levels of BSF larvae have shown a similar performance to that of fish fed traditional feedstuff, which may be explained by high larval protein content (Zhang et al., 2014a). High inclusion levels in fish feed (> 33\%) reduced not only fish growth (Kroeckel et al., 2012), but also palatability of the diet and protein digestibility (Kroeckel et al., 2012). The type of substrate on which BSF larvae were reared and the processing method might affect their utilization by fish. For instance, BSF was included at least up to $50 \%$ in Atlantic salmon diet without affecting growth or fillet quality (Lock et al., 2015).

Although the replacement of fish meal with insect meal can increase the amount of fat or change the nature of lipids in fish (St-Hilaire et al., 2007b) and could, therefore, change the taste of the fish fillets, a partial inclusion of insect meal (10-50\%) in the diet of fish does not affect FA profiles, aroma or flavour to the extent that this is perceived by consumers (Makkar et al., 2014). For instance, no difference in organoleptic properties was found in Atlantic salmon (Lock et al., 2015) or rainbow trout (Sealey et al., 2011) fed up to $50 \%$ of BSF meal.

\section{BSF as feed for other animal species}

Whole BSF larvae and pupae have been used to feed animals like alligators (Alligator mississippiensis) (Bodri \& Cole, 2007) and mountain chicken frogs (Leptodactylus fallax) (Dierenfeld \& King, 2008). A complete replacement of commercial feeds by BSF larvae fed to young alligators resulted in lower consumption and growth compared to commercial feeds. BSF larvae fed to Mountain chicken frogs resulted in poor nutrient digestibility. It seems that an unprocessed form of BSF may be less useful for species that swallow their food whole like these species. For example, calcium digestibility of whole BSF larvae in frogs was only $44 \%$ compared to $88 \%$ for BSF larvae that had been "mashed" (Dierenfeld $\&$ King, 2008). Conversely, BSF larvae have been successfully utilized in captive feeding 
and breeding programs for a number of lizard and amphibian species, mainly as source of minerals (Dierenfeld \& King, 2008). Frass of BSF reared on dried distillers grains was evaluated as feed for commercial Giant River prawn (Macrobrachium rosenbergii), resulting in similar performance as regular prawn feed, with better economic returns (Tiu, 2012).

\section{BSF as minilivestock}

Traditionally, the mass-rearing of insects has been focused on the production of beneficial insects, used as biological control agents for crop protection (Van Lenteren, 2003). In particular, most of the currently developed insect production businesses focus on predators and parasitoids for biological control (Manzano-Agugliaro et al., 2012). Small non-domesticated animals, such as BSF and other insect species that have a potential benefit either nutritionally for food and/or economically for animal feed or other revenues, and are currently not being utilized to their full potential, could be bred under controlled conditions in captivity as in a traditional animal production system and have been called 'minilivestock' (Hardouin, 1995).

The development of BSF is influenced by abiotic factors (Furman et al., 1959). In temperate countries reproduction of BSF requires temperature-controlled conditions (Alvarez, 2012). Therefore, technical improvements are necessary to arrive at economically viable BSF production systems (Alvarez, 2012). The use of BSF in low and middle income countries, where temperatures and sunlight are well suited for the propagation of the species year-round, offers small entrepreneurs the possibility of income generation without high investment costs. For instance, under field conditions in tropical countries, BSF was able to reduce organic waste more efficiently $(65-75 \%)$ than in laboratory conditions in temperate countries (40\%) (Diener, 2010). Tomberlin et al. (2002) found that specimens of a wild population reared under laboratory conditions had reduced size, weight, longevity, and caloric content in comparison to specimens collected directly from the wild.

\section{Rearing BSF}

The BSF is not active in the winter months in temperate countries, and this requires that rearing needs to take place indoors under artificial conditions (Zhang et al., 2010). Under laboratory conditions BSF larvae, which have six larval instars including prepupae, reach the prepupal stage in two weeks at $30^{\circ} \mathrm{C}$ (Furman et al., 1959). Prepupae leave the food substrate to pupate (Sheppard et al., 1994). Adults emerge after $10-14 \mathrm{~d}$ at $27-30^{\circ} \mathrm{C}$ (Sheppard et al., 2002). Adult BSF do not require food to survive but their longevity is increased when provided with a source of water (Tomberlin et al., 2002), and sugar (Nakamura et al., 2016) or honey (Rachmawati et al., 2010). Two-day-old adults mate and females oviposit two days after copulation (Tomberlin \& Sheppard, 2002). Females tend 
to lay eggs in crevices near food sources, with eggs hatching after four days at $27^{\circ} \mathrm{C}$ (Booth \& Sheppard, 1984).

As previously mentioned, life history characteristics of BSF, such as survival rate and development time, are determined by a variety of factors such as temperature (May, 1961; Holmes et al., 2016), relative humidity (Holmes et al., 2012), food availability (Diener $e t$ al., 2009), and food composition (Gobbi et al., 2013), among others. The wide geographic distribution of BSF demonstrates its tolerance for a wide range of abiotic conditions. However, it is clear that there are optimal values for these conditions to maximize BSF performance. Threshold values of abiotic factors for BSF development are shown in Table 5.

Table 5. Abiotic factors for rearing BSF

\begin{tabular}{ccccl}
\hline Abiotic factor & Min. & Optimal & Max. & \multicolumn{1}{c}{ References } \\
\hline Temperature $\left({ }^{\circ} \mathbf{C}\right)$ & 12 & $26-27$ & 36 & Holmes (2010); Holmes et al. $(2016)$ \\
Relative humidity (\%) & 25 & $60-70$ & 99 & Tomberlin \& Sheppard (2002); Gobbi (2012); Holmes et al. (2012) \\
Substrate moisture (\%) & 40 & $52-70$ & 70 & Tomberlin et al. (2002) \\
Light intensity $^{1}$ & 60 & $135-200$ & - & Alvarez (2012); Holmes (2010); Zhang et al. (2010) \\
\hline
\end{tabular}

${ }^{1}$ Light intensity is expressed in $\mu \mathrm{mol} / \mathrm{m}^{2} / \mathrm{s}$ and affects mating and egg fertilisation of BSF. However, it has been suggested that light spectral composition plays a more important role in fertilisation than light intensity. Light-emitting diodes producing wavelengths in the UV, blue and green ranges have proved to increase the proportion of fertilized eggs (Oonincx et al., 2016).

\section{Larval food quality}

Larval food quality is the determinant for the fitness of phytophagous insects with a non-feeding adult stage (Moreau et al., 2006), this applies also to the BSF which stores most of its nutrients during the larval stage. BSF larvae prefer to consume diets with high fat content to build up a fat body necessary to complete development (Nguyen et al., 2015). This is the reason why food quality is one of the most important factors affecting BSF growth rate and positively correlates with survival rate and larval length (Gobbi et al., 2013). Moreover, BSF larval weight gain is also affected because of their potential dependence on bacteria as food (Liu et al., 2008), which has also been found for other dipterans (Spiller, 1964). For instance, Yu et al. (2011) observed that the bacterium Bacillus subtilis, which was isolated from the BSF larval gut, promotes the growth and development of conspecific larvae by fermenting their food. This is probably because $B$. subtilis has the ability to digest protein and provide organic phosphorus (GuoHui et al., 2010). Zheng et al. (2013b) classified 78 genera of bacterial species obtained from larval, prepupal, pupal, adult, and egg samples of BSF. Bacteroidetes (42.0\%) and Proteobacteria (33.4\%) were the most dominant phyla associated with BSF across all life stages. These results indicate the high diversity of bacterial species associated with BSF. However, food substrate might influence microbial flora composition (Jeon et al., 2011). 
There are some studies about the effects of artificial diets on BSF development and adult life-history traits (Gobbi et al., 2013), and others related to the effects of different types of organic waste or industrial by-products on BSF life-history traits (Lardé, 1989; Larde, 1990). Unfortunately, it is difficult to derive conclusions on the effect of food quality, because there are other aspects that also affect larval performance (larval density, substrate humidity or relative humidity) which are not reported.

In Table 6 life-history traits and performance are shown for BSF fed diets of similar macronutrient content (crude protein $\sim 17 \%$, crude fat $\sim 4 \%$ ): chicken feed, Chemical Specialties Manufacturers' Association fly larval medium (CSMA) and Gainesville house fly diet (Tomberlin et al., 2002), at similar larval feeding rations $(0.82 \pm 0.005 \mathrm{~g} /$ larva) and abiotic conditions (temperature $27 \pm 2{ }^{\circ} \mathrm{C}$, relative humidity $70 \pm 10 \%$ and food moisture $66 \pm 4$ $\%$, and larval densities between 0.1 and 2.5 larvae $/ \mathrm{cm}^{2}$.

Table 6. Life-history traits and performance of BSF fed either chicken feed or diets of similar crude protein and fat contents

\begin{tabular}{|c|c|c|c|}
\hline Life-history or performance trait & $n^{6}$ & Mean \pm SD & References \\
\hline Larval developmental time (d) & 13 & $24.6 \pm 6.2$ & $\begin{array}{l}\text { Tomberlin \& Sheppard (2001); Diener et al. (2011); Gobbi } \\
\text { (2012); Nguyen et al. (2013); Li (2014); Oonincx et al. (2015a) }\end{array}$ \\
\hline Pupal developmental time (d) & 8 & $14.8 \pm 6.8$ & Nguyen et al. (2013) \\
\hline Total cycle (d) & 8 & $40.2 \pm 6.4$ & Tomberlin (2001); Gobbi (2012); Nguyen et al. (2013) \\
\hline Larval survival rate $(\%)$ & 5 & $89.4 \pm 9.4$ & Oonincx et al. (2015a) \\
\hline Pupal survival rate (\%) & 1 & 91 & Gobbi (2012) \\
\hline Larval weight ( F $\left.^{1}\right)^{1}$ & 6 & $0.158 \pm 0.02$ & Oonincx et al. (2015a) \\
\hline Larval weight $\left(\mathrm{g} \mathrm{DM}^{2}\right)$ & 1 & 0.044 & $\mathrm{Li}(2014)$ \\
\hline Prepupal weight (g FM) & 5 & $0.105 \pm 0.005$ & Tomberlin and Sheppard (2001) \\
\hline Prepupal weight (g DM) & 3 & $0.037 \pm 0.004$ & Diener et al. (2011) \\
\hline Pupal weight (g FM) & 3 & $0.150 \pm 0.03$ & Gobbi (2012) \\
\hline Adult weight (g FM) & 3 & $0.053 \pm 0.01$ & Tomberlin and Sheppard (2001) \\
\hline Adult weight (g DM) & 1 & 0.021 & Tomberlin and Sheppard (2001) \\
\hline Adult length (mm) & 1 & 15.8 & Gobbi (2012) \\
\hline Adult longevity (d) & 3 & $9.4 \pm 0.2$ & Tomberlin and Sheppard (2001) \\
\hline $\mathrm{ECI}^{3} \mathrm{DM}(\%)$ & 4 & $17.6 \pm 6.3$ & Diener et al. (2011); Li (2014); Oonincx et al. (2015a) \\
\hline $\mathrm{ECD}^{4} \mathrm{DM}(\%)$ & 3 & $32.1 \pm 4.3$ & Diener et al. 2011; Li (2014) \\
\hline FCR $^{5}$ & 1 & 1.8 & $\mathrm{Li}(2014)$ \\
\hline Larval DM content $(\%)$ & 3 & $36 \pm 1.8$ & Diener et al. (2011); Oonincx et al. (2015a) \\
\hline
\end{tabular}

${ }^{1} \mathrm{FM}$ (fresh matter), ${ }^{2} \mathrm{DM}$ (dry matter), ${ }^{3} \mathrm{ECI}$ : efficiency of conversion of ingested food; ${ }^{4} \mathrm{ECD}$ : efficiency of conversion of digested food; ${ }^{5} \mathrm{FCR}$ : feed conversion ratio, defined as feed intake /average daily gain).

${ }^{6}$ Number of independent experiments.

More food available per larva positively affects both development and larval weight in BSF (Banks et al., 2014), but negatively affects waste reduction efficiency (Diener et al., 2009). For chicken feed, Diener et al. (2009) reported an extended larval development (42 d) and a lower prepupal weight $(0.09 \mathrm{~g})$ but higher efficiency of conversion of digested food (ECD) (38\%) at a low feeding ration $(0.5 \mathrm{~g} /$ larva over the total larval development until 
prepupa), and observed shorter larval development time (15-16 d) and heavier prepupae (0.12 - $0.16 \mathrm{~g} \mathrm{FM),} \mathrm{but} \mathrm{low} \mathrm{ECD} \mathrm{(24.4} \mathrm{-} \mathrm{25.8 \% )} \mathrm{at} \mathrm{high} \mathrm{feeding} \mathrm{rations} \mathrm{(1.66} \mathrm{-} 3.18 \mathrm{~g} /$ larva). However, since BSF metabolism was not measured independently, these unexpected results for ECD may be spurious (van Loon, 1991). For chicken feed, an optimum feeding ration seems to lie between $0.8-1.2 \mathrm{~g}$ of food per larva.

Information on the quality of organic waste as feed for BSF larvae is scattered and many of the biotic and abiotic factors that were mentioned above have not been reported. Thus, we have tried to compare life-history traits and performance of BSF larvae fed different substrates. Hence, we organized the information per type of substrate: faeces, vegetable and meat waste (Table 7).

Table 7. Life-history traits and performance of BSF fed organic waste

\begin{tabular}{lcccccc}
\hline \multirow{2}{*}{ Life-history or performance trait } & \multicolumn{5}{c}{ Diet } \\
\cline { 2 - 7 } Larval developmental time (d) & Faeces $^{\mathbf{1}}$ & $\mathbf{n}$ & Vegetable waste $^{\mathbf{2}}$ & $\mathbf{n}$ & Meat waste $^{\mathbf{3}}$ & $\mathbf{n}$ \\
\cline { 2 - 7 } Pupal developmental time (d) & $27.5 \pm 3.8$ & 13 & $34 \pm 13.5$ & 17 & $32.5 \pm 8.2$ & 6 \\
Larval survival rate (\%) & $17.8 \pm 3$ & 5 & $22.9 \pm 1.2$ & 3 & $16.5 \pm 7.5$ & 6 \\
Larval weight (g FM) & $89 \pm 7.5$ & 3 & $78.9 \pm 13.2$ & 10 & $48.2 \pm 8.7$ & 3 \\
Larval weight (g DM) & $0.17 \pm 0.03$ & 5 & $0.13 \pm 0.03$ & 13 & 0.158 & 1 \\
Prepupal weight (g FM) & $0.031 \pm 0.02$ & 4 & $0.028 \pm 0.01$ & 5 & - & - \\
Prepupal weight (g DM) & $0.193 \pm 0.08$ & 11 & $0.179 \pm 0.03$ & 4 & - & - \\
Pupal weight (g FM) & $0.018 ; 0.04$ & 2 & $0.071 \pm 0.01$ & 6 & - \\
Adult weight (g FM) & - & - & - & - & $0.115 \pm 0.01$ & - \\
Adult longevity (d) & $0.046 \pm 0.01$ & 4 & - & - & - & - \\
ECI (DM) (\%) & $12.5 \pm 2.1$ & 4 & - & - & - \\
FCR (FM) & $13.1 \pm 1.3$ & 4 & $17.2 \pm 4.3$ & 9 & - \\
Larval DM content (\%) & $7.6 \pm 5.4$ & 8 & $8.3 \pm 6.2$ & 8 & - & - \\
\hline
\end{tabular}

Values represent mean \pm standard deviation. $\mathrm{n}$ gives the number of replicates. If $\mathrm{n}=2$, individual values are stated, separated by a semicolon.

${ }^{1}$ Swine, poultry, cow and human faeces: Sheppard et al. (1994); Newton et al. (2005a); St-Hilaire et al. (2007a); Myers et al. (2008); Diener et al. (2011); Li et al. (2011b); Li et al. (2011d); Nguyen et al. (2013); Banks et al. (2014); Oonincx et al. (2015b).

${ }^{2}$ Kitchen, fruit and vegetables, market, municipal organic and catering wastes, by-products, decaying palm kernel meal - PKM, coffee pulp, spent grains and distilled grains: Larde (1990); Diener (2010); Rachmawati et al. (2010); Kalová \& Borkovcová (2013); Nguyen et al. (2013); Li (2014); Oonincx et al. (2015a).

${ }^{3}$ Swine meal, meat meal, pig liver, fish rendering, cow manure plus fish offal: Nguyen et al. (2013). 
In order to assess statistical differences among the studies, we performed parametric and non-parametric tests on the variables that were sufficiently replicated ${ }^{1}$. Larval developmental time was similar among all the diets (Kruskal-Wallis, $\mathrm{P}=0.119$ ). However, survival rate was significantly lower when fed meat waste (ANOVA, Tukey post-hoc test, $\mathrm{P}$ $<0.05$ ). BSF larval dry matter yield (faeces and vegetable waste) differs neither among substrates (Student's t-test, $\mathrm{P}=0.249$ ) nor does fresh matter yield differ between substrates (chicken feed or similar diets, faeces and vegetable waste; ANOVA, $\mathrm{P}=0.084$ ). Prepupal weight (FM) tended to be higher in larvae fed faeces and vegetable waste than in larvae fed chicken feed (Kruskal-Wallis, $\mathrm{P}=0.053$ ). However, prepupal dry weight was higher on vegetable waste than on faeces and chicken feed (Kruskal-Wallis, Pairwise comparisons, $\mathrm{P}<0.05$ ). Neither ECI (chicken, faeces, vegetables) (Kruskal-Wallis, $\mathrm{P}=0.838$ ) nor FCR (chicken, faeces, vegetables) (Kruskal-Wallis, $\mathrm{P}=0.097$ ) were different across substrates.

These results should be considered as an attempt to explore how BSF performance is affected by food quality. The literature data available do not allow to identify the best substrate for BSF larvae in terms of larval performance. Overall conclusions are hampered due to the fact that variables differ not only among substrates, but also because of different biotic and abiotic conditions, as mentioned above. It is possible that controlled biotic and abiotic factors under laboratory conditions could influence the performance more strongly than the nutritional content of the substrate. In any case, larvae fed on good quality diets might need lower feeding rations to achieve a good performance than larvae fed on low quality diets. Thus, it seems possible to use a low quantity of feeding ration for BSF fed high quality food, as was suggested by Sheppard (1983), and to get a higher efficiency through more of the feed being converted to body mass.

As previously seen for chicken feed, higher feeding rations (i.e. amounts of food per larva) also positively affected development and larval, pupal and adult weights in BSF reared on cow manure. Myers et al. (2008) obtained a shorter developmental time $(25.8-26.2 \mathrm{~d})$ and, higher larval (0.16-0.18 g FM), prepupal (0.12 - 0.14 g FM) and adult (0.05-0.06 g FM) weights at high feeding ration for the whole experiment ( 4.7 - $6 \mathrm{~g} / \mathrm{larva})$. Moreover, adult longevity was also positively affected by high feeding ration. On the other hand, BSF prepupal weight (FM) could be more influenced by frequency of adding food than by feeding ration, for instance Banks et al. (2014) found that prepupae fed human manure at different feeding rations ( 12 and $1.2 \mathrm{~g} / \mathrm{larva}$ ), but at a same frequency (fed a single amount of faeces during the experiment) both reached an average body mass of $0.32 \mathrm{~g}$ FM. In

1 One way ANOVA test and t-test were applied if the assumptions of homogeneity of variance and normality were met, while the Kruskal Wallis test was utilized for the data that did not meet these assumptions. Post-hoc Tukey test was performed to determine significance of differences ( $\mathrm{P}$ $<0.05$ ). IBM SPSS Statistics version 21.0 was used (IBM Corp., Armonk, NY). 
contrast, larvae with a high feeding ration $(12 \mathrm{~g} /$ larva) fed twice per week were on average lighter $(0.23 \mathrm{~g} \mathrm{FM})$.

Regarding the effects of different types of manure on BSF larvae, Tomberlin et al. (2002) found that the growth period to prepupae on cow manure (almost 2 months) was slower than what has been reported for poultry manure or swine manure (4-6 weeks). Nguyen et al. (2013) obtained the lowest values for both weight and length gain for larvae fed pig manure in comparison with other organic wastes. Tomberlin et al. (2002) found that BSF larvae fed fresh ( $5 \mathrm{~d}$-old) hen manure grew at half the rate of larvae fed $18 \mathrm{~h}$ old manure. It seems that aging of manure influences BSF development. This is probably due to a higher protein content of fresh manure (Sheppard, 1983). Oonincx et al. (2015b) reported extended development periods for BSF fed chicken (144 d), pig (144 d) and cow (215 d) dried manure. These extended development times could be an effect of the drying of the manure prior to the feeding experiment resulting in reduced nutritional quality.

Simon et al. (2011) suggested that diets with a higher proportion of protein increase the development period and survival rate of some predatory fly species. This may be a result of extended larval development periods, which allowed greater time for storing nutrients. Conversely in BSF, Oonincx et al. (2015), who used vegetable by-products, observed larvae fed a diet high in both protein and fat and larvae fed control diet (chicken feed), also high in protein, resulted in a shorter development time $(21 \mathrm{~d})$ than the low protein diets (37 d). Nguyen et al. (2013) also observed a higher weight gain and length on both high protein and fat diets. In addition, low fat and protein content caused larvae to have longer developmental times ( $\pm 30 \mathrm{~d})$. However, high fat contents in feed $(20-36 \%$ DM crude fat) could be detrimental for both larval and adult survival (Nguyen et al., 2015; Nguyen et al., 2013).

The biodegradability of manure has been shown to be highly dependent on its lignin content, which comes mainly from forage fibre in the animal diet. Because poultry and swine diets generally contain little forage, it would be expected that their faeces would be better degradable than that of ruminants (St-Hilaire et al., 2007a). The lower nutritional value of cow manure may explain why the larvae fed mixed (cow manure and fish offal) diets had higher average larval weights $(0.14-0.16 \mathrm{~g} \mathrm{FM})$ compared to prepupae fed cow manure only (0.1g FM) (St-Hilaire et al., 2007a).

\section{Substrate characteristics}

On the other hand, there are also physical factors influencing insect performance. For example, if the layer of food substrate is too thick, such as meat meal, swine meat, fish or liver, this reduces larval food intake resulting in lower survival and longer development (Nguyen et al., 2013). Lardé (1989) observed that BSF larvae like to grow on a more 
homogeneous, more dense and drier substrate, and it has been established that 60-70\% moisture in chicken feed is adequate for BSF larvae. However, due to the variable composition of organic waste, food moisture is difficult to control and needs to be evaluated not only under laboratory, but also under field conditions where evaporation rate tends to be variable. Kalová and Borkovcová (2013) found that BSF larvae fed organic waste with high moisture content (>90\%), survived, but had lower performance.

\section{Larval crowding}

Larval crowding could be a major factor affecting the rate of development like has been reported for other dipteran species (Jannat \& Roitberg, 2013). Unfortunately, in few studies on BSF larval density has been reported. However, taking into account the size of containers used in different studies (Sheppard et al., 2002; Myers et al., 2008; Diener et al., 2009; Tomberlin et al., 2009; Gobbi, 2012; Nguyen et al., 2013; Oonincx et al., 2015a) and assuming that the substrate layer is around $1-2 \mathrm{~cm}$ thick, an average density of 1.4 larvae per $\mathrm{cm}^{2}$ can be calculated (min. 0.1 and max. 3.33 larvae/ $\mathrm{cm}^{2}$ ). Sheppard et al. (2002) suggest a density of 2.5 larvae per $\mathrm{cm}^{2}$ of surface area for BSF fed chicken feed, in order to obtain an adequate growth. Banks et al. (2014) recorded similar larval developmental time $(28-30 \mathrm{~d})$ in BSF larvae fed human faeces at different densities $(0.02,0.2$, and 0.31 larva $\left./ \mathrm{cm}^{2}\right)$, but they reached the highest prepupal weight $(0.32 \mathrm{~g} \mathrm{FM})$ and the lowest FCR (10.4) at the lowest density ${ }^{2}$. Density is an important biotic factor for dipterans such as BSF, because larval aggregation is characteristic for the biology of these species (Rivers \& Dahlem, 2013). Larval aggregation has consequences such as heat accumulation and coprophagy and, resulting in more exhaustive nutrient utilization and should be studied more in depth.

Since biotic and abiotic factors can affect both BSF performance and its nutritional value, it would be useful to select BSF strains adapted to specific factors, for a particular target animal to be fed with BSF larval meal. Many of the factors that clearly impact the performance of larval stages remain poorly studied. For instance, moisture and texture of the food, larval density and feeding ration could in part explain differences among the studies on BSF fed diets of similar composition.

\section{Perspectives on BSF as animal feed}

Most feeding studies with diets containing BSF larvae and prepupae have been conducted on fish, pigs and poultry. The available studies that include BSF larvae in poultry, pig and fish diets suggest that it could partially replace traditional feedstuff in their diets, because

2 Expression of density per unit surface is a proxy for actual relevant density which should be expressed per unit of volume. 
high or complete replacement did not result in good growth performance. There are some factors that might be affecting the performance of animals fed on diets containing BSF larvae or prepupae. First, BSF not only contains a high protein content, but also contains more fat than necessary in the diet of most animals, which could affect the digestibility and/or the palatability of BSF larval meal, as it was showed by Kroeckel et al. (2012). Second, BSF larvae also contain high levels of ash and hence higher levels of inclusion in the diet, especially of monogastrics, can decrease feed intake and cause other adverse effects (Makkar et al., 2014). Third, an unprocessed form of BSF may affect its digestibility and be less utilizable for species that swallow their food whole (Dierenfeld \& King, 2008). Fourth, although many authors have stated that BSF larval meal contains high quality protein, it is important to evaluate the quality for specific animals fed BSF meal and to define what limiting amino acids are provided by BSF meal.

In order to enhance the percentage replacement of traditional feedstuff, without compromising both growth or health, different strategies could be adopted in order to enhance nutritive value, the palatability and/or digestibility of the BSF larval meal. For example, it might be advisable to defatten BSF larvae and use the proteins for animal feed and the lipids for other purposes e.g. biodiesel production (Li et al., 2011a; Surendra et al., 2016), or as a good alternative lipid source in practical diets for animal feed ( $\mathrm{Li}$ et al., 2016). Thus, BSF larvae can convert dairy manure into biodiesel ( $\mathrm{Li}$ et al., 2011c), and compared with oil crops, BSF has higher reproductive capacity and a shorter lifecycle. BSF production requires less land than growing oil crops and may thereby alleviate conflicts between human food use and industrial use of crops (Li et al., 2011b; Li et al., 2011c). Additionally, processing of BSF larvae (e.g. drying, defattening, cuticle removal) appears to increase nutrient availability and/or acceptability of the larvae, and their high dry matter content makes them easier and less costly to dehydrate than other fresh by-products (Sheppard $e t$ al., 2008). In order to increase the crude protein content of the insect meal, defattening is a feasible option (Makkar et al., 2014). Surendra et al. (2016) found that mechanical pressing and solvent extraction significantly decrease the crude fat content (3.4\%). For some species like frogs, mashed, rendered or chopped BSF larvae might increase Ca and P digestibilities (Dierenfeld \& King, 2008).

Although most essential amino acid levels in BSF larvae are high, even higher than in soymeal or the FAO Reference Protein (Makkar et al., 2014), some amino acids are low, like methionine which is one of the major limiting amino acids for growing pigs and broilers. However, each animal species has particular requirements. For example, while total sulphur-containing amino acids are first limiting when insects are incorporated into diets fed to mammals, to uricotelic animals such as birds and reptiles or ammoneotelic animals such as fish, arginine may also be important (Finke, 2013). Regarding young cats and dogs, Bosch et al. (2014) found that the first limiting amino acid in BSF larvae was 
the combined requirement for methionine and cystine. Moreover, in vitro protein digestibility of BSF larvae is high, $82-90 \%$ (Bosch et al., 2014). However, the digestibility of BSF pupae was lower (77.7\%) (Bosch et al., 2014), which is likely caused by a high chitin content. On the other hand, BSF could be used to provide macro- and micro-nutrients other than protein. For instance, this species can be used as suitable alternative feed high in minerals, taking away the need for mineral supplementation for some wild animals in captivity (Dierenfeld \& King, 2008).

Further work is necessary to evaluate the possible use of BSF as a feed supplement or as the main source of protein in commercial diets. Bacteria isolated from BSF larvae also can be used as probiotic for improving animal performance, as was found in fish (Ushakova et al., 2016). Before incorporating BSF larvae into the diet of an animal species, it is necessary to evaluate the exact composition of the BSF larvae and to compare it with the requirements of the animal species of interest, species with high protein requirements being particularly suitable candidates. In addition, digestibility measurements (in vitro, in vivo and in situ) are also considered necessary to predict accurately the protein quality of foods for animal diets. Likewise, differences in nutrient composition, digestibility and availability among the BSF developmental stages have been found. Since prepupae are easy to collect, high in protein, and have lower chitin content than pupae, the best larval stage to use as animal feed might be the prepupa. In any case, BSF processing issues also require further studies as the chitin content may not be the only factor responsible for these issues, and may even not be involved at all (Makkar et al., 2014).

As discussed above, nutrient composition in BSF varies according to the diet, life stage and rearing conditions; therefore, the use of low-nutrient organic wastes to feed BSF larvae are aspects that require more in-depth studies (Henry et al., 2015). Although there are some studies on the effect of various rearing media on biological parameters of BSF, most of them did not evaluate how those affected its nutritional composition. Hence, it is indispensable to perform rigorous experimental work on the nutritional quality of different diets and their effect on both feed conversion efficiency and body nutrient composition.

Next to nutrient quality, also other aspects like product safety and processability are important for using BSF in future animal feed formulations. For example, defatting has been showed a good method to process BSF larvae, however, temperatures involved need to be evaluated as they can influence nutrient composition and the growth of animals fed on them (Lock et al., 2015). Regarding to palatability, the problem with lipids may be related more to their oxidation at a high temperature than to the actual high dietary lipid content or the presence of anti-nutritional factors, flavonoids and terpenoids in the insect meals (Shantibala et al., 2014). 
It is important to underline that BSF is a member of the complex detritivore community competing for resources, and the interaction with microbes significantly influences BSF oviposition preference (Zheng et al., 2013a) and changes the composition of the substrate. Hence, BSF larvae have been shown to reduce not only waste dry mass but also its content of nutrients such as nitrogen and phosphorus (Myers et al., 2008; Sheppard et al., 2008), and modify the microflora of manure, potentially reducing counts of harmful bacteria (Liu et al., 2008). For example, larval activity significantly reduced Escherichia coli 0157:H7 and Salmonella enterica serotype Enteritidis (ME 18) populations in poultry manure (Erickson et al., 2004). Lalander et al. (2013) found a reduction in Salmonella spp. in human faeces after eight days of starting the experiment. Arango Gutiérrez et al. (2004) conducted a microbiological study on BSF prepupal meal and found Salmonella spp. and E. coli to be absent.

Temperature also significantly influenced the ability of BSF larvae to develop and reduce E. coli counts with greatest suppression occurring at $27^{\circ} \mathrm{C}$ (Liu et al., 2008). Zheng et al. (2013b) mentioned that Providencia appears to be a candidate for vertical transmission in $\mathrm{BSF}$ as it was found in adults and eggs. The possibility of bacteria being retained through successive BSF life stages should be investigated and if shown could necessitate the testing of the initial bacterial load and diversity in these flies before introduction into waste or feed. In this way any inadvertent disease transmission can be mitigated and can eliminate those bacteria that pose potential harm to animals or humans. Additionally, BSF larvae seem to secrete chemicals that prevent other fly species to lay eggs on a food source colonized by BSF, which results in effective reductions of the common housefly $M$. domestica L. (Bradley \& Sheppard, 1984).

Regarding toxic feed contaminants, Diener (2010) found cadmium, lead and zinc in BSF prepupae fed on organic waste. None of the three heavy metals had significant effects on life cycle traits (prepupal weight, development time, sex ratio) nor on the bilateral symmetry of the adult flies. However, cadmium accumulated in the prepupae and could thereby potentially limit its use in the production of animal feed. Diener (2010) also concluded that neither lead nor zinc accumulate in larvae or prepupae, which means concerns about the use of prepupae in animal feed might be less critical. Potential hurdles, such as the bioaccumulation of insecticides, medical drugs, heavy metals and natural toxins can be controlled in mass rearing setups through quality control of their rearing substrates (van der Spiegel et al., 2013), especially when organic by-products are an important feed source for BSF.

In relation to its ecological footprint, the BSF has favorable properties, not only due to its ability to recycle nutrients, but also because insects have been reported to emit fewer greenhouse gases and less ammonia than cattle or pigs (Oonincx et al., 2010). Moreover, they require significantly less land and water than cattle rearing (van Huis et al., 2013). 
Accurate data must still be generated on feed conversion efficiency of BSF and its use of water and substrate both per unit of biomass and nutrient production, to make decisions on the environmental impacts of using BSF meals rather than other conventional feed resources. Therefore, even though BSF larvae are not a major contender of other ingredients for animal feed yet, taking into account these economical and ecological aspects, BSF larvae might be included in the industrial formulation of animal feed. These perspectives will still require further research and adaptations, but are already supported by scientific results from several research projects or applications around the world.

\section{Perspectives on BSF as minilivestock}

If BSF meal is to become a significant part of the animal diets produced by the feed industry, it is necessary to ensure a steady production of BSF in terms of quantity, quality and price. Despite BSF having a favorable nutritional content, the actual cost of the production and harvesting of BSF is still high. There is a need for establishing cost-effective and optimized insect mass-rearing facilities that use well-defined substrates, producing insects of a defined quality (macro- and micronutrients). It is necessary to take advantage of the multiple benefits of using it in an animal production system and/or a mass-rearing production (minilivestock). Given that BSF larvae consume a wide range of organic resources, recycling nutrients not only adds to overall sustainability of its production, but the use of locally produced material to feed BSF larvae might contribute to the economic efficiency of the operations, reducing the costs of the feed. In addition, the use of BSF oil for biofuel production and use of the defatted meal as animal feed would enhance the economic returns from the mass-rearing establishments. An alliance between companies and both small and big agricultural producers should be reached in order to achieve economic profit for both sides.

The use of BSF minilivestock is a challenge because despite ample research on various topics related to the effect of biotic and abiotic factors on its larval biology not only in tropical regions, but also in temperate regions, little information is available on how these factors affect the mature stages of BSF, such as mating success, fecundity, egg size and fertility. The latter is particularly important because reproductive potential critically depends upon resource accumulation during the larval stage in BSF. Therefore, it is essential to study all fitness related life-history traits to fully understand the effects of larval food quality on fitness. This knowledge will allow to increase body mass and/or size of individuals to maximize the continuous production of eggs necessary for the mass-rearing of this species.

Filling all the knowledge gaps identified above will contribute to controlled management of BSF mass rearing. There is a need to improve risk assessment methodologies. Scientific understanding of BSF as minilivestock, embedded in local contexts, needs to be addressed 
to achieve that people not only in tropical and developing countries, but also in temperate regions could take advantage of this species through new approaches, based on sustainability, on protection of the environment, to meet increasing food demands. Indeed, this species holds promise to become an integral part of livestock and agriculture.

\section{Acknowledgements}

This work was supported by the Scholarship Program No. 568 from COLCIENCIAS Departamento Administrativo de Ciencia, Tecnología e Innovación - Colombia.

\section{References}

Alvarez L (2012) The role of black soldier fly, Hermetia illucens (L.) (Diptera: Stratiomyidae) in sustainable waste management in northern climates. Electronic Theses and Dissertations. University of Windsor, Ontario, Canada.

Arango Gutiérrez GP (2005) Aportes nutricionales de la biomasa de Hermetia illucens L. (Diptera: Stratiomyiidae) en la cría de pollos de engorde. Ciencias Animales. Universidad Nacional de Colombia, Medellin, Colombia.

Arango Gutiérrez GP, Vergara Ruiz RA, Mejía Vélez H (2004) Compositional, microbiological and protein digestibility analysis of the larva meal of Hermetia illucens L.(Diptera: Stratiomyiidae) at Angelópolis-Antioquia, Colombia. Revista Facultad Nacional de Agronomia, Medellin, 57, 2491-2500.

Awomyi T (2007) Health, nutritional and consumers' acceptability assurance of maggotmeal inclusion in livestock diet: a review. International Journal of Tropical Medicine, 2, 52-56.

Banks IJ, Gibson WT, Cameron MM (2014) Growth rates of black soldier fly larvae fed on fresh human faeces and their implication for improving sanitation. Tropical Medicine \& International Health, 19, $14-22$.

Bodri MS, Cole ER (2007) Black soldier fly (Hermetia illucens Linnaeus) as feed for the American Alligator (Alligator mississippiensis Daudin). The Georgia Journal of Science 65, 82-88.

Bondari K, Sheppard DC (1987) Soldier fly, Hermetia illucens L., larvae as feed for channel catfish, Ictalurus punctatus (Rafinesque), and blue tilapia, Oreochromis aureus (Steindachner). Aquaculture and Fisheries Management, 18, 209-220.

Booth DC, Sheppard C (1984) Oviposition of the black soldier fly, Hermetia illucens (Diptera: Stratiomyidae): eggs, masses, timing, and site characteristics. Environmental Entomology, 13, 421-423.

Bosch G, Zhang S, Oonincx DG, Hendriks WH (2014) Protein quality of insects as potential ingredients for $\operatorname{dog}$ and cat foods. Journal of Nutritional Science, 3, e29.

Bradley SW, Sheppard DC (1984) House fly oviposition inhibition by larvae of Hermetia illucens, the Black Soldier Fly. Journal of Chemical Ecology, 10, 853-859.

Calvert CC, Martin RD, Morgan NO (1969) House fly pupae as food for poultry. Journal of Economic Entomology, 62, 938-939.

Caruso D, Devic E, Subamia I, Talamond P, Baras E (2014) Technical handbook of domestication and production of Diptera black soldier fly (BSF), Hermetia illucens, Stratiomyidae, PT Penerbit IPB Press, Taman Kencana.

Cerda H, Martinez R, Briceno N, Pizzoferrato L, Manzi P, Ponzetta MT, et al. (2001) Palm worm (Rhynchophorus palmarum) traditional food in Amazonas, Venezuela-nutritional composition, small scale production and tourist palatability. Ecology of Food and Nutrition, 40, 13-32.

Cullere M, Tasoniero G, Giaccone V, Miotti-Scapin R, Claeys E, De Smet S, et al. (2016) Black soldier fly as dietary protein source for broiler quails: apparent digestibility, excreta microbial load, feed choice, performance, carcass and meat traits. Animal, 24, 1-8. 
De Marco M, Martínez S, Hernandez F, Madrid J, Gai F, Rotolo L, et al. (2015) Nutritional value of two insect larval meals (Tenebrio molitor and Hermetia illucens) for broiler chickens: Apparent nutrient digestibility, apparent ileal amino acid digestibility and apparent metabolizable energy. Animal Feed Science and Technology, 209, 211-218.

Defoliart GR (1989) The human use of insects as food and as animal feed. Bulletin of the Entomological Society of America, 35, 22-35.

Diener S (2010) Valorisation of organic solid waste using the black soldier fly, Hermetia illucens. Swiss Federal Institute of Aquatic Science and Technology (Eawag). ETH Zürich.

Diener S, Zurbrügg C, Gutiérrez FR, Nguyen DH, Morel A, Koottatep T, et al. (2011) Black soldier fly larvae for organic waste treatment-prospects and constraints. Proceedings of the WasteSafe-2nd International Conference on Solid Waste Management in the Developing Countries. Khulna, Bangladesh.

Diener S, Zurbrügg C, Tockner K (2009) Conversion of organic material by black soldier fly larvae: establishing optimal feeding rates. Waste Management \& Research, 27, 603-610.

Dierenfeld ES, King J (2008) Digestibility and mineral availability of phoenix worms, Hermetia illucens, ingested by mountain chicken frogs, Leptodactylus fallax. Journal of Herpetological Medicine and Surgery, 18, 100-105.

Elemo BO, Elemo GN, Makinde M, Erukainure OL (2011) Chemical evaluation of African palm weevil, Rhychophorus phoenicis, larvae as a food source. Journal of Insect Science, 11, 1-6.

Erickson MC, Islam M, Sheppard C, Liao J, Doyle MP (2004) Reduction of Escherichia coli O157:H7 and Salmonella enterica serovar Enteritidis in chicken manure by larvae of the black soldier fly. Journal of Food Protection, 67, 685-690.

Finke MD (2013) Complete nutrient content of four species of feeder insects. Zoo Biology, 32, 27-36.

Furman DP, Young RD, Catts PE (1959) Hermetia illucens (Linnaeus) as a factor in the natural control of Musca domestica Linnaeus. Journal of Economic Entomology, 52, 917-921.

Furrer T (2011) Finding an adequate tilapia feed for rural fish farmers in Mombasa. Zürich University of Applied Sciences - ZHAW, Zürich.

Gobbi FP (2012) Biología reproductiva y caracterización morfológica de los estadios larvarios de Hermetia illucens (L., 1758)(Diptera: Stratiomyidae). Bases para su producción masiva en Europa. Instituto Universitario de Investigación. Universidad de Alicante.

Gobbi P, Martínez-Sánchez A, Rojo S (2013) The effects of larval diet on adult life-history traits of the black soldier fly, Hermetia illucens (Diptera: Stratiomyidae). European Journal of Entomology, 110, 461-468.

Gujarathi G, Pejaver M (2013) Occurrence of black soldier fly Hermetia illucens (Diptera: Stratiomyidae) in biocompost. Research Journal of Recent Sciences, 2, 65-66.

Guohui Y, Chunyan N, Guobao H, Lin Z, Qiang X, Ping C (2010) Isolation and identification of bacteria producing enzymes from gut and skin of black soldier fly (Hermetia illucens) larvae. Chinese Bulletin of Entomology, 47, 889-894.

Hale OM (1973) Dried Hermetia illucens larvae (Diptera: Stratiomyidae) as a feed additive for poultry. Journal of the Georgia Entomological Society, 8, 16-20.

Hardouin J (1995) Minilivestock - from gathering to controlled production. Biodiversity and Conservation, 4, 220-232.

Henry M, Gasco L, Piccolo G, Fountoulaki E (2015) Review on the use of insects in the diet of farmed fish: past and future. Animal Feed Science and Technology, 203, 1-22.

Holmes L, Vanlaerhoven S, Tomberlin J (2016) Lower temperature threshold of black soldier fly (Diptera: Stratiomyidae) development. Journal of Insects as Food and Feed, 2, 255-262.

Holmes LA (2010) Role of abiotic factors on the development and life history of the black soldier fly, Hermetia illucens (L.) (Diptera: Stratiomyidae). Electronic Theses and Dissertations. Paper 285. University of Windsor.

Holmes LA, Vanlaerhoven SL, Tomberlin JK (2012) Relative humidity effects on the life history of Hermetia illucens (Diptera: Stratiomyidae). Environmental Entomology, 41, 971-978.

Jannat KNE, Roitberg BD (2013) Effects of larval density and feeding rates on larval life history traits in Anopheles gambiae ss (Diptera: Culicidae). Journal of Vector Ecology, 38, 120-126. 
Jeon H, Park S, Choi J, Jeong G, Lee S-B, Choi Y, et al. (2011) The intestinal bacterial community in the food waste-reducing larvae of Hermetia illucens. Current Microbiology, 62, 1390-1399.

Kalová M, Borkovcová M (2013) Voracious larvae Hermetia illucens and treatment of selected types of biodegradable waste. Acta Universitatis Agriculturae et Silviculturae Mendelianae Brunensis, 61, 77-83.

Kim W, Bae S, Kim A, Park K, Lee S, Choi Y, et al. (2011) Characterization of the molecular features and expression patterns of two serine proteases in Hermetia illucens (Diptera: Stratiomyidae) larvae. BMB Reports, 44, 387-392.

Kroeckel S, Harjes A-GE, Roth I, Katz H, Wuertz S, Susenbeth A, et al. (2012) When a turbot catches a fly: Evaluation of a pre-pupae meal of the Black Soldier Fly (Hermetia illucens) as fish meal substitute - Growth performance and chitin degradation in juvenile turbot (Psetta maxima). Aquaculture and Fisheries Management, 364-365, 345-352.

Lalander C, Diener S, Magri ME, Zurbrügg C, Lindström A, Vinnerås B (2013) Faecal sludge management with the larvae of the black soldier fly (Hermetia illucens) - From a hygiene aspect. Science of the Total Environment, 458, 312-318.

Larde G (1990) Recycling of Coffee Pulp by Hermetia Illucens (Diptera, Stratiomyidae) larvae. Biological Wastes, 33, 307-310.

Lardé G (1989) Investigation on some factors affecting larval growth in a coffee-pulp bed. Biological Wastes, 30, 11-19.

Li C (2014) Conversion of spent grains and DDGS by black soldier flies. MSc thesis. Laboratory of Entomology. Wageningen University. 24.

Li L, Zhao Z, Liu H (2013) Feasibility of feeding yellow mealworm (Tenebrio molitor L.) in bioregenerative life support systems as a source of animal protein for humans. Acta Astronautica, 92, 103-109.

Li Q, Zheng L, Cai H, Garza E, Yu Z, Zhou S (2011a) From organic waste to biodiesel: Black soldier fly, Hermetia illucens, makes it feasible. Fuel, 90, 1545-1548.

Li Q, Zheng L, Hou Y, Yang S, Yu Z, Al. LE (2011b) Insect fat, a promising resource for biodiesel. Journal of Petroleum \& Environmental Biotechnology S2.

Li Q, Zheng L, Qiu N, Cai H, Tomberlin JK, Yu Z (2011c) Bioconversion of dairy manure by black soldier fly (Diptera: Stratiomyidae) for biodiesel and sugar production. Waste Management, 31, 1316-1320.

Li S, Ji H, Zhang B, Tian J, Zhou J, Yu H (2016) Influence of black soldier fly (Hermetia illucens) larvae oil on growth performance, body composition, tissue fatty acid composition and lipid deposition in juvenile Jian carp (Cyprinus carpio var. Jian). Aquaculture, 465, 43-52.

Liu Q, Tomberlin JK, Brady JA, Sanford MR, Yu Z (2008) Black soldier fly (Diptera: Stratiomyidae) larvae reduce Escherichia coli in dairy manure. Environmental Entomology, 37, 1525-1530.

Lock E, Arsiwalla T, Waagbø R (2015) Insect larvae meal as an alternative source of nutrients in the diet of Atlantic salmon (Salmo salar) postsmolt. Aquaculture Nutrition, 22, 1202-1213.

Makkar HP, Tran G, Heuzé V, Ankers P (2014) State-of-the-art on use of insects as animal feed. Animal Feed Science and Technology, 197, 1-33.

Manzano-Agugliaro F, Sanchez-Muros M, Barroso F, Martínez-Sánchez A, Rojo S, Pérez-Bañón C (2012) Insects for biodiesel production. Renewable and Sustainable Energy Reviews, 16, 3744-3753.

Martínez-Sánchez A, Magaña C, Saloña M, Rojo S (2011) First record of Hermetia illucens (Diptera: Stratiomyidae) on human corpses in Iberian Peninsula. Forensic Science International, 206, e76-e78.

Maurer V, Holinger M, Amsler Z, Früh B, Wohlfahrt J, Stamer A, et al. (2016) Replacement of soybean cake by Hermetia illucens meal in diets for layers. Journal of Insects as Food and Feed, 2, 83-90.

May B (1961) The occurrence in New Zealand and the life-history of the soldier fly Hermetia illucens (L.) (Diptera: Stratiomyidae). The New Zealand Journal of Science and Technology, 4, 55-65.

Moreau J, Benrey B, Thiéry D (2006) Assessing larval food quality for phytophagous insects: are the facts as simple as they appear? Functional Ecology, 20, 592-600.

Myers HM, Tomberlin JK, Lambert BD, Kattes D (2008) Development of black soldier fly (Diptera: Stratiomyidae) larvae fed dairy manure. Environmental Entomology, 37, 11-15.

Nakamura S, Ichiki RT, Shimoda M, Morioka S (2016) Small-scale rearing of the black soldier fly, Hermetia illucens (Diptera: Stratiomyidae), in the laboratory: low-cost and year-round rearing. Applied Entomology and Zoology, 51, 161-166. 
Chapter 2

Newton GL, Booram CV, Barker RW, Hale OM (1977) Dried Hermetia illucens larvae meal as supplement for swine. Journal of Animal Science, 44, 395-400.

Newton L, Sheppard C, Watson DW, Burtle G (2005) Using the black soldier fly, Hermetia illucens, as a value-added tool for the management of swine manure Smithfield Foods, and Premium Standard Farms, and Frontline Farmers. North Carolina State University, USA.

Nguyen TT, Tomberlin JK, Vanlaerhoven S (2013) Influence of resources on Hermetia illucens (Diptera: Stratiomyidae) larval development. Journal of Medical Entomology, 50, 898-906.

Nguyen TT, Tomberlin JK, Vanlaerhoven S (2015) Ability of black soldier fly (Diptera: Stratiomyidae) larvae to recycle food waste. Environmental Entomology, 44, 406-410.

NRC (1994) Nutrient requirements of poultry. National Research Council. National Academy Press Washington^ eUSA USA.

Oonincx D, Van Broekhoven S, Van Huis A, Van Loon JJA (2015a) Feed conversion, survival and development, and composition of four insect species on diets composed of food by-products. PLOS ONE, 10, e 0144601.

Oonincx D, Van Huis A, Van Loon JJA (2015b) Nutrient utilisation by black soldier flies fed with chicken, pig, or cow manure. Journal of Insects as Food and Feed, 1, 131-139.

Oonincx D, Volk N, Diehl J, Van Loon JJA, Belušič G (2016) Photoreceptor spectral sensitivity of the compound eyes of black soldier fly (Hermetia illucens) informing the design of LED-based illumination to enhance indoor reproduction. Journal of Insect Physiology, 95, 133-139.

Oonincx DGaB, Van Itterbeeck J, Heetkamp MJW, Van Den Brand H, Van Loon JJA, Van Huis A (2010) An exploration on greenhouse gas and ammonia production by insect species suitable for animal or human consumption. PLOS ONE, 5, e14445.

Rachmawati R, Buchori D, Hidayat P, Hem S, Fahmi MR (2010) Perkembangan dan kandungan nutrisi larva Hermetia illucens (Linnaeus)(Diptera: Stratiomyidae) pada bungkil Kelapa Sawit. Jurnal Entomologi Indonesia, 7, 28-41.

Rivers DB, Dahlem GA (2013) The Science of Forensic Entomology, Wiley-Blackwell, Chichester, UK.

Sealey WM, Gaylord TG, Barrows FT, Tomberlin JK, Mcguire MA, Ross C, et al. (2011) Sensory analysis of Rainbow Trout, Oncorhynchus mykiss, fed enriched Black Soldier Fly prepupae, Hermetia illucens. Journal of the World Aquaculture Society, 42, 34-45.

Shantibala T, Lokeshwari R, Debaraj H (2014) Nutritional and antinutritional composition of the five species of aquatic edible insects consumed in Manipur, India. Journal of Insect Science, 14, 1-10.

Sheppard CD, Larry Newton G, Thompson SA, Savage S (1994) A value added manure management system using the black soldier fly. Bioresource Technology, 50, 275-279.

Sheppard CD, Tomberlin JK, Joyce JA, Kiser BC, Sumner SM (2002) Rearing methods for the black soldier fly (Diptera: Stratiomyidae). Journal of Medical Entomology, 39, 695-698.

Sheppard DC (1983) House fly and lesser fly control utilizing the black soldier fly in manure management systems for caged laying hens. Environmental Entomology, 12, 1439-1442.

Sheppard DC, Newton GL, Burtle G (2008) Black soldier fly prepupae a compelling alternative to fish meal and fish oil. Alternative Feeds for Aquaculture The National Marine Fisheries Service.

Simon P, Krüger R, Ribeiro P (2011) Influence of diets on the rearing of predatory flies of housefly larvae. Arquivo Brasileiro de Medicina Veterinária e Zootecnia, 63, 1414-1420.

Smetana S, Palanisamy M, Mathys A, Heinz V (2016) Sustainability of insect use for feed and food: life cycle assessment perspective. Journal of Cleaner Production, 137, 741-751.

Spiller D (1964) Nutrition and diet of muscoid flies. Bulletin of the World Health Organization, 31, 551.

St-Hilaire S, Cranfill K, Mcguire MA, Mosley EE, Tomberlin JK, Newton L, et al. (2007a) Fish offal recycling by the black soldier fly produces a foodstuff high in omega-3 fatty acids. Journal of the World Aquaculture Society, 38, 309-313.

St-Hilaire S, Sheppard C, Tomberlin JK, Irving S, Newton L, Mcguire MA, et al. (2007b) Fly prepupae as a feedstuff for rainbow trout, Oncorhynchus mykiss. Journal of the World Aquaculture Society, 38, 59-67.

Stanley-Samuelson DW, Jurenka RA, Cripps C, Blomquist GJ, De Renobales M (1988) Fatty acids in insects: composition, metabolism, and biological significance. Archives of Insect Biochemistry and Physiology, 9, 1-33. 
Surendra K, Olivier R, Tomberlin JK, Jha R, Khanal SK (2016) Bioconversion of organic wastes into biodiesel and animal feed via insect farming. Renewable Energy, 98, 197-202.

Tiu L (2012) Enhancing sustainability of freshwater prawn production in Ohio. Ohio State Univ. South Cent. Newsl. Fall, 11.

Tomberlin JK, Sheppard DC (2001) Lekking behavior of the black soldier fly (Diptera: Stratiomyidae). Florida Entomologist, 84, 729-730.

Tomberlin JK, Sheppard DC, Joyce JA (2002) Selected life-history traits of black soldier flies (Diptera: Stratiomyidae) reared on three artificial diets. Annals of the Entomological Society of America 95, 379-386.

Tomberlin JK, Sheppard DG (2002) Factors influencing mating and oviposition of black soldier flies (Diptera: Stratomyidae) in a colony. Journal of Entomological Society, 37, 345-352.

Ushakova N, Bastrakov A, Kozlova A, Ponomarev S, Bakaneva YM, Fedorovykh YV, et al. (2016) Features of the effect of a complex probiotic with Bacillus bacteria and the larvae of Hermetia illucens biomass on Mozambique tilapia (Oreochromis mossambicus $\times$ O. niloticus) and Russian sturgeon (Acipenser gueldenstaedti) fry. Biology Bulletin, 43, 450-456.

Van Der Spiegel M, Noordam MY, Van Der Fels-Klerx HJ (2013) Safety of Novel Protein Sources (Insects, Microalgae, Seaweed, Duckweed, and Rapeseed) and Legislative Aspects for Their Application in Food and Feed Production. Comprehensive Reviews in Food Science and Food Safety, 12, 662-678.

Van Huis A (2013) Potential of insects as food and feed in assuring food security. Annual Review of Entomology, 58, 563-583.

Van Huis A, Itterbeeck JV, Klunder H, Mertens E, Halloran A, Muir G, et al. (2013) Edible insects: future prospects for food and feed security. FAO Forestry Paper 171. Rome, Food and Agriculture Organization of the United Nations, Rome and Wageningen University and Research Centre, the Netherlands. $187 \mathrm{pp}$.

Van Lenteren JC (2003) Quality control and production of biological control agents: theory and testing procedures, CABI Publ. , Wallingford, UK.

Van Loon JJA (1991) Measuring food utilization in plant-feeding insects- Toward a metabolic and dynamic approach. In: Bernays EA (ed.) Insect- Plant Interactions. CRC Press, Boca Raton.

Veldkamp T, Van Duinkerken G, Van Huis A, Lakemond CMM, Ottevanger E, Van Boekel MAJS (2012) Insects as a sustainable feed ingredient in pig and poultry diets - a feasibility study, Wageningen UR Livestock Research, Report 638, The Netherlands.

Yu G, Cheng P, Chen Y, Li Y, Yang Z, Chen Y, et al. (2011) Inoculating poultry manure with companion bacteria influences growth and development of black soldier fly (Diptera: Stratiomyidae) larvae. Environmental Entomology, 40, 30-35.

Zhang J, Zheng L, Jin P, Zhang D, Yu Z (2014a) Fishmeal substituted by production of chicken manure conversion with microorganisms and black soldier fly. Abstract Book First International Conference Insects to Feed the World, May 14-17, 2014, Ede, The Netherlands.

Zhang J, Zheng L, Jin P, Zhang D, Yu Z (2014b) Kitchen waste converted by black soldier fly and partly substituting soymeal in chicken feed. Abstract Book First International Conference Insects to Feed the World, May 14-17, 2014, Ede, The Netherlands.

Zhang JB, Huang L, He J, Tomberlin JK, Li JH, Lei CL, et al. (2010) An artificial light source influences mating and oviposition of black soldier flies, Hermetia illucens. Journal of Insect Science, 10, 1-7.

Zheng L, Crippen TL, Holmes L, Singh B, Pimsler ML, Benbow ME, et al. (2013a) Bacteria mediate oviposition by the black soldier fly, Hermetia illucens (L.), (Diptera: Stratiomyidae). Scientific Reports 3, 1-8.

Zheng L, Crippen TL, Singh B, Tarone AM, Dowd S, Yu Z, et al. (2013b) A survey of bacterial diversity from successive life stages of black soldier fly (Diptera: Stratiomyidae) by using 165 rDNA pyrosequencing. Journal of Medical Entomology, 50, 647-658.

Zheng L, Hou Y, Li W, Yang S, Li Q, Yu Z (2012) Biodiesel production from rice straw and restaurant waste employing black soldier fly assisted by microbes. Energy, 47, 225-229. 



\section{Chapter 3}

Influence of larval density and dietary nutrient concentration on performance, body protein and fat contents of Black Soldier Fly (Hermetia illucens L.)

Karol B. Barragan-Fonseca, Marcel Dicke \& Joop J. A. van Loon
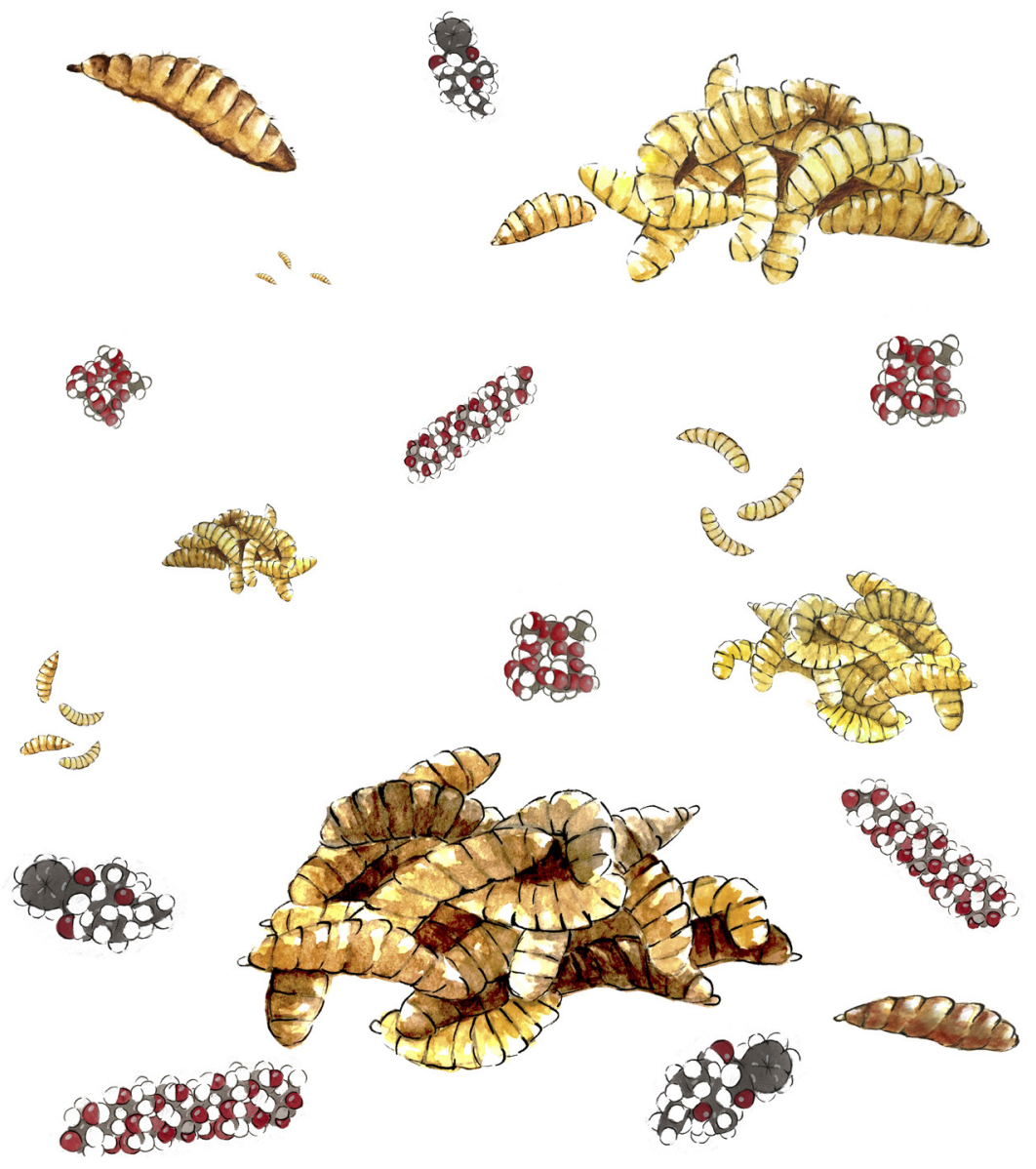


\section{Abstract}

Performance and body composition of insect larvae depends on quality and quantity of their diet, and on biotic factors such as larval density. Experiments were conducted on the Black Soldier Fly [BSF; Hermetia illucens L. (Diptera: Stratiomyidae)] to investigate the effect of dietary nutrient concentration, larval rearing density on larval survival, development, growth and larval protein and fat contents. Neonate larvae were fed with either a low (NC1), an intermediate (NC2) or a high nutrient concentration (NC3), and four rearing densities $(50,100,200$ or 400 larvae per container). Two feeding regimes were tested: in feeding regime 1 (FR1), the amount of diet added during the experiment was based on the visually estimated larval mass present, whereas in feeding regime 2 (FR2), a fixed feeding ration of $0.6 \mathrm{~g}$ of food per larva was applied at the start. FR1 resulted in food limitation resulting in significantly lower body crude protein contents on diet NC1 than on NC2 at larval densities 100 and 200. Larval crude fat content was higher on diets with higher nutrient concentration and at lower larval densities. For FR2, development time was shorter on diets with higher nutrient concentration and at lower larval densities. Individual larval weight and total larval yield increased with higher nutrient concentration at all four larval densities. At lower nutrient concentration, higher larval density resulted in higher individual larval weight and total larval yield, revealing an interaction between larval density and dietary quality. Larval crude protein content was higher at lower densities and lower nutrient concentration. Larval crude fat was higher at higher larval densities and nutrient concentrations. This study shows that larval protein content is regulated within narrow limits whereas larval crude fat content is strongly affected by nutrient concentration and also by larval density.

Key words: Black Soldier fly, detritivory, diet quality, growth, nutritional value, ration, survival. 


\section{Introduction}

The size to which an individual grows is affected by both genetic and environmental factors that operate through complex molecular and physiological mechanisms (Nijhout, 2003). Growth rate varies substantially in response to various stimuli, including resource availability, competition, predator presence, time of season, humidity and temperature (Scriber \& Slansky, 1981; Harnden \& Tomberlin, 2016). Moreover, food quality affects many life-history traits of insects such as larval and adult performance (Moreau et al., 2006).

High food quality enhances the rate of development and increases survival in some insect species (De Haas et al., 2006)2006. For example in the detritivorous larvae of the Black Soldier fly (Hermetia illucens L.; henceforth abbreviated as BSF), Nguyen et al. (2013) and Oonincx et al. (2015a), who fed larvae on vegetable by-products, observed that larvae fed diets high in protein had a shorter development time $(21 \mathrm{~d})$ than larvae fed low protein diets (37 d). Conversely, Simon et al. (2011) suggested that diets with a higher proportion of protein increase development time and survival rate of some predatory fly species.

Nguyen et al. (2013) observed an increase in growth rate and decrease in developmental duration of BSF larvae on both high protein and high fat diets. However, indications have been found that high levels of fat (20 - 36\% crude fat based on DM) may be detrimental for both larval and adult survival, lifespan and reproductive output (Ujvari et al., 2009; Nguyen et al., 2013). It seems that availability of balanced amounts of calories, fat, and protein may be more important for fast development and higher larval weight than only a high protein content (Nguyen et al., 2013).

Although BSF larvae on average contain both a high protein and fat content (Zheng et al., 2012a), body composition of the larvae depends on the quality and quantity of ingested food (Nguyen et al., 2015). For instance, larvae fed swine manure have higher protein content than those fed cow manure (Oonincx et al., 2015b), and cereal-based diets, such as chicken feed, result in higher body crude protein and fat content. Consequently larvae fed on different substrates had varying body protein contents (ranging from 37.0 to $62.7 \%$ $\mathrm{DM}$ ) and fat content, which showed more variation (ranging from 6.6 to $39.2 \% \mathrm{DM}$ ) than protein content (Barragan-Fonseca et al., 2017).

Furthermore, also physical factors may influence insect performance. For example, if the layer of food substrate consisting of meat meal, swine meat, fish or liver is too thick, larval food intake is reduced resulting in lower survival and longer developmental time (Nguyen et al., 2013). On the other hand, Lardé (1989) who fed BSF larvae on coffee-pulp substrates with different composition, observed that BSF larvae grow better on the most homogeneous, dense and dry substrate (780 $\mathrm{g} \mathrm{kg}^{-1}$ wet matter solids). Moisture levels of $60-70 \%$ 
in manure and chicken feed have been found adequate for BSF larvae (Fatchurochim et al., 1989; Myers et al., 2008). However, due to the variable composition of organic waste, food moisture is difficult to control and needs to be evaluated not only under laboratory, but also under field conditions where evaporation rate tends to be variable.

Biotic factors may also affect BSF performance. For example, larval density can be a major factor affecting the rate of development (Tomberlin et al., 2002; Diener et al., 2009). For instance, Parra Paz et al. (2015) showed that larval density has a significant influence on the bioconversion process in BSF. When the main goal of the BSF production is obtaining biomass, then working with high larval density is important, as long as overcrowding is prevented. Larval aggregation is an intrinsic trait of BSF biology and overcrowding increases the length of larval development due to competition for feed (Rivers \& Dahlem, 2013). Moreover, high larval densities may result in decreased substrate quality by accumulation of larval waste products (Green \& Popa, 2012) and may generate direct energetic costs if larvae spend extra energy interacting with each other (Jannat \& Roitberg, 2013).

Compensatory mechanisms are activated in response to crowding and nutritional deficiencies. Insects have a tendency to prolong the larval period (Miller, 1964), or to increase either the rate of ingestion or the total amount of food ingested during larval development (Green et al., 2003). Sullivan and Sokal (1963) proposed two basic types of responses to crowding: the first type is a reduction in the number of individuals able to complete their life cycles, with the emerging adults maintaining normal body size. The second type of response is sustaining survival accompanied by reduction in body weight, as has been reported for the dipterans Phormia regina (Meigen) (Calliphoridae) (Green et al., 2002), Drosophila melanogaster L., D. simulans Sturtevant (Miller, 1964), and Aedes albopictus Skuse (Yoshioka et al., 2012). According to Sullivan and Sokal (1963) for the second type of response, substantial losses in numbers will occur only at densities above which adult weight drops below a critical limit.

Lower larval densities are not always better to maximize growth rate. In some insect species, larval aggregations provide adaptive benefits to individuals due to heat generation, which might enhance food assimilation (Green, 1999 (in Green et al., 2002), and provide protection from low temperatures and possibly predators (Rivers \& Dahlem, 2013). Moreover, BSF larval weight gain would also be affected because of their potential dependence on bacteria as food (Liu et al., 2008). Higher larval densities are associated with higher bacterial densities which might allow larvae to have better access to bacterially recycled nutrients, thereby resulting in more effective nutrient absorption. Therefore, optimizing density may benefit the productivity of insect rearing. 
The aim of the present study is to investigate the effect of dietary nutrient concentration, larval rearing density, and the possible interaction between these two factors on growth characteristics and nutritional composition of BSF larvae.

\section{Materials and Methods}

\section{Experimental insects}

Hermetia illucens L. (Diptera: Stratiomyidae) larvae were obtained from a colony maintained at constant conditions in a climate room $\left(27 \pm 1{ }^{\circ} \mathrm{C}, 70 \%\right.$ R.H., L12:D12) at the Laboratory of Entomology, Wageningen University (The Netherlands).

\section{Experimental design}

This experiment was based on a $3 \times 4$ factorial design with three levels of dietary nutrients obtained by diluting commercial chicken feed (Opfokmeel Farmfood, Agruniek Rijnvallei Voer BV, Wageningen, The Netherlands) with cellulose (Alphacel non-nutritive bulk, MP Biomedicals, LLC, Illkirch, France) (Table 1), and four rearing densities (D) obtained by placing 50,100, 200 and 400 larvae $(<24 \mathrm{~h}$ since larval hatching) per plastic container $\left(15.5 \times 10.5 \times 6 \mathrm{~cm}\right.$; resulting in $0.31,0.62,1.23$, and 2.47 larva $/ \mathrm{cm}^{2}$ respectively). The expression of density per unit surface is a proxy for actual relevant density which should be expressed per unit of volume. The densities were selected according to the minimal and maximal densities calculated from information presented in studies on BSF performed by (Sheppard et al., 2002). The plastic containers were covered with transparent plastic lids with 90 holes (diameter $0.05 \mathrm{~cm}$ each) for ventilation.

Table 1. Composition of experimental diets

\begin{tabular}{cccc}
\hline & \multicolumn{3}{c}{ Experimental Diets } \\
\hline Ingredient (\%) & NC1 & NC2 & NC3 \\
Chicken feed & 23 & 43 & 85 \\
Cellulose & 77 & 57 & 15 \\
\hline Nutrient (\%) & & & \\
Protein & 3.5 & 7 & 14 \\
Fat & 0.7 & 1.4 & 1.8 \\
Carbohydrate & 12 & 23 & 46 \\
\hline
\end{tabular}

${ }^{1}$ Non-cellulose carbohydrate

Two experiments tested two feeding regimes respectively: Feeding Regime 1 (FR1) and Feeding Regime 2 (FR2). In FR1, the amount of diet added per occasion (three times per week) was based on the visually estimated larval mass present. On each occasion a standard amount of food per treatment was added (all replicates of the same treatment received the same amount of food). If the food in the containers was almost fully consumed, based on visual assessment of the colour of the residue, which is leftover diet mixed with frass, 
more food was provided. For each gram of food provided to the larvae, 1.6, 2.6 and $3 \mathrm{ml}$ of tap water was added for NC3, NC2, and NC1 diets respectively, to account for the greater water absorption by higher amounts of cellulose, to obtain $-70 \%$ of moisture. In FR2, there was a fixed food ration of $0.6 \mathrm{~g}$ of food (dry matter basis) per larva (density-independent food availability), which was provided at the beginning of the experiment. A preliminary experiment had shown that larvae fed once rather than three times per week reached a higher biomass. For each diet 6 replicates were performed. One replicate was one container with either 50,100, 200 or 400 larvae. Both feeding experiments were conducted in a climate room $\left(4.5 \mathrm{~m}^{2}\right)$ and conducted at $27 \pm 1{ }^{\circ} \mathrm{C}, 55 \pm 5 \%$ R.H., and photoperiod L12:D12. In order to eliminate possible effects of position in the chamber, all containers were randomly relocated three times per week.

\section{Immature life-history traits}

All larvae in a container were harvested when the first prepupa was observed, distinguished by the characteristic black cuticle of prepupae contrasting with the white larvae (May, 1961). All animals from each container were harvested with forceps, and counted. Larvae were washed under running water to remove feed and faecal residues, their integument dried with paper tissue. To obtain dry mass, the samples were oven-dried at $70^{\circ} \mathrm{C}$ until constant weight. BSF larval yield ( $\mathrm{g}$ dry matter) was determined using a precision balance (Ohaus, Adventurer Pro AV313, Parsippany - USA, precision $\pm 0.001 \mathrm{~g}$ ). To determine survival rate, the number of live BSF larvae at the end of the experiment was divided by the initial number of larvae per replicate. Development time was considered to be the number of days between the start of the experiment, and the day the first prepupa was observed.

\section{Proximate chemical analysis of larvae}

BSF samples were stored in a freezer $\left(-25^{\circ} \mathrm{C}\right)$ after dry mass had been assessed until all replicates were harvested. Both the larvae and the diets were analysed for dry matter (DM), crude protein, and crude fat at the Animal Nutrition Laboratory of Wageningen University. The samples were oven-dried at $70^{\circ} \mathrm{C}$ until constant weight and homogenised by grinding the sample in an ultra-centrifugal mill (Retsch ZM 200, Haan - Germany). Nitrogen content was determined using the Kjeldahl method (ISO 5983-1, 2005) and converted to crude protein content by multiplication with factor 6.25. Crude fat was analysed according to the Berntop method (ISO 6492, 1999).

\section{Statistical analysis}

Data were analysed using Generalized Linear Models to test the effect of nutrient concentration and rearing density as the two factors. To compare the effect of nutrient concentration within a larval density, one-way Analysis of Variance (ANOVA) at a significance level of 0.05 was performed, followed by post-hoc Tukey tests. Kruskal-Wallis tests were 
performed when assumptions of normality and/or homoscedasticity were not met. IBM SPSS Statistics version 21.0 was used (IBM Corp., Armonk, NY).

\section{Results}

\section{Feeding regime 1}

\section{Performance}

Survival rate was significantly affected by rearing density and density-nutrient interaction (GLM, $\mathrm{P} \leq 0.001)$ but only marginally significantly by nutrient concentration $(\mathrm{P}=$ 0.064) (Table 2). Development time, individual larval weight, and larval yield (DM basis) were significantly affected by nutrient concentration, rearing density, and their interaction (GLM, P $\leq$ 0.001). Overall, development time increased with lower protein content. At densities D200 and D400 fed on the low nutrient diet (NC1) no prepupae were observed until 45 days after the start of the experiment (Table 2). Individual larval weight was higher at higher nutrient levels at each larval density (Figure 1A). Total larval yield per container was higher at higher nutrient levels (Figure 1B).

Table 2. Food added, survival rate and development time (mean \pm standard deviation) of Hermetia illucens larvae on three diets differing in nutrient concentration (NC) under feeding regime 1, kept at four larval densities per container.

\begin{tabular}{|c|c|c|c|c|}
\hline \multirow{2}{*}{\multicolumn{2}{|c|}{ Diet }} & \multicolumn{3}{|c|}{ Feeding Regime 1} \\
\hline & & \multirow{2}{*}{$\begin{array}{c}\text { Food added } \\
\text { (g/larva) }\end{array}$} & \multirow{2}{*}{$\begin{array}{c}\text { Survival rate } \\
(\%)\end{array}$} & \multirow{2}{*}{$\begin{array}{l}\text { Development time } \\
\text { (d) }\end{array}$} \\
\hline Density & NC & & & \\
\hline 50 & 1 & 0.24 & $97.7 \pm 2.5 \mathrm{e}^{1}$ & $22.5 \pm 1.5 \mathrm{e}^{1}$ \\
\hline 50 & 2 & 0.41 & $98.1 \pm 2.7 \mathrm{e}$ & $16.7 \pm 0.9 \mathrm{f}$ \\
\hline 50 & 3 & 0.51 & $93.6 \pm 4.1 \mathrm{f}$ & $15.9 \pm 0.3 \mathrm{f}$ \\
\hline 100 & 1 & 0.14 & $95.5 \pm 2.1 \mathrm{~g}^{2}$ & $26.8 \pm 3.1 \mathrm{~g}^{1}$ \\
\hline 100 & 2 & 0.25 & $94.7 \pm 2.7 \mathrm{~g}$ & $16.7 \pm 1.0 \mathrm{~h}$ \\
\hline 100 & 3 & 0.36 & $89.5 \pm 6.4 \mathrm{~h}$ & $15.8 \pm 0.4 \mathrm{~h}$ \\
\hline 200 & 1 & 0.09 & $87.1 \pm 6.9 \mathrm{i}^{2}$ & $-^{a}$ \\
\hline 200 & 2 & 0.17 & $92.0 \pm 4.9 \mathrm{i}$ & $21.0 \pm 0.6 \mathrm{i}^{3}$ \\
\hline 200 & 3 & 0.2 & $93.9 \pm 3.5 \mathrm{i}$ & $15.8 \pm 0.4 j$ \\
\hline 400 & 1 & 0.06 & $88.2 \pm 3.5 \mathrm{k}^{2}$ & $-^{a}$ \\
\hline 400 & 2 & 0.1 & $90.5 \pm 4.9 \mathrm{k}$ & $21.5 \pm 0.8 \mathrm{k}^{3}$ \\
\hline 400 & 3 & 0.13 & $91.7 \pm 1.0 \mathrm{k}$ & $19.2 \pm 1.5 \mathrm{k}$ \\
\hline
\end{tabular}

${ }^{a}$ No prepupae were observed until 45 days after the start of the experiment.

${ }^{1}$ Comparison of means between NC-levels per larval density performed by Kruskal-Wallis test;

${ }^{2}$ Comparison of means by ANOVA and Tukey post-hoc test; ${ }^{3}$ Comparison of means by Student's t-test. Number of replicates per density/NC combination was 6. Different letters next to the standard deviation indicate differences between means at the indicated larval density. 


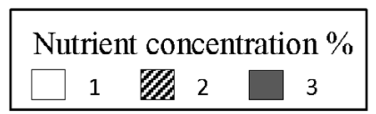

(A)

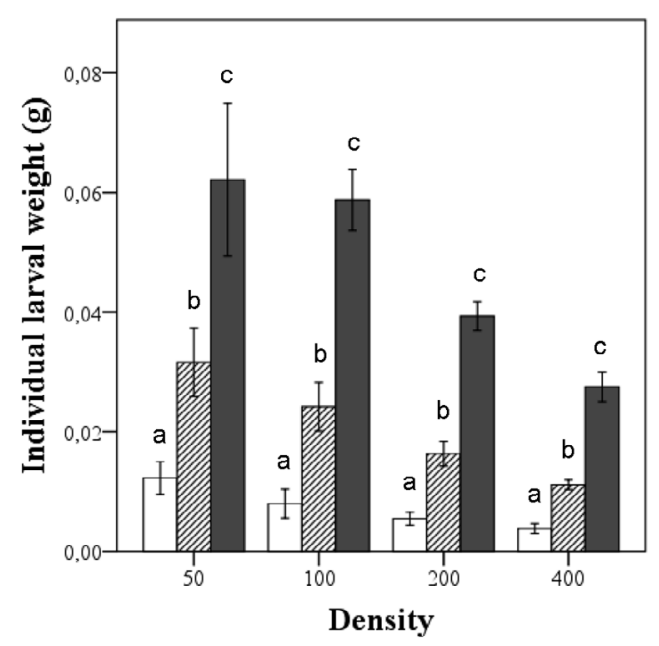

(B)

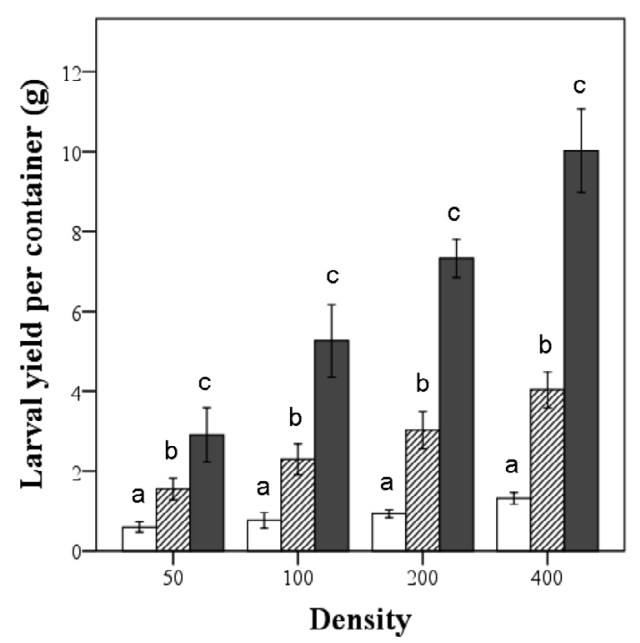

Figure 1. Black Soldier Fly individual larval weight and larval yield per container for Feeding Regime 1 (FR1). Bars (mean \pm SD) indicate (A) individual larval weight on DM basis (g) and (B) larval yield on DM basis ( $\mathrm{g}$ ) at different larval densities and nutrient concentrations. Statistical tests based on Generalized Linear Models are explained in the Results section. Different letters above bars indicate differences between means at the indicated larval density (D100 and D200: ANOVA followed by Tukey post-hoc test, $\mathrm{P}<0.05$; D50 and D400: Kruskal-Wallis test).

\section{Larval body composition}

Larval crude protein content was affected by nutrient content of the $\operatorname{diet}(\mathrm{F}(2,24)=6.3, \mathrm{P}$ $<0.001)$, rearing density $(\mathrm{F}(3,24)=6.3, \mathrm{P}<0.001)$, and their interaction $(\mathrm{F}(6,24)=2.7$, $\mathrm{P}=0.039)$. At $\mathrm{D} 50$ and $\mathrm{D} 100$, crude protein content was slightly but significantly higher for larvae fed NC2-diet (D50, Kruskal-Wallis test, P < 0.05; D100, ANOVA, P < 0.05) (Figure 2a). Also crude fat content was affected by dietary nutrient content $(F(2,24)=71.9$, $\mathrm{P}<0.001)$, rearing density $(\mathrm{F}(3,24)=30.2, \mathrm{P}<0.001)$, and their interaction $(\mathrm{F}(6,24)=$ 2.9, $\mathrm{P}=0.026$ ). Crude fat was clearly higher in BSF larvae fed NC3 compared to the lower two nutrient concentrations and higher for larvae fed NC2 compared to NC1 (Figure 2b). 


\section{Nutrient concentration \%}

$\square 1 \square_{1} \mathbb{Z}_{2} \quad \square_{3}$

(A)

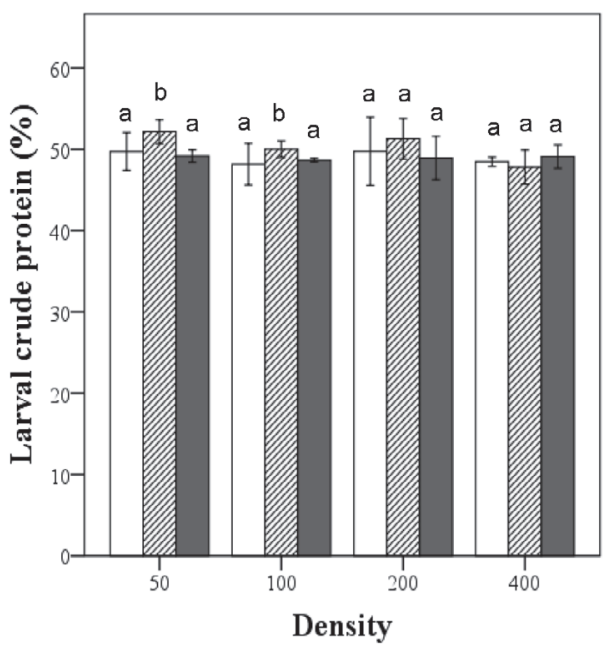

(B)

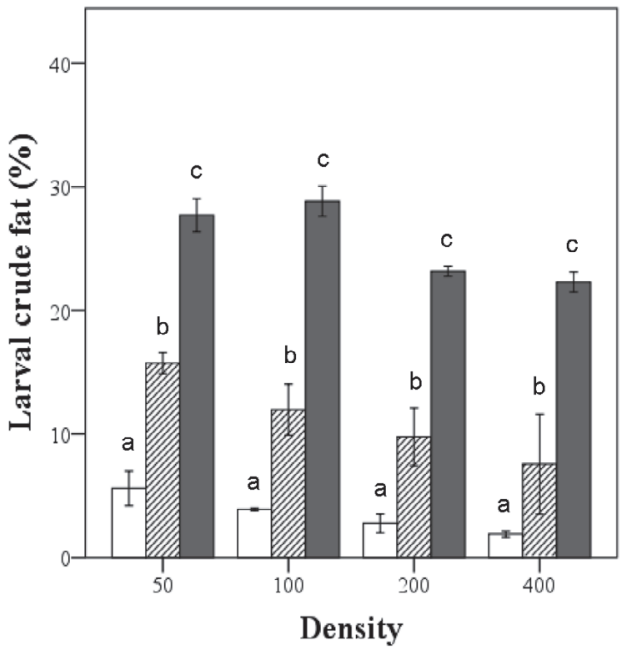

Figure 2. Black Soldier Fly larval crude protein and fat contents for Feeding Regime 1 (FR1). Bars (mean \pm SD) indicate (A) larval crude protein (DM\%), and (B) larval crude fat (DM\%) for different larval densities and dietary nutrient concentrations. Different letters above bars indicate differences between means at the indicated larval density (Crude protein: ANOVA followed by Tukey post-hoc test, $\mathrm{P}<0.05$. Crude fat: ANOVA followed by Tukey post-hoc test, $\mathrm{P}<0.05$ ).

\section{Feeding regime 2}

\section{Performance}

Larval survival rate was not significantly affected by either rearing density $(\mathrm{F}(3,60)=0.84$, $\mathrm{P}=0.47)$, nor by nutrient concentration $(\mathrm{F}(2,60)=1.2, \mathrm{P}=0.307)$ or their interaction $(\mathrm{F}(6,60)=2.62, \mathrm{P}=0.25)$ (Table 3 ). Overall, larval performance was positively affected by both higher nutrient concentration and larval density. Development time was affected by nutrient content $(\mathrm{GLM}, \mathrm{P} \leq 0.0001)$ and rearing density $(\mathrm{P} \leq 0.0001)$, but not by their interaction $(\mathrm{P}=0.124)$. Lower densities and higher nutrient content accelerated larval development (Table 3). Individual larval weight and larval yield per container were affected by nutrient content (GLM, $\mathrm{P} \leq 0.0001)$, rearing density $(\mathrm{P} \leq 0.0001)$, and their interaction $(\mathrm{P} \leq 0.0001)$ (Figure 3A). Higher nutrient concentration resulted in significantly higher individual larval weight for D100 and D200 densities. Larval yield per container increased at higher nutrient levels and densities (Figure 3B). 
Table 3. Survival rate and development time of Hermetia illucens larvae on different diets FR2 ${ }^{\mathrm{a}}$.

\begin{tabular}{|c|c|c|c|}
\hline \multirow{2}{*}{\multicolumn{2}{|c|}{ Diet }} & \multicolumn{2}{|c|}{ Feeding regime 2} \\
\hline & & \multirow{2}{*}{$\begin{array}{c}\text { Survival rate } \\
(\%)\end{array}$} & \multirow{2}{*}{$\begin{array}{c}\text { Development time }^{2} \\
\text { (d) }\end{array}$} \\
\hline Density & $\mathrm{NC}$ & & \\
\hline 50 & 1 & $87.3 \pm 4.1 \mathrm{e}$ & $15.3 \pm 0.5 \mathrm{e}$ \\
\hline 50 & 2 & $93.0 \pm 3.3 \mathrm{ef}$ & $13.7 \pm 0.8 \mathrm{f}$ \\
\hline 50 & 3 & $95.0 \pm 5.0 \mathrm{f}$ & $13.3 \pm 0.5 f$ \\
\hline 100 & 1 & $92.8 \pm 3.4 \mathrm{~g}$ & $15.7 \pm 0.5 \mathrm{~g}$ \\
\hline 100 & 2 & $90.2 \pm 4.8 \mathrm{~g}$ & $13.8 \pm 0.4 h$ \\
\hline 100 & 3 & $92.0 \pm 4.9 \mathrm{~g}$ & $13.5 \pm 0.5 \mathrm{~h}$ \\
\hline 200 & 1 & $90.0 \pm 4.7 \mathrm{i}$ & $16.7 \pm 0.5 \mathrm{i}$ \\
\hline 200 & 2 & $90.5 \pm 2.9 \mathrm{i}$ & $15.7 \pm 1.4 \mathrm{ij}$ \\
\hline 200 & 3 & $89.2 \pm 2.1 \mathrm{i}$ & $13.8 \pm 0.4 \mathrm{j}$ \\
\hline 400 & 1 & $93.2 \pm 3.7 \mathrm{k}$ & $17.8 \pm 1.3 \mathrm{k}$ \\
\hline 400 & 2 & $88.7 \pm 2.1 \mathrm{k}$ & $17.0 \pm 0.6 \mathrm{kl}$ \\
\hline 400 & 3 & $92.8 \pm 2.8 \mathrm{k}$ & $15.3 \pm 1.61$ \\
\hline
\end{tabular}

${ }^{a}$ Values are mean \pm standard deviation; $\mathrm{n}=6$ per density $/ \mathrm{NC}$ combination.

${ }^{1}$ Comparison of means between NC-levels per larval density performed using ANOVA and Tukey post-hoc test; ${ }^{2}$ Comparison of means performed using Kruskal-Wallis test. Different letters next to the standard deviation indicate differences between means at the indicated larval density.

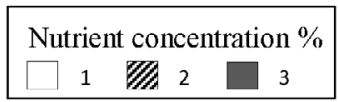

(A)

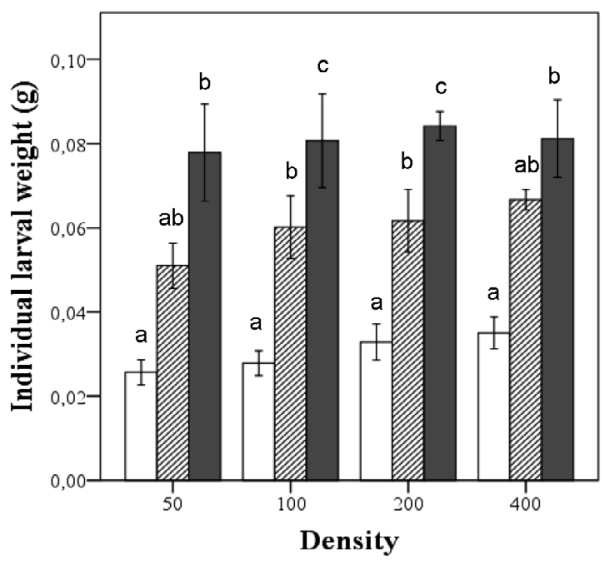

(B)

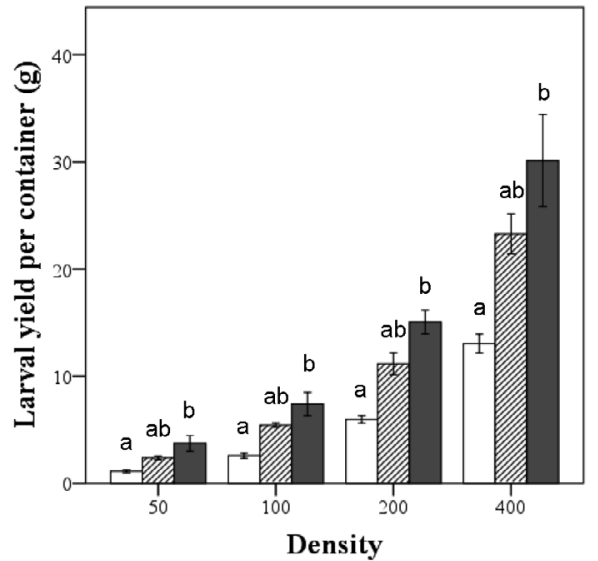

Figure 3. Black Soldier Fly individual larval weight and larval yield per container for Feeding Regime 2 (FR2). Bars (mean \pm SD) indicate (A) individual larval weight (g) on DM basis and (B) larval yield $(\mathrm{g})$ on DM basis for different densities and dietary nutrient concentrations. Statistical comparisons were made by Generalized Linear Model analysis, details of which are presented in the Results section. Mean values that have no letters in common differ significantly at the indicated larval density (Larval weight: ANOVA followed by Tukey post-hoc test, $\mathrm{P}<0.05$; Larval yield: Kruskal-Wallis test). 


\section{Larval body composition}

Crude protein content was affected by nutrient concentration $(\mathrm{F}(2,54)=8.5, \mathrm{P}<0.001)$, rearing density $(\mathrm{F}(3,54)=32.1, \mathrm{P}<0.001)$, and their interaction $(\mathrm{F}(6,54)=3.4, \mathrm{P}=0.006)$. Overall, crude protein content in BSF larvae was lower at higher larval densities. Crude protein content was similar among NC-levels per larval density; only at D100, crude protein content was significantly higher for larvae fed on NC1-diet (ANOVA, $\mathrm{P}<0.05$ ) (Figure 4A). Crude fat was affected by nutrient content $(\mathrm{F}(2,54)=67.1, \mathrm{P}<0.001)$, and rearing density $(\mathrm{F}(3,54)=48.9, \mathrm{P}<0.001)$, but not by their interaction $(\mathrm{F}(6,54)=1.9, \mathrm{P}$ $=0.096$ ). Larval crude fat was lower at NC1-diet at all four densities (ANOVA, $\mathrm{P}<0.05$ ), and similar at $\mathrm{NC} 2$ and $\mathrm{NC} 3$ at each density except for D50 at which larval crude fat was significantly higher at NC3 (ANOVA, P < 0.05) (Figure 4b). There was a significant relationship between larval weight and larval crude fat content (Pearson correlation coefficient $\mathrm{r}=0.66, \mathrm{P}<0.005)$. Plotting larval body crude protein against body crude fat contents, a trend appears by which higher NC at higher larval densities increased larval crude fat content. Conversely, lower NC at lower larval densities increased larval crude protein content (Figure 5).

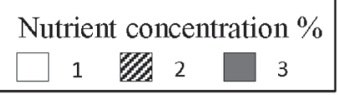

(A)

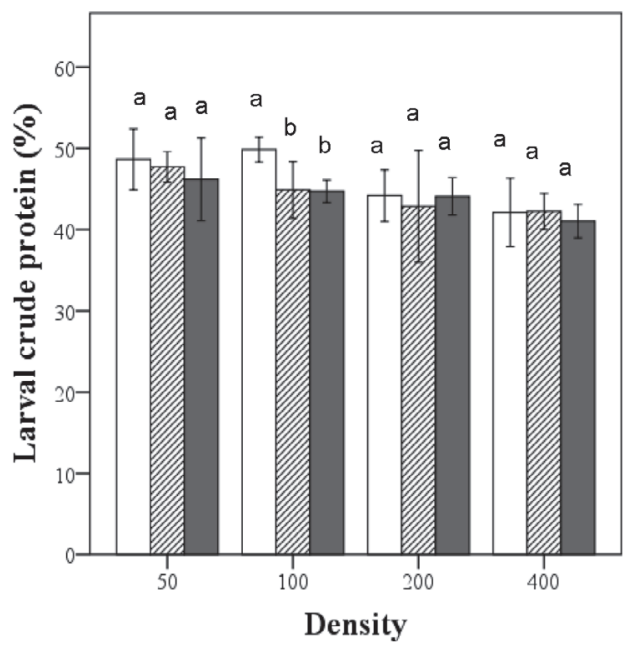

(B)

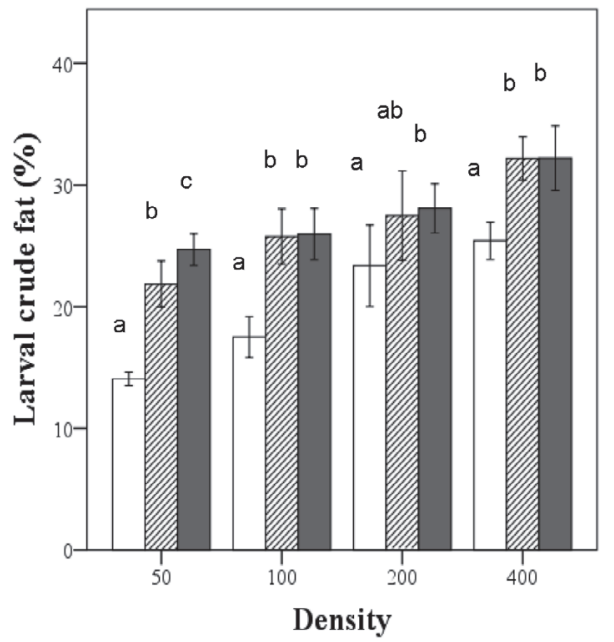

Figure 4. Black Soldier Fly larval crude protein and fat contents in feeding regime 2 (FR2). Bars $($ mean $\pm S D)$ indicate $(A)$ larval crude protein $(\mathrm{DM} \%)$, and $(\mathrm{B})$ larval crude fat $(\mathrm{DM} \%)$ for different larval densities and dietary nutrient concentrations. Different letters above bars indicate differences between means at the indicated larval densities (ANOVA followed by Tukey post-hoc test, $\mathrm{P}<0.05)$. 


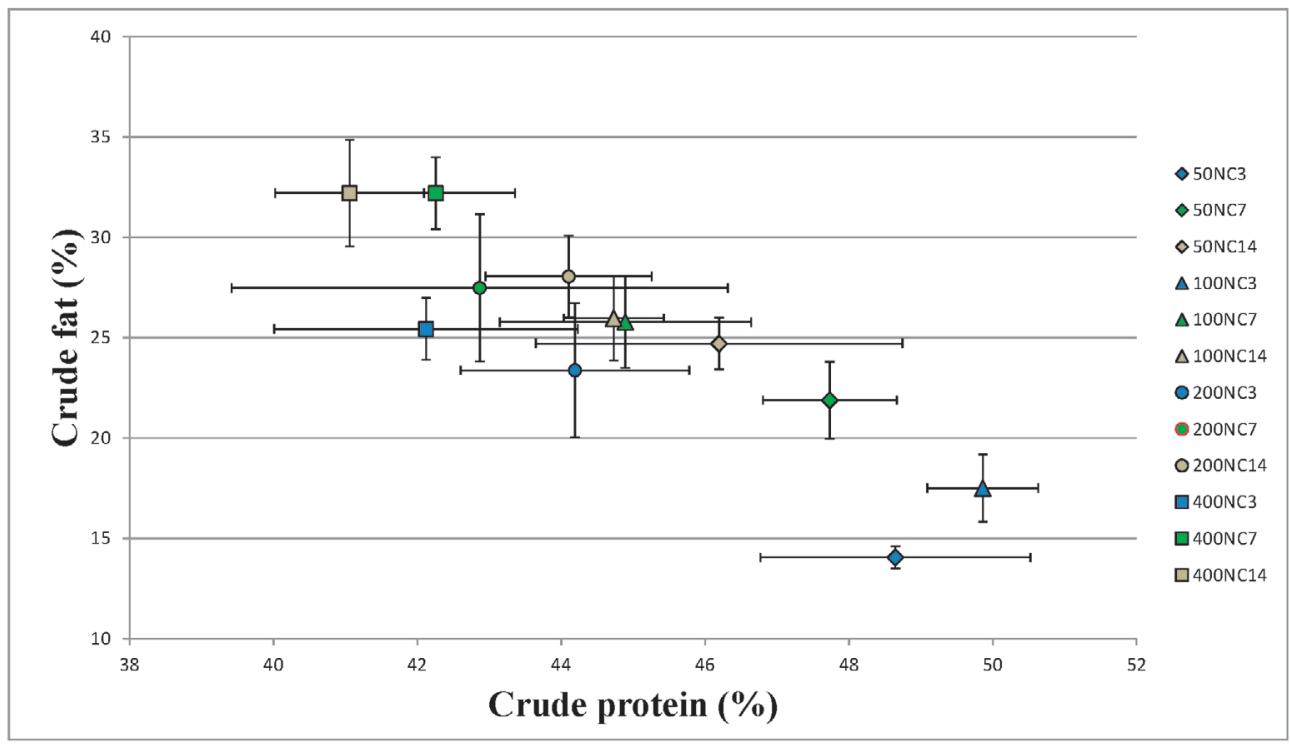

Figure 5. Black Soldier Fly larval crude fat and protein contents as a percentage of dry matter plotted for each treatment. Treatment symbols are explained in the legend at the right hand side: the first two or three digits refer to the larval density (number of larvae per container), followed by $\mathrm{NC} 1$ for low nutrient concentration, $\mathrm{NC} 2$ for intermediate or NC3 for high nutrient concentration (see Material and methods). Vertical and horizontal error bars represent standard error of the mean.

\section{Discussion}

Nutritional strategies used by an individual or group of insects are shaped by their physiology, behaviour and performance (Lihoreau et al., 2015). The processes of seeking, obtaining, allocating and utilising food are influenced by several biotic and abiotic factors, such as insect density and nutrient concentrations. Studying the effect of these factors on nutrition and development of insects is particularly important for mass-rearing insects for feed and food in order to optimise productive performance and nutritional quality. Detailed knowledge of the conditions required for optimal growth, development and nutrient allocation of BSF is necessary for implementation of large-scale production systems (Coelho et al., 2013). The effect of nutrient density of the ingested food on development, growth and body composition of BSF (Gobbi et al., 2013) in interaction with larval density has not been systematically investigated before.

\section{Larval performance}

In FR1 food consumption was difficult to estimate for the low and medium nutrient concentrations due to the high content of cellulose, that had been added as non-nutritive bulk 
used for dilution of nutrients. The cellulose bulk interfered with visual estimation of how much diet was uneaten, causing that we added less food to the lower NC treatments which in turn caused food limitation. Insects can respond to reduced nutrient levels in their diets by increasing either the rate of ingestion or extending the duration of ingestion (Slansky \& Scriber, 1985; Slansky \& Wheeler, 1989). During food shortage or other unfavourable conditions, BSF larvae reduce food intake or cease to feed (Diener et al., 2011a). Since we did not measure food intake directly, we cannot distinguish which of the two responses occurred. We subsequently fed larvae ad libitum in FR2 to properly assess the effects of nutrient concentration and larval density.

BSF larvae are extremely resilient due to their capability of dealing with unfavourable conditions (Diener et al., 2011b). This is confirmed by our findings of high survival rate, not only in FR2, but also in FR1, despite the strong feed limitation in the latter regime at the lowest $\mathrm{NC}$ and highest densities. The data from this study show that BSF larvae, similar to Drosophila melanogaster and $D$. simulans larvae, are capable of physiological adjustments which allow them to survive in nearly equal proportions at low and high larval densities (Miller, 1964). Other factors may impact survival more than diet availability or larval density, in particular temperature (Couret et al., 2014). The direct dependence of development on temperature has been shown for a variety of dipteran species. In Musca domestica, survival rate and larval development time are more affected by temperature than by larval density (Barnard \& Geden, 1993). Ambient temperature largely determines metabolic and development rates of BSF (Jarośík et al., 2004). Development time is increased at high (> $\left.32^{\circ} \mathrm{C}\right)$ or low $\left(<16^{\circ} \mathrm{C}\right)$ temperatures, $26-27^{\circ} \mathrm{C}$ being the optimum temperature for $\mathrm{BSF}$ larvae (Tomberlin et al., 2009; Holmes et al., 2016).

Insect survival rates can be affected not only by a low nutrient quality diet, but also by an excess of macronutrients like protein or fat. For example, BSF larvae reared on diets high in protein (32-50\% crude protein on DM basis) such as Dried Distillers Grains with Solubles (DDGS), meat meal, liver or fish had high mortalities (78, 80, 43 and 53\% respectively) (Tschirner \& Simon, 2015). This may be explained by an excessive energy use for metabolizing this nutrient excess or by a high ammonium $\left(\mathrm{NH}_{4}^{+}\right)$accumulation. Excess protein nitrogen is excreted as uric acid, as purines related to uric acid, as ammonia or ammonium salts, and in several other forms. Dipteran species excrete the water-soluble allantoin, the immediate degradation product of uric acid, which is converted to urea, and by the action of urease to ammonium (Green \& Popa, 2012). Thus, BSF larvae fed on high protein diets markedly increase $\mathrm{N}$-mineralization and have an elevated faecal ammonium concentration.

The high survival rate observed for all NC-levels shows that BSF maintain a high survival rate at the expense of body weight under unfavourable food conditions, as it is observed in 
Musca domestica (Sullivan \& Sokal, 1963). Despite the high survival rate, under extreme food limitation BSF larvae had extended development time (ranging from 16 - 27 days) or could not complete larval development at all. In FR1, the larvae with the strongest food limitation at higher densities (D200 and 400 at NC1) did not reach the prepupal stage until 45 days, after which observations were stopped. The increases in developmental period upon crowding are apparently related to the inability of the larvae to complete larval development with the limited amount of feed and/or its low nutrient content.

In FR2, development time was affected by NC and larval density, increased with lower protein content and higher density, a pattern similar to that observed by Green et al. (2003) in larvae of Phormia regina. Larvae ingested food for a longer period of time, increasing their developmental time to obtain sufficient nutrition for pupation. The shortest development time (13 d) was achieved at the highest NC and lowest density, very similar to the time reported for BSF larvae fed with chicken feed (Spranghers et al., 2016). Larvae of the mosquito species Aedes albopictus and Anopheles gambiae Giles on high nutrient diets had shorter development times (Yoshioka et al., 2012; Jannat \& Roitberg, 2013).

Although for FR2 feed availability was density-independent, high larval densities still resulted in prolonged development time. Probably, larvae have to spend more time to locate food or overcrowding may result in toxic concentrations of by-products (Green \& Popa, 2012, Yoshioka et al., 2012). Under crowded conditions, BSF has a tendency to prolong the larval period similar as has been suggested to occur for Drosophila spp. (Miller, 1964), Aedes aegypti L. (Couret et al., 2014) and An. gambiae (Jannat \& Roitberg, 2013). A compound that retards growth is produced by overcrowded larvae of these mosquito species that also acts on the other species (Couret et al., 2014).

For FR2, individual larval weight and yield were positively affected by nutrient concentration at all four larval densities. Several authors observed that BSF larvae fed a diet high in protein and fat had a higher growth rate than fed low protein and fat diets (Nguyen et al., 2013; Oonincx et al., 2015a; Tschirner \& Simon, 2015). Grasshopper nymphs (Schistocerca americana Drury) fed diets having intermediate to high nutrient contents were significantly larger than nymphs fed low nutrient content diets (Hahn, 2005). However, high dietary fat content can also reduce BSF larval performance, either increasing the development time or reducing larval weight, ascribed to difficulties in processing fat (Spranghers et al., 2016). Considering highest larval weight as an indicator of dietary quality (Green et al., 2003), the NC3 diet was the most favourable diet composition tested.

Achieving high larval weight is not only increasing biomass production, but also improving BSF fertility, because increase in pupal weight generally increases fecundity of flies (Gobbi et al., 2013). Maintaining population numbers at the expense of weight (and hence 
fertility) may also maintain the genetic variability of the population (Bhalla \& Sokal, 1964). This mechanism is considered to be adaptive (Black \& Krafsur, 1986) .

Protein, carbohydrates and fat are not the only components to consider in studying assimilation by BSF. Cellulose, another main component of the diet supplied, could play a role in BSF nutrition. Lee et al. (2014) and Supriyatna and Ukit (2016) studied the digestive capabilities of BSF and reported cellulase activity in the gut microflora of the species, produced by cellulolytic bacteria, in particular Bacillus spp., hence BSF could be using cellulose nutritionally. However, the quantity of cellulose that BSF ingests and digests has not been quantified.

In this study, higher densities positively affected individual larval weight at $\mathrm{NC1}$ and NC2 in FR2. Larval aggregation produces higher temperatures that enhance food assimilation (Rivers \& Dahlem, 2013). For instance, in blowfly larvae (Phormia regina), larval aggregation has been reported to result in more efficient feeding, because the increased concentration of tryptic and alkaline excretions from groups of $P$. regina larvae may release more nutrients from the diet and allowed groups of larvae to forestall the toxic effects of some chemicals that interfere with conversion of amino acids and peptides into body mass, such as mimosine (Green et al., 2002). Probably, the alkaline excretions of groups of larvae neutralises the acidity associated with bacterial growth and pre-digests the substrate (Green et al., 2003).

Overall, because our second experiment separated crowding per se from the effects of crowding via reduced food consumption, it appears that larval crowding affects positively larval performance. For instance, in view of the high survival rate observed for all densities and the enhanced overall larval performance at the highest densities, we conclude that overcrowding did not occur in BSF larvae. Parra Paz et al. (2015) found that larval density values of up to 5 larvae $/ \mathrm{cm}^{2}$ do not have significant influence on larval performance (development time and weight) as long as they are provided with an amount of food no lower than $1.7 \mathrm{~g} /$ larva (DM). It is possible that an overcrowding environment reduces final larval weight as it has been seen in Musca domestica L. (Barnard and Geden, 1993).

\section{Larval body content}

BSF larvae on average have both a high protein and fat content and their body composition depends on the quality of food ingested (Barragan-Fonseca et al., 2017). In this study, we found that larval crude protein was affected by nutrient concentration, density and their interaction in both feeding regimes. Larval crude protein content was similar in both feeding regimes and similar to values found in previous studies for larvae fed on chicken feed, by-products and manure (43.2 $\pm 2.7 \% \mathrm{DM})$ (Barragan-Fonseca et al., 2017). Larvae fed on high protein substrates, such as liver or meat, have higher protein content $(60.3 \pm$ $3.3 \% \mathrm{DM})$, and larvae fed on vegetable waste have lower protein content (38.5\% DM) 
(Nguyen et al., 2015). Although there were significant differences in larval crude protein content among the three diets we tested, the absolute differences were small.

Although larval body composition depends on diet quality, dietary protein content did not determine the protein content in the larval body. In our study, the low protein content $(3.5 \%)$ in the $\mathrm{NC1}$ diet resulted in a similarly high larval crude protein content as on the NC2 and NC3 diets. Indeed, at FR2 the highest crude protein content was found in larvae at the lowest NC. This is in line with the findings of Tschirner and Simon (2015) who reported that crude protein was higher $(52.3 \% \mathrm{DM})$ in larvae fed on the diet with the lowest crude protein content (8.5\% DM). Spranghers et al. (2016) also found a similar protein content (ranging from 40 to $43 \%$ DM) in larvae fed on diets having protein contents ranging from 9 to $25 \% \mathrm{DM}$.

Insect crude protein levels have commonly been calculated from total elemental nitrogen content using the standard nitrogen to protein conversion factor of 6.25. According to Janssen et al. (2017), this factor overestimates the protein content, due to the presence of non-protein nitrogen in insects. For instance, Diener et al. (2009) and Spranghers et al. (2016) reported that BSF larvae had between 5 and $20 \%$ lower crude protein content when corrected for chitin. Janssen et al. (2017) propose the conversion factor of 4.67 to be adopted for determining protein content of BSF larvae to avoid overestimation.

Larval crude fat content was also affected by nutrient concentration, density and their interaction, and strong differences were observed between both feeding regimens. In FR1 overall crude fat content was lower than in FR2, likely due to food limitation. Larvae that did not reach the prepupal stage had the lowest crude fat contents and the lowest larval weights, which points to starvation of the larvae; thus they had to mobilise their fat reserves (Tschirner \& Simon, 2015), did not grow and could not complete development. From a physiological perspective development time is an emergent property, because moulting and metamorphosis are triggered by size, not by time (Grunert et al., 2015). In FR2, the crude fat content was lower in larvae fed with diet NC1, than in larvae fed on the NC2 and NC3 diets at all three densities. Larvae fed on NC2 and NC3 diets had similar fat content. These fat contents are in the range of values reported in the literature on BSF larvae and vary substantially among substrates (ranging from 7 to $39 \% \mathrm{DM}$ ) (Barragan-Fonseca et al., 2017). For instance, substrates with high fat and carbohydrate contents increase larval crude fat content (Zheng et al., 2012b), whereas larvae fed on high fibre and/or low fat diets have lower crude fat content (3.4-6.6\% DM) (Nguyen et al., 2015; Tschirner \& Simon, 2015).

The fat body is the main energy storage organ of larval holometabolous insects such as BSF, to be used during metamorphosis as well as to provide reserves for the adult stage 
(Andrewartha, 1952). Lipid is the main fat body component, and more than $90 \%$ of the lipid stored is in the form of triglycerides, which are synthesized from dietary carbohydrates, fatty acids, or proteins (Arrese \& Soulages, 2010). In BSF, a large proportion of dietary fatty acids are converted to lauric acid (C12:0) (Oonincx et al., 2015a). The large differences in larval crude fat content can likely be explained by the differences in energy content of the feed, and diets high in energy content would increase larval crude fat.

The body size at which a larva stops growing determines adult body size (Grunert et al., 2015). In BSF adult weight is positively correlated with adult fertility, females with larger bodies had the largest ovaries and basal oocytes (Gobbi et al., 2013). In this study we also found that heavier BSF larvae had higher crude fat contents, which could be important for adult fitness (Andrewartha, 1952). Grasshopper nymphs (S. americana) fed diets with intermediate to high nutrient contents contained a significantly greater proportion of lipid stores in the adult stage, but not greater protein or carbohydrate reserves than individuals fed low nutrient content diets (Hahn, 2005).

In conclusion, our experiments demonstrated that larval density and nutrient concentration affect BSF performance and body composition, high nutrient concentration being a determining factor. Moreover, larval protein content is regulated within narrow limits whereas larval crude fat content is strongly affected by both nutrient concentration and by larval density. Larger-scale experiments are required to verify that the results reported here can be extrapolated. Follow-up experiments should also evaluate consequences for the adult stage as reproduction is a main factor in the continuity of an animal production system.

\section{Acknowledgements}

This work was supported by the Scholarship Program No. 568 from COLCIENCIAS Departamento Administrativo de Ciencia, Tecnología e Innovación - Colombia.

\section{References}

Andrewartha H (1952) Diapause in relation to the ecology of insects. Biological Reviews, 27, 50-107. Arrese EL, Soulages JL (2010) Insect fat body: energy, metabolism, and regulation. Annual Review of Entomology, 55, 207-225.

Barnard D, Geden C (1993) Influence of larval density and temperature in poultry manure on development of the house fly (Diptera: Muscidae). Environmental Entomology, 22, 971-977.

Barragan-Fonseca KB, Dicke M, Van Loon JJA (2017) Nutritional value of the black soldier fly (Hermetia illucens L.) and its suitability as animal feed - a review. Journal of Insects as Food and Feed, 3, 105-120.

Coelho AR, Dinis MT, Reis J (2013) Effect of diet and stocking densities on life history traits of Clea helena (Philippi 1847) reared in captivity. Journal of Aquaculture \& Research Development, 4, 1-4.

Couret J, Dotson E, Benedict MQ (2014) Temperature, larval diet, and density effects on development rate and survival of Aedes aegypti (Diptera: Culicidae). PLoS ONE, 9, e87468. 
De Haas EM, Wagner C, Koelmans AA, Kraak MH, Admiraal W (2006) Habitat selection by chironomid larvae: fast growth requires fast food. Journal of Animal Ecology, 75, 148-155.

Diener S, Studt Solano N, Roa Gutiérrez F, Zurbrügg C, Tockner K (2011a) Biological treatment of municipal organic waste using black soldier fly larvae. Waste and Biomass Valorization, 2, 357-363.

Diener S, Zurbrügg C, Gutiérrez FR, Nguyen DH, Morel A, Koottatep T, et al. (2011b) Black soldier fly larvae for organic waste treatment-prospects and constraints. Proceedings of the WasteSafe - 2nd International Conference on Solid Waste Management in the Developing Countries. Khulna, Bangladesh.

Diener S, Zurbrügg C, Tockner K (2009) Conversion of organic material by black soldier fly larvae: establishing optimal feeding rates. Waste Management \& Research, 27, 603-610.

Fatchurochim S, Geden C, Axtell R (1989) Filth fly (Diptera) oviposition and larval development in poultry manure of various moisture levels. Journal of Entomological Science, 24, 224-231.

Gobbi P, Martínez-Sánchez A, Rojo S (2013) The effects of larval diet on adult life-history traits of the black soldier fly, Hermetia illucens (Diptera: Stratiomyidae). European Journal of Entomology, 110, 461-468.

Green PW, Simmonds MS, Blaney WM (2002) Does the size of larval groups influence the effect of metabolic inhibitors on the development of Phormia regina (Diptera: Calliphoridae) larvae? European Journal of Entomology, 99, 19-22.

Green PW, Simmonds MS, Blaney WM (2003) Diet nutriment and rearing density affect the growth of black blowfly larvae, Phormia regina (Diptera: Calliphoridae). European Journal of Entomology, 100, 39-42.

Green TR, Popa R (2012) Enhanced ammonia content in compost leachate processed by black soldier fly larvae. Applied Biochemistry and Biotechnology, 166, 1381-1387.

Grunert LW, Clarke JW, Ahuja C, Eswaran H, Nijhout HF (2015) A quantitative analysis of growth and size regulation in Manduca sexta: the physiological basis of variation in size and age at metamorphosis. PLOS ONE, 10, e0127988.

Hahn DA (2005) Larval nutrition affects lipid storage and growth, but not protein or carbohydrate storage in newly eclosed adults of the grasshopper Schistocerca americana. Journal of Insect Physiology, 51, 1210-1219.

Harnden LM, Tomberlin JK (2016) Effects of temperature and diet on black soldier fly, Hermetia illucens (L.) (Diptera: Stratiomyidae), development. Forensic Science International, 266, 109-116.

Holmes L, Vanlaerhoven S, Tomberlin J (2016) Lower temperature threshold of black soldier fly (Diptera: Stratiomyidae) development. Journal of Insects as Food and Feed, 2, 255-262.

Jannat KNE, Roitberg BD (2013) Effects of larval density and feeding rates on larval life history traits in Anopheles gambiae ss (Diptera: Culicidae). Journal of Vector Ecology, 38, 120-126.

Janssen RH, Vincken J-P, Van Den Broek LA, Fogliano V, Lakemond CM (2017) Nitrogen-to-protein conversion factors for three edible insects: Tenebrio molitor, Alphitobius diaperinus, and Hermetia illucens. Journal of Agricultural and Food Chemistry, 65, 2275-2278.

Jarośík V, Kratochvíl L, Honék A, Dixon AF (2004) A general rule for the dependence of developmental rate on temperature in ectothermic animals. Proceedings of the Royal Society of London B: Biological Sciences, 271, S219-S221.

Lardé G (1989) Investigation on some factors affecting larval growth in a coffee-pulp bed. Biological Wastes, 30, 11-19.

Lee C-M, Lee Y-S, Seo S-H, Yoon S-H, Kim S-J, Hahn B-S, et al. (2014) Screening and characterization of a novel cellulase gene from the gut microflora of Hermetia illucens using metagenomic library. Journal of Microbiology and Biotechnology, 24, 1196-1206.

Lihoreau M, Buhl J, Charleston MA, Sword GA, Raubenheimer D, Simpson SJ (2015) Nutritional ecology beyond the individual: a conceptual framework for integrating nutrition and social interactions. Ecology Letters, 18, 273-286.

Liu Q, Tomberlin JK, Brady JA, Sanford MR, Yu Z (2008) Black soldier fly (Diptera: Stratiomyidae) larvae reduce Escherichia coli in dairy manure. Environmental Entomology, 37, 1525-1530.

May B (1961) The occurrence in New Zealand and the life-history of the soldier fly Hermetia illucens (L.) (Diptera: Stratiomyidae). The New Zealand Journal of Science and Technology, 4, 55-65.

Miller RS (1964) Larval competition in Drosophila melanogaster and D. simulans. Ecology, 45, 132-148. 
Moreau J, Benrey B, Thiéry D (2006) Assessing larval food quality for phytophagous insects: are the facts as simple as they appear? Functional Ecology, 20, 592-600.

Myers HM, Tomberlin JK, Lambert BD, Kattes D (2008) Development of black soldier fly (Diptera: Stratiomyidae) larvae fed dairy manure. Environmental Entomology, 59, 77-88.

Nguyen TT, Tomberlin JK, Vanlaerhoven S (2013) Influence of resources on Hermetia illucens (Diptera: Stratiomyidae) larval development. Journal of Medical Entomology, 50, 898-906.

Nguyen TT, Tomberlin JK, Vanlaerhoven S (2015) Ability of black soldier fly (Diptera: Stratiomyidae) larvae to recycle food waste. Environmental Entomology, 44, 406-410.

Nijhout H (2003) The control of body size in insects. Developmental Biology, 261, 1-9.

Oonincx D, Van Broekhoven S, Van Huis A, Van Loon JJA (2015a) Feed conversion, survival and development, and composition of four insect species on diets composed of food by-products. PLOS ONE, 10, e0144601.

Oonincx D, Van Huis A, Van Loon JJA (2015b) Nutrient utilisation by black soldier flies fed with chicken, pig, or cow manure. Journal of Insects as Food and Feed, 1, 131-139.

Parra Paz AS, Carrejo NS, Gómez Rodríguez CH (2015) Effects of larval density and feeding rates on the bioconversion of vegetable waste using black soldier fly larvae Hermetia illucens (L.), (Diptera: Stratiomyidae). Waste and Biomass Valorization, 6, 1059-1065.

Rivers DB, Dahlem GA (2013) The Science of Forensic Entomology, Wiley-Blackwell, Chichester, UK.

Scriber JM, Slansky FJ (1981) The nutritional ecology of immature insects. Annual Review of Entomology, 26, 183-211.

Sheppard CD, Tomberlin JK, Joyce JA, Kiser BC, Sumner SM (2002) Rearing methods for the black soldier fly (Diptera: Stratiomyidae). Journal of Medical Entomology, 39, 695-698.

Simon P, Krüger R, Ribeiro P (2011) Influence of diets on the rearing of predatory flies of housefly larvae. Arquivo Brasileiro de Medicina Veterinária e Zootecnia, 63, 1414-1420.

Slansky F, Scriber JM (1985) Food consumption and utilization. In: Kerkut GA, Gilbert LI (eds.) Comprehensive insect physiology biochemistry and pharmacology. Pergamon Press, Oxford.

Slansky FJ, Wheeler GS (1989) Compensatory increases in food consumption and utilization efficiencies by velvetbean caterpillars mitigate impact of diluted diets on growth. Entomologia Experimentalis et Applicata, 51, 175-187.

Spranghers T, Ottoboni M, Klootwijk C, Ovyn A, Deboosere S, De Meulenaer B, et al. (2016) Nutritional composition of black soldier fly (Hermetia illucens) prepupae reared on different organic waste substrates. Journal of the Science of Food and Agriculture, 97, 2594-2600.

Sullivan RL, Sokal RR (1963) The effects of larval density on several strains of the house fly. Ecology, 44, 120-130.

Supriyatna A, Ukit U (2016) Screening and isolation of cellulolytic bacteria from gut of black soldier flays larvae (Hermetia illucens) feeding with rice straw. Biosaintifika: Journal of Biology \& Biology Education, 8, 314-320.

Tomberlin JK, Adler PH, Myers HM (2009) Development of the black soldier fly (Diptera: Stratiomyidae) in relation to temperature. Environmental Entomology, 38, 930-934.

Tomberlin JK, Sheppard DC, Joyce JA (2002) Selected life-history traits of black soldier flies (Diptera: Stratiomyidae) reared on three artificial diets. Annals of the Entomological Society of America 95, 379-386.

Tschirner M, Simon A (2015) Influence of different growing substrates and processing on the nutrient composition of black soldier fly larvae destined for animal feed. Journal of Insects as Food and Feed, 1, 249-259.

Ujvari B, Wallman JF, Madsen T, Whelan M, Hulbert A (2009) Experimental studies of blowfly (Calliphora stygia) longevity: a little dietary fat is beneficial but too much is detrimental. Comparative Biochemistry and Physiology Part A: Molecular \& Integrative Physiology, 154, 383-388.

Yoshioka M, Couret J, Kim F, Mcmillan J, Burkot TR, Dotson EM, et al. (2012) Diet and density dependent competition affect larval performance and oviposition site selection in the mosquito species Aedes albopictus (Diptera: Culicidae). Parasites \& Vectors 5, 1-11.

Zheng L, Hou Y, Li W, Yang S, Li Q, Yu Z (2012a) Biodiesel production from rice straw and restaurant waste employing black soldier fly assisted by microbes. Energy, 47, 225-229. 
Chapter 3

Zheng L, Qing L, Jibin Z, Ziniu Y (2012b) Double the biodiesel yield: Rearing black soldier fly larvae, Hermetia illucens, on solid residual fraction of restaurant waste after grease extraction for biodiesel production. Renewable Energy, 41, 75-79. 


\section{Chapter 4}

Exploring the effect of dietary protein and carbohydrate on life-history traits and body protein and fat contents of the Black Soldier Fly

\section{(Hermetia illucens L.)}

Karol B. Barragan-Fonseca, Gerrit Gort, Marcel Dicke \& Joop J. A. van Loon
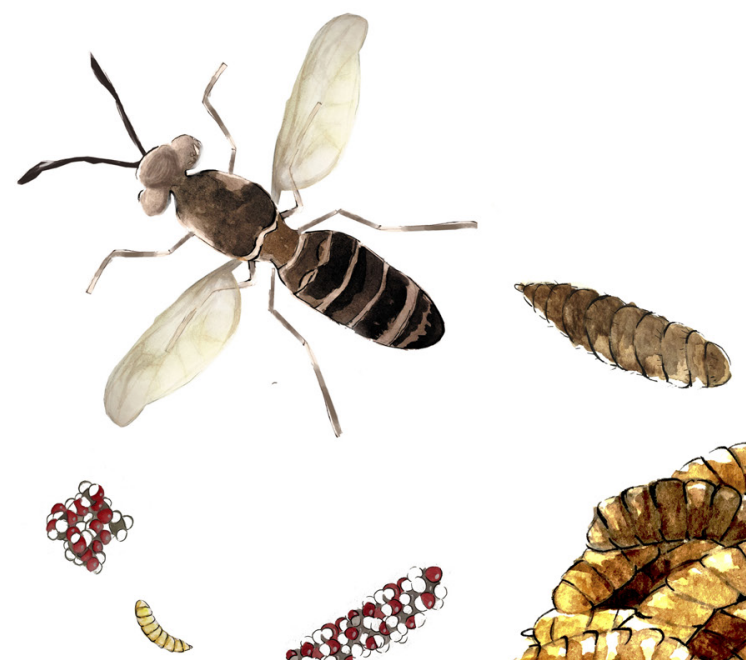
engys
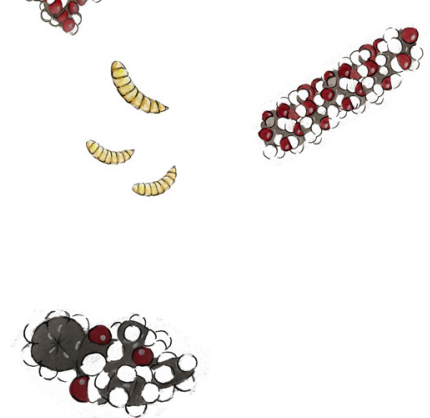

$$
\text { (1) }
$$

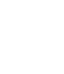




\section{Abstract}

Dietary composition can affect larval development time, larval weight, mortality, and adult fitness in Black Soldier Fly (BSF). Despite the studies on BSF performance on different diets published thus far, it is unknown how BSF larvae respond to protein and carbohydrate contents and ratios and how this affects larval and adult performance. We investigated the influence of dietary protein $(\mathrm{P})$ and digestible carbohydrate $(\mathrm{C})$ contents and protein to carbohydrate $(\mathrm{P}: \mathrm{C})$ ratio on both immature and adult life-history traits of BSF, and on larval body composition. Nine chicken-feed based diets varying in their P:C ratio were formulated. We tested three protein concentrations $(10,17,24 \%)$ and three carbohydrate concentrations $(35,45,55 \%)$ and their combinations. All nine diets supported complete development and reproduction of BSF. Survival was high on all diets. Development time, larval yield, larval crude fat and egg yield were more influenced by $\mathrm{P}$ and $\mathrm{C}$ contents than by P:C ratio. Low contents resulted in shorter development time. Larval yield was higher on diets with higher C-contents. Pupal development was faster on low dietary P-content for all three C-contents. Egg yield, a proxy for egg number, only increased when P-content increased but also varied with P:C ratio, and was found to be highest at P17:C55 (1:3) and P24:C35 (1:1.5). The highest egg yield was recorded on P17:C55, followed by the three P24-diets. Hatching percentage of F1-larvae was similar on all nine diets. Larval crude protein content was similar on all nine diets, but increased when $\mathrm{C}$-content was low (10\%) in P10 and P17. Larval crude fat content was high at P24-diets irrespective of C-content. However, larval crude fat was higher when C-content increased at P10 and P17. We conclude that on the semi-artificial diets tested, BSF performance was not sensitive to dietary P:C ratio, but to carbohydrate and protein contents. High macronutrient content combined with a low P:C ratio positively affected BSF performance. The best diet was P17:C55 as it supported the highest larval and adult performance and resulted in high larval body protein content and an intermediate crude fat content, which are favourable from the perspective of quality of BSF as animal feed.

Key words: Macronutrients, larval performance, fecundity, body nutrient composition, food quality. 


\section{Introduction}

For optimal performance, insects not only need sufficient food, they also need to maintain a diet that has the optimal content and balance of nutrients required by them over a stated time period (Simpson \& Raubenheimer, 1995; Raubenheimer \& Simpson, 1999). In order to compensate for an unbalanced diet and obtain an optimal intake of energy and nutrients, insects have two mechanisms of regulation body nutrient content: a) pre-ingestive mechanisms that involve innate responses to sensory properties, and/or b) post-ingestive mechanisms, involving absorption and differential utilization of ingested nutrients (Raubenheimer \& Simpson, 1997; Zudaire et al., 1998; Raubenheimer \& Simpson, 2003; Behmer, 2009).

To study nutrient regulation in insects, Simpson and Raubenheimer (1993) developed the Geometric Framework (GF), a multidimensional "nutrient space" model, that measures the amount and balance of nutrients which an animal must ingest (intake target) to achieve the best performance, at minimal cost to fitness. The model predicts the relative costs and benefits of over-ingesting some of the nutrients and under-ingesting others when they experience nutritionally imbalanced food (rules of compromise) (Simpson \& Raubenheimer, 1995; Raubenheimer \& Simpson, 1997). Specifically, the GF explores how nutrients interact, the mechanisms animals use to regulate different classes of nutrients, and the effects of a food's nutrient content on animal performance (Roeder, 2010).

The ratio between intake of protein and carbohydrate (P:C) provides a fruitful starting point to investigate the regulatory trade-offs in macronutrient intake in insects (Simpson \& Raubenheimer, 1993; Raubenheimer \& Simpson, 1999). This is plausible since proteins and carbohydrates are the most important nutrients for insect survival, growth and reproduction (Aguila et al., 2013; Nash \& Chapman, 2014), in particular for species having a non-feeding adult stage (Arrese \& Soulages, 2010) and those holometabolous insect species which acquire most of their adult protein needs as larvae (Waldbauer et al., 1984).

Most studies on the balance between proteins and digestible carbohydrates and its effect on insect performance have focused on grasshoppers, caterpillars, larval beetles, aphids and cockroaches (Simpson et al., 1988; Raubenheimer \& Simpson, 2003; Behmer, 2008; Behmer, 2009; Roeder \& Behmer, 2014). Those studies have found that optimal dietary P:C ratio varies among species because of their life-history strategy and phylogeny (Raubenheimer \& Simpson, 1997). For instance, insects with the lowest P:C requirements are those with endosymbiotic bacteria which contribute to nitrogen metabolism, such as aphids and generalist cockroaches (Periplaneta americana L. and Blatella germanica L.) (Raubenheimer \& Simpson, 2003). 
Nutritional studies on some caterpillars (Heliothis subflexa and Spodoptera exigua) have demonstrated optimal P:C ratios close to 1:1, based on self-selected protein-carbohydrate intake targets (Lee et al., 2002; Behmer, 2009). In other insects the optimal ratio is more biased towards carbohydrates or to proteins. For instance, worker bumblebees (Bombus terrestris) (1:15) (Pereboom, 2000) or grasshoppers such as L. migratoria (0.7:1), Schistocerca gregaria (0.8:1) and Melanoplus spp. (0.6:1) are carbohydrate biased, whereas caterpillars such as Heliothis virescens (1.5:1), or Malacosoma disstria (2:1) prefer protein-biased diets (Despland \& Noseworthy, 2006; Behmer, 2009). Additionally, fast-growing species seem to have higher protein requirements than slow growers (Waldbauer et al., 1984). For example, the fast-growing caterpillars Heliothis zea (4:1) and S. litorallis (2:1) need protein-biased diets whereas species that grow slowly perform best on carbohydrate-biased diets (e.g. L. migratoria, 0.7:1) (Simpson et al., 1988).

Regarding rules of compromise, generalists such as cockroaches, the desert locust $(S$. gregaria) and some lepidopteran species (e.g. Spodoptera littoralis), which experience a greater degree of nutritional heterogeneity in their diets than do specialists (Roeder, 2010) tend to be more capable of capitalizing on excess available nutrients in imbalanced foods, even if this means deviating further in nutrient space from the intake target (equal distance - ED rule). By contrast, specialist species such as the migratory locust (L. migratoria) are more sensitive to the magnitude of deviations from the intake target, so they stay close to the intake target (closest distance - CD rule) (Raubenheimer \& Simpson, 1997; Raubenheimer $\&$ Simpson, 2003). Thus, generalists ingest and tolerate excess of nutrients to a higher extent than specialists because they have developed robustness to enforced periods of nutritional imbalance and an ability to redress imbalances by compensatory food selection also termed self-selection (Raubenheimer \& Jones, 2006). However, specialists might be more efficient in using lower amounts of nutrients they ingest (Behmer, 2009). For instance, $L$. migratoria has a low dietary $\mathrm{P}: \mathrm{C}$ ratio, but it is more efficient in retaining nitrogen than the generalist $S$. gregaria (Raubenheimer \& Simpson, 2003).

Optimal P:C ratio can also vary within species dependent on developmental stage and even gender, due to different physiological needs which can result in a different optimal P:C ratio biased towards carbohydrate or protein needs (Canato \& Zucoloto, 1998). For instance, the optimum P:C ratio for reproductive performance not always coincides with that for other life-history traits. For example, in field crickets (Gryllus veletis), adult weight gain and egg production were maximized on high-protein diets (3:1), whereas adult lifespan was maximized on high-carbohydrate diets (males: 1:3; females: 1:8) (Harrison et al., 2014). In the fruit fly Drosophila melanogaster, there are large differences in nutrient-dependent optima for lifespan and reproduction between females and males (Jensen $e t$ al., 2015). Indeed, some studies have illustrated reproductive consequences of a persistent unbalanced diet in insects. Thus, in D. melanogaster dietary $\mathrm{P}$ and $\mathrm{C}$ contents can affect the 
sexual activity and longevity (Prabhu et al., 2008), and in H. virescens high protein levels are associated with a higher offspring production rate (Roeder, 2010).

Nutritional studies on Black Soldier Fly (BSF; Hermetia illucens L.) thus far have addressed the effects of diets on BSF development and adult life-history traits focussing on oligidic or natural diets containing many undefined components such as organic waste or industrial by-products (Barragan-Fonseca et al., 2017). Cammack and Tomberlin (2017) examined the impact of artificial diets $(\mathrm{P}+\mathrm{C}$ content 42\%) with three $\mathrm{P}: \mathrm{C}$ ratios $(1: 1,1: 5$ and 5:1) on life history traits of BSF and found higher survival rate on 1:1 ratio, but no conclusive effects on adult life-history traits. It is largely unknown how BSF responds to protein and carbohydrate contents and ratios and how this affects its body composition and adult performance. This saprophagous species exploits diverse diets, so larval stages are likely to encounter a wide range of dietary macronutrient ratios. When analyzing food sources on which this species is found in the wild (vegetable waste, manure, etc.) P:C ratios tend to be carbohydrate-biased (P:C ratios 1:1.5, 1:2) and present a wide range of crude protein and digestible carbohydrate contents (40-80\% DM). Larvae of BSF hide inside feed substrates and mix uneaten diet with their faeces, making it unsuitable for self-selection experiments. Based on its natural food sources we can assume that its intake target might be carbohydrate biased.

It is clear that dietary macronutrient content is important to insects and even small departures from an optimal P:C ratio can have dramatic physiological effects and affect insect fitness (Prabhu et al., 2008; Le Gall \& Behmer, 2014). However, most nutrient regulation studies in insects fail to address consequences for fitness (Roeder, 2010). By varying dietary P:C ratios and contents, it is possible to explore how performance, both within developmental stages and across the entire lifespan, is affected by these nutrients. Therefore, the objective of this study was to explore the effects of dietary P and C contents and P:C ratios within the range of its natural food sources under controlled conditions on both immature and adult life-history traits of BSF and on larval body macronutrient composition.

\section{Materials and Methods}

\section{Experimental insects}

Hermetia illucens L. (Diptera: Stratiomyidae) eggs were obtained from a colony maintained at constant conditions in a climate room $\left(27 \pm 1{ }^{\circ} \mathrm{C}, 70 \% \mathrm{RH}, \mathrm{L} 12: \mathrm{D} 12\right)$ at the Laboratory of Entomology, Wageningen University (The Netherlands).

\section{Experimental design}

Nine diets varying in their protein to carbohydrate (P:C) ratio and contents were formulated. We tested three protein concentrations $(10,17,24 \%)$ and three concentrations of digestible carbohydrates $(35,45,55 \%)$, total macronutrient ( $\mathrm{P}$ and $\mathrm{C}$ ) content of these 
diets ranging from 45 - 79\%: (1) P10:C35 (10\% protein and 35\% carbohydrate; combined macronutrient content $=45 \%$ ), (2) P10:C45, (3) P10:C55, (4) P17:C35, (5) P17:C45, (6) P17:C55, (7) P24:C35, (8) P24:C45, (9) P24:C55. P:C ratios are listed in Table 1. The diets were formulated by including a standard proportion of chicken feed (Opfokmeel Farmfood, Agruniek Rijnvallei Voer BV, Wageningen, The Netherlands) in the diet (63\% of the total dry mass of the experimental diet, which contributed $10 \%$ protein and $31.5 \%$ carbohydrate to each treatment). This was used because it supports the full life cycle of BSF (K. Barragán-Fonseca, personal observation from BSF rearing and previous experiments (Barragan-Fonseca et al., 2018). The remaining 37\% of the experimental diet was composed of the protein casein (Bio-connect, Huissen, NL), containing all the essential amino acids in high and for insects well-balanced proportions (Cohen, 2004), and the digestible carbohydrate starch (Duchefa Biochemie BV, Haarlem, NL), which served both as a nutrient and as a texturing agent. The $\alpha$-sugar linkages in starch make it highly susceptible to digestion by insects (Cohen, 2004). The remaining proportion was cellulose (Alphacel non-nutritive bulk; Bio-connect, Huissen, NL), considered to be a poorly digestible bulk agent (Table 1).

Table 1. Composition of experimental diets

\begin{tabular}{cccccccccc}
\hline & \multicolumn{10}{c}{ Experimental Diets } \\
\hline & $\mathbf{1}$ & $\mathbf{2}$ & $\mathbf{3}$ & $\mathbf{4}$ & $\mathbf{5}$ & $\mathbf{6}$ & $\mathbf{7}$ & $\mathbf{8}$ & $\mathbf{9}$ \\
\hline Ingredient (\%) & & & & & & & & & \\
Chicken feed & 63 & 63 & 63 & 63 & 63 & 63 & 63 & 63 & 63 \\
Casein & 0 & 0 & 0 & 7 & 7 & 7 & 14 & 14 & 14 \\
Starch & 3 & 13 & 23 & 3 & 13 & 23 & 3 & 13 & 23 \\
Cellulose & 34 & 24 & 14 & 27 & 17 & 7 & 21 & 10 & 0 \\
\hline Nutrient (\%) & & & & & & & & & \\
Crude protein (P) & 10 & 10 & 10 & 17 & 17 & 17 & 24 & 24 & 24 \\
Digestible carbohydrate (C) & 35 & 45 & 55 & 35 & 45 & 55 & 35 & 45 & 55 \\
Sum of crude P and C contents & 45 & 55 & 65 & 52 & 62 & 72 & 59 & 69 & 79 \\
P:C ratio & $1: 3.5$ & $1: 4.5$ & $1: 5.5$ & $1: 2.1$ & $1: 2.6$ & $1: 3.2$ & $1: 1.5$ & $1: 1.9$ & $1: 2.3$ \\
\hline
\end{tabular}

${ }^{1}$ Non-cellulose carbohydrate

The larvae were reared on the nine experimental diets, each containing $60 \%$ water. Each treatment group consisted of 100 larvae (hatched from the egg less than $24 \mathrm{~h}$ before) per $750 \mathrm{ml}$ container. A fixed ration of $0.6 \mathrm{~g}$ (dry matter basis) of food per larva was added once at the beginning of the experiment, as a preliminary experiment showed that larvae fed once rather than three times per week reached a higher biomass. The feeding experiments were conducted in a climatic room $\left(4.5 \mathrm{~m}^{2}\right)$ and maintained at constant conditions $\left(27 \pm 1{ }^{\circ} \mathrm{C}, 55 \% \pm 5 \mathrm{RH}, \mathrm{L} 12: \mathrm{D} 12\right)$. In order to eliminate positional effects, all containers were randomly relocated three times per week.

\section{Larval life-history traits}

Per dietary treatment, nine replicates were set up. Larvae were harvested when at least $50 \%$ of the larvae were observed to have reached the pre-pupal stage, as appearing from 
the characteristic melanized cuticle of prepupae (May, 1961). Development time was considered to be the number of days between the start of the experiment, and the day of harvesting. All animals from each container were harvested with forceps, counted, and weighed collectively. Larvae were washed under running water to remove residues consisting of left-over feed and faeces, their integument dried with paper tissue, and their weight registered as BSF larval yield ( $\mathrm{g}$ fresh matter) on a precision balance (Ohaus, Adventurer Pro AV313, Parsippany - USA, precision $\pm 0.001 \mathrm{~g}$ ). To determine survival, the number of live BSF larvae at the day of harvesting was divided by the initial number of larvae per replicate (100). When at least $50 \%$ of the larvae were observed to have reached the pupal stage, individual pupal weight ( $\mathrm{g}$ fresh matter) was determined in the same way as larval weight.

\section{Adult life-history traits}

Forty newly eclosed ( $<12 \mathrm{~h}$ old) adult BSF from each container were released into a BugDorm cage $(30 \times 30 \times 30 \mathrm{~cm})$ and kept in a greenhouse compartment under controlled conditions $\left(25 \pm 1{ }^{\circ} \mathrm{C}, 70 \% \pm 5\right.$ R.H. and natural light). Per dietary treatment four replicates were set up. Adults were provided with water and sugar ad libitum and two days after eclosion, a mixture of sand $(80 \mathrm{~g})$, chicken feed $(80 \mathrm{~g})$ and water $(100 \mathrm{ml})$ in a plastic container $(10 \times 10 \times 6 \mathrm{~cm})$ was offered for oviposition. On the surface of each container four corrugated cardboard pieces, each measuring $4 \mathrm{~cm}$ (height) $x 9 \mathrm{~cm}$ (length) were put as a substrate for egg laying. Every three days the cardboards were removed from all containers, the sand-feed-water medium replaced and new cardboard pieces put in place. In order to determine fecundity, number of egg masses, and percentage of eggs from which larvae hatched (F1) were recorded. We also measured surface of viable egg masses $\left(\mathrm{mm}^{2}\right)$ as a proxy of viable egg number; thus we registered the surface of all the egg masses we collected, but only took into account the surface of those egg masses from which F1 larvae hatched; this variable was called egg yield $\left(\mathrm{mm}^{2}\right)$. To determine survival until the adult stage, the number of BSF adults eclosed at the end of the experiment was divided by the initial number of larvae per replicate. The development time until the adult stage was considered to be the number of days between the start of the experiment, and the day the first adult was observed.

\section{Proximate chemical analysis of larvae}

Samples were stored in a freezer $\left(-25^{\circ} \mathrm{C}\right)$ until all replicates were harvested. Both the larvae and the diets were analysed for dry matter (DM), crude protein, and crude fat contents at the Animal Nutrition Laboratory of Wageningen University. The samples were oven-dried at $70^{\circ} \mathrm{C}$ until constant weight and homogenized by grinding the sample in an ultra-centrifugal mill (Retsch ZM 200, Haan - Germany). Crude protein (6.25 x N-content) was determined using the Kjeldahl method (ISO 5983-1, 2005) and crude fat was analysed according to the Berntop method (ISO 6492, 1999). 


\section{Statistical analysis}

To examine how protein and carbohydrate levels affected the response variables on insect performance and larval body content data we used R version 3.3.3 (R-Core-Team, 2017), specifically package rsm (Lenth, 2009), for response surface models. We first fitted quadratic response surface models using the total content of protein and carbohydrate $(\mathrm{P}+\mathrm{C})$, and their ratio $(\mathrm{P}: \mathrm{C})$ as regressors. The relative importances of subsets of regressors were visualized in a stacked barplot, showing which part of the total variation was explained by 1) linear and quadratic effects of $\mathrm{P}+\mathrm{C}(2 \mathrm{df}), 2)$ linear and quadratic effects of $\mathrm{P}: \mathrm{C}(2$ $\mathrm{df}), 3)$ interactions among $\mathrm{P}+\mathrm{C}$ and $\mathrm{P}: \mathrm{C}(4 \mathrm{df}), 4)$ residual errors (72 $\mathrm{df}$ for larval data, $45 \mathrm{df}$ for larval body composition data, $27 \mathrm{df}$ for adult data). Next, we fitted quadratic response surface models using the actual protein $(\mathrm{P})$ and carbohydrate $(\mathrm{C})$ contents as regressors. Results were summarized with an overall F-test (testing for any effect at all), and with F-tests for linear effects of $\mathrm{P}$ and of $\mathrm{C}$, for quadratic effects of $\mathrm{P}$ and of $\mathrm{C}$ (after linear effects of $\mathrm{P}$ and $\mathrm{C}$ ), for interaction of $\mathrm{P}$ and $\mathrm{C}$ (after linear effects of $\mathrm{P}$ and $\mathrm{C}$ ), and lack of fit for the quadratic response surface model (indicating higher order interactions). If the overall F-test showed a significant result, we made contour plots showing the fitted response surfaces. For contour plots the $\mathrm{P}-\mathrm{C}$ interaction and quadratic terms were removed from the model if found to be unnecessary $(\mathrm{P}>0.05)$ and in case of significant lack of fit $(\mathrm{P}<0.05)$, higher order terms were added. For all fitted models residual plots were made to check for potential outliers and deviations of assumptions (i.e. approximate normality and constant variance). The relationship between egg mass production and pupal weight was studied using the Pearson correlation coefficient.

\section{Results}

$\mathrm{P}+\mathrm{C}$ content had a stronger effect than $\mathrm{P}: \mathrm{C}$ ratio on larval yield, larval development time, egg yield, development time until adult and larval crude fat content. Hardly any variation was explained neither by $\mathrm{P}+\mathrm{C}$, nor $\mathrm{P}: \mathrm{C}$ for larval survival, adult emergence and larval hatching. Some variation was explained by $\mathrm{P}+\mathrm{C}$ and by $\mathrm{P}: \mathrm{C}$ for number of egg masses and larval crude protein content. (Fig. 1). 


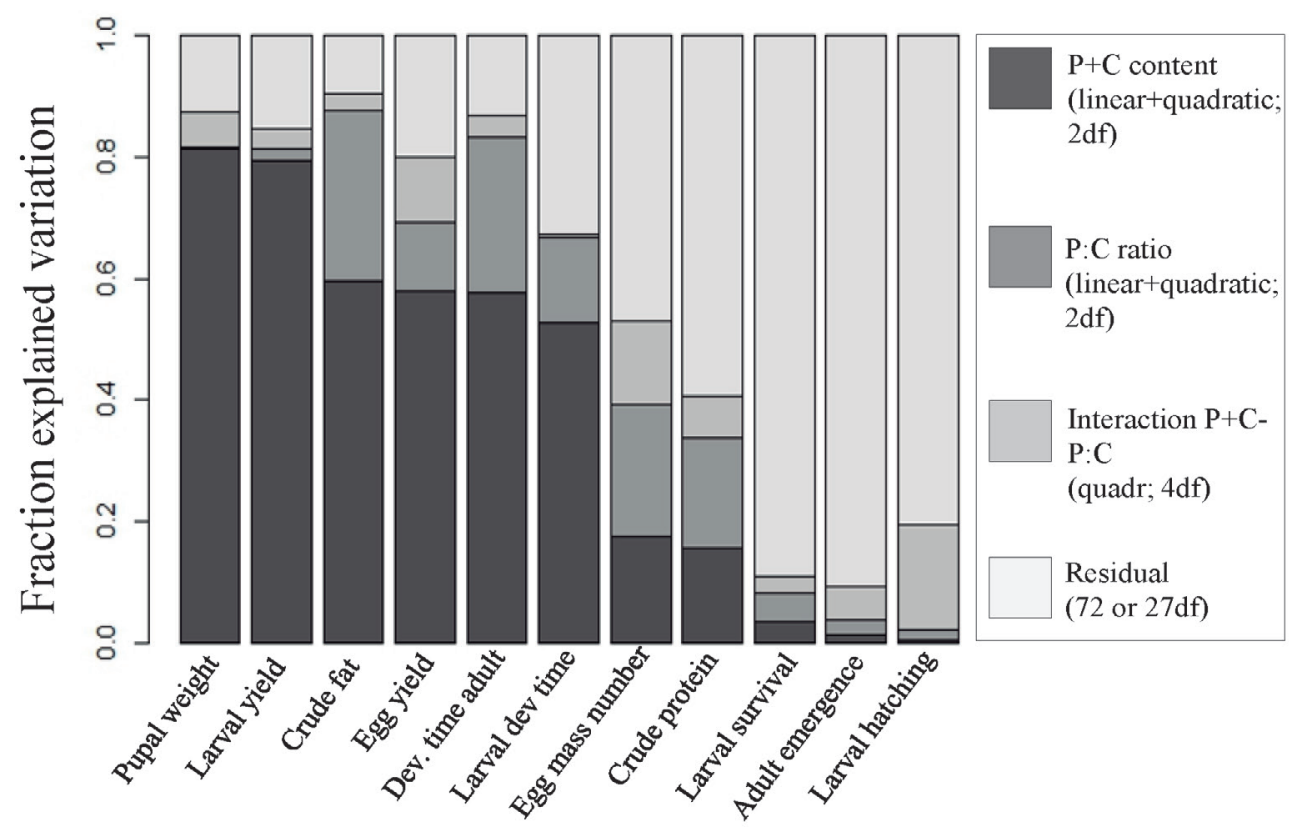

Figure 1. Relative importance of summed protein and carbohydrate $(\mathrm{P}+\mathrm{C})$ content and ratio $(\mathrm{P}: \mathrm{C})$ on performance and larval body content variables of Black Soldier fly.

\section{Immature life-history traits}

\section{Performance}

Survival rate was not affected by protein or carbohydrate content $(\mathrm{P}=0.36$, Table 2$)$. Development time showed strong linear effects of protein and of carbohydrate content $(\mathrm{P}<0.001)$, but also some interaction $(\mathrm{P}=0.003)$ and a quadratic effect of protein $(\mathrm{P}=0.008)$ occurred. (Table 2). Development time was shorter at lower protein and carbohydrate contents (Fig. 2a). Larval yield showed a very strong linear effect of carbohydrate content $(\mathrm{P}<0.001)$ and less so of protein $(\mathrm{P}<0.001)$, but also second and higher order effects were present (Table 2). Like larval yield, individual pupal weight showed a strong linear effect of carbohydrates $(\mathrm{P}<0.001)$, and less so for protein $(\mathrm{P}<0.001)$; second and higher order effects were significant to a lesser extent. Larval yield and individual pupal weight were highest on the diet with the highest carbohydrate content at all three protein contents, and then decreased in a linear fashion as the dietary carbohydrate concentration decreased (Fig. 2b,c). 
Table 2. Response surface model significance shown as $P$ values ( $F$ values in parentheses) for the full model ( $F$ with 8 and $72 \mathrm{df}$; for pupal weight 8 and $27 \mathrm{df}$ ), linear effects ( $P$ is protein content and $\mathrm{C}$ is carbohydrate content), their interactions and quadratic terms for larval performance measurements (F with 1 and $72 \mathrm{df}$; for pupal weight 1 and $27 \mathrm{df}$ ).

\begin{tabular}{ccccc}
\hline Source & $\begin{array}{c}\text { Survival rate } \\
\text { \% }\end{array}$ & $\begin{array}{c}\text { Development time } \\
\mathbf{d}\end{array}$ & $\begin{array}{c}\text { Larval yield } \\
\text { g DM }\end{array}$ & $\begin{array}{c}\text { Pupal weight } \\
\text { g FM }\end{array}$ \\
\hline Full model & $0.364(1.11)$ & $<\mathbf{0 . 0 0 1}(18.46)$ & $<\mathbf{0 . 0 0 1}(49.5)$ & $<\mathbf{0 . 0 0 1}(\mathbf{2 3 . 4 )}$ \\
$\mathbf{P}$ & $0.192(1.73)$ & $<\mathbf{0 . 0 0 1}(86.7)$ & $<\mathbf{0 . 0 0 1}(57.7)$ & $<\mathbf{0 . 0 0 1}(35.2)$ \\
$\mathbf{C}$ & $0.242(1.39)$ & $<\mathbf{0 . 0 0 1}(42.3)$ & $<\mathbf{0 . 0 0 1}(305.7)$ & $<\mathbf{0 . 0 0 1}(119.1)$ \\
$\mathbf{P x C}$ & $0.142(2.20)$ & $\mathbf{0 . 0 0 3}(9.75)$ & $<\mathbf{0 . 0 0 1}(12)$ & $<\mathbf{0 . 0 0 1}(14.4)$ \\
$\mathbf{P}^{\mathbf{2}}$ & $0.310(1.10)$ & $\mathbf{0 . 0 0 8}(7.42)$ & $0.447(0.58)$ & $0.060(3.96)$ \\
$\mathbf{C}^{2}$ & $0.750(1.10)$ & $0.61(0.27)$ & $\mathbf{0 . 0 2 2}(5.49)$ & $0.063(3.73)$ \\
LOF & $0.496(0.80)$ & $0.73(0.43)$ & $\mathbf{0 . 0 0 5}(4.71)$ & $\mathbf{0 . 0 2 5}(3.64)$ \\
R-Square & 0.11 & 0.67 & 0.84 & 0.85 \\
\hline
\end{tabular}

a) Development time (d)

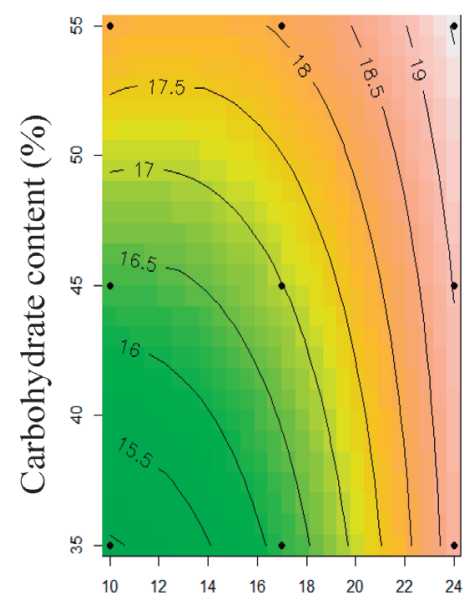

b) Larval yield (g DM)

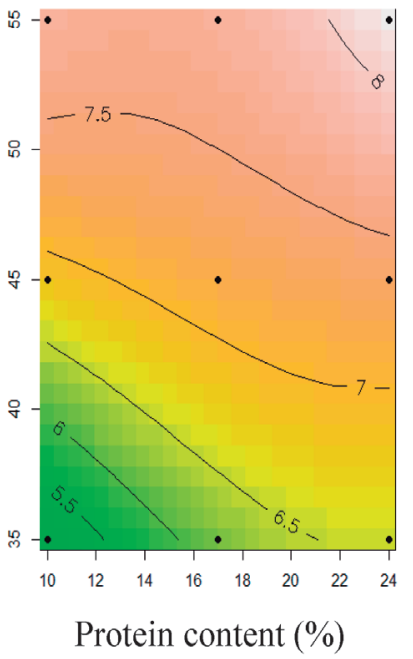

c) Pupal weight (g FM)

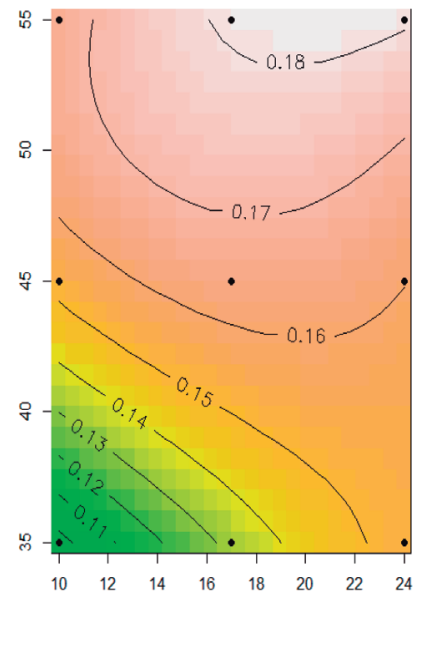

Figure 2. Response surfaces for Black Soldier fly larval performance variables on diets of different protein and carbohydrate contents. a) Development time (d), b) Larval yield per container (g DM), and c) Individual pupal weight (g FM). A fitness landscape corresponding to insect response to each diet has been fitted over nutrient space; contour lines delimit colour areas going from the lowest (green) to highest (orange) values calculated for each performance variable. Black points indicate the nine experimental diets.

\section{Larval body composition}

Larval crude protein was affected in a linear fashion by dietary protein $(\mathrm{P}<0.001$; Table 3$)$, and by the interaction of protein $x$ carbohydrate contents $(P=0.004$; Table 3$)$. At low carbohydrate content, larval crude protein decreased with increasing protein level in the diet. At high carbohydrate content, larval crude protein did not change with increasing protein content (Fig. 3a). Larval crude fat was very well explained by the model $\left(\mathrm{R}^{2}=0.90\right)$ and 
showed strongest linear trend for protein $(\mathrm{P}<0.001$; Table 3$)$ and less so for carbohydrate $(\mathrm{P}<0.001$; Table 3); smaller interaction and quadratic protein effects were also significant (Table 3). At high protein content of the diet no effect of carbohydrate was seen on larval crude fat, at low protein content a positive effect of carbohydrate was seen on larval crude fat (Fig. 3b).

Table 3. Response surface significance shown as P-values (F-values between parentheses) for the full model ( $F$ with 8 and $45 \mathrm{df}$ ), linear effects ( $\mathrm{P}$ is protein and $\mathrm{C}$ is carbohydrate content), their interactions and quadratic terms for larval body protein and fat contents (F with 1 and $45 \mathrm{df}$ ).

\begin{tabular}{ccc}
\hline Source & $\begin{array}{c}\text { Larval crude protein } \\
\text { \% }\end{array}$ & $\begin{array}{c}\text { Larval crude fat } \\
\text { \% }\end{array}$ \\
\hline Full model & $\mathbf{0 . 0 0 2}(3.87)$ & $<\mathbf{0 . 0 0 1}(53.2)$ \\
$\mathbf{P}$ & $<\mathbf{0 . 0 0 1}(13.4)$ & $<\mathbf{0 . 0 0 1}(309.1)$ \\
$\mathbf{C}$ & $0.543(9.23)$ & $<\mathbf{0 . 0 0 1}(66.1)$ \\
$\mathbf{P x C}$ & $\mathbf{0 . 0 0 4}(9.1)$ & $<\mathbf{0 . 0 0 1}(25.9)$ \\
$\mathbf{P}^{\mathbf{2}}$ & $0.565(0.36)$ & $<\mathbf{0 . 0 0 1}(27.7)$ \\
$\mathbf{C}^{2}$ & $0.945(0.005)$ & $0.565(1.30)$ \\
LOF & $0.176(1.72)$ & $0.820(0.31)$ \\
R-Square & 0.41 & 0.90 \\
\hline
\end{tabular}

a) Larval crude protein (\%)

b) Larval crude fat (\%)
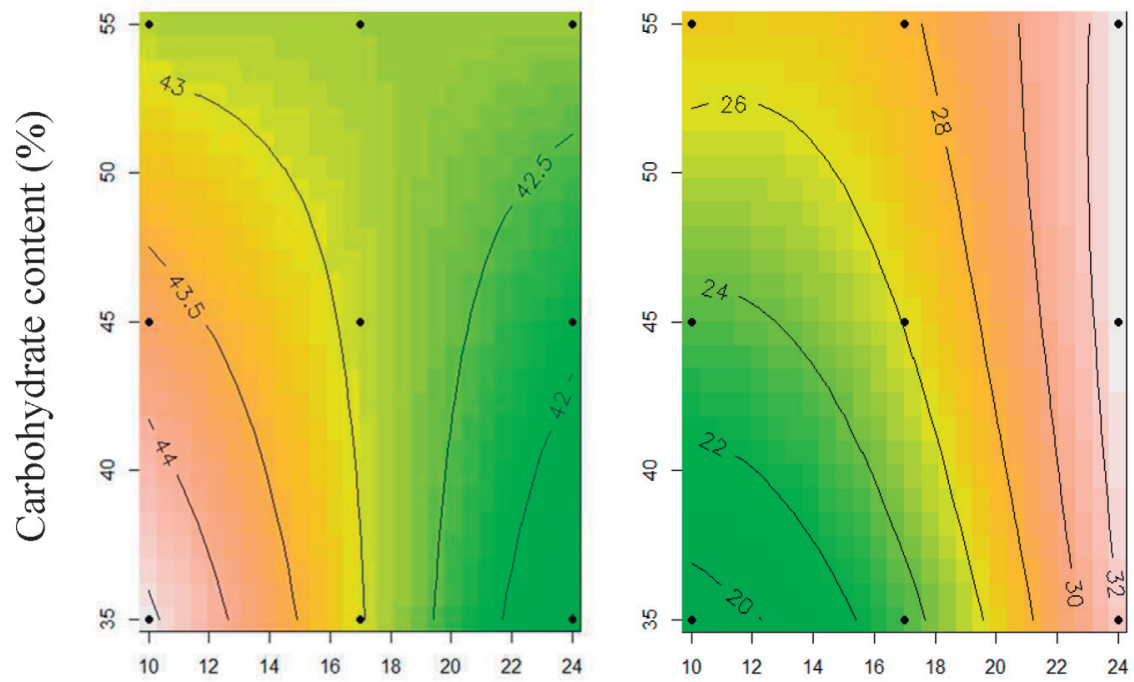

Protein content $(\%)$

Figure 3. Black Soldier fly larval body composition when feeding on diets differing in $\mathrm{P}$ and $\mathrm{C}$ contents. a) Larval crude protein (\%), and b) Larval crude fat (\%). A fitness landscape corresponding to insect response to each diet has been fitted over nutrient space; contour lines delimit colour areas going from the lowest (green) to highest (orange) values for each performance variable. Black points indicate the nine experimental diets. 


\section{Adult life-history traits}

\section{Performance}

Development time from egg until adulthood was affected in a strongly linear fashion, first in size by protein $(\mathrm{P}<0.001$, Table 4$)$ and next by carbohydrate content $(\mathrm{P}<0.001$, Table 4$)$; a considerable protein-carbohydrate interaction was found $(\mathrm{P}<0.001$, Table 4$)$, and a relatively small quadratic protein effect $(\mathrm{P}=0.01$; Table 4$)$. Development was fastest on diets with the lowest protein content at all carbohydrate contents (Fig. 4a). Adult emergence and hatching of F1 larvae were not affected by diet $(\mathrm{P}=0.94$ and $\mathrm{P}=0.60$, respectively; Table 4). The number of egg masses produced per female showed a strong linear effect of protein $(\mathrm{P}<0.001$, Table 4). Egg yield, which was log-transformed, was affected in a linear fashion by protein and carbohydrate (both $\mathrm{P}<0.001$, Table 4), and also showed second and higher order effects (Table 4). Egg yield was highest on P17:C55 and lowest on P10:C35 (Fig. 4c), however, there are minor differences compared with the other seven diets. There was a significant relationship between pupal weight and egg yield (Pearson correlation coefficient $\mathrm{r}=0.63, \mathrm{P}<0.05$ ).

Table 4. Response surface significance shown as $\mathrm{P}$ values (F values between parentheses) for the full model ( $\mathrm{F}$ with 8 and $27 \mathrm{df}$ ), linear effects ( $\mathrm{P}$ is protein content and $\mathrm{C}$ is carbohydrate content), their interactions and quadratic terms for adult performance measurements ( $F$ with 1 and $27 \mathrm{df}$ )

\begin{tabular}{cccccc}
\hline Source & $\begin{array}{c}\text { Adult emergence } \\
\text { \% }\end{array}$ & $\begin{array}{c}\text { Development time } \\
\text { until adult } \\
\mathbf{d}\end{array}$ & $\begin{array}{c}\text { Number of egg } \\
\text { masses }^{\mathbf{1}}\end{array}$ & $\begin{array}{c}\text { Larval hatching } \\
\%\end{array}$ & $\begin{array}{c}\text { Egg yield }^{\mathbf{2}} \\
\mathbf{\text { mm }}^{\mathbf{2}}\end{array}$ \\
\hline Full model & $0.940(0.35)$ & $<\mathbf{0 . 0 0 1}(22.5)$ & $\mathbf{0 . 0 0 5}(3.81)$ & $0.599(0.81)$ & $<\mathbf{0 . 0 0 1}(13.5)$ \\
$\mathbf{P}$ & $0.356(0.88)$ & $<\mathbf{0 . 0 0 1}(119)$ & $<\mathbf{0 . 0 0 1}(20.8)$ & $0.834(0.04)$ & $<\mathbf{0 . 0 0 1}(54.1)$ \\
$\mathbf{C}$ & $1.0(<0.001)$ & $<\mathbf{0 . 0 0 1}(22.1)$ & $0.44(0.61)$ & $0.762(0.09)$ & $<\mathbf{0 . 0 0 1}(25.2)$ \\
$\mathbf{P x C}$ & $0.820(0.06)$ & $<\mathbf{0 . 0 0 1}(27.6)$ & $0.46(0.55)$ & $0.638(0.23)$ & $\mathbf{0 . 0 2}(6.32)$ \\
$\mathbf{P}^{2}$ & $0.670(0.19)$ & $\mathbf{0 . 0 1 4}(6.95)$ & $0.16(2.12)$ & $0.652(0.21)$ & $\mathbf{0 . 0 0 9}(7.73)$ \\
$\mathbf{C}^{2}$ & $0.915(0.01)$ & $0.635(0.23)$ & $0.80(0.06)$ & $0.454(0.57)$ & $0.062(3.80)$ \\
LOF & $0.649(0.55)$ & $0.314(1.24)$ & $0.121(2.11)$ & $0.175(1.78)$ & $\mathbf{0 . 0 2 8}(3.53)$ \\
R-Square & 0.1 & 0.87 & 0.53 & 0.2 & 0.53 \\
\hline
\end{tabular}

${ }^{1}$ Sqrt transformation because of count data.

${ }^{2} \log ^{10}$ transformation. 
a) Development time until adult stage $(d)$

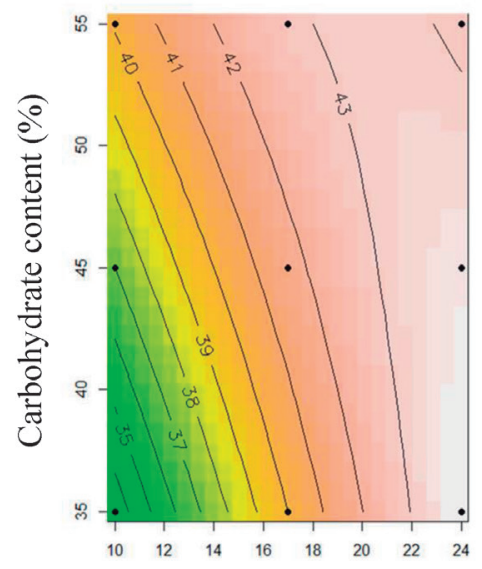

b) Egg mass number

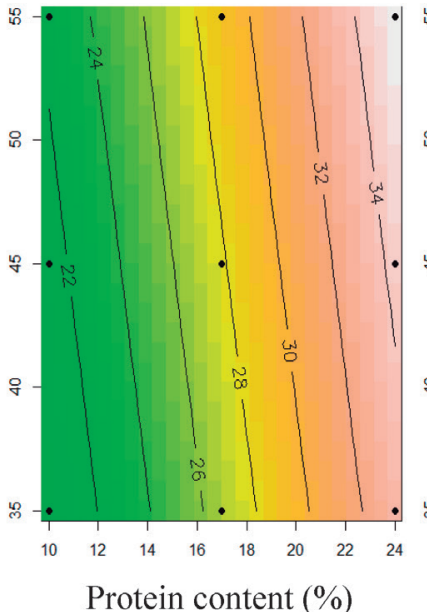

c) Egg yield $\left(\mathrm{mm}^{2}\right)$

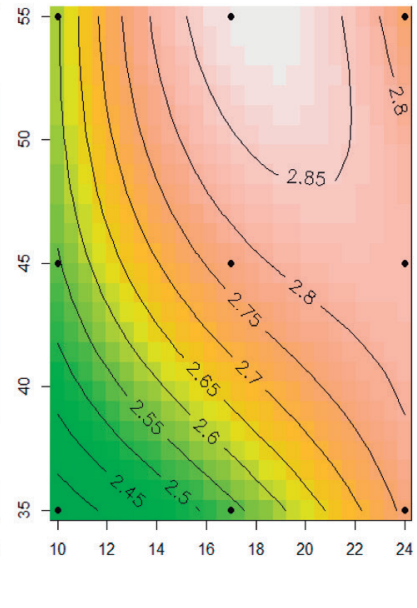

Figure 4. Black Soldier Fly adult performance when feeding on diets differing in P and C contents a) Development time until adult stage (d), b) Number of egg masses per treatment group, c) Egg yield $\left(\mathrm{mm}^{2}\right)-\log 10$ transformation. A fitness landscape corresponding to insect response to each diet has been fitted over nutrient space; contour lines delimit colour areas going from the lowest (green) to highest (orange) values gotten by each performance variable. Black points indicate the nine experimental diets.

\section{Discussion}

Our data suggest that BSF performance was affected by dietary carbohydrate and protein contents rather than by $\mathrm{P}: \mathrm{C}$ ratio. The $\mathrm{P}: \mathrm{C}$ ratios we tested are probably within the wide range of $\mathrm{P}: \mathrm{C}$ ratios found in the diverse substrates utilized by BSF in nature. Cammack and Tomberlin (2017) who examined the impact of artificial diets ( $\mathrm{P}+\mathrm{C}$ content 42\%) with three P:C ratios (1:1, 1:5 and 5:1) and two moisture levels, found a greater effect of diet moisture than of $\mathrm{P}: \mathrm{C}$ ratio and larval performance was quite similar among all the $\mathrm{P}: \mathrm{C}$ ratios. In herbivorous insect species, such as the grasshopper Melanoplus differentialis, the contents of dietary macronutrients also had more pronounced effects than did the P:C ratio (Le Gall \& Behmer, 2014). However, the impact of low quality food can be amplified by a suboptimal P:C ratio, as was found for $S$. littoralis for which the negative impact of a low quality protein diet on larval performance was amplified as the P:C ratio of the diet decreased (Lee, 2007).

\section{Larval life-history traits}

\section{Performance}

Since BSF can be found in manure (Sheppard et al., 1994) and in carrion (Martínez-Sánchez et al., 2011) it experiences a high degree of nutritional heterogeneity in its dietary 
protein and carbohydrate contents. We used diets containing macronutrient contents and ratios similar to those found for nutrient sources exploited by BSF in nature, in particular chicken, pig and cow manure (K. Barragán-Fonseca, unpubl. data). We therefore expected that BSF would perform well in terms of survival and growth. This is confirmed by the high survival rate on all diets. However, differences in performance among diets were significant in terms of development time and larval weight gain. Our analysis of the relative importance of contents and ratio of macronutrients (Figure 1) demonstrated that duration of development was a function of protein and carbohydrate content $(>50 \%)$ and their interaction $(-20 \%)$, whereas larval and pupal weight were mostly a function of protein and carbohydrate content $(>80 \%)$. We observed longer development time at higher carbohydrate contents; similarly Cammack and Tomberlin (2017) found that a carbohydrate-biased diet increased the development time in BSF larvae. In herbivorous insects like Melanoplus differentialis the duration of development is a function of an interaction between plant protein and carbohydrate contents; however, weight gain is a function of only carbohydrate content (Le Gall \& Behmer, 2014). Our results for BSF clearly demonstrate an effect of carbohydrate content on body mass.

The highest larval weights were achieved by larvae fed on the diets with the highest contents of both protein and carbohydrate. Since BSF larvae were restricted to one diet, they were unable to regulate the intake of one component without simultaneously altering intake of all others. The high larval weight associated with high dietary carbohydrate concentration even on the low and medium protein diets, may indicate that BSF larval and pupal weight are more affected by dietary carbohydrate than by dietary protein content. This could result in the high body fat contents we found, especially when the protein concentration in food is low (Le Gall \& Behmer, 2014). Deposition of lipids has important physiological costs - theoretical estimates suggest that the conversion of hexoses to storage fat can take up to $20-25 \%$ of the energy content of the food supplied (Westerterp, 1994 in (Le Gall \& Behmer, 2014)).

We found that BSF larvae may trade-off developing faster over growing bigger since faster development results in lighter larvae. It is possible that the positive relationship between development time and final body mass has a fitness benefit only when the constraints for long development are relaxed (Kause et al., 2001). In the case of BSF that fed on diets with varying resource qualities with increasing level of competition, they might gain higher fitness by rapid development, to avoid the possible cost of increased mortality due to larval predation and parasitism and to start adult foraging sooner (Kaspi et al., 2002; Lee et al., 2006; Dmitriew, 2011). This trend has been reported for other species such as the autumnal moth (Epirrita autumnata), the birch-feeding sawfly (Amauronematus amplus) (Kause et al., 2001) and the larval stages of the Mediterranean fruit fly (Ceratitis capitata) (Kaspi et al., 2002). A shorter development time without a reduction in body size could be con- 
sidered an indicator of a high-quality resource. For example, larvae of the Spotted-wing fruit fly (Drosophila suzukii) are able to develop faster without a reduction in adult body size on low P:C ratio diets (Jaramillo et al., 2015). An alternative interpretation, however, is that adaptation to a protein-poor food constrains the ability to respond plastically when presented with a higher quality resource (Hardin et al., 2015; Jaramillo et al., 2015).

\section{Larval body composition}

Our study showed that only a small fraction of variation in larval crude protein is explained by dietary protein and carbohydrate contents and their interaction (ca. 20\%). In our study, larval crude protein content (range 41.4-44.2\%DM) was high and similar on all nine diets. Similar values for protein content have been found in previous studies for larvae fed on chicken feed, by-products of food manufacturing and manure $(43.2 \% \pm 2.7$ DM) (Barragan-Fonseca et al., 2017). We found that larval crude protein content was higher when dietary P-content was lower (P10 and P17). This is in line with the findings of Barragan-Fonseca et al. (2018) and Tschirner and Simon (2015) who reported that body crude protein content was higher in larvae fed on the diet with the lowest crude protein content. However, recently it has been argued that this content has been overestimated thus far by $-20 \%$ due to the presence of non-protein nitrogen in insects (Janssen et al., 2017). Our nitrogen analysis data do not allow a distinction between protein- and non-protein-nitrogen. A high level of larval crude protein on low quality diets could explain the shorter larval development time of BSF larvae as they may use protein to develop faster into prepupae.

Low $\mathrm{P}+\mathrm{C}$ content diets resulted in lower larval weights. This indicates that BSF larvae fed on low protein diets use dietary protein efficiently, as is seen for insects with symbionts (Raubenheimer \& Simpson, 2003). BSF larvae have a diverse microbial community in their digestive tract that is likely to harbour such symbionts (Jeon et al., 2011). The high larval weight we recorded on diets with a high protein content is associated with increased lipid contents, as was explained before. However, in other studies on BSF, larvae fed on high protein substrates, such as liver or meat, had higher protein contents $(60.3 \% \pm 3.3$ $\mathrm{DM})$, and larvae fed on vegetable waste had lower protein contents (38.5\% DM) (Nguyen et al., 2015). This suggests that quality of dietary protein affects larval protein content.

Larval crude fat content was also affected by protein and carbohydrate contents of the substrate, and their interaction, and strong differences were observed between treatments. Larval crude fat content increased when C-content was high, and it was also high at all P24-diets. The high larval crude fat content at high dietary protein and carbohydrate levels may have stimulated lipogenic activity and lipid incorporation in reserves (Nestel \& Nemny-Lavy, 2008). These fat contents are in the range of values reported in the literature on BSF larvae, which vary substantially among substrates (ranging from 7 to $39 \% \mathrm{DM}$ ) 
(Barragan-Fonseca et al., 2017). The wide range in larval crude fat content can likely be explained by the differences in energy content of the feed, and diets high in energy content would increase larval crude fat (Barragan-Fonseca et al., 2018). For instance, substrates high in fat and carbohydrate contents increased larval crude fat contents (Zheng et al., 2012). In contrast to BSF, providing the fruit fly Ceratitis capitata with diets with excess dietary carbohydrates resulted in pupating larvae having lower lipid and also low protein contents. High P:C ratios in the diet yielded C. capitata larvae with high protein and lipid contents. Differences between BSF and other species may be due to differential post-ingestion regulation where a high dietary carbohydrate diet reduces the lipogenic activity of the larvae, and induces a shift from lipid to glucose oxidation, resulting in a relatively low incorporation of lipid reserves (Nestel \& Nemny-Lavy, 2008).

In this study we also found that heavier BSF larvae had higher crude fat content, which could be important for adult fitness because increase in weight generally increases fecundity of flies (Gobbi et al., 2013). In most insects, carbohydrates ingested in excess of requirement are converted to lipids and stored (Zanotto et al., 1993). For instance, in locusts that were fed diets high in carbohydrates and low in protein lipogenesis increased (Zanotto et al., 1993), which could be more beneficial for females because lipids are an important egg component, with triacylglycerol comprising about $40 \%$ of a mature oocyte (Chapman et al., 2013).

Our results clearly demonstrate that high larval weight is associated with high $\mathrm{P}+\mathrm{C}$ content, and a key role for digestible carbohydrates. A similar trend was found in $M$. differentialis (Le Gall \& Behmer, 2014), and H. virescens (Roeder, 2010) where high dietary carbohydrate levels increased insect weight. Moreover, an excess of carbohydrates leads to high lipid levels, especially when the protein concentration in their food is low (Le Gall \& Behmer, 2014). Similarly, in the grasshopper S. americana, nymphs fed diets with intermediate to high nutrient content were significantly larger and contained a significantly greater proportion of lipid stores at adult eclosion, but not protein or carbohydrate stores than individuals fed low nutrient content diets. It has been suggested that larva-derived lipid stores may be more important to fitness than carbohydrate or protein stores (Hahn, 2005). However, high dietary crude protein content might be used by BSF larvae for energy production (Waldbauer et al., 1984), as it also directly impacted body mass on high P-diets.

\section{Adult life-history traits}

Suboptimal nutrition during larval development can significantly affect physiological processes later in life in insects (Jones \& Raubenheimer, 2001; Hahn, 2005; Prabhu et al., 2008; Roeder \& Behmer, 2014). Our results show that food macronutrient contents during the larval phase significantly affected development time until adult and egg yield, protein content having the main effect. Protein content certainly was the limiting factor with respect to development rate. High dietary nutrient concentration resulted in heavy 
larvae and adults compared to larvae fed on low $\mathrm{P}$ and $\mathrm{C}$ contents that were smaller and had lower fecundity.

Development time until the adult stage is affected by $\mathrm{P}$ - and C-content and $\mathrm{PxC}$ interaction, and similarly to larval development, it is shorter on low P-content at all C-contents. An important cost of the short larval developmental time is limited opportunities to build up metabolic reserves for adult life (Hanski, 1987). The number of egg masses produced per female was higher on P17:C55 and P24:C35 diets, being influenced only by protein content. As with larval survival rate, adult emergence was not affected by $\mathrm{P}$ or $\mathrm{C}$ levels, did not show differences among treatments and was high for all treatments (83-93\%). Similarly, our experiments allow to infer that BSF follows an Equal Distance rule (Raubenheimer \& Simpson, 1997) as it could deal with the variable dietary P and C levels tested in our study. However, we still need to investigate the effects of extreme contents of digestible carbohydrates and protein to be able to be more conclusive.

In general, the results of this study reveal that dietary protein and carbohydrate contents are more important than $\mathrm{P}: \mathrm{C}$ ratio and affect larval performance, larval body composition and fecundity of BSF, and high $\mathrm{P}+\mathrm{C}$-contents tended to improve $\mathrm{BSF}$ larval performance over a wide range of carbohydrate-biased $\mathrm{P}: \mathrm{C}$ ratios. Even though all $\mathrm{P}+\mathrm{C}$-contents tested are suitable for the complete life cycle of $\mathrm{BSF}$, since diet P17:C55 (P:C=1:3; $\mathrm{P}+\mathrm{C}=72$ ) supported highest larval and adult performance and resulted in high body crude protein content (42.3\%) and an intermediate crude fat content $(27.6 \%)$ on the diets tested, this would be the intake target for BSF fed on chicken feed-based diets, which matches with the $\mathrm{P}+\mathrm{C}$ content of those resources that BSF colonises in the wild. Additionally, we also confirm our previous findings of regulation of larval protein content within narrow limits whereas larval crude fat content was strongly affected by nutrient concentration (Barragan-Fonseca et al., 2018).

We cannot conclude from the present study how BSF deals with protein or carbohydrate excess as all diets used here are likely to be in the range of its food under natural conditions. Future studies addressing diets with a broader range of $\mathrm{P}: \mathrm{C}$ ratios at different $\mathrm{P}+\mathrm{C}$ contents and defined diet components are warranted in order to gain information on physiological mechanisms used by BSF on nutritionally unbalanced diets. From the perspective of quality of BSF as animal feed, a broad perspective on dietary macronutrient efficiency is desirable. Such information will improve our understanding of the effects of diets on BSF development, growth and body composition, and provide tools for economic decisions.

\section{Acknowledgements}

This work was supported by the Scholarship Program No. 568 from COLCIENCIAS Departamento Administrativo de Ciencia, Tecnología e Innovación - Colombia. 


\section{References}

Aguila JR, Hoshizaki DK, Gibbs AG (2013) Contribution of larval nutrition to adult reproduction in Drosophila melanogaster. Journal of Experimental Biology, 216, 399-406.

Arrese EL, Soulages JL (2010) Insect fat body: energy, metabolism, and regulation. Annual Review of Entomology, 55, 207-225.

Barragan-Fonseca KB, Dicke M, Van Loon JJA (2018) Influence of larval density and nutrient concentration on performance and body protein and fat composition of Hermetia illucens larvae. Manuscript submitted for publication.

Barragan-Fonseca KB, Dicke M, Van Loon JJA (2017) Nutritional value of the black soldier fly (Hermetia illucens L.) and its suitability as animal feed - a review. Journal of Insects as Food and Feed, 3, 105-120.

Behmer ST (2009) Insect herbivore nutrient regulation. Annual Review of Entomology, 54, 165-187.

Cammack JA, Tomberlin JK (2017) The impact of diet protein and carbohydrate on select life-history traits of the black soldier fly Hermetia illucens (L.)(Diptera: Stratiomyidae). Insects, 8, 1-14.

Canato CM, Zucoloto FS (1998) Feeding behavior of Ceratitis capitata (Diptera, Tephritidae): influence of carbohydrate ingestion. Journal of Insect Physiology, 44, 149-155.

Chapman RF, Simpson SJ, Douglas AE (eds.) (2013) The insects: structure and function, Cambridge University Press.

Cohen AC (2004) Insect diets: science and technology, CRC press.

Despland E, Noseworthy M (2006) How well do specialist feeders regulate nutrient intake? Evidence from a gregarious tree-feeding caterpillar. Journal of Experimental Biology, 209, 1301-1309.

Dmitriew CM (2011) The evolution of growth trajectories: what limits growth rate? Biological Reviews, 86, $97-116$.

Gobbi P, Martínez-Sánchez A, Rojo S (2013) The effects of larval diet on adult life-history traits of the black soldier fly, Hermetia illucens (Diptera: Stratiomyidae). European Journal of Entomology, 110, 461-468.

Hahn DA (2005) Larval nutrition affects lipid storage and growth, but not protein or carbohydrate storage in newly eclosed adults of the grasshopper Schistocerca americana. Journal of Insect Physiology, 51, 1210-1219.

Hanski I (1987) Nutritional ecology of dung-and carrion-feeding insects. In: Slansky Jr., F. and Rodriguez, J. G. (eds), Nutritional ecology of insects, mites, spiders, and related invertebrates, Oxford, Pergamon Press. 837-884.

Hardin JA, Kraus DA, Burrack HJ (2015) Diet quality mitigates intraspecific larval competition in Drosophila suzukii. Entomologia Experimentalis et Applicata, 156, 59-65.

Harrison SJ, Raubenheimer D, Simpson SJ, Godin J-GJ, Bertram SM (2014) Towards a synthesis of frameworks in nutritional ecology: interacting effects of protein, carbohydrate and phosphorus on field cricket fitness. Proceedings of the Royal Society of London B: Biological Sciences, 281, 1-9.

Janssen RH, Vincken J-P, Van Den Broek LA, Fogliano V, Lakemond CM (2017) Nitrogen-to-protein conversion factors for three edible insects: Tenebrio molitor, Alphitobius diaperinus, and Hermetia illucens. Journal of Agricultural and Food Chemistry, 65, 2275-2278.

Jaramillo SL, Mehlferber E, Moore PJ (2015) Life-history trade-offs under different larval diets in Drosophila suzukii (Diptera: Drosophilidae). Physiological Entomology, 40, 2-9.

Jensen K, Mcclure C, Priest NK, Hunt J (2015) Sex-specific effects of protein and carbohydrate intake on reproduction but not lifespan in Drosophila melanogaster. Aging Cell, 14, 605-615.

Jeon H, Park S, Choi J, Jeong G, Lee S-B, Choi Y, et al. (2011) The intestinal bacterial community in the food waste-reducing larvae of Hermetia illucens. Current Microbiology, 62, 1390-1399.

Jones S, Raubenheimer D (2001) Nutritional regulation in nymphs of the German cockroach, Blattella germanica. Journal of Insect Physiology, 47, 1169-1180.

Kaspi R, Mossinson S, Drezner T, Kamensky B, Yuval B (2002) Effects of larval diet on development rates and reproductive maturation of male and female Mediterranean fruit flies. Physiological Entomology, 27, 29-38. 
Kause A, Saloniemi I, Morin J-P, Haukioja E, Hanhimäki S, Ruohomäki K (2001) Seasonally varying diet quality and the quantitative genetics of development time and body size in birch feeding insects. Evolution, 55, 1992-2001.

Le Gall M, Behmer ST (2014) Effects of protein and carbohydrate on an insect herbivore: the vista from a fitness landscape. Integrative and Comparative Biology, 54, 942-954.

Lee K, Behmer S, Simpson S, Raubenheimer D (2002) A geometric analysis of nutrient regulation in the generalist caterpillar Spodoptera littoralis (Boisduval). Journal of Insect Physiology, 48, 655-665.

Lee KP (2007) The interactive effects of protein quality and macronutrient imbalance on nutrient balancing in an insect herbivore. Journal of Experimental Biology, 219, 3236-3244.

Lee KP, Behmer ST, Simpson SJ (2006) Nutrient regulation in relation to diet breadth: a comparison of Heliothis sister species and a hybrid. Journal of Experimental Biology, 209, 2076-2084.

Martínez-Sánchez A, Magaña C, Saloña M, Rojo S (2011) First record of Hermetia illucens (Diptera: Stratiomyidae) on human corpses in Iberian Peninsula. Forensic Science International, 206, e76-e78.

May B (1961) The occurrence in New Zealand and the life-history of the soldier fly Hermetia illucens (L.) (Diptera: Stratiomyidae). The New Zealand Journal of Science and Technology, 4, 55-65.

Nash WJ, Chapman T (2014) Effect of dietary components on larval life history characteristics in the Medfly (Ceratitis capitata: Diptera, Tephritidae). PLOS ONE, 9, e86029.

Nestel D, Nemny-Lavy E (2008) Nutrient balance in medfly, Ceratitis capitata, larval diets affects the ability of the developing insect to incorporate lipid and protein reserves. Entomologia Experimentalis et Applicata, 126, 53-60.

Nguyen TT, Tomberlin JK, Vanlaerhoven S (2015) Ability of black soldier fly (Diptera: Stratiomyidae) larvae to recycle food waste. Environmental Entomology, 44, 406-410.

Pereboom J (2000) The composition of larval food and the significance of exocrine secretions in the bumblebee Bombus terrestris. Insectes Sociaux, 47, 11-20.

Prabhu V, Perez-Staples D, Taylor P (2008) Protein: carbohydrate ratios promoting sexual activity and longevity of male Queensland fruit flies. Journal of Applied Entomology, 132, 575-582.

R-Core-Team (2017) R: A language and environment for statistical computing. R Foundation for Statistical Computing, Vienna, Austria.

Raubenheimer D, Jones S (2006) Nutritional imbalance in an extreme generalist omnivore: tolerance and recovery through complementary food selection. Animal Behaviour, 71, 1253-1262.

Raubenheimer D, Simpson SJ (1997) Integrative models of nutrient balancing: application to insects and vertebrates. Nutrition Research Reviews, 10, 151-179.

Raubenheimer D, Simpson SJ (1999) Integrating nutrition: A geometrical approach. Entomologia Experimentalis et Applicata, 91, 67-82.

Raubenheimer D, Simpson SJ (2003) Nutrient balancing in grasshoppers: Behavioural and physiological correlates of dietary breadth. Journal of Experimental Biology, 206, 1669-1681.

Roeder KA (2010) Dietary effect on the performance and body composition of the generalist insect herbivore, Heliothis virescens (Lepidoptera: Noctuidae). Entomology. Texas A\&M University, College Station, TX.

Roeder KA, Behmer ST (2014) Lifetime consequences of food protein-carbohydrate content for an insect herbivore. Functional Ecology, 28, 1135-1143.

Sheppard CD, Larry Newton G, Thompson SA, Savage S (1994) A value added manure management system using the black soldier fly. Bioresource Technology, 50, 275-279.

Simpson S, Raubenheimer D (1993) A multi-level analysis of feeding behaviour: the geometry of nutritional decisions. Philosophical Transactions of The Royal Society of London: Biological Sciences, 342, 381-402.

Simpson S, Raubenheimer D (1995) The geometric analysis of feeding and nutrition: a user's guide. Journal of Insect Physiology, 41, 545-553.

Simpson SJ, Simmonds MSJ, Blaney WM (1988) A comparison of dietary selection behaviour in larval Locusta migratoria and Spodoptera littoralis. Physiological Entomology, 13, 225-238.

Tschirner M, Simon A (2015) Influence of different growing substrates and processing on the nutrient composition of black soldier fly larvae destined for animal feed. Journal of Insects as Food and Feed, 1, 249-259. 
Chapter 4

Waldbauer GP, Cohen RW, Friedman S (1984) Self-selection of an optimal nutrient mix from defined diets by larvae of the corn-earworm, Heliothis zea (Boddie). Physiological Zoology, 57, 590-597.

Zanotto F, Simpson S, Raubenheimer D (1993) The regulation of growth by locusts through post-ingestive compensation for variation in the levels of dietary protein and carbohydrate. Physiological Entomology, 18, 425-434.

Zheng L, Qing L, Jibin Z, Ziniu Y (2012) Double the biodiesel yield: Rearing black soldier fly larvae, Hermetia illucens, on solid residual fraction of restaurant waste after grease extraction for biodiesel production. Renewable Energy, 41, 75-79.

Zudaire E, Simpson SJ, Montuenga LM (1998) Effects of food nutrient content, insect age and stage in the feeding cycle on the FMRFamide immunoreactivity of diffuse endocrine cells in the locust gut. Journal of Experimental Biology, 201, 2971-2979. 


\section{Chapter 5}

Performance of the Black Soldier Fly, Hermetia illucens L. (Diptera: Stratiomyidae) on vegetable residue-based diets formulated based on protein and carbohydrate contents

Karol B. Barragan-Fonseca, Julián Pineda-Mejia, Marcel Dicke \& Joop J. A. van Loon

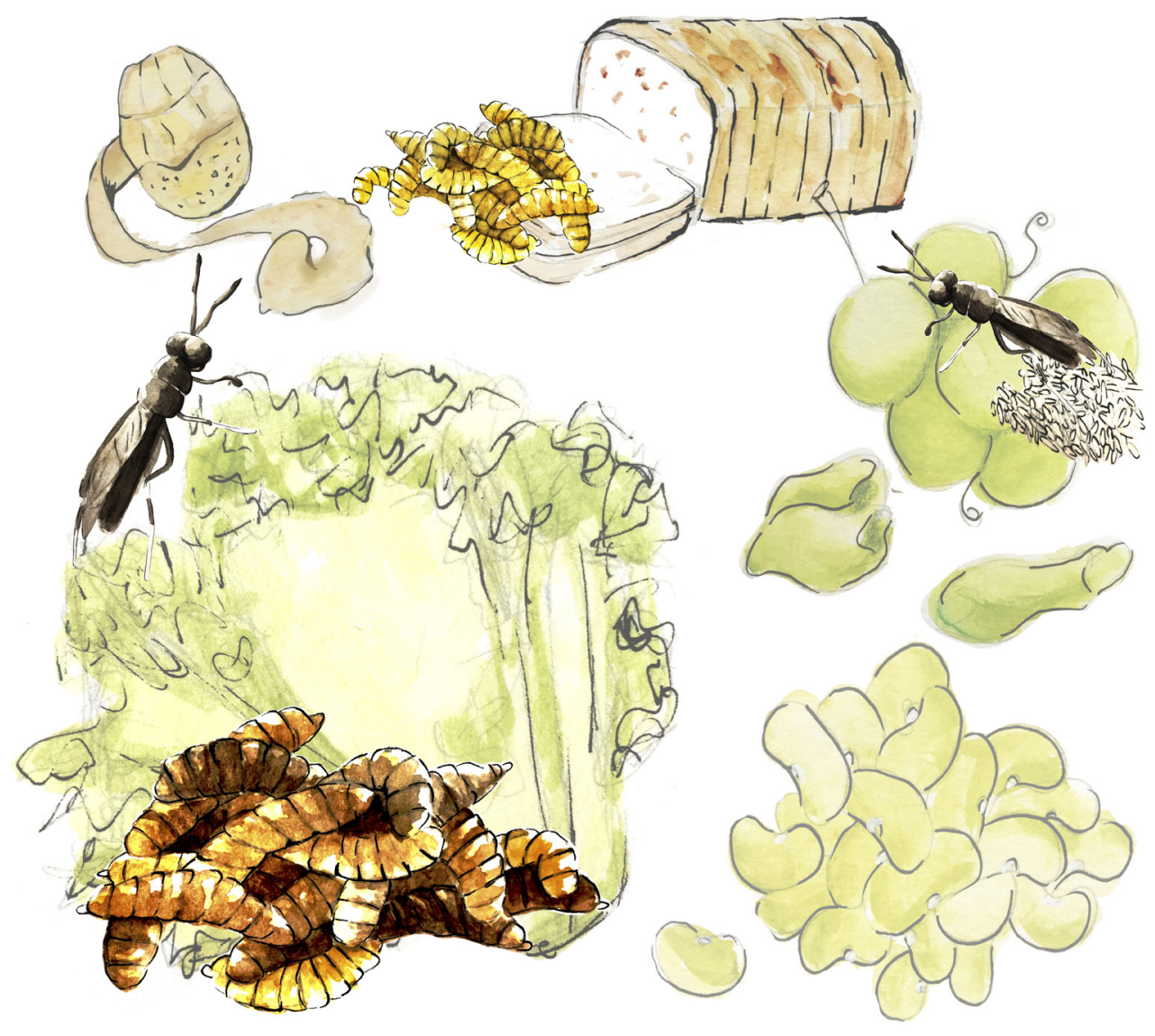




\begin{abstract}
The Black Soldier Fly [BSF; Hermetia illucens L. (Diptera: Stratiomyidae)] can be sustainably reared on organic waste streams and thereby provide a novel animal protein source for animal feed. BSF performance and body composition depend to a large extent on the nutrient composition of the waste stream. The contents of protein and carbohydrate present in the diet of insects need to be balanced to maximize their performance. BSF larvae were fed on four diets consisting of vegetable by-products from the food industry. The diets were formulated based on an average summed protein and carbohydrate $(\mathrm{P}+\mathrm{C})$ concentration tested in previous experiments and a 1:2 protein:carbohydrate $(\mathrm{P}: \mathrm{C})$ ratio. In a second experiment we took the ingredients from the best vegetable waste-based diet from the first experiment, and formulated diets having P:C ratios of $1: 2$ or $1: 3$ and 40 or $47 \%$ $\mathrm{DM}$ of $\mathrm{P}+\mathrm{C}$ and we quantified both larval and adult performance. In the first experiment, although there were differences in larval performance among the diets, all diets supported a higher larval performance than reported previously, with the diet composed of cabbages leaves, old bread and dried distiller's grains with solubles (DDGS) (47\% P+C) being the best diet. We infer that not only total macronutrient content but also nutritional quality of proteins and carbohydrates affected performance. In the second experiment, the two vegetable residue-based larval diets resulted in similar larval and adult performance. High dietary protein resulted in increases in larval crude fat content. Further research is needed to learn how different sources of protein and carbohydrates affect macronutrient intake and performance of BSF in terms of immature and adult life-history traits and larval body composition and how BSF regulates macronutrient intake.
\end{abstract}

Key words: Macronutrients, proteins, carbohydrates, plant waste, larval performance, fecundity, body composition, food quality. 


\section{Introduction}

The balance between dietary protein and carbohydrates is an important factor affecting the life history of insects (Raubenheimer \& Simpson, 2003). Proteins and carbohydrates influence animal survival, growth and reproduction (Karasov \& del Rio, 2007; Prabhu et al., 2008). Saprophagous species such as the Black Soldier Fly (BSF), Hermetia illucens L. (Diptera: Stratiomyidae) have a very broad diet, including different types of organic waste such as vegetable residues, manure, carrion. Its larval stages are therefore likely to encounter a wide range of concentrations and ratios of proteins and carbohydrates, the two main groups of macronutrients. When analyzing food consumed by this species in the wild, its diets are generally lower in protein than in carbohydrate levels and have a wide range of nutrient levels in terms of summed crude protein and digestible carbohydrates such as starch (40-80\% DM) (Barragan-Fonseca et al., 2018b).

Barragan-Fonseca et al. (2018b) tested a range of chicken-feed-based diets with varying $\mathrm{P}: \mathrm{C}$ ratios $(1: 2-1: 4)$ and $\mathrm{P}+\mathrm{C}$ concentrations (45-79\%) corresponding to BSF's natural food sources to explore how life-history traits of BSF were affected by these nutrients. They showed that dietary protein and carbohydrate levels during the larval phase significantly affect larval and adult performance, protein content being most influential. Thus, high dietary nutrient levels resulted in high larval and adult body mass and fecund females as shown for other Diptera as well (Boggs \& Freeman, 2005). Their results also revealed that dietary macronutrient density has a stronger effect than differences in P:C ratio. A P:C ratio of $1: 3$ and $\mathrm{P}+\mathrm{C}$ content of $70 \%$ seemed optimal values for chicken-feed-based diets since these supported the best larval and adult performance.

Food quality is one of the most important factors that affects BSF growth rates. High quality positively correlates with survival rate and negatively with duration of the larval phase (Newton et al., 2005; Gobbi et al., 2013), protein level being a limiting factor. For instance, Oonincx et al. (2015) who used vegetable by-products, observed that larvae fed a diet high in both protein and fat and larvae fed control diet (chicken feed), also high in protein, displayed a shorter development time $(21 \mathrm{~d})$ than larvae fed the low-protein diets $(37 \mathrm{~d})$. High protein and fat diets appear to increase BSF larval weight and size (Nguyen $e t$ al., 2013; Nguyen et al., 2015; Oonincx et al., 2015). Larval body composition of the BSF varies among substrates, mainly in macronutrient levels (Barragan-Fonseca et al., 2017) and to a lesser extent in micronutrient concentrations (Tschirner \& Simon, 2015; Spranghers et al., 2016; Barragan-Fonseca et al., 2017).

In addition, sources of protein or digestible carbohydrates differ in their nutritional value to BSF. Barragan-Fonseca et al. (2017) reviewed life-history traits and performance of BSF larvae fed (semi-)artificial diets and plant- and animal-derived organic waste and found 
that larvae fed on good quality diets might need lower feeding rations to achieve a good performance than larvae fed on low-quality diets. However, biotic and abiotic conditions that may affect larval performance (e.g. larval density, substrate humidity or air humidity) have often not been reported, complicating conclusions on the effect of food quality as such. Thus, studying the effect of nutrient quality on BSF performance under the same biotic and abiotic conditions is needed.

The objective of this study is to explore the effects of diet composition on life-history traits of immature and mature BSF, using different types of vegetable waste under the same biotic and abiotic conditions. We performed two experiments, one in which we formulated four vegetable waste-based diets with the same $\mathrm{P}+\mathrm{C}$ concentration (47\%), and $\mathrm{P}: \mathrm{C}$ ratio 1:2. In the second experiment we took the ingredients from the vegetable waste-based diet that supported the highest larval performance in the first experiment, and formulated two vegetable waste-based diets with carbohydrate-biased $\mathrm{P}: \mathrm{C}$ ratios $(1: 2-1: 3)$ and two $\mathrm{P}+\mathrm{C}$ concentrations (40 and 47\%) to assess their effects on both immature and adult life-history traits of BSF, and on larval body protein and fat contents.

\section{Materials and Methods}

\section{Experimental insects}

Hermetia illucens L (Diptera: Stratiomyidae) larvae were obtained from a colony maintained at constant conditions in a climate room $\left(27 \pm 1{ }^{\circ} \mathrm{C}, 70 \% \mathrm{RH}, \mathrm{L} 12: \mathrm{D} 12\right)$ at the Laboratory of Entomology, Wageningen University (The Netherlands).

\section{Experimental design}

Experiment 1

Four vegetable organic waste-based diets were formulated to contain a $\mathrm{P}+\mathrm{C}$ content of $47 \%$ and a P:C ratio of 1:2 (P 17\% and C 30\%). Ingredients were chosen depending on availability from the agro-industrial sector. The ingredients selected were: dried distiller's grains with solubles (DDGS), grape pulp, potato peels, bean seeds, cabbage leaves and old bread (sliced white bread - Jumbo brand). Grapes, potatoes, bean seeds and cabbages were purchased at a vegetable store and processed to get the ingredients (pulps, peels, etc.). All ingredients were ground (mini food-processor - Onyx) in order to obtain particles of homogenous size for all diets $(<5 \mathrm{~mm})$. Inclusion of the ingredients was based on proximate nutritional analyses of fat, crude protein, carbohydrate and neutral detergent fibre contents at Mérieux NutriSciences (Ede, The Netherlands). The remaining proportion was cellulose, considered to be a poorly digestible bulk agent. The formulation was calculated using the expansion solver in Excel (Table 1). The diets were mixed in the laboratory after weighing the exact amount of the different ingredients calculated. 
Table 1. Composition of experimental diets*

\begin{tabular}{cccccccc}
\hline Diet & Ingredient & DM & CP & NFC & CF & EE & Inclusion \\
\hline $\mathbf{1}$ & DDGS** & 91.8 & 27.1 & 19.5 & 7 & 11.7 & 53.6 \\
& Grape pulp & 30.6 & 7.3 & 57.5 & 11.4 & 1.9 & 34 \\
& Cellulose & 100 & 0 & 0 & 100 & 0 & 12.4 \\
& Total & $\mathbf{7 2 . 1}$ & $\mathbf{1 7}$ & $\mathbf{3 0}$ & $\mathbf{2 0 . 1}$ & $\mathbf{6 . 9}$ & $\mathbf{1 0 0}$ \\
& DDGS & 91.8 & 27.1 & 19.5 & 7 & 11.7 & 44.5 \\
& Potato peels & 15.3 & 15.8 & 68.3 & 4.5 & 0.3 & 31.2 \\
& Cellulose & 100 & 0 & 0 & 100 & 0 & 24.2 \\
$\mathbf{3}$ & Total & $\mathbf{6 9 . 9}$ & $\mathbf{1 7}$ & $\mathbf{3 0}$ & $\mathbf{2 8 . 7}$ & $\mathbf{5 . 3}$ & $\mathbf{1 0 0}$ \\
& DDGS & 91.8 & 27.1 & 19.5 & 7 & 11.7 & 32.4 \\
& Bean seeds & 89.9 & 18.7 & 53.9 & 3.6 & 1.6 & 44 \\
& Sunflower Oil & 100 & 0 & 0 & 0 & 100 & 1.5 \\
& Cellulose & 100 & 0 & 0 & 100 & 0 & 22.1 \\
$\mathbf{4}$ & Total & $\mathbf{9 2 . 9}$ & $\mathbf{1 7}$ & $\mathbf{3 0}$ & $\mathbf{2 6 . 1}$ & $\mathbf{5 . 9}$ & $\mathbf{1 0 0}$ \\
& DDGS & 91.8 & 27.1 & 19.5 & 7 & 11.7 & 37.2 \\
& Cabbage leaves & 12.1 & 19.2 & 40.1 & 17 & 1.4 & 24.7 \\
& Old bread & 76.1 & 13.5 & 79.9 & 0.3 & 0.7 & 16 \\
& Cellulose & 100 & 0 & 0 & 100 & 0 & $\mathbf{2 2}$ \\
& Total & $\mathbf{5 5 . 4}$ & $\mathbf{1 7}$ & $\mathbf{3 0}$ & $\mathbf{2 8 . 8}$ & $\mathbf{4 . 8}$ & $\mathbf{1 0 0}$ \\
\hline
\end{tabular}

*Expressed in \% Dry Matter (DM). CP: Crude protein; NFC: Non-fibre carbohydrates; CF: Crude fibre; EE: Ether extractable fraction

**Dried distiller's grains with solubles

\section{Experiment 2}

Two vegetable organic waste-based diets were formulated: protein $17 \%$ and digestible carbohydrate $30 \%$ and protein $10 \%$ and digestible carbohydrate 30\% (Table 2). The selected ingredients were chosen based on the ingredients from the diet on which the best larval performance was observed in experiment 1 (DDGS, cabbage leaves, old bread and cellulose). For this experiment, we included sunflower oil to have similar EE-content in both diets.

Table 2. Composition of experimental diets*

\begin{tabular}{cccccccc}
\hline Diet & DM & CP & NFC & CF & EE & P+C (\%) & P:C ratio \\
\hline Diet 1 & 72.6 & 10 & 30 & 43 & 5.7 & 40 & $1: 2$ \\
Diet 2 & 71.1 & 17 & 30 & 27 & 5.9 & 47 & $1: 3$ \\
\hline
\end{tabular}

*Expressed in \% Dry Matter (DM). CP: Crude protein; NFC: Non-fibre carbohydrates; CF: Crude fibre; EE: Ether extractable fraction

The larvae were reared on the 4 experimental diets (experiment 1 ) and on the 2 experimental diets (experiment 2), that had been thoroughly mixed with water to get $60 \%$ moisture based on fresh weight of diet. Each replicate consisted of 100 larvae (less than 24 $\mathrm{h}$ after they had hatched from the egg) per $750 \mathrm{ml}$ container. A fixed feeding ration of 1 $\mathrm{g} \mathrm{DM}$ of food per larva was added once at the beginning of the experiment. The feeding experiments were conducted in a climatic room $\left(4.5 \mathrm{~m}^{2}\right)$ under constant conditions $(27 \pm$ $\left.1{ }^{\circ} \mathrm{C}, 70 \pm 5 \% \mathrm{RH}, \mathrm{L} 12: \mathrm{D} 12\right)$. In order to eliminate positional effects, all containers were randomly relocated three times per week. 


\section{Immature life-history traits}

For experiment 1, ten replicates were set up per dietary treatment. For experiment 2, per dietary treatment six replicates were set up. Larvae were harvested when at least $50 \%$ of the larvae were observed to have reached the pre-pupal stage, as appearing from the characteristic black cuticle of prepupae (May, 1961). Development time was considered to be the number of days between the start of the experiment, and the day of harvesting. All animals from each container were harvested with forceps, counted, and weighed collectively. Larvae were washed under running water to remove residues consisting of left-over feed and faeces, their integument dried with paper tissues, and their weight registered as BSFL yield (g fresh matter) on a precision balance (Ohaus, Adventurer Pro AV313, Parsippany - USA, precision $\pm 0.001 \mathrm{~g}$ ). To determine survival rate, the number of live BSF at the end of the experiment (day of harvesting) was divided by the initial number of larvae per replicate. The individual pupal weight was determined ( $\mathrm{g}$ fresh matter) as was done with larval weight. For experiment 1 growth curves were recorded. Larvae were weighed every two days beginning on day 5 since egg hatch because in the first days the larvae are too small to be removed from the substrate. Ten random larvae were collected from each container and body weight recorded on a precision balance (Mettler Toledo, NewClassicML, Switzerland, precision $\pm 0.001 \mathrm{~g}$ ) to obtain an average weight for each replicate. Recording the growth curve was terminated when more than half of the replicates were harvested.

\section{Adult life-history traits}

Experiment 2. Per dietary treatment six replicates were set up. Forty newly eclosed $(<12$ $\mathrm{h}$ old) adult BSF from each container in which larvae had been reared were released into a BugDorm-1 cage (30 x 30 × 30 cm; MegaView Science Co., Ltd. Taiwan) and kept in a greenhouse compartment under controlled conditions $\left(25 \pm 1{ }^{\circ} \mathrm{C}, 70 \pm 5 \% \mathrm{RH}\right)$ and natural light. Per dietary treatment six replicates were set up and sex ratio was determined. Adults were provided with water and sugar ad libitum and two days after eclosion, a mixture of sand $(250 \mathrm{~g})$, chicken feed $(250 \mathrm{~g})$ and water $(800 \mathrm{ml})$ in a plastic container $(10 \mathrm{x}$ $10 \times 6 \mathrm{~cm}$ ) was offered for oviposition. The surface of each container had four corrugated cardboards, each measuring $4 \mathrm{~cm}$ (height) $\mathrm{x} 9 \mathrm{~cm}$ (length) as a substrate for egg laying. Every three days from all containers the cardboards were removed, and both the sandfeed-water medium and the cardboards were substituted. In order to determine fecundity, number of egg masses, surface of egg masses $\left(\mathrm{mm}^{2}\right)$, and percentage of larval hatching were recorded after $24-36 \mathrm{~h}$. To determine the survival rate until the adult stage, the number of BSF adults eclosed at the end of the experiment was divided by the initial number of larvae per replicate. The development time until the adult stage was considered to be the number of days between the start of the experiment, and the day the first adult was observed. Adult fresh weight was measured within $36 \mathrm{~h}$ since eclosion. Adults were put into a centrifuge tube to measure their weight on a precision balance (Mettler Toledo, NewClassicML, Switzerland, precision $\pm 0.001 \mathrm{~g}$ ). To determine longevity, $6-19$ males 
and females from each replicate (other individuals than adults used for fecundity) were selected and kept in the BugDorm cage. Longevity was recorded as the period from the average eclosion date to the time of death. The average longevity of adults from each cage was used in data analysis.

\section{Proximate chemical analysis of larvae}

Experiment 2. Samples were stored in a freezer $\left(-25^{\circ} \mathrm{C}\right)$ until all replicates had been harvested. The samples were oven-dried at $70^{\circ} \mathrm{C}$ until constant weight and homogenized by grinding the sample in an ultra-centrifugal mill (Retsch ZM 200, Haan - Germany). Both the larvae and the diets were analysed for dry matter (DM), crude protein, and crude fat and Neutral Detergent Fibre (NDF) at Mérieux NutriSciences (Ede, The Netherlands).

\section{Statistical analysis}

Experiment 1. One way ANOVA was applied if the assumptions of the model were met. If the assumptions were not met, the non-parametric Kruskal Wallis-test was applied. Experiment 2. Student's t-test was used to investigate if significant differences between the two treatments occurred $(\mathrm{p}<0.05)$. Pearson (if assumption of normality was met) or Spearman (non-parametric) correlation tests were conducted to investigate if egg mass production was associated with adult weight. IBM SPSS Statistics version 21.0 was used (IBM Corp., Armonk, NY).

\section{Results}

\section{Experiment 1}

Development times differed significantly between diets $(\mathrm{H}(3)=31.54, \mathrm{p}<0.001)$ (Figure 1A). Survival rates showed significant differences between diets as well $(\mathrm{H}(3)=16.011, \mathrm{p}$ $=0.001)$. Figure $1 \mathrm{~B}$ shows that larvae fed diets 1,3 and 4 resulted in similar survival rates. Diet 2 resulted in a significantly lower survival rate than diets 1 and 4. Individual larval weight (DM basis) $(\mathrm{F}(3,36)=43.22, \mathrm{p}<0.001)$ (Figure $1 \mathrm{C})$, and total yield of larvae (DM basis) were significantly different among diets $(\mathrm{H}(3)=26.07, \mathrm{p}<0.001)$, diets 1 and 4 resulting in the highest larval yields (Figure 1D). 
(A)

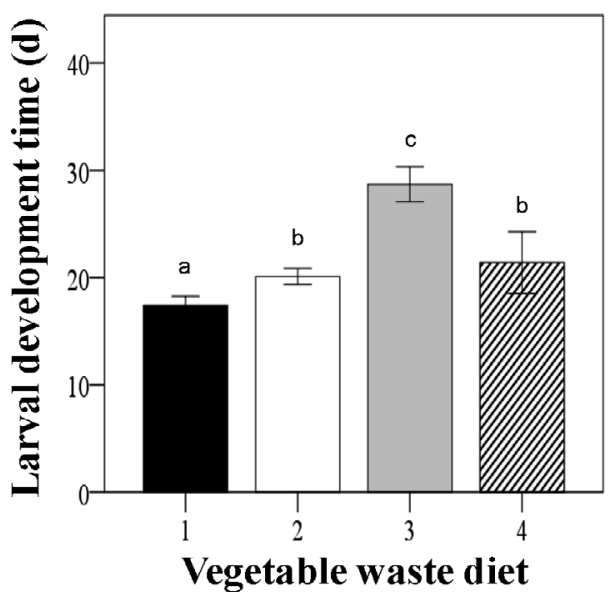

(C)

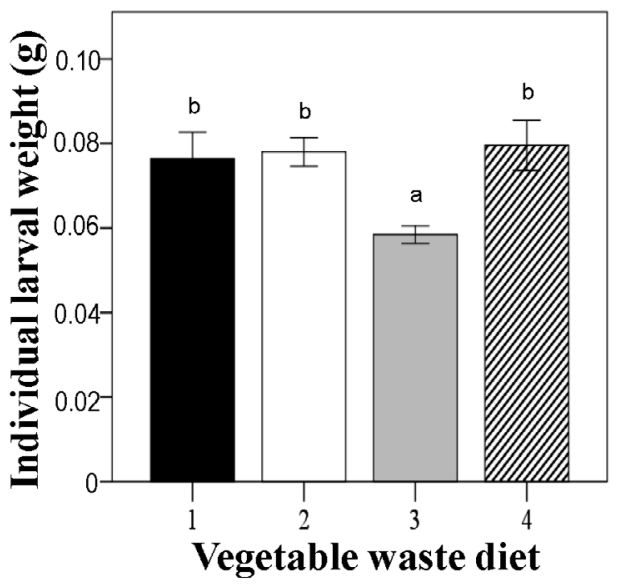

(B)

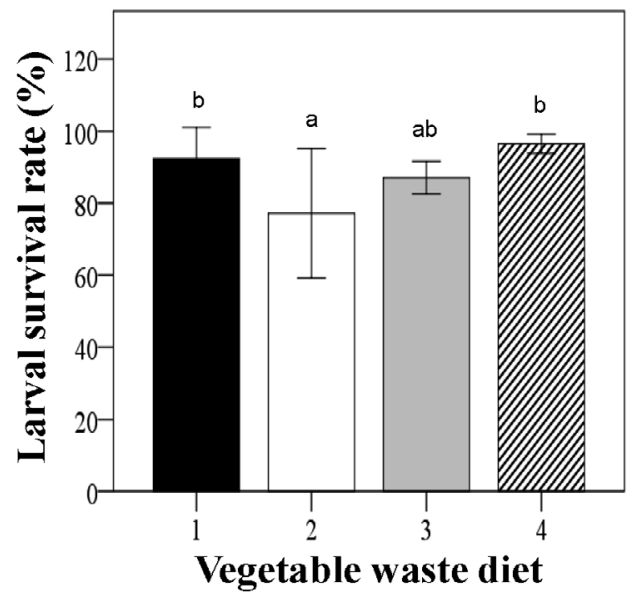

(D)

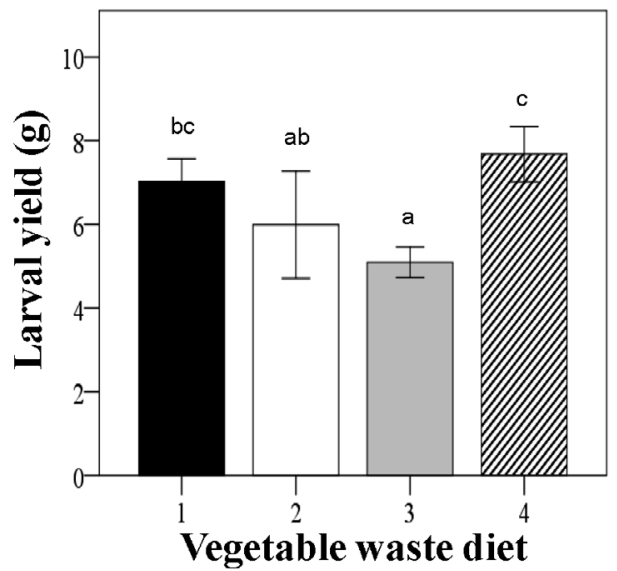

Figure 1. Black Soldier Fly life-history parameters of larvae fed different diets composed of vegetable organic waste $(n=10)$. For composition of diets refer to Table 1 . Bars (mean \pm SD) indicate (A) larval development time (days), (B) Larval survival rate (\%), (C) Individual larval weight on DM basis (g), and (D) Larval yield on DM basis (g). Bars having no letters in common represent significantly different mean values.

Time course of growth (FM basis) differed between the four diets (Figure 2). During the first 10 days, growth of larvae fed on diets 1 and 4 followed the same time course, however, after day 11 growth on diet 1 slowed down and levelled off. Larval growth on diet 2 showed a delay of 2 days compared to larvae on diets 1 and 4 and afterwards was similar to that for larvae on diet 4 . Larvae fed on diet 3 had slower growth and took longer to reach their maximum body weight which was lower than on the other three diets. 


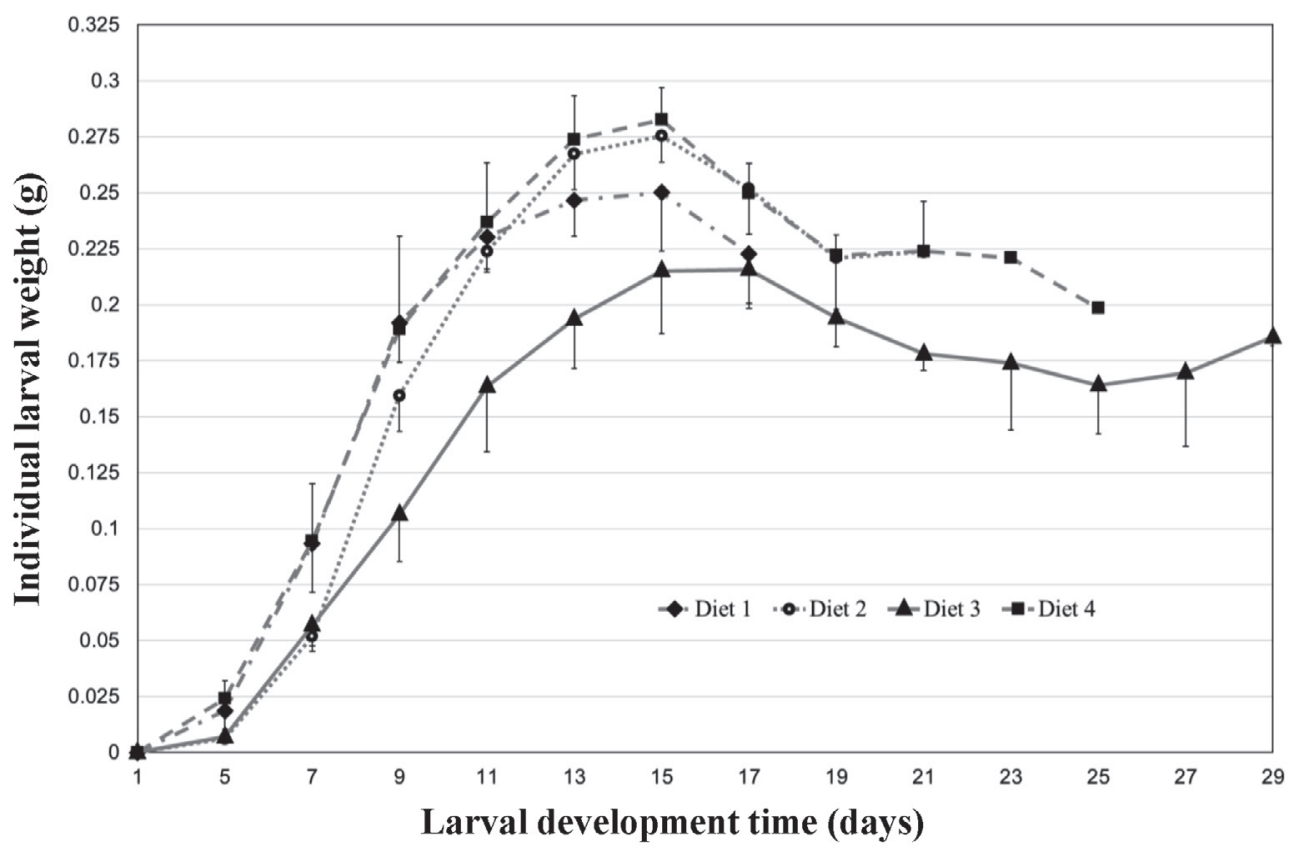

Figure 2. Growth curves of Black Soldier Fly larvae fed different diets composed of vegetable organic waste. Vertical error bars represent standard error of the mean.

\section{Experiment 2}

\section{Immature life-history traits}

Survival rate was significantly lower on diet $2(47 \% \mathrm{P}+\mathrm{C})$ than on diet $1(40 \% \mathrm{P}+\mathrm{C})(\mathrm{t}(10)$ $=3.76 ; \mathrm{p}<0.05)$. Neither development time $(\mathrm{t}(10)=0.47 ; \mathrm{p}=0.65)$ nor individual larval weight $(\mathrm{DM}$ basis $)(\mathrm{t}(10)=-1.9 ; \mathrm{p}=0.079)$ or larval yield $(\mathrm{DM}$ basis $)(\mathrm{t}(10)=1.94 ; \mathrm{p}=$ 0.081) were affected by diet (Table 3).

Table 3. Survival rate, development time and individual larval weight (mean $\pm \mathrm{SD} ; \mathrm{n}=6$ ) of Hermetia illucens larvae on the two diets tested in Experiment 2.

\begin{tabular}{ccccc}
\hline Diet & $\begin{array}{c}\text { Survival rate } \\
(\%)\end{array}$ & $\begin{array}{c}\text { Development time } \\
(\mathbf{d})\end{array}$ & $\begin{array}{c}\text { Individual larval weight } \\
(\mathbf{g ~ D M})\end{array}$ & $\begin{array}{c}\text { Larval yield } \\
(\mathbf{g ~ D M})\end{array}$ \\
\hline $\mathbf{1}$ & $93.7 \pm 6.2 \mathrm{a}$ & $22 \pm 1.3 \mathrm{a}$ & $0.039 \pm 0.003 \mathrm{a}$ & $3.65 \pm 0.46 \mathrm{a}$ \\
$\mathbf{2}$ & $75.7 \pm 6.8 \mathrm{~b}$ & $21.6 \pm 1.2 \mathrm{a}$ & $0.042 \pm 0.003 \mathrm{a}$ & $3.17 \pm 0.39 \mathrm{a}$ \\
\hline
\end{tabular}

Values within the same column having no letter in common differ significantly ( $<<0.05$ ) (Student's t-test).

\section{Larval body composition}

Larval crude protein content was not affected by diet $(\mathrm{t}(4)=1.49 ; \mathrm{p}=0.21)$ (Fig. 3A). Crude fat was higher in BSF larvae fed Diet $2(t(4)=-9.65 ; \mathrm{p}<0.05)$ (Fig. 3B). 
(A)

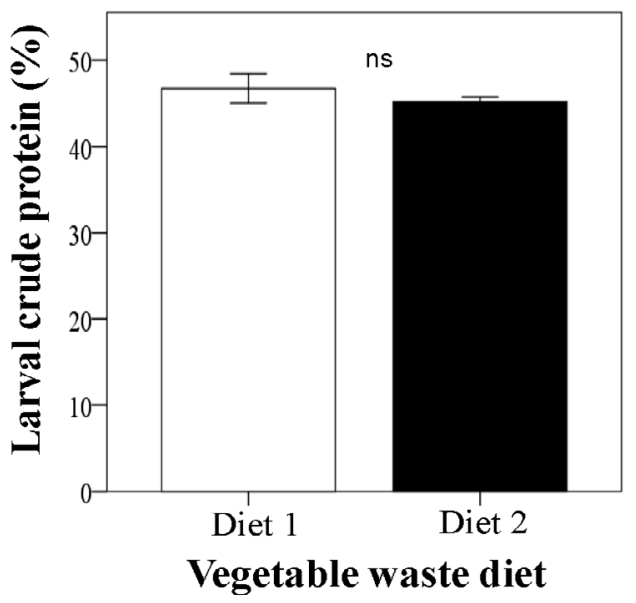

(B)

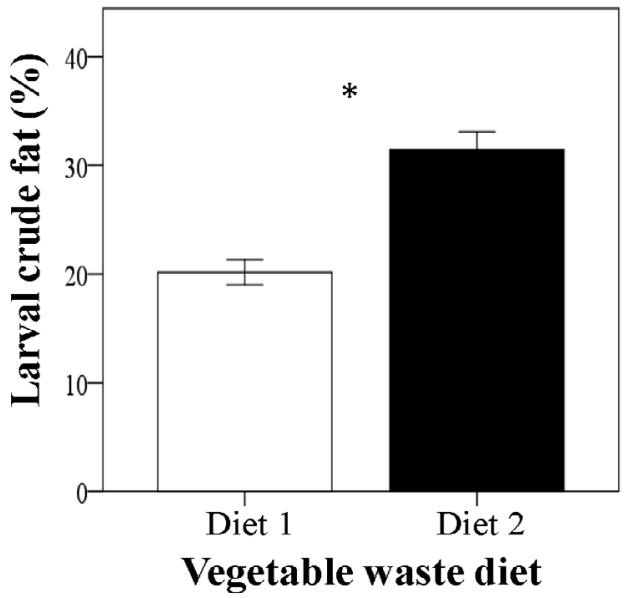

Figure 3. Larval nutritional composition in Black Soldier Fly larvae fed two vegetable waste diets $(\mathrm{n}=6)$. Bars (mean $\pm \mathrm{SD})$ indicate $(A)$ larval crude protein $(\% \mathrm{DM})$ and $(\mathrm{B})$ larval crude fat $(\% \mathrm{DM})$ (ns: $\mathrm{p}>0.05 ;{ }^{*}: \mathrm{p}<0.05$ ).

\section{Adult life-history traits}

Adult female or male weight did not differ between diets (females: $\mathrm{t}(10)=-1.24 ; \mathrm{p}=0.24$; males: $\mathrm{t}(10)=-1.51 ; \mathrm{p}=0.17$ ) (Figure 4a). However, for Diet 1 females were heavier than males $(\mathrm{t}(10)=2.1 ; \mathrm{p}<0.05)$, while they did not differ for Diet $2(\mathrm{t}(10)=1.27 ; \mathrm{p}=0.23)$. Adult longevity was similar for the two diets for both females $(t(10)=1.16 ; p=0.27)$ and males $(\mathrm{t}(10)=1.14 ; \mathrm{p}=0.28)$ (Figure 4b). However, females fed on either diet lived longer than males (Diet $1(\mathrm{t}(10)=2.88 ; \mathrm{p}<0.05)$ and Diet $2(\mathrm{t}(10)=3.82 ; \mathrm{p}<0.05)$. There were significant differences in development time between diets $(\mathrm{t}(10)=-5.33 ; \mathrm{p}<$ $0.05)$. There were no differences in pupal eclosion $(\mathrm{t}(10)=1.004 ; \mathrm{p}=0.34)$, nor egg mass number $(\mathrm{t}(10)=-0.94 ; \mathrm{p}=0.37)$, nor egg mass surface $(\mathrm{t}(10)=-1.93 ; \mathrm{p}=0.082)$, nor sex ratio $(\mathrm{t}(10)=-2.14 ; \mathrm{p}=0.058)$ (Table 4$)$. There was no significant relationship between egg mass surface and female weight (Pearson test, $r=0.32, p=0.32$ ). However, the number of egg masses per female was significantly correlated with female weight (Spearman test, $\mathrm{r}=0.63, \mathrm{p}=0.03)$. 
Table 4. Survival rate, development time, number of egg masses, egg mass surface and sex ratio (mean $\pm \mathrm{SD} ; \mathrm{n}=6$ ) of Hermetia illucens adults on the two diets in Experiment 2.

\begin{tabular}{cccccc}
\hline Diet & $\begin{array}{c}\text { Pupal eclosion } \\
(\%)\end{array}$ & $\begin{array}{c}\text { Development time } \\
(\mathbf{d})\end{array}$ & Egg masses (N) & $\begin{array}{c}\text { Egg mass surface } \\
\left(\mathbf{m m}^{2}\right)\end{array}$ & $\begin{array}{c}\text { Sex ratio } \\
\left(\mathbf{0}: \mathbf{0}^{\boldsymbol{1}}\right)\end{array}$ \\
\hline $\mathbf{1}$ & $70.3 \pm 18.1 \mathrm{a}$ & $34.3 \pm 0.8 \mathrm{a}$ & $15.8 \pm 6.8 \mathrm{a}$ & $195 \pm 105 \mathrm{a}$ & $0.93 \pm 0.3 \mathrm{a}$ \\
$\mathbf{2}$ & $62.7 \pm 4.8 \mathrm{a}$ & $39.3 \pm 2.2 \mathrm{~b}$ & $20.1 \pm 8.5 \mathrm{a}$ & $362 \pm 183 \mathrm{a}$ & $1.22 \pm 0.2 \mathrm{a}$ \\
\hline
\end{tabular}

Values in the same column having no letter in common differ significantly $(\mathrm{p}<0.05)(\mathrm{t}$-test).

(A)

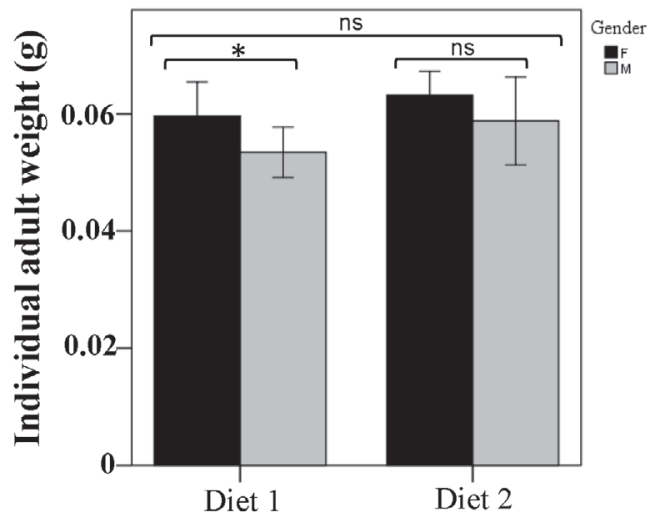

Vegetable waste diet
(B)

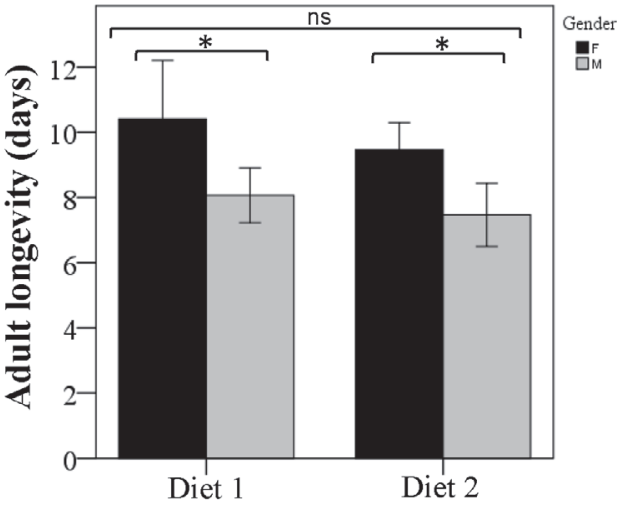

Vegetable waste diet

Figure 4. Bars (mean \pm SD) indicate (A) Individual adult weight on FM basis (g) and (B) Adult longevity (days) per gender (F: females; $\mathrm{M}$ : males) of BSF larvae fed with two organic waste diets (ns: $\left.\mathrm{p}>0.05 ;{ }^{*}: \mathrm{p}<0.05\right) . \mathrm{n}=6$.

\section{Discussion}

\section{Experiment 1}

Saprophagous insects feed on a wide range of diets that contain variable levels of proteins and carbohydrates. We studied the effects of composition of four diets having the same $\mathrm{P}: \mathrm{C}$ ratio based on commonly available vegetable waste types in order to evaluate larval performance. Compared with other studies, all four diets supported a good performance in terms of developmental time, survival rate and larval yield. We observed a high survival rate on all diets compared to larvae fed manure, vegetable and meat waste (Nguyen et al., 2013). A higher mortality on diet 2 in experiment 1 may have been caused by fungi growing on this diet at the beginning of the experiment. Development times recorded on diets 1, 2 and 4 formulated in this experiment were shorter than reported in the studies cited. Development time on diet 3 (bean seeds and DDGS) was longer, but comparable with development times previously reported for vegetable organic waste (Gobbi et al., 2013; 
Nguyen et al., 2013). However, development time was shorter on diets based on chicken/ hen feed for which an average of 15 days was found (Gobbi et al., 2013; Barragan-Fonseca et al., 2018a; Barragan-Fonseca et al., 2018b).

Regarding larval growth, the growth curves showed that BSF larvae fed diet 4 grew faster (Figure 2). Since BSF larvae lose weight when becoming prepupae (Gobbi, 2012), similar to other dipteran species such as the Housefly Musca domestica L. (Silverman \& Levinson, 1954), the best day to harvest larvae without weight loss occurring after the prepupal stage is during day 15 for diets 1, 2 and 4 and day 17 for diet 3, on which it took more time to reach the highest point in the curve. The total biomass of the harvested larvae differed among the four tested diets. The highest larval weights were observed for larvae fed diet 4 $(0.16-0.22 \mathrm{~g} \mathrm{FM/larva})$ which was higher than reported in other studies investigating suitability of organic waste for which average individual larval weight ranged from 0.11 to 0.17 g FM/larva (Spranghers et al., 2016). However, Tschirner and Simon (2015) and Gamboa Rojas (2008), who used a mixture of middlings, DDGS or a mixture of Manihot esculenta tubers (80\%) and banana fruit (Musa sp.) (20\%), reported higher individual weights for BSF larvae ( $0.27-0.29 \mathrm{~g} \mathrm{FM/larva).} \mathrm{Since} \mathrm{body} \mathrm{weight} \mathrm{of} \mathrm{larvae} \mathrm{fed} \mathrm{on} \mathrm{chicken/hen} \mathrm{feed}$ is higher (average $0.2 \mathrm{~g} \mathrm{FM/larva} \mathrm{or} 0.06 \mathrm{~g} \mathrm{DM} /$ larva) than of larvae fed on organic waste, diet 4 gave results comparable to chicken/hen feed diets. Additionally, considering that in this experiment larvae were harvested later, after weight loss had occurred by passing to the prepupal state and survival rate was higher than reported by Tschirner and Simon (2015), the total yield we recorded was higher than in the studies cited.

Taking into account that diets tested in our experiments resulted in high larval body weight, high larval yield and short development times, we conclude that carbohydrate-biased organic waste positively affects BSF performance. Also on semi-artificial diets, low P:C ratios resulted in higher performance of BSF (Barragan-Fonseca et al., 2018b) and other dipteran species (Prabhu et al., 2008). In a large-scale production of BSF larvae produced for live feed, one of the main parameters to assess productivity of the system is individual body weight. Performance results found in our experiment demonstrate that organic waste consisting of vegetable by-products at the nutrient content and ratio employed support high productivity. However, the quality of nutrients had significant effects on larval performance. For example, larvae fed diet 3 had lower performance (long development, lower weight and yield) than larvae fed on diet 4, even though both diets had the same $\mathrm{P}$ and $\mathrm{C}$ contents. Amino acid profile differences between bean seeds (diet 3) and cabbage leaves (diet 4) might explain these performance differences, as seed protein and leaf protein are different (Edelman \& Colt, 2016). In addition, the content of protease inhibitors in bean seeds might affect BSF larval growth as has been demonstrated for other insect species (Ryan, 1990; Jongsma \& Beekwilder, 2011). Other nutritional or anti-nutritional elements that may influence larval growth efficiency need 
to be studied. Tannins, major anti-nutritional factors in grapes did not seem to affect performance of BSF larvae.

Diet 4, containing cabbage leaves and old bread, supported the best larval performance, possibly due to its different types of carbohydrates and amino acid profiles (Žilić et al., 2011; Edelman \& Colt, 2016). Nutritional values vary depending on the plant species, even if they have a similar proportion of proteins and/or carbohydrates. In terms of protein, a significant difference between seed protein and leaf protein has been demonstrated; leafy plants contain all the essential amino acids in percentages meeting FAO standards, while seed protein often needs to be a mix of several sources in order to meet with all nutritional requirements (Edelman \& Colt, 2016). Regarding carbohydrates, Gamboa Rojas (2008) who tested different carbohydrate resources on BSF larvae (banana, Musa sp.; potato, Solanum tuberosum; cassava, Manihot esculenta, arracacha, Arracacia xanthorrhiza) found significant differences among them. However, a mix of carbohydrates might result in a more efficient production system as larvae fed on a mixture of banana and cassava reached the highest body mass ( $0.24 \mathrm{~g}$ FM/larva). Other nutrients such as vitamins and minerals might play a role in larval performance as their concentration in both seeds and leaves seems to be different (Edelman \& Colt, 2016).

\section{Experiment 2}

Although we used the same ingredients as for diet 4 (cabbage leaves, old bread, DDGS and cellulose) and the same abiotic conditions as in experiment 1 , we observed a lower performance in terms of larval yield and survival rate in the second experiment, whereas development time until prepupa was similar. The lower larval performance observed during experiment 2 , might be a result of external factors. All the replicates of diet 2 in experiment 2 were heavily colonized by fungi, possibly explaining the lower performance than observed on the same diet in experiment 1 .

There are several mutualistic interactions between insects and fungi, however, also antagonistic effects of fungi on dipterans have been reported (Martin, 1992). For instance, Wertheim et al. (2002) and Hodge et al. (1999) described that fungal growth can have deleterious effects on Drosophila melanogaster and D. hydei, affecting larval survival and size of emerging flies. They stated that especially the development and survival rate of the younger larvae was negatively affected by the degree of mycelium coverage. In the case of BSF larvae, Tschirner and Simon (2015) reported high mortality and suppressed development due to fungal species belonging to the genera Mucor spp., Penicillium spp. and Aspergillus spp. that colonised the substrate. In BSF it seems that early larval stages are more susceptible to fungal growth than later stages. It is also possible that in later stages of BSF the interaction with fungi becomes beneficial, because some species feeding on decaying vegetable material might be expected to increase digestibility, as is the case for the dipteran Tipula abdomina- 
lis, whose maximal larval growth rate occurred when the fungal content of the detrital food reached its maximum (Martin, 1992).

Larval body composition of the BSF varies among substrates, mainly in macronutrient contents (Barragan-Fonseca et al., 2017) and to a lesser extent in micronutrient contents (Barragan-Fonseca et al., 2017). For example, larvae reared on energy-rich diets and/or high levels of non-fibre carbohydrate substrates tend to have a high crude fat content, and larvae reared on energy-rich substrates with a low content of ash and fibre, appear to have a low ash content (Spranghers et al., 2016). With respect to how body composition is affected by dietary macronutrients, there is only one study available on BSF (Barragan-Fonseca et al., 2018b). They found that protein, digestible carbohydrates and their interaction do affect larval body composition of BSF in terms of crude protein and fat. However, larval body protein content was not only affected by dietary protein content. Conversely, larval crude fat content increases when dietary carbohydrate is high, and is also high on diets high in dietary protein. It seems that larval protein content is regulated within narrow limits whereas larval crude fat content is strongly affected by dietary nutrient concentration (Spranghers et al., 2016; Barragan-Fonseca et al., 2018a; Barragan-Fonseca et al., 2018b).

In this study, we found that larval crude protein was not different between larvae reared on diets 1 and 2, but crude fat content was significantly higher in larvae reared on diet 2. Thus, higher dietary protein did not affect the larval protein content, but did increase the larval fat content. This trend has been reported previously by Barragan-Fonseca et al. (2018a). Lipid is mainly stored in the fat body which contains lipid, glycogen, and proteins (Hoshizaki, 2005). In BSF larvae, the fat body is mainly composed of trophocytes, which are rich in lipid droplets and protein granules (Pimentel et al., 2017). Sufficient protein provided to BSF larvae seems to promote lipid storage and likely enhances reproduction capacity, as has been recorded in BSF larvae where protein-poor diet affects both lipid and protein accumulation in fat body cells as well as the expression of key genes involved in these metabolic processes (Pimentel et al., 2017).

As observed for the larval stage, no significant differences were observed for the adult performance between diets 1 and 2. On diet 1, females had higher body mass than males, and on both diets, females lived longer than males. Greater BSF weight may contribute to extend adult longevity to some extent, as part of the weight is energy storage (Tomberlin et al., 2002) and higher fat content is associated with greater longevity (Ellers, 1995). However, the amount of energy reserve in the larval stage is not the only factor determining adult longevity. The fact that males live shorter than females, in polygynous insect species, may be due to male reproductive cost reducing longevity (Papadopoulos et al., 2010). 
Since body size is positively correlated with weight, females with higher weight are able to deposit more eggs (Jarosik, 1989), increasing fecundity (Evans, 1982). In BSF, larger females have larger numbers and sizes of ovarioles (Gobbi et al., 2013). We found a positive correlation between female body mass and the number of egg clusters that females laid. Additionally, females with higher body weight tend to have a shorter pre-oviposition period (Zanuncio et al., 2002). This leads to higher energy consumption for oviposition which accelerates aging. In summary, diets 1 and 2 supported similar larval and adult performance. Fungal growth may have affected larval development on diet 2 and in this way may have also affected adult performance. This may have interfered with nutritional effects per se, although we did observe a trend where higher dietary protein resulted in heavier adults and higher egg production.

Further research needs to be done to confirm this trend and to learn how different sources of protein and carbohydrates affect BSF performance, how microorganisms may benefit the larvae, for instance by making indigestible nutrients available to them (Yu et al., 2011), and what types of protein and carbohydrates are favorable to them. This will provide more comprehensive information about nutritionally favorable diets for BSF larvae, which will promote the efficiency of organic waste conversion. Additionally, knowing the physiological mechanisms that BSF employs to deal with different nutrient concentrations and $\mathrm{P}: \mathrm{C}$ ratios, and their impacts on BSF life-history traits, could yield valuable insights into nutritional ecology of BSF in order to improve its mass production.

\section{Acknowledgements}

This work was supported by the Scholarship Program No. 568 from COLCIENCIAS Departamento Administrativo de Ciencia, Tecnología e Innovación - Colombia.

\section{References}

Barragan-Fonseca KB, Dicke M, Van Loon JJA (2017) Nutritional value of the black soldier fly (Hermetia illucens L.) and its suitability as animal feed - a review. Journal of Insects as Food and Feed, 3, 105-120.

Barragan-Fonseca KB, Dicke M, Van Loon JJA (2018a) Influence of larval density and nutrient concentration on performance and body protein and fat composition of Hermetia illucens larvae. Manuscript submitted for publication.

Barragan-Fonseca KB, Gort G, Dicke M, Van Loon JJA (2018b) An exploratory study of the effect of dietary protein and carbohydrate on life history traits and body protein and fat composition of the Black Soldier Fly (Hermetia illucens L.) Manuscript submitted for publication.

Boggs CL, Freeman KD (2005) Larval food limitation in butterflies: effects on adult resource allocation and fitness. Oecologia, 144, 353-361.

Edelman M, Colt M (2016) Nutrient value of leaf vs. seed. Frontiers in Chemistry, 4, 1-5.

Ellers J (1995) Fat and eggs: an alternative method to measure the trade-off between survival and reproduction in insect parasitoids. Netherlands Journal of Zoology, 46, 227-235. 
Evans EW (1982) Consequences of body size for fecundity in the predatory stinkbug, Podisus maculiventris (Hemiptera: Pentatomidae). Annals of the Entomological Society of America, 75, 418-420.

Gamboa Rojas EM (2008) Degradación de residuos de almidón y carnicos, mediante la producción de la larva soldada negra (Hermetia illucens L.). Ingeniería Ambiental y Sanitaria. Universidad de la Salle, Colombia.

Gobbi FP (2012) Biología reproductiva y caracterización morfológica de los estadios larvarios de Hermetia illucens (L., 1758)(Diptera: Stratiomyidae). Bases para su producción masiva en Europa. Instituto Universitario de Investigación. Universidad de Alicante.

Gobbi P, Martínez-Sánchez A, Rojo S (2013) The effects of larval diet on adult life-history traits of the black soldier fly, Hermetia illucens (Diptera: Stratiomyidae). European Journal of Entomology, 110, 461-468.

Hodge S, Mitchell P, Arthur W (1999) Factors affecting the occurrence of facilitative effects in interspecific interactions: an experiment using two species of Drosophila and Aspergillus niger. Oikos, 87, 166-174.

Hoshizaki D (2005) Fat-cell development. Comprehensive Molecular Insect Science, 2, 315-339.

Jarosik V (1989) Mass vs. length relationship for carabid beetles (Col., Carabidae). Pedobiologia, 33, 87-90.

Jongsma M, Beekwilder J (2011) Co-evolution of insect proteases and plant protease inhibitors. Current Protein and Peptide Science, 12, 437-447.

Karasov WH, Del Rio CM (2007) Physiological ecology: how animals process energy, nutrients, and toxins, Princeton University Press Princeton.

Martin MM (1992) The evolution of insect-fungus associations: from contact to stable symbiosis. American Zoologist, 32, 593-605.

May B (1961) The occurrence in New Zealand and the life-history of the soldier fly Hermetia illucens (L.) (Diptera: Stratiomyidae). The New Zealand Journal of Science and Technology, 4, 55-65.

Newton L, Sheppard C, Watson DW, Burtle G (2005) Using the black soldier fly, Hermetia illucens, as a value-added tool for the management of swine manure Smithfield Foods, and Premium Standard Farms, and Frontline Farmers. North Carolina State University, USA.

Nguyen TT, Tomberlin JK, Vanlaerhoven S (2013) Influence of resources on Hermetia illucens (Diptera: Stratiomyidae) larval development. Journal of Medical Entomology, 50, 898-906.

Nguyen TT, Tomberlin JK, Vanlaerhoven S (2015) Ability of black soldier fly (Diptera: Stratiomyidae) larvae to recycle food waste. Environmental Entomology, 44, 406-410.

Oonincx D, Van Broekhoven S, Van Huis A, Van Loon JJA (2015) Feed conversion, survival and development, and composition of four insect species on diets composed of food by-products. PloS ONE, 10, $\mathrm{e} 0144601$.

Papadopoulos NT, Liedo P, Müller H-G, Wang J-L, Molleman F, Carey JR (2010) Cost of reproduction in male medflies: the primacy of sexual courting in extreme longevity reduction. Journal of Insect Physiology, 56, 283-287.

Pimentel AC, Montali A, Bruno D, Tettamanti G (2017) Metabolic adjustment of the larval fat body in Hermetia illucens to dietary conditions. Journal of Asia-Pacific Entomology, 20, 1307-1313.

Prabhu V, Perez-Staples D, Taylor P (2008) Protein: carbohydrate ratios promoting sexual activity and longevity of male Queensland fruit flies. Journal of Applied Entomology, 132, 575-582.

Raubenheimer D, Simpson SJ (2003) Nutrient balancing in grasshoppers: Behavioural and physiological correlates of dietary breadth. Journal of Experimental Biology, 206, 1669-1681.

Ryan CA (1990) Protease inhibitors in plants: genes for improving defenses against insects and pathogens. Annual Review of Phytopathology, 28, 425-449.

Silverman P, Levinson Z (1954) Lipid requirements of the larva of the housefly Musca vicina (Macq.) reared under non-aseptic conditions. Biochemical Journal, 58, 291-294.

Spranghers T, Ottoboni M, Klootwijk C, Ovyn A, Deboosere S, De Meulenaer B, et al. (2016) Nutritional composition of black soldier fly (Hermetia illucens) prepupae reared on different organic waste substrates. Journal of the Science of Food and Agriculture, 97, 2594-2600.

Tomberlin JK, Sheppard DC, Joyce JA (2002) Selected life-history traits of black soldier flies (Diptera: Stratiomyidae) reared on three artificial diets. Annals of the Entomological Society of America 95, 379-386. 
Tschirner M, Simon A (2015) Influence of different growing substrates and processing on the nutrient composition of black soldier fly larvae destined for animal feed. Journal of Insects as Food and Feed, 1, 249-259.

Wertheim B, Marchais J, Vet LE, Dicke M (2002) Allee effect in larval resource exploitation in Drosophila: an interaction among density of adults, larvae, and micro-organisms. Ecological Entomology, 27, 608-617.

Yu G, Cheng P, Chen Y, Li Y, Yang Z, Chen Y, et al. (2011) Inoculating poultry manure with companion bacteria influences growth and development of black soldier fly (Diptera: Stratiomyidae) larvae. Environmental Entomology, 40, 30-35.

Zanuncio JC, Molina-Rugama AJ, Santos GP, Ramalho FDS (2002) Effect of body weight on fecundity and longevity of the stinkbug predator Podisus rostralis. Pesquisa Agropecuária Brasileira, 37, $1225-1230$.

Žilić S, Barać M, Pešić M, Dodig D, Ignjatović-Micić D (2011) Characterization of proteins from grain of different bread and durum wheat genotypes. International Journal of Molecular Sciences, 12, 5878-5894. 



\section{Chapter 6}

Tipping the balance: effects of protein and carbohydrate contents on life-history traits and larval nutrient content of the Black Soldier Fly (Hermetia illucens L.)

Karol B. Barragan-Fonseca, Gerrit Gort, Marcel Dicke \& Joop J. A. van Loon

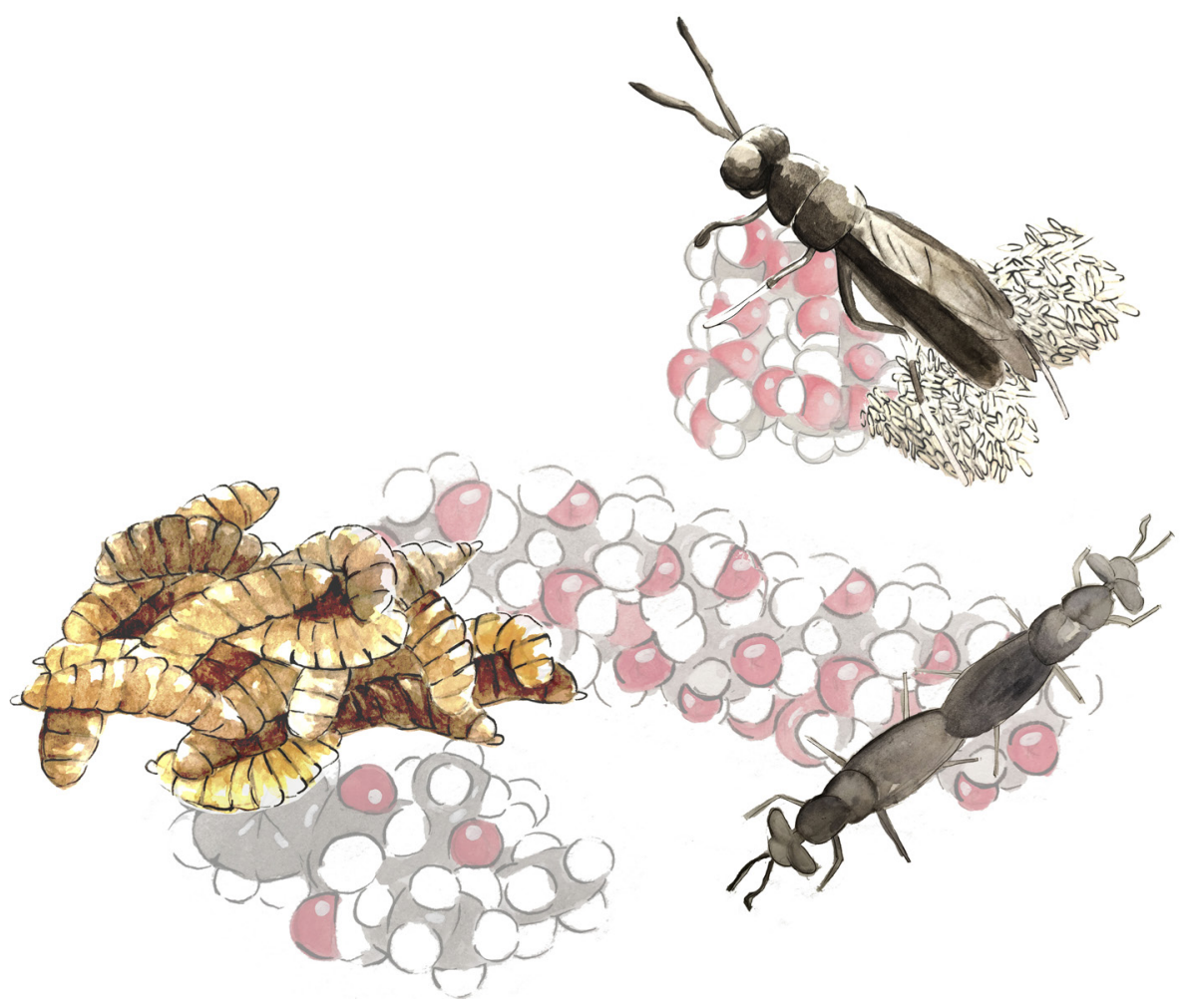




\begin{abstract}
Dietary contents of protein $(\mathrm{P})$ and carbohydrate $(\mathrm{C})$ affect larval performance, larval body nutrient content and fecundity of the Black Soldier Fly (BSF). Studying a wider range of $\mathrm{P}+\mathrm{C}$ contents and $\mathrm{P}: \mathrm{C}$ ratios than reported thus far is warranted in order to identify effects on the performance and life history of BSF. We investigated the influence of P- and C-contents on both larval and adult life-history traits of BSF, and on larval body nutrient content. Twenty five artificial diets varying in their $\mathrm{P}$ - and $\mathrm{C}$-content and ratio were formulated. We tested five macronutrient $(\mathrm{P}+\mathrm{C})$ concentrations $(5,15,25,50$ and $75 \%)$ and five $\mathrm{P}: \mathrm{C}$ ratios $(1: 1,1: 2,1: 4,2: 1$ and 4:1). BSF performance was affected by dietary content of carbohydrate and protein ( $\mathrm{P}+\mathrm{C}$-content) rather than by $\mathrm{P}: \mathrm{C}$ ratios. Since BSF tolerated a wide range of $\mathrm{P}$ - and $\mathrm{C}$-contents, we conclude that $\mathrm{BSF}$ has post-ingestive mechanisms to deal with imbalanced foods. A P-content between 10 and $15 \%$ and a C-content between 10 and 60\% supported high larval and adult performance. P-content is limiting for most of the performance variables and a P-content higher than $37 \%$ was deleterious in terms of survival. C-content affected egg production more strongly than P-content. In general, at $\mathrm{P}+\mathrm{C}$ values of 25 and 50\%, 1:2 and 1:4 ratios resulted in the highest values of most of the larval and adult performance variables we measured. Our results show that P-content and $\mathrm{C}$-content significantly affect adult performance, and high $\mathrm{P}+\mathrm{C}$-diets can increase adult weight and egg production. Follow-up experiments assessing the effects of other nutrient sources, e.g. vegetable organic waste or manure, are required to verify that the results we report here are also valid for sources that contain proteins and carbohydrates of different nutrient quality.
\end{abstract}

Key words: protein, carbohydrate, nutrient dilution, larval performance, fecundity, body nutrient content, fitness. 


\section{Introduction}

One of the aims of nutritional ecology is to describe how animals deal with dietary nutrients in order to maintain a balanced nutritional state maximising fitness (Lihoreau et al., 2015). Nutrition profoundly affects the physiology, behaviour and performance of individuals, which in turn impact their life-history traits. In the case of the Black Soldier Fly (BSF; Hermetia illucens L.), larval food quality affects its fitness and body composition because its reproductive potential critically depends upon resource accumulation during the larval stage. Understanding the effects of larval food quality on BSF performance will allow to increase body mass and/or size of individuals to maximize the continuous production of eggs necessary for the mass-rearing of this species and to improve larval quality for animal feed.

Since insects are able to compensate for a sub-optimal intake of energy and nutrients when feeding on an unbalanced diet through both behavioural and physiological mechanisms (Zudaire et al., 1998), the ratio between intake of protein and carbohydrate (P:C ratio) is likely to provide a fruitful starting point to investigate the regulatory trade-offs in macronutrient intake in insects (Simpson \& Raubenheimer, 1993; Raubenheimer \& Simpson, 1999). This saprophagous species exploits diverse diets, so larval stages are likely to encounter a wide range of dietary macronutrient contents and ratios. When analysing food sources on which this species is found in the wild (vegetable waste, manure, etc.) P:C ratios tend to be carbohydrate-biased and present a wide range of crude protein and digestible carbohydrate contents (40-80\% DM). Thus, by varying P:C ratios and contents we can explore how the life history of BSF is affected by these nutrients.

Varying dietary $\mathrm{P}$ and $\mathrm{C}$ contents can best be achieved by formulating artificial diets. Barragan-Fonseca et al. (2018b) tested a range of semi-artificial diets based on chicken feed to which protein and starch had been added to obtain varying P:C ratios $(1: 2-1: 4)$ and $\mathrm{P}+\mathrm{C}$ contents (45-79\%) within the range of its natural food sources to explore how the life history of BSF was affected by these nutrients. They found that dietary P- and C-contents during the larval phase significantly affected larval and adult performance, protein content having the strongest effect. High dietary nutrient concentrations resulted in high larval and adult biomass and high egg production as in other dipterans (Boggs \& Freeman, 2005). Dietary $\mathrm{P}+\mathrm{C}$ content was more important than $\mathrm{P}: \mathrm{C}$ ratio. A P+C content of $70 \%$ and $\mathrm{P}: \mathrm{C}$ ratios ranging between 1:2 and 1:3 resulted in the highest larval and adult performance on the chicken-feed-based diets evaluated.

Based on the optimum contents and ratio from a previous study, Barragan-Fonseca et al. (2018c) explored the effects of nutrient quality on larval and adult life-history traits of BSF, using different vegetable by-products from the food industry. They found that larvae fed on diets derived from vegetable waste with a summed content of protein and carbohydrates of 
47\%, and a C-biased carbohydrate ratio (1:2) had a better larval performance in terms of larval yield and survival than reported in other studies testing organic waste diets. However, they also found that diets that had the same $\mathrm{P}+\mathrm{C}$ content and ratio, but composed of different vegetable resources resulted in different performance of the larvae. A trend was seen by which high dietary protein levels resulted in higher larval crude fat content, increased adult weight and fecundity. These results confirmed previous findings on regulation of larval protein content within narrow limits whereas larval crude fat content was strongly affected by nutrient concentration (Barragan-Fonseca et al., 2018a). The contents and ratios of dietary protein and carbohydrate tested thus far were within the range of food sources utilised by $\mathrm{BSF}$ in nature and do not allow conclusions on the effects of protein or carbohydrate excess or deficit (Barragan-Fonseca et al., 2018b).

Studies of diets with a broad range of P:C ratios at more extreme nutrient concentration are warranted in order to identify physiological compensation mechanisms used by the BSF on nutritionally unbalanced diets. From the perspective of quality of BSF as animal feed, a broad perspective on dietary macronutrient efficiency is desirable. The results may improve our understanding of the effects of diets on BSF development, growth and body composition, and provide tools for economic decisions. Thus, the objective of this study was to investigate the influence of dietary protein and digestible carbohydrate contents on both larval and adult life-history traits of BSF, and on larval body nutrient contents, using artificial diets varying in protein and carbohydrate contents and ratios.

\section{Materials and Methods}

\section{Experimental insects}

Hermetia illucens L. (Diptera: Stratiomyidae) eggs were obtained from a colony maintained at constant conditions in a climate room $\left(27 \pm 1{ }^{\circ} \mathrm{C}, 70 \% \mathrm{RH}, \mathrm{L} 12: \mathrm{D} 12\right)$ at the Laboratory of Entomology, Wageningen University (The Netherlands).

\section{Experimental design}

Twenty five artificial diets varying in protein $(\mathrm{P})$ and digestible carbohydrate $(\mathrm{C})$ content and ratio were formulated. We tested five macronutrient $(\mathrm{P}+\mathrm{C})$ concentrations $(5,15,25$, 50 and $75 \%)$ and five P:C ratios $(1: 1,1: 2,1: 4,2: 1$ and 4:1). The diets were formulated by including the protein casein (Bio-connect, Huissen, NL) (contains all the amino acids essential for insects in high quantities and well-balanced proportions) (Cohen, 2004), the digestible carbohydrate starch (Duchefa Biochemie BV, Haarlem, NL) (serves both as a nutrient as a texturing agent, and $\alpha$-sugar linkages make it highly susceptible to digestion by insects (Cohen, 2004), and a standard content of Wesson's mineral mix (Sigma-Aldrich, Zwijndrecht, NL) (2.3\%) and Vanderzant's vitamin mix (Sigma-Aldrich, Zwijndrecht, NL) (4.5\%), cholesterol (0.12\%) and linseed oil (0.6\%). The remaining proportion 
was cellulose (Alphacel non-nutritive bulk; Bio-connect, Huissen, NL), considered to be a poorly digestible bulk agent.

The larvae were reared on the twenty five experimental diets. Each replicate had 100 larvae (less than $24 \mathrm{~h}$ after they had hatched from the egg) per $750 \mathrm{ml}$ container. There was a fixed feeding ration of $0.8 \mathrm{~g}$ of food per larva (dry matter basis), which was added once at the beginning of the experiment, as a preliminary experiment had shown that larvae fed once rather than three times per week reached a higher biomass. The total amount of feed was $80 \mathrm{~g}$ per container. The amount of water added at the start of the experiment was 120 $\mathrm{g}$ to the $75 \%$ macronutrient treatments, 140 to $50 \%, 160$ to $25 \%, 180$ to $15 \%$ and 200 to $5 \%$ to account for the greater water absorption by higher amounts of cellulose, to obtain $-70 \%$ of moisture and a similar consistency for all the treatments. The plastic containers were covered with transparent plastic lids with 90 holes (diameter $0.05 \mathrm{~cm}$ each) for ventilation during the first 4 days. After 4 days, the lid was replaced by a lid with a window of $c a .3 \times 7 \mathrm{~cm}$ in the centre and a nylon pantyhose of 20 denier stretched around the container, so that no larvae could escape. The feeding experiments were conducted in a climatic room $\left(4.5 \mathrm{~m}^{2}\right)$ and maintained at constant conditions $\left(27 \pm 1{ }^{\circ} \mathrm{C}, 70 \% \pm 2\right.$ r.h., L12:D12). In order to eliminate positional effects, all containers were randomly relocated three times per week.

\section{Larval Life-History Traits}

Per dietary treatment three replicates were set up. Larvae were harvested when at least $40 \%$ of the larvae were observed to have reached the pre-pupal stage, as apparent from the characteristic black cuticle of prepupae (May, 1961). The development time was considered to be the number of days between the start of the experiment, and the day of harvesting. All animals from each container were harvested with forceps, counted, and weighed collectively. Larvae were washed under running water to remove residues consisting of left-over feed and faeces, their integument dried with paper tissues, and their weight registered as BSFL yield ( $\mathrm{g}$ fresh matter) on a precision balance (Ohaus, Adventurer Pro AV313, Parsippany - USA, precision $\pm 0.001 \mathrm{~g}$ ). To determine survival rate, the number of live BSF at the end of the experiment (day of harvesting) was divided by the initial number of larvae per replicate.

\section{Adult Life History Traits}

Thirty (15 females and 15 males) newly eclosed ( $<12$ h old) adult BSF from each container were released into a BugDorm-1 cage $(30$ x 30 x 30 cm, MegaView Science Co., Ltd.) Taiwan and kept in a climate room under controlled conditions $\left(27 \pm 1^{\circ} \mathrm{C}, 70 \% \pm 2\right.$ r.h., L12:D12). Per dietary treatment three replicates were set up. Adults were provided with water and sugar ad libitum and two days after eclosion, a mixture of sand (25 g), BSFL substrate from the rearing $(25 \mathrm{~g})$ and water $(25 \mathrm{ml})$ in a plastic container $(150 \mathrm{ml})$ was 
offered for oviposition. The surface of each container had one corrugated cardboard measuring $4 \mathrm{~cm}$ (height) $\mathrm{x} 9 \mathrm{~cm}$ (length) as a substrate for egg laying. Every two days from all containers the cardboards were removed, and substituted. In order to determine fecundity, number of egg masses, and percentage of larval hatching were recorded. We also measured surface of viable egg masses $\left(\mathrm{mm}^{2}\right)$ as a proxy of viable egg number; thus we registered the surface of all the egg masses we collected, but only took in account the surface of those eggs masses that hatched and produced F1; this variable was called egg yield $\left(\mathrm{mm}^{2}\right)$. To determine the survival rate until the adult stage, the number of BSF adults eclosed at the end of the experiment was divided by the initial number of larvae per replicate. The development time until the adult stage was considered to be the number of days between the start of the experiment, and the day the first adult was observed. Adult weight $(<24 \mathrm{~h}$ old) was determined on a precision balance (Mettler Toledo, NewClassicML, Switzerland, precision $\pm 0.001 \mathrm{~g}$ ), and sex ratio was determined for each treatment. Longevity was determined by placing adults $(<24 \mathrm{~h}$ old $)$ in plastic containers $(200 \mathrm{ml})$ and counting the number of days between placing them in the container without water and sugar, and the day they died. In order to analyse BSF fitness, we used a proxy for rate of population growth, denoted as $r_{\mathrm{p}}$. Because we did not quantify egg numbers per female the intrinsic rate of population increase $r_{\mathrm{m}}$ could not be determined. The formula we used to calculate $r_{\mathrm{p}}$ was $(\operatorname{lnEY}) / T$, where EY is egg yield $\left(\mathrm{mm}^{2}\right)$ and $\mathrm{T}$ is development time until adult stage (days).

\section{Proximate chemical analysis of larvae}

Samples were stored in a freezer $\left(-25^{\circ} \mathrm{C}\right)$ until all replicates were harvested. Both the larvae and the diets were analysed for dry matter $(\mathrm{DM})$, crude protein, and crude fat at the Animal Nutrition Laboratory of Wageningen University. The samples were oven-dried at $70^{\circ} \mathrm{C}$ until constant weight and homogenized by grinding the samples in an ultra-centrifugal mill (Retsch ZM 200, Haan - Germany). Crude protein (6.25 x N-content) was determined using the Kjeldahl method (ISO 5983-1, 2005) and crude fat was analysed according to the Berntop method (ISO 6492, 1999).

\section{Statistical analysis}

To examine how protein and carbohydrate levels affected the response variables of insect performance and larval body content we specified quadratic response surface models, using the R package rsm (Lenth, 2009), of R version 3.3.3 (R-Core-Team, 2017). First we fitted quadratic response surface models using the total content of protein and carbohydrate $(\mathrm{P}+\mathrm{C})$ and their ratio $(\mathrm{P}: \mathrm{C})$ as regressors. The relative importance of subsets of regressors was visualized in a stacked barplot, showing which part of the total variation was explained by 1) linear and quadratic effects of $\mathrm{P}+\mathrm{C}(2 \mathrm{df}), 2)$ linear and quadratic effects of P:C (2 df), 3) lack of fit (higher order effects of and interactions among $\mathrm{P}+\mathrm{C}$ and P:C; $17 \mathrm{df}$ for larval data, $16 \mathrm{df}$ for larval body content and adult data), 4) residual errors (44 $\mathrm{df}$ for larval data, $31 \mathrm{df}$ for larval body composition data, $33 \mathrm{df}$ for adult data). Next, we 
fitted quadratic response surface models using the actual protein $(\mathrm{P})$ and carbohydrate (C) contents as regressors. Results were summarized with an overall F-test (testing for any effect at all), and with F-tests for linear effects of $\mathrm{P}$ and of $\mathrm{C}$, for quadratic effects of $\mathrm{P}$ and of $\mathrm{C}$ (after linear effects of $\mathrm{P}$ and $\mathrm{C}$ ), for interaction of $\mathrm{P}$ and $\mathrm{C}$ (after linear effects of $\mathrm{P}$ and $\mathrm{C}$ ), and lack of fit for the quadratic response surface model (indicating higher order effects and interactions of $\mathrm{P}$ and $\mathrm{C}$ ). Results were shown in a stacked barplot showing relative importances, showing 1) linear and quadratic effects of $\mathrm{P}(2 \mathrm{df}), 2)$ linear and quadratic effects of C ( $2 \mathrm{df}), 3)$ interaction between $\mathrm{P}$ and $\mathrm{C}(1 \mathrm{df})$, lack of fit (higher order effects and interactions; $16 \mathrm{df}$ for larval data, $15 \mathrm{df}$ for larval body content and adult data), and residual error (44, 31 or $33 \mathrm{df}$, like described earlier). If the overall F-test showed a significant result, we made contour plots showing the fitted response surfaces. For contour plots the $\mathrm{P}-\mathrm{C}$ interaction and quadratic terms were removed from the model if found to be unnecessary $(\mathrm{P}>0.05)$. If lack of fit was significant $(\mathrm{P}<0.05)$, terms of order three were included to arrive at a well-fitting model. Models with $\log (\mathrm{P})$ and $\log (\mathrm{C})$ as regressors were fitted for comparison and selected if shown to be superior (higher $\mathrm{R}^{2}$ ). In the experimental design for larval and adult data, a temporal block was present, which was partially confounded with dietary levels. For all response variables the block effect was initially included in the quadratic response surface models, but removed if found to be unimportant $(P>0.05)$. For all fitted models residual plots were made to check for potential outliers and deviations of assumptions (i.e. approximate normality and constant variance). The relationship between egg mass production and longevity with adult weight was studied using the Pearson correlation coefficient.

\section{Results}

The analysis of the relative importance of dietary contents and ratio of protein and carbohydrate (Fig. 1) demonstrated that BSF performance was affected by content of carbohydrate and protein $(\mathrm{P}+\mathrm{C})$ rather than by $\mathrm{P}: \mathrm{C}$ ratio. Larval crude fat, larval yield, and adult weight were mainly a function of protein and carbohydrate content $(>50 \%$ explained variation). 


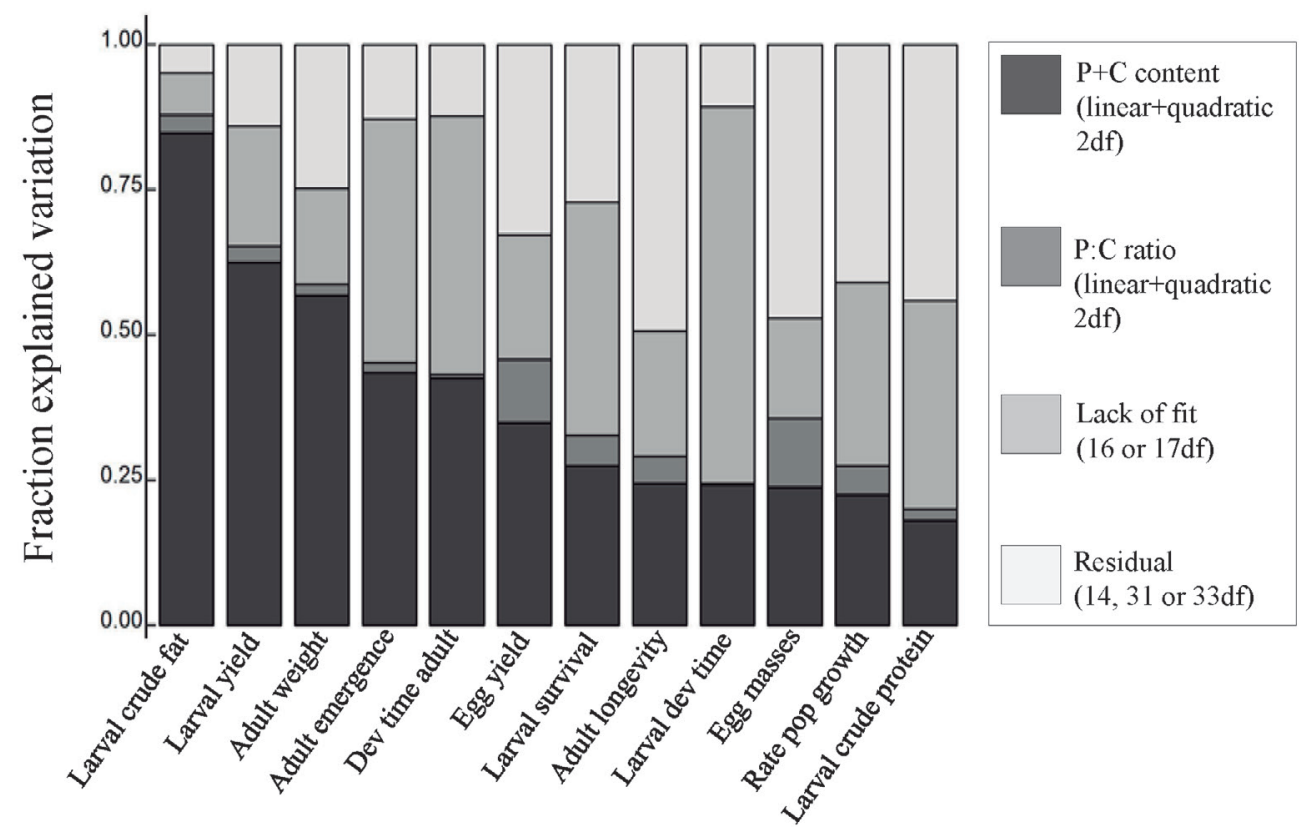

Figure 1. Relative importance of $\mathrm{P}+\mathrm{C}$ content and $\mathrm{P}: \mathrm{C}$ ratio on larval and adult performance variables of the Black Soldier fly.

Our analysis of the relative importance of these macronutrients (Fig. 2) demonstrates that $\mathrm{P}$ and $\mathrm{C}$-content explains most variation in larval development time and larval crude fat, with P-content having a stronger effect (>50\%). Similarly, P-content had a stronger effect than $\mathrm{C}$-content on adult emergence, development time until adult stage, larval survival, and larval crude protein. On the other hand, C-content had a stronger effect than P-content on adult weight, egg yield and egg mass number. P and C-content had similar effects on larval yield, rate of population growth and adult longevity. It should be noted that for larval crude protein and adult longevity the models explain a low percentage of variation. The effects of the interaction $\mathrm{PxC}$ are not strong for most of the variables; only for larval yield a substantial part of variation is explained by the interaction. 


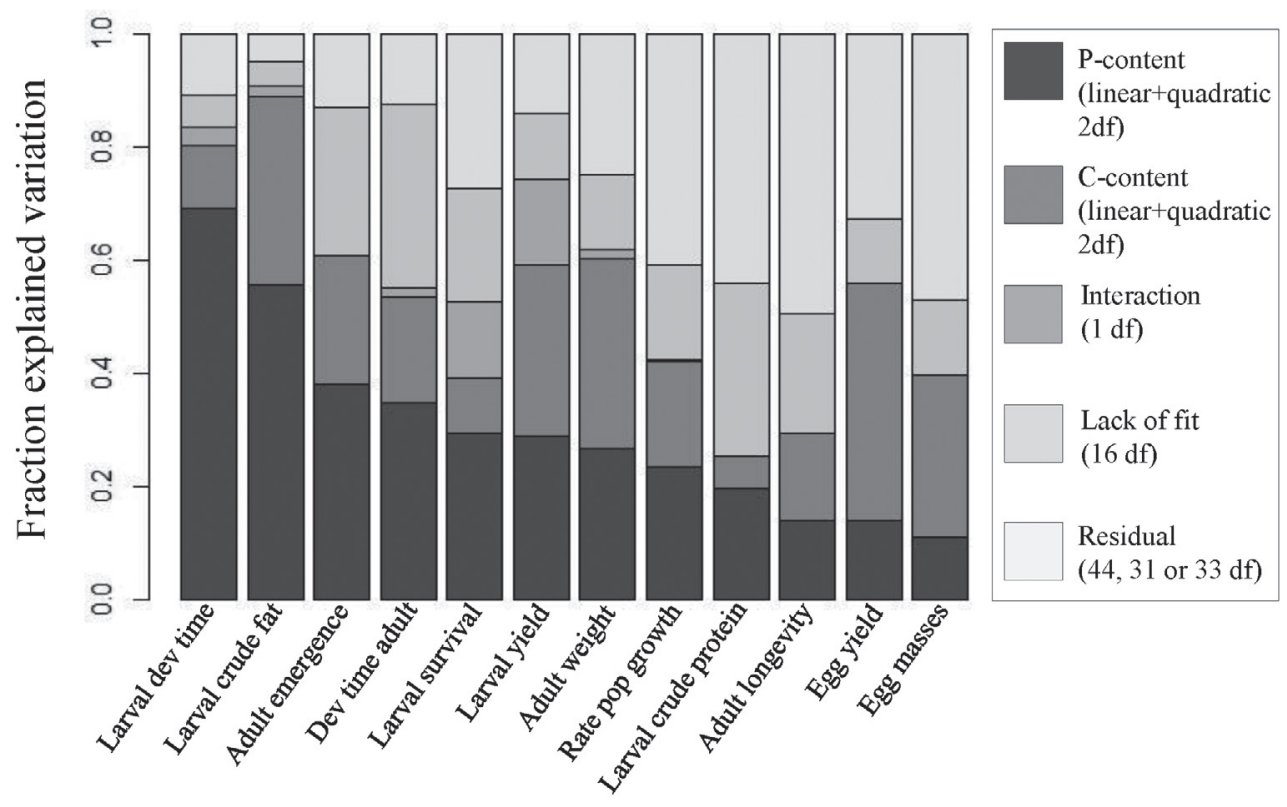

Figure 2. Relative importance of C-content, $\mathrm{P}$-content and their interaction $(\mathrm{PxC})$ on larval, adult and larval body content performance measurements of the Black Soldier fly.

\section{Larval Life-History Traits}

\section{Performance}

Larvae were not able to survive at $\mathrm{P}+\mathrm{C} 75 \%$ and $\mathrm{P}: \mathrm{C}$ ratios 1:1, $2: 1$ and 4:1 $(37.5,50$ and $60 \%$ P-content, respectively). Therefore, those treatments were excluded from performance measurement analysis for both larvae and adults. Survival rate showed a strong linear effect of protein content $(\mathrm{P}<0.001)$ and carbohydrate content $(\mathrm{P}<0.001)$, but also some higher order effects (Table 1) and was higher at $15 \%$ diets at all P:C ratios, decreasing as the nutrient concentration increased (Fig. 3a). Development time showed strongest effects of $\mathrm{P}$ and $\mathrm{P}^{2}$ (both $\mathrm{P}<0.001$ ), smaller effects of $\mathrm{C}$ and $\mathrm{C}^{2}$, and a very strong interaction effect $(\mathrm{P}<0.001)$ (Table 1). Development time was shortest on $15 \%$ diets with high protein content, but it was longest at all 5\% diets, mainly the P:C 1:4 diet with the lowest protein content and at $\mathrm{P}+\mathrm{C}$ of 25 and 50\% with the highest $\mathrm{P}$-content (Fig. 3b). High P:C ratios at high $\mathrm{P}+\mathrm{C}$ content (protein content $>20 \%$ ) resulted in low survival rates. Larval yield showed very strong linear, quadratic and interaction effects of protein and carbohydrates $(\mathrm{P}<0.001)$ (Table 1). Larval yield was highest on the diets with highest carbohydrate content at 50 and $75 \% \mathrm{P}+\mathrm{C}$. However, larval yield was low at all $\mathrm{P}+\mathrm{C} 5 \%$, being even lower at lower P:C ratio (Fig. 3c). 
Table 1. Response surface model significance shown as $\mathrm{P}$ values ( $\mathrm{F}$ values in parentheses) for the full model ( $F$ with 21 and $44 \mathrm{df}$ ), linear effects ( $P$ is protein content and $C$ is carbohydrate content), their interactions and quadratic terms for larval performance measurements ( $\mathrm{F}$ with 1 and $44 \mathrm{df})$.

\begin{tabular}{cccc}
\hline Source & $\begin{array}{c}\text { Survival rate } \\
\mathbf{\%}^{\mathbf{2}}\end{array}$ & $\begin{array}{c}\text { Development time } \\
\mathbf{d}^{1,2}\end{array}$ & $\begin{array}{c}\text { Larval yield } \\
\mathbf{g ~ D M}\end{array}$ \\
\hline Full model & $<\mathbf{0 . 0 0 1}(11.9)$ & $<\mathbf{0 . 0 0 1}(20.8)$ & $<\mathbf{0 . 0 0 1}(12.9)$ \\
$\mathbf{P}$ & $<\mathbf{0 . 0 0 1}(90.3)$ & $<\mathbf{0 . 0 0 1}(61.7)$ & $<\mathbf{0 . 0 0 1}(13.1)$ \\
$\mathbf{C}$ & $\mathbf{0 . 0 0 8}(30.9)$ & $<\mathbf{0 . 0 0 1}(18.0)$ & $<\mathbf{0 . 0 0 1}(23.6)$ \\
$\mathbf{P x C}$ & $\mathbf{0 . 0 0 8}(7.71)$ & $<\mathbf{0 . 0 0 1}(114.1)$ & $<\mathbf{0 . 0 0 1}(69.8)$ \\
$\mathbf{P}^{\mathbf{2}}$ & $0.007(7.86)$ & $<\mathbf{0 . 0 0 1}(206.1)$ & $<\mathbf{0 . 0 0 1}(26.7)$ \\
$\mathbf{C}^{2}$ & $\mathbf{0 . 1 6 7}(1.97)$ & $\mathbf{0 . 0 0 3 4}(9.60)$ & $<\mathbf{0 . 0 0 1}(19.6)$ \\
LOF & $\mathbf{0 . 0 2 4}(2.16)$ & $0.1282(1.55)$ & $\mathbf{0 . 0 1 6}(2.28)$ \\
\hline
\end{tabular}

${ }^{1}$ Lack of fit was handled by logarithmic regressors.

${ }^{2}$ Block effect was included

a) Larval survival rate $(\%)$

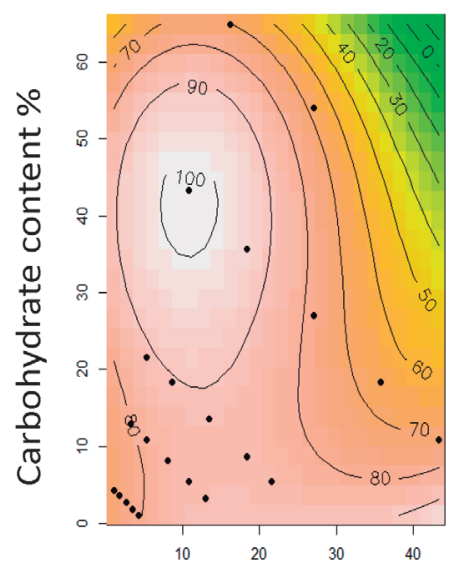

b) Development time (d)

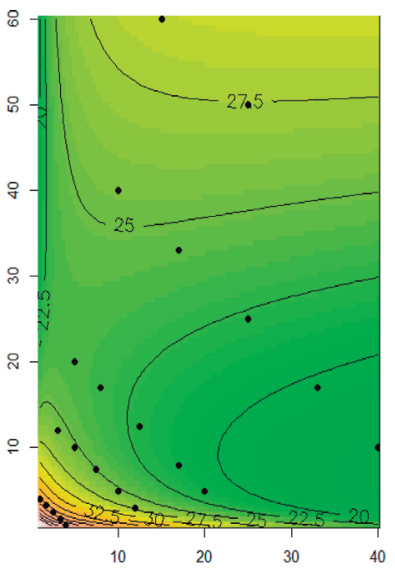

Protein content (\%) c) Larval yield (g DM)

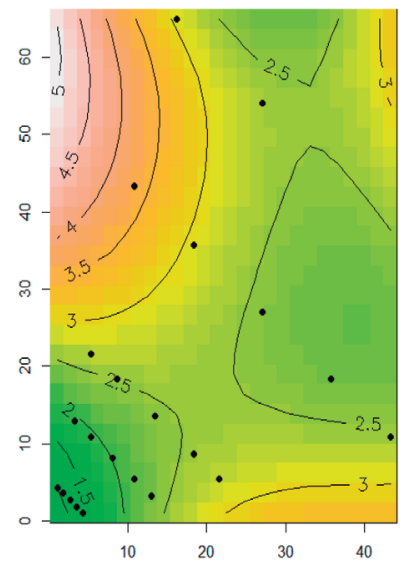

Figure 3. Black Soldier Fly larval performance on diets differing in $\mathrm{P}+\mathrm{C}$ content and $\mathrm{P}: \mathrm{C}$ ratio. a) Survival rate (\%), b) Development time (days), using - Log (carbohydrate \%) and Log (protein $\%)$ as regressors (contour plot on original regressors scale), and c) Larval yield (g DM). A fitness landscape corresponding to insect response to each diet has been fitted over nutrient space; contour lines delimit colour areas going from the lowest (green) to highest (orange) values calculated for each performance variable. Black points indicate the twenty two experimental diets.

\section{Larval body composition}

Larval crude protein is affected in a linear fashion by protein ( $\mathrm{P}=0.002$; Table 2$)$. Higher dietary P levels lead to lower larval crude protein values (Fig. 4a). Larval crude fat is very well explained by the model $\left(\mathrm{R}^{2}=0.95\right)$ and shows the strongest linear effect for protein and less for carbohydrate (both $\mathrm{P}<0.001$; Table 2). The interaction effect and quadratic effect of $\mathrm{P}$ are also significant (Table 2). Larval crude fat is high on diets with high $\mathrm{P}$ content; 
on diets with low P content larval crude fat increases with C-content, but this relationship vanishes at higher values of P (Fig. 4b).

Table 2. Response surface significance shown as P-values (F-values between parentheses) for the full model (F with 20 and $31 \mathrm{df}$ ), linear effects ( $\mathrm{P}$ is protein and $\mathrm{C}$ is carbohydrate content), their interactions and quadratic terms for larval body protein and fat contents ( $\mathrm{F}$ with 1 and $31 \mathrm{df}$ ).

\begin{tabular}{ccc}
\hline Source & $\begin{array}{c}\text { Larval crude protein } \\
\mathbf{\%}^{\mathbf{1}}\end{array}$ & $\begin{array}{c}\text { Larval crude fat } \\
\mathbf{\%}\end{array}$ \\
\hline Full model & $<\mathbf{0 . 0 4 4}(1.97)$ & $<\mathbf{0 . 0 0 1}(30.1)$ \\
$\mathbf{P}$ & $\mathbf{0 . 0 0 2}(10.9)$ & $<\mathbf{0 . 0 0 1}(236.9)$ \\
$\mathbf{C}$ & $0.183(1.85)$ & $<\mathbf{0 . 0 0 1}(87.6)$ \\
$\mathbf{P x C}$ & $0.834(0.04)$ & $<\mathbf{0 . 0 0 1}(16.4)$ \\
$\mathbf{P}^{2}$ & $0.293(1.14)$ & $0.273(1.24)$ \\
$\mathbf{C}^{2}$ & $0.807(0.06)$ & $<\mathbf{0 . 0 0 5}(9.24)$ \\
LOF & $0.192(1.43)$ & $0.083(1.79)$ \\
\hline
\end{tabular}

${ }^{1}$ First order model.

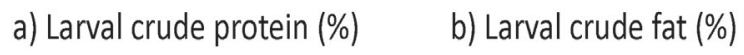

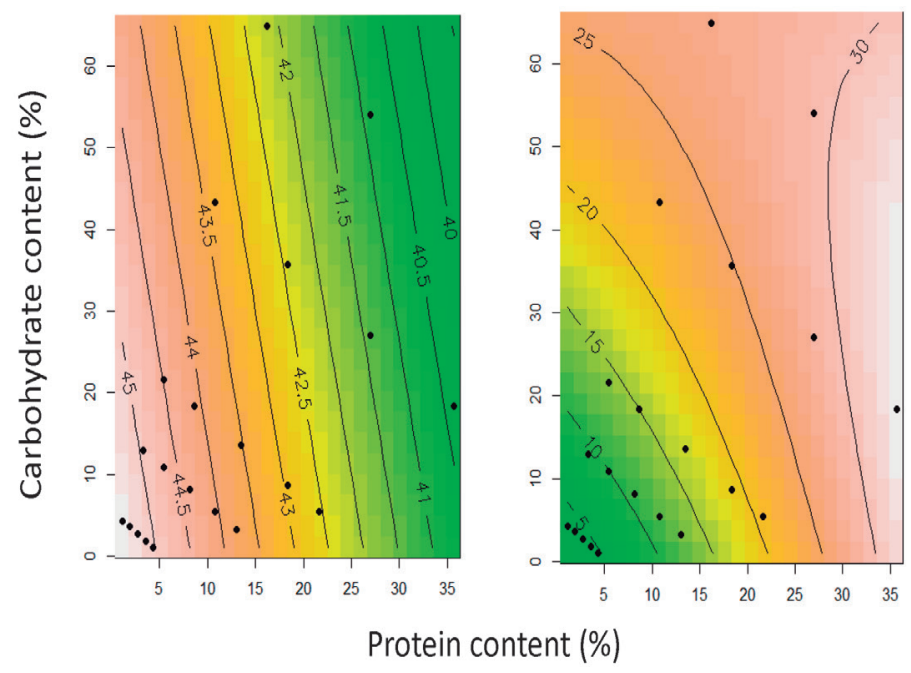

Figure 4. Black Soldier fly larval body composition on different $\mathrm{P}$ and $\mathrm{C}$ contents and $\mathrm{P}: \mathrm{C}$ ratios. a) Larval crude protein (\%), and b) Larval crude fat (\%). A fitness landscape corresponding to insect response to each diet has been fitted over nutrient space; contour lines delimit colour areas going from the lowest (green) to highest (orange) values calculated for each performance variable. Black points indicate the twenty two experimental diets.

\section{Adult Life-History Traits}

\section{Performance}

Larvae were not able to reach the adult stage at $50 \%$ and $4: 1$ ratio ( $40 \%$ protein content). Therefore, this treatment was excluded from the analyses. Adult emergence percentage showed strong quadratic relationships with $\mathrm{P}$ and with $\mathrm{C}$, as well as by their interaction (all $\mathrm{P}<0.001$ ) (Table 3). Lowest adult emergence was observed at $\mathrm{P}+\mathrm{C}$ contents of 5 and 
75\%, and 50\% when the P:C ratio was 2:1. However, high P:C ratios increased adult emergence at $\mathrm{P}+\mathrm{C} 5 \%$ (Fig. 5a). Development time was strongly affected in a linear fashion by protein and carbohydrate, their interaction, and a quadratic effect of carbohydrate was seen (Table 3). Development was slowest on $\mathrm{P}+\mathrm{C} 5 \%$, and shorter at higher protein content. Although development was faster on $\mathrm{P}+\mathrm{C}$ values of 25, 50 and 75\%, higher protein content did not accelerate it (Fig. 5b). Individual adult weight showed a strong linear effect of carbohydrates $(\mathrm{P}<0.001)$, and less so for protein $(\mathrm{P}=0.006)$, smaller interaction and quadratic protein effects were also significant (Table 3). Similar to larval yield, adult weight was highest on the diets with highest C-content at $\mathrm{P}+\mathrm{C} 50$ and 75\%, and low at all $\mathrm{P}+\mathrm{C} 5 \%$ diets, mainly at low P:C ratios (Fig. 5c). Females are heavier than males $(\mathrm{t}(112)=$ 2.05; $\mathrm{P}<0.05$ ). Adult longevity was affected in a linear fashion by carbohydrate (Table 3 ). Adults lived shorter at 5\% $\mathrm{P}+\mathrm{C}$ and longer at $\mathrm{P}+\mathrm{C} 50$ and $75 \%$ at $1: 2$ and 1:4 ratios (Fig. $5 \mathrm{~d})$. Females lived longer than males $(\mathrm{t}(112)=2.16 ; \mathrm{P}<0.05)$. Number of egg masses and egg yield were strongly affected in a linear fashion by carbohydrate, and small quadratic protein effects were also significant (Table 3). The highest number of egg masses was found on $\mathrm{P}+\mathrm{C} 50 \%$ at $1: 2$ and 1:4 ratios. The highest number of egg masses was found for flies reared on diets with a $1: 4$ ratio at most $\mathrm{P}+\mathrm{C}$ contents $(5,25,50$ and $75 \%)$, for $\mathrm{P}+\mathrm{C} 15 \%$ this was at the 1:2 ratio (Fig. 5e). The highest egg yield was found on $\mathrm{P}+\mathrm{C} 50 \%$ at $1: 4$ ratio. The highest egg yield found on $\mathrm{P}+\mathrm{C} 50$ and $75 \%$ was at $1: 4$ ratio, for $\mathrm{P}+\mathrm{C} 15 \%$ at $1: 2$ ratio, for P:C 5\% at 4:1 and for P+C 25\% at 1:1 ratio (Fig. 5f). There was a significant relationship between egg mass surface and adult weight (Pearson test, $\mathrm{r}=0.72, \mathrm{P}<0.05$ ), adult weight and longevity (Pearson correlation test, $\mathrm{r}=0.69$, $\mathrm{P}<0.05$ ). Regarding the proxy of the rate of population growth $\left(r_{\mathrm{p}}\right)$, it was only lightly affected in a linear fashion by carbohydrate, and in a quadratic fashion by protein (Table 3). The highest rates of population growth are found at $\mathrm{P}+\mathrm{C}$ values of 50 and $75 \%$ and $1: 2$ and 1:4 ratios, at $\mathrm{P}+\mathrm{C} 25 \% 1: 1$ and 1:4 ratios and P+C 15\% 1:2 (Fig. 5g).

Table 3. Response surface significance shown as $P$ values ( $F$ values between parentheses) for the full model ( $\mathrm{F}$ with 20 and $33 \mathrm{df}$ ), linear effects ( $\mathrm{P}$ is protein content and $\mathrm{C}$ is carbohydrate content), their interactions and quadratic terms for adult performance measurements ( $F$ with 1 and $33 \mathrm{df}$ ).

\begin{tabular}{|c|c|c|c|c|c|c|c|}
\hline Source & $\begin{array}{c}\text { Adult } \\
\text { emergence } \\
\%^{1}\end{array}$ & $\begin{array}{c}\text { Development } \\
\text { time until } \\
\text { adult stage } \\
\text { days }{ }^{1}\end{array}$ & $\begin{array}{l}\text { Individual } \\
\text { adult weight } \\
\text { mg FM }\end{array}$ & $\begin{array}{c}\text { Adult } \\
\text { longevity } \\
\text { days }\end{array}$ & $\begin{array}{l}\text { Number of } \\
\text { egg masses }\end{array}$ & $\begin{array}{c}\text { Egg yield } \\
\text { mm }^{2}\end{array}$ & $\mathbf{r}_{\mathrm{p}}$ \\
\hline $\begin{array}{c}\text { Full } \\
\text { model }\end{array}$ & $<\mathbf{0 . 0 0 1}(11.2)$ & $<\mathbf{0 . 0 0 1}(11.7)$ & $<\mathbf{0 . 0 0 1}(5.0)$ & $0.087(1.69)$ & $0.056(1.85)$ & $<\mathbf{0 . 0 0 1}(3.39)$ & $\mathbf{0 . 0 1 3}(2.38)$ \\
\hline P & $\mathbf{0 . 0 3 8}(4.65)$ & $<\mathbf{0 . 0 0 1}(46.4)$ & $\mathbf{0 . 0 0 6}(8.71)$ & $0.225(1.53)$ & $0.490(0.48)$ & $0.424(0.65)$ & $0.964(0.002)$ \\
\hline C & $0.425(0.65)$ & $<\mathbf{0 . 0 0 1}(15.3)$ & $<\mathbf{0 . 0 0 1}(25.3)$ & 0.020 & $<\mathbf{0 . 0 0 1}(15.5)$ & $<\mathbf{0 . 0 0 1}(35.4)$ & $\mathbf{0 . 0 0 5}(8.94)$ \\
\hline $\mathrm{PxC}$ & $<\mathbf{0 . 0 0 1}(58.1)$ & $<\mathbf{0 . 0 0 1}(33.1)$ & $\mathbf{0 . 0 0 7}(8.42)$ & $0.235(1.46)$ & $0.078(3.28)$ & $0.082(3.22)$ & $0.059(3.82)$ \\
\hline $\mathbf{P}^{2}$ & $<\mathbf{0 . 0 0 1}(89.9)$ & $<\mathbf{0 . 0 0 1}$ & $\mathbf{0 . 0 0 6}(8.51)$ & $0.066(3.59)$ & $\mathbf{0 . 0 4 4}(4.37)$ & $\mathbf{0 . 0 1 2}(7.01)$ & $<\mathbf{0 . 0 0 1}(14.5)$ \\
\hline $\mathrm{C}^{2}$ & $<\mathbf{0 . 0 0 1}(54.3)$ & $\mathbf{0 . 0 0 4}(9.41)$ & $0.363(0.85)$ & $0.720(1.13)$ & $0.208(1.64)$ & $0.468(0.53)$ & $0.227(1.51)$ \\
\hline LOF & $<\mathbf{0 . 0 0 1}(4.54)$ & $<\mathbf{0 . 0 0 1}(5.80)$ & $0.335(1.18)$ & $0.533(0.94)$ & $0.845(0.61)$ & $0.711(0.76)$ & $0.893(0.89)$ \\
\hline
\end{tabular}

${ }^{1}$ Lack of fit was reduced by logarithmic regressors. 
a) Adult emergence (\%)

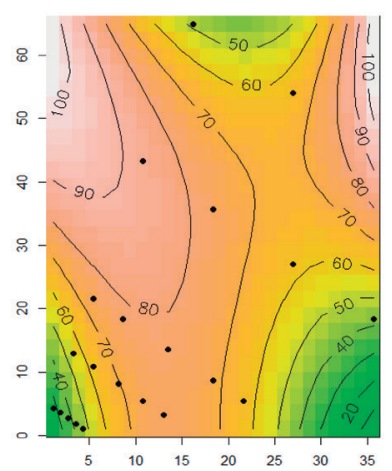

d) Adult longevity (days)

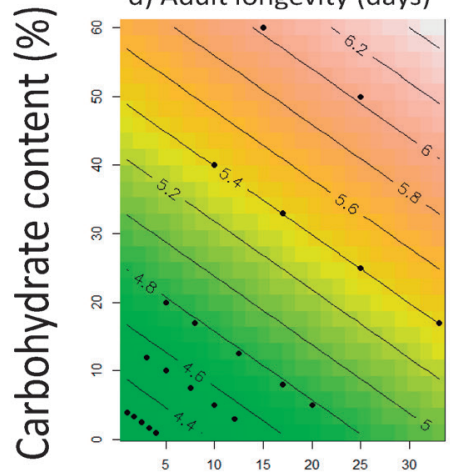

b) Development time until adult stage (days)

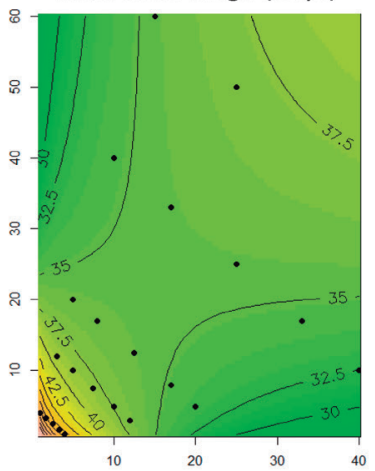

e) Egg mass number

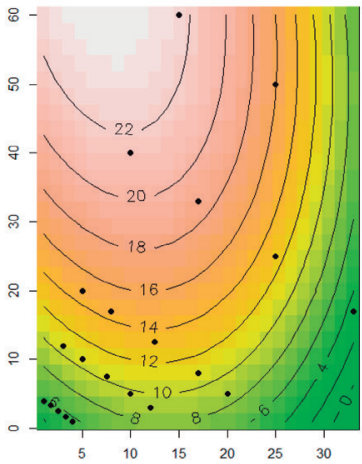

c) Individual adult weight (mg FM)

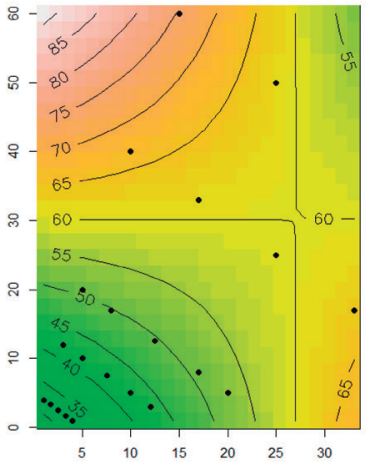

f) Egg yield $\left(\mathrm{mm}^{2}\right)$

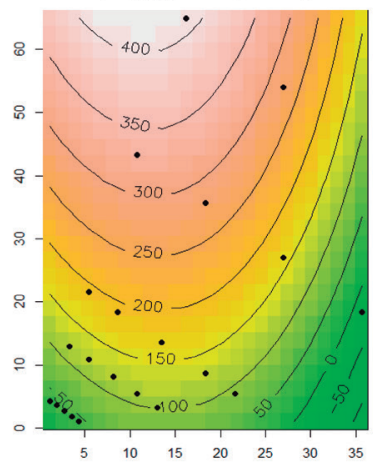

g) Rate of population growth $\left(r_{p}\right)$

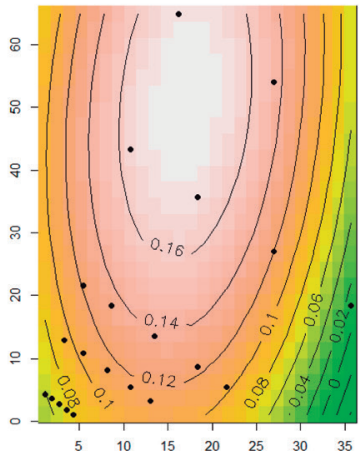

\section{Protein content (\%)}

Figure 5. Black Soldier Fly adult performance on different $\mathrm{P}$ and $\mathrm{C}$ contents and P:C ratios. a) Adult eclosion (\%), b) Development time until adult stage (d), using - Log (carbohydrate \%) and $\log ($ protein \%) as regressors (contour plot on original regressors scale), c) Individual adult weight (mg FM), d) Adult longevity (days), e) Number of egg masses per treatment group, f) Egg yield $\left(\mathrm{mm}^{2}\right)$, and $\mathrm{g}$ ) Proxy of intrinsic rate of population growth. A fitness landscape corresponding to insect response to each diet has been fitted over nutrient space; contour lines delimit colour areas going from the lowest (green) to highest (orange) values calculated for each performance variable. Black points indicate the twenty one experimental diets. 


\section{Discussion}

Our analysis of the relative importance of dietary contents and ratio of protein and carbohydrate demonstrated that BSF performance was affected by content of carbohydrate and protein $(\mathrm{P}+\mathrm{C})$ rather than by $\mathrm{P}: \mathrm{C}$ ratios. This finding was similar to that reported by Barragan-Fonseca et al. (2018b) in BSF fed on semi-artificial chicken feed-based diets, and in herbivorous insect species (Le Gall \& Behmer, 2014). Similarly, Cammack and Tomberlin (2017) examined the impact of artificial diets ( $\mathrm{P}+\mathrm{C}$ content 42\%) with three P:C ratios $(1: 1,1: 5$ and $5: 1)$ on life history traits of BSF, finding similar performance among larvae fed on diets with these three P:C ratios. For larval crude fat, larval yield, and adult weight the model reveals that a high percentage of their variation $(>50 \%)$ is due to $\mathrm{P}+\mathrm{C}$ content. For egg mass, $\mathrm{P}+\mathrm{C}$ content has only a slightly higher importance $(-20 \%)$ than $\mathrm{P}: \mathrm{C}$ ratio $(-15 \%)$. The importance of P-content itself, C-content itself or their interaction (PxC) seems to change depending on their concentration and development stage of the BSF. For example, P-content had a stronger effect than C-content for larval performance, specifically development time, survival rate, and larval body content. Whereas C-content had a stronger effect than protein for adult performance regarding egg production (mass number and yield), longevity, and weight. However, development not only for the larval stage but also for the adult is more affected by P-content than by C-content. In herbivorous insects e.g. Melanoplus differentialis the duration of development is a function of an interaction between P- and C-content (Le Gall \& Behmer, 2014), however, in our study the PxC interaction was quite low for most of the variables and in some cases zero; in the case of survival rate the $\mathrm{PxC}$ interaction was slightly higher than the effect of $\mathrm{C}$-content.

\section{Immature Life-History Traits}

\section{Performance}

Our results show that larvae can deal with a wide range of nutrient concentrations, however, a high P-content is reducing their performance. In this study, larvae were not able to survive on diets with 75\% $\mathrm{P}+\mathrm{C}$ and 1:1, 2:1 and 4:1 ratios, indicating that high dietary $\mathrm{P}$-content $(>37 \%)$ is harmful for them. Excess of dietary protein has been found to negatively affect survival rate of BSF in some studies. For example, BSF larvae reared on diets high in protein (32-50\% crude protein on DM basis) such as Dried Distillers Grains with Solubles (DDGS), meat meal, liver or fish had high mortalities (78, 80, 43 and 53\% respectively) (Tschirner \& Simon, 2015). This may be explained by an excessive energy use for excreting or metabolizing this nutrient excess and/or high uric acid levels. Dipteran species excrete the water-soluble allantoin, the immediate degradation product of uric acid, which is converted to urea, and by the action of urease to ammonium (Green \& Popa, 2012). Thus, BSF larvae fed on high protein diets markedly increase $\mathrm{N}$-mineralization and have an elevated faecal ammonium concentration. Although an excess of protein can be deleterious for BSF larvae, a high P:C ratio (4:1) at low $\mathrm{P}+\mathrm{C}$ contents (5 and 15\%) increased survival rate. 
The fastest development was found at 15\% $\mathrm{P}+\mathrm{C}$ at $\mathrm{P}: \mathrm{C}$ ratios of 2:1 and 4:1 and at 25, 50 and $75 \% \mathrm{P}+\mathrm{C}$ at high $\mathrm{C}$-content (1:4). The shortest development time was found at 5\% $\mathrm{P}+\mathrm{C}$, but a high $\mathrm{P}: \mathrm{C}$ ratio accelerated it. It seems that high $\mathrm{P}$-content accelerates larval development at low $\mathrm{P}+\mathrm{C}$ contents whereas at high $\mathrm{P}+\mathrm{C}, \mathrm{C}$-content accelerates development when P-content suffices to cover larval needs (8-17\%). In other studies on BSF, shorter development times were recorded at high dietary nutrient levels (Barragan-Fonseca et al., 2018a) and high P-content (Nguyen et al., 2013; Oonincx et al., 2015). However, Barragan-Fonseca et al. (2018b) found that BSF larvae fed on low $\mathrm{P}+\mathrm{C}$ diets developed faster than larvae fed on high $\mathrm{P}+\mathrm{C}$ diets with a P-content between 10 and $24 \%$. We suggest that $\mathrm{BSF}$ larvae develop faster on low $\mathrm{P}+\mathrm{C}$ if they can ingest enough protein to develop. In any case, protein is limiting and affects development time and survival rate, both P-content and high P:C ratio being important. BSF larvae fed on diets with high P:C ratios on low $\mathrm{P}+\mathrm{C}$ diets might use protein more efficiently, as is seen for insects with symbionts (Raubenheimer \& Simpson, 2003).

The highest larval weights were achieved by larvae fed on the diets with high $\mathrm{P}+\mathrm{C}(25$, 50 and 75\%). A similar observation was made by Barragan-Fonseca et al. (2018b), who found high larval weights associated with high $\mathrm{P}+\mathrm{C}$ contents, with $\mathrm{C}$-content having a stronger effect than P-content. We also saw a somewhat stronger effect of C-content than of P-content on larval yield. Since the fastest development was observed at $15 \%$ $\mathrm{P}+\mathrm{C}$ that did not result in high larval weights, we can infer that BSF larvae may tradeoff developing faster over growing bigger because fast development resulted in individuals having lower biomass, as long as larvae are provided with enough protein to grow (7 - 12\%). Barragan-Fonseca et al. (2018b) also observed that BSF rather develop faster than grow bigger on chicken feed-based semi-artificial diets. In the case of BSF that fed on diets with varying resource qualities with increasing level of competition, they might gain high fitness by rapid development, to avoid the possible cost of increasing mortality by larval predation and parasitism and to start adult foraging sooner (Kaspi et al., 2002; Lee et al., 2006).

In general, high $\mathrm{P}+\mathrm{C}$ contents tend to improve larval yield, but in terms of survival rate was higher and development time shorter at low $\mathrm{P}+\mathrm{C}$ and high P-content. Our data indicate that protein excess has a deleterious effect. In contrast, when carbohydrates are in excess we hypothesize that BSF larvae are able to use post-ingestive physiological mechanisms when carbohydrates are in excess as they performed well on carbohydrate- biased diets at high $\mathrm{P}+\mathrm{C}$ contents (C-content 40-60\%), and no deleterious effects were seen due to carbohydrate excess. We conclude that BSF larvae can handle excess of carbohydrates, either by respiring carbohydrates or by converting them to lipids and storing them, mainly in the fat body (Zanotto et al., 1993; Zanotto et al., 1997; Simpson \& Raubenheimer, 2001; Telang et al., 2003; Behmer \& Joern, 2012). 


\section{Larval body composition}

Our study shows that larval crude protein content is mainly a function of P-content of the diet. Larval crude protein content (range 38.2-46.5\%DM) was similar to values found in previous studies for larvae fed on chicken feed, by-products of food manufacturing, manure and semi-artificial diets $(43.2 \% \pm 2.7$ DM) (Barragan-Fonseca et al., 2018a; Barragan-Fonseca et al., 2017; Barragan-Fonseca et al., 2018b). Although there were no big differences among treatments, there was a trend for the lowest crude protein being recorded at 50 and $75 \% \mathrm{P}+\mathrm{C}$, and the highest value at 5 and $15 \% \mathrm{P}+\mathrm{C}$. This is in line with findings of Barragan-Fonseca et al. (2018a), Barragan-Fonseca et al. (2018b) and Tschirner and Simon (2015) who reported that body crude protein content was higher in larvae fed on the diet with the lowest crude protein content. The current data confirm that larval P-content is regulated within narrow limits.

Larval crude fat content (range 3.02- $32.7 \% \mathrm{DM}$ ) was affected by $\mathrm{P}+\mathrm{C}$ and mainly by P-content. The highest larval crude fat contents were found at $\mathrm{P}+\mathrm{C} 50 \%$, and at high P-content (33\% protein). Crude fat was also high at 5, 25 and 50\% $\mathrm{P}+\mathrm{C}$. These findings are in line with those of Barragan-Fonseca et al. (2018b), who reported that larval crude fat was higher at the highest P-content irrespective of C-content. Similarly, the fruitfly Ceratitis capitata had higher larval lipid contents when fed on high P:C ratio diets. Excess dietary protein can be used by the insect for energy production and eventually increase larval crude fat content (Waldbauer et al., 1984). The wide range in larval crude fat content can likely be explained by the differences in energy content of the feed, and diets high in energy content would increase larval crude fat (Zheng et al., 2012; Barragan-Fonseca et al., 2018a).

Our results clearly demonstrate that high larval weight is associated with high dietary macronutrient content, with a similar role of $\mathrm{P}$ and $\mathrm{C}$-content. However, at $\mathrm{P}+\mathrm{C}$ values of 25 and 50\%, high P:C ratios (4:1) seem to increase larval yield. Sufficient protein provided to BSF larvae seems to promote lipid storage and likely enhances reproduction capacity, as has been recorded in BSF larvae where a protein-poor diet affected both lipid and protein accumulation (Barragan-Fonseca et al., 2018c), as well as the expression of key genes involved in these metabolic processes (Pimentel et al., 2017). However, although high P-content at $\mathrm{P}+\mathrm{C}$ $50 \%$ increases larval yield, the larvae did not develop into adults. In plant-feeding insect species C-content seems to play a more prominent role than protein. For example, in $M$. differentialis (Le Gall \& Behmer, 2014), and H. virescens (Roeder, 2010), high dietary carbohydrate levels increase insect weight. In addition, P-content can also have an important effect on low C-content diets, as is the case for larval Manduca sexta that, in the absence of dietary carbohydrate, maintains blood trehalose level by gluconeogenesis which is dependent on dietary protein consumption. Thus, when carbohydrates are limiting and protein is in excess, using excess amino acids for gluconeogenesis is an option (Thompson, 2004). 


\section{Adult Life-History Traits}

Nutrition during larval development significantly affects physiological processes later in insect life (Jones \& Raubenheimer, 2001; Hahn, 2005; Prabhu et al., 2008; Roeder $\&$ Behmer, 2014), mainly in holometabolous species, which acquire most of their adult nutrient needs as larvae (Waldbauer et al., 1984, Boggs \& Freeman, 2005) as is the case for BSF. Although adult BSF do not require food to survive, some adult life-history traits can be affected by adult feeding. For instance, BSF adult longevity is increased when provided with a source of water (Tomberlin \& Sheppard, 2002), and sugar (Nakamura $e t$ al., 2016) or honey (Rachmawati et al., 2010). When adults feed as well, the combination of incoming adult nutrients and stored larval nutrients is then used in specific proportions to support the adult functions of reproduction, survival, and dispersal (Boggs \& Freeman, 2005).

Similar to that we observed for BSF larval survival rate, an excess of P-content cannot always be handled by adult BSF. Despite larvae having 60\% survival at $\mathrm{P}+\mathrm{C} 50 \%$ and $\mathrm{P}: \mathrm{C}$ ratio 4:1, and reached relatively high weights, they were not able to reach the adult stage. For adult emergence and development time until adult stage, $\mathrm{P}$-content had a bigger effect than C-content. However, for egg mass number and egg yield C-content seemed to have a more important role than P-content. During the adult stage, feeding mostly affects egg production and carbohydrates have a more important role than protein as is the case for other dipterans such as C. capitata and the Caribbean fruit fly Anastrepha suspensa, which show a low degree of utilization of proteins and lipids as sources of energy (Sharp \& Chambers, 1984; Cangussu \& Zucoloto, 1992).

As for larval development time, high P-content accelerated development at low $\mathrm{P}+\mathrm{C}$, but did not increase adult weight. The lowest adult weights were recorded for individuals fed on 5 and $15 \% \mathrm{P}+\mathrm{C}$-diets, and the highest weights on $75 \% \mathrm{P}+\mathrm{C}$-diets. In addition, the highest values for egg yield and egg mass number were found at the highest $\mathrm{P}+\mathrm{C}$-diets; $\mathrm{P}+\mathrm{C} 50 \%$ at $\mathrm{P}: \mathrm{C}$ ratio 1:4 was the best diet for producing eggs. Therefore, high $\mathrm{P}+\mathrm{C}$-diets promote heavier adults and increase egg production, as was reported by Barragan-Fonseca et al. (2018c), probably because in BSF, larger females have larger numbers and sizes of ovarioles (Gobbi et al., 2013). We also found a positive correlation between adult weight and egg yield. As was mentioned before, this increment of dry mass at high $\mathrm{P}+\mathrm{C}$-diets could be related to lipogenesis, which could be more beneficial for females because lipids are an important egg component (Chapman et al., 2013), and it explains that egg yield and egg mass number were more affected by $\mathrm{C}$-content than by $\mathrm{P}$-content. Female adults are heavier than males, as has been previously reported (Barragan-Fonseca et al., 2018c). This is commonly found for insect species whose reproductive strategy is producing a high number of eggs, thus larger and heavier females contribute to a greater reproductive success (Danks, 2013). 
Besides the fact that heavier females can produce more offspring, longevity can have an important role in increasing fitness of polyandric insects like BSF, as females gain directly from multiple matings in terms of increased lifetime offspring production (Arnqvist $\&$ Nilsson, 2000). Higher longevity can increase the number of egg masses laid by one female, as has been recorded in BSF, whose females can produce more than one egg mass in a short period (Barragan-Fonseca et al., 2018b; Barragan-Fonseca et al., 2018c). In this study there was a significant positive relationship between adult weight and longevity. Thus, greater BSF weight may contribute to extending adult longevity to some extent, as part of the weight is energy storage (Tomberlin et al., 2002), and higher fat content is associated with greater longevity (Ellers, 1995). However, the amount of energy reserve in the larval stage is not the only factor determining adult longevity. The fact that males live shorter than females in polygynous insect species, may be due to male reproductive cost reducing longevity (Papadopoulos et al., 2010). In our study we found that females live longer than males, which was also observed for BSF by Barragan-Fonseca et al. (2018c). In our study, the model did not show a significant effect of P-content on longevity, and the effect of $\mathrm{C}$-content was low. Adults lived longer when provided with a source of carbohydrates (Rachmawati et al., 2010; Nakamura et al., 2016). In the case of the fruit fly Drosophila melanogaster and the Queensland fruit fly, Bactrocera tryoni, longevity was maximized at low P:C ratio and high C-contents (Lee et al., 2008).

Our results show that $\mathrm{P}$-content and $\mathrm{C}$-content significantly affect adult performance, and high $\mathrm{P}+\mathrm{C}$ diets can improve adult weight and egg production, mainly at low $\mathrm{P}: \mathrm{C}$ ratios. In the case of BSF, high $\mathrm{P}+\mathrm{C}$ content resulted in high egg production. For example, the model shows an optimum $\mathrm{P}$ and $\mathrm{C}$-content to increase rate of population growth $(-16 \%$ $\mathrm{P}$-content and $-50 \% \mathrm{C}$-content). Although BSF performance was affected by dietary $\mathrm{P}+\mathrm{C}$ content rather than by $\mathrm{P}: \mathrm{C}$ ratios, in some cases BSF performance can be reduced or enhanced by $\mathrm{P}: \mathrm{C}$ ratio as $\mathrm{P}+\mathrm{C}$ content changes. For example in our study, a high $\mathrm{P}$-content accelerated development time (larval and adult) at low $\mathrm{P}+\mathrm{C}$ contents, probably because this species efficiently uses dietary protein. In the case of adult weight and egg production, high P:C ratio seems to have an important effect, as 1:2 and 1:4 ratios increased adult weight when supplied protein was enough, and 1:4 resulted in higher egg masses number at all $\mathrm{P}+\mathrm{C}$ contents, except $\mathrm{P}+\mathrm{C} 15 \%$ where 1:2 was better. The impact of nutrient dilution was clear on all $\mathrm{P}+\mathrm{C} 5 \%$ contents which showed the lowest larval and adult performance, however the performance was lightly improved at high $\mathrm{P}: \mathrm{C}$ ratios $(2: 1$ and $4: 1)$ at this $\mathrm{P}+\mathrm{C} 5 \%$.

The Black Soldier fly is a generalist species that can tolerate a high degree of nutritional heterogeneity in its diets. Other generalist insects such as cockroaches, locusts and lepidopteran species (e.g. Spodoptera littoralis), which experience a greater degree of nutritional heterogeneity in their diets than do specialists (Roeder, 2010), tend to be more capable of capitalizing on excess available nutrients in imbalanced foods, even if this means deviating 
further in nutrient space from the intake target. This characteristic of generalist species is called the Equal Distance rule (ED rule) (Raubenheimer \& Simpson, 1997). BSF seems to have post-ingestive mechanisms, involving absorption and differential utilization of ingested nutrients to deal with this imbalance, mechanisms used also by other insect species (Raubenheimer \& Simpson, 1997; Zudaire et al., 1998; Raubenheimer \& Simpson, 2003; Behmer, 2009). In the case of BSF we observed that this species can tolerate a high range of $\mathrm{P}$ and $\mathrm{C}$-contents, using high $\mathrm{P}$-content as energy source, and efficiently using protein at low dietary P-content. However, in the case of P-content there is a threshold, where $>37 \%$ seems to be toxic and reduces survival rate and adult emergence percentage.

BSF seems to move its intake target depending on its life stage. Intake targets and nutritional rules are considered patterns integrated over a fixed time period. Thus, intake target and requirements can change depending on developmental phase as the animal grows, reproduces, senesces and responds to its longer term nutritional experience (Raubenheimer \& Simpson, 1997). We observed differences in the effects of $\mathrm{P}$ and C-content among larval and adult performance measurements. For example, 15 and 25\% P+C seemed to benefit larval performance, as at these concentrations survival rate, development time and larval yield was high. In the case of adult performance, adult emergence and development time was also higher at 15 and $25 \% \mathrm{P}+\mathrm{C}$. On the other hand, adult weight, adult longevity and egg production were higher at high values of $\mathrm{P}+\mathrm{C}$ (50 and 75\%).

We document here that BSF can handle diets with a wide range of $\mathrm{P}$ and C-contents and $\mathrm{P}: \mathrm{C}$ ratios, pointing at a remarkable degree of nutritional plasticity. Our response surface analysis did not reveal optimum $\mathrm{P}+\mathrm{C}$ contents and $\mathrm{P}: \mathrm{C}$ ratios for all the performance variables. In general, a C-biased content of 25 and $50 \% \mathrm{P}+\mathrm{C}$ enhanced most of the larval and adult performance variables we measured. Our findings are useful in guiding the formulation of diets in mass-rearing of BSF as minilivestock aimed at obtaining high yields of larval biomass of desired body composition. Follow-up experiments on e.g. vegetable organic waste and manure that contain different proteins and carbohydrates are required to verify that the results reported here can be extrapolated to such diets.

\section{Acknowledgements}

This work was supported by the Scholarship Program No. 568 from COLCIENCIAS Departamento Administrativo de Ciencia, Tecnología e Innovación - Colombia.

\section{References}

Arnqvist G, Nilsson T (2000) The evolution of polyandry: multiple mating and female fitness in insects. Animal Behaviour, 60, 145-164. 
Barragan-Fonseca KB, Dicke M, Van Loon JJA (2017) Nutritional value of the black soldier fly (Hermetia illucens L.) and its suitability as animal feed - a review. Journal of Insects as Food and Feed, 3, 105-120.

Barragan-Fonseca KB, Dicke M, Van Loon JJA (2018a) Influence of larval density and nutrient concentration on performance and body protein and fat composition of Hermetia illucens larvae. Manuscript submitted for publication.

Barragan-Fonseca KB, Gort G, Dicke M, Van Loon JJA (2018b) An exploratory study of the effect of dietary protein and carbohydrate on life history traits and body protein and fat composition of the Black Soldier Fly (Hermetia illucens L.) Manuscript submitted for publication.

Barragan-Fonseca KB, Pineda-Mejia J, Dicke M, Van Loon JJA (2018c) Performance of the Black Soldier Fly, Hermetia illucens (Diptera: Stratiomyidae) on vegetable residue-based diets formulated based on protein and carbohydrate contents. Manuscript submitted for publication.

Behmer ST (2009) Insect herbivore nutrient regulation. Annual Review of Entomology, 54, 165-187.

Behmer ST, Joern A (2012) Insect herbivore outbreaks viewed through a physiological framework: insights from Orthoptera, Blackwell Publishing Ltd, Oxford, UK.

Boggs CL, Freeman KD (2005) Larval food limitation in butterflies: effects on adult resource allocation and fitness. Oecologia, 144, 353-361.

Cammack JA, Tomberlin JK (2017) The impact of diet protein and carbohydrate on select life-history traits of the black soldier fly Hermetia illucens (L.)(Diptera: Stratiomyidae). Insects, 8, 1-14.

Cangussu JA, Zucoloto FS (1992) Nutritional value and selection of different diets by adult Ceratitis capitata flies (Diptera, Tephritidae). Journal of Insect Physiology, 38, 485-491.

Chapman RF, Simpson SJ, Douglas AE (eds.) (2013) The insects: structure and function, Cambridge University Press.

Danks HV (2013) Insect life-cycle polymorphism: theory, evolution and ecological consequences for seasonality and diapause control, Springer Science \& Business Media.

Ellers J (1995) Fat and eggs: an alternative method to measure the trade-off between survival and reproduction in insect parasitoids. Netherlands Journal of Zoology, 46, 227-235.

Gobbi P, Martínez-Sánchez A, Rojo S (2013) The effects of larval diet on adult life-history traits of the black soldier fly, Hermetia illucens (Diptera: Stratiomyidae). European Journal of Entomology, 110, 461-468.

Green TR, Popa R (2012) Enhanced ammonia content in compost leachate processed by black soldier fly larvae. Applied Biochemistry and Biotechnology, 166, 1381-1387.

Hahn DA (2005) Larval nutrition affects lipid storage and growth, but not protein or carbohydrate storage in newly eclosed adults of the grasshopper Schistocerca americana. Journal of Insect Physiology, 51, 1210-1219.

Jones S, Raubenheimer D (2001) Nutritional regulation in nymphs of the German cockroach, Blattella germanica. Journal of Insect Physiology, 47, 1169-1180.

Kaspi R, Mossinson S, Drezner T, Kamensky B, Yuval B (2002) Effects of larval diet on development rates and reproductive maturation of male and female Mediterranean fruit flies. Physiological Entomology, 27, 29-38.

Le Gall M, Behmer ST (2014) Effects of protein and carbohydrate on an insect herbivore: the vista from a fitness landscape. Integrative and Comparative Biology, 54, 942-954.

Lee KP, Behmer ST, Simpson SJ (2006) Nutrient regulation in relation to diet breadth: a comparison of Heliothis sister species and a hybrid. Journal of Experimental Biology, 209, 2076-2084.

Lee KP, Simpson SJ, Clissold FJ, Brooks R, Ballard JWO, Taylor PW, et al. (2008) Lifespan and reproduction in Drosophila: New insights from nutritional geometry. Proceedings of the National Academy of Sciences of the United States of America, 105, 2498-2503.

Lenth RV (2009) Response-Surface Methods in R, using rsm. Journal of Statistical Software, 32, 1-17.

Lihoreau M, Buhl J, Charleston MA, Sword GA, Raubenheimer D, Simpson SJ (2015) Nutritional ecology beyond the individual: a conceptual framework for integrating nutrition and social interactions. Ecology Letters, 18, 273-286.

May B (1961) The occurrence in New Zealand and the life-history of the soldier fly Hermetia illucens (L.) (Diptera: Stratiomyidae). The New Zealand Journal of Science and Technology, 4, 55-65. 
Nakamura S, Ichiki RT, Shimoda M, Morioka S (2016) Small-scale rearing of the black soldier fly, Hermetia illucens (Diptera: Stratiomyidae), in the laboratory: low-cost and year-round rearing. Applied Entomology and Zoology, 51, 161-166.

Nguyen TT, Tomberlin JK, Vanlaerhoven S (2013) Influence of resources on Hermetia illucens (Diptera: Stratiomyidae) larval development. Journal of Medical Entomology, 50, 898-906.

Oonincx DG, Van Broekhoven S, Van Huis A, Van Loon JJA (2015) Feed conversion, survival and development, and composition of four insect species on diets composed of food by-products. PLoS ONE, 10, $\mathrm{e} 0144601$.

Papadopoulos NT, Liedo P, Müller H-G, Wang J-L, Molleman F, Carey JR (2010) Cost of reproduction in male medflies: the primacy of sexual courting in extreme longevity reduction. Journal of Insect Physiology, 56, 283-287.

Pimentel AC, Montali A, Bruno D, Tettamanti G (2017) Metabolic adjustment of the larval fat body in Hermetia illucens to dietary conditions. Journal of Asia-Pacific Entomology, 20, 1307-1313.

Prabhu V, Perez-Staples D, Taylor P (2008) Protein: carbohydrate ratios promoting sexual activity and longevity of male Queensland fruit flies. Journal of Applied Entomology, 132, 575-582.

R-Core-Team (2017) R: A language and environment for statistical computing. R Foundation for Statistical Computing, Vienna, Austria.

Rachmawati R, Buchori D, Hidayat P, Hem S, Fahmi MR (2010) Perkembangan dan kandungan nutrisi larva Hermetia illucens (Linnaeus)(Diptera: Stratiomyidae) pada bungkil Kelapa Sawit. Jurnal Entomologi Indonesia, 7, 28-41.

Raubenheimer D, Simpson SJ (1997) Integrative models of nutrient balancing: application to insects and vertebrates. Nutrition Research Reviews, 10, 151-179.

Raubenheimer D, Simpson SJ (1999) Integrating nutrition: A geometrical approach. Entomologia Experimentalis et Applicata, 91, 67-82.

Raubenheimer D, Simpson SJ (2003) Nutrient balancing in grasshoppers: Behavioural and physiological correlates of dietary breadth. The journal of Experimental Biology, 206, 1669-1681.

Roeder KA (2010) Dietary effect on the performance and body composition of the generalist insect herbivore, Heliothis virescens (Lepidoptera: Noctuidae). Department of Entomology. Texas A\&M University, College Station, TX.

Roeder KA, Behmer ST (2014) Lifetime consequences of food protein-carbohydrate content for an insect herbivore. Functional Ecology, 28, 1135-1143.

Sharp JL, Chambers DL (1984) Consumption of carbohydrates, proteins, and amino acids by Anastrepha suspensa (Loew)(Diptera: Tephritidae) in the laboratory. Environmental Entomology, 13, 768-773.

Simpson S, Raubenheimer D (1993) A multi-level analysis of feeding behaviour: the geometry of nutritional decisions. Philosophical Transactions of The Royal Society of London: Biological Sciences, 342, 381-402.

Simpson SJ, Raubenheimer D (2001) The geometric analysis of nutrient - Allelochemical interactions: A case study using locusts. Ecology, 82, 422-439.

Telang A, Buck NA, Chapman RF, Wheeler DE (2003) Sexual differences in postingestive processing of dietary protein and carbohydrate in caterpillars of two species. Physiological and Biochemical Zoology, 76, 247-255.

Thompson S (2004) Dietary fat mediates hyperglycemia and the glucogenic response to increased protein consumption in an insect, Manduca sexta L. Biochimica et Biophysica Acta (BBA)-General Subjects, 1673, 208-216.

Tomberlin JK, Sheppard DC, Joyce JA (2002) Selected life-history traits of black soldier flies (Diptera: Stratiomyidae) reared on three artificial diets. Annals of the Entomological Society of America 95, 379-386.

Tomberlin JK, Sheppard DG (2002) Factors influencing mating and oviposition of black soldier flies (Diptera: Stratomyidae) in a colony. Journal of Entomological Society, 37, 345-352.

Tschirner M, Simon A (2015) Influence of different growing substrates and processing on the nutrient composition of black soldier fly larvae destined for animal feed. Journal of Insects as Food and Feed, 1, 249-259. 
Chapter 6

Waldbauer GP, Cohen RW, Friedman S (1984) Self-selection of an optimal nutrient mix from defined diets by larvae of the corn-earworm, Heliothis zea (Boddie). Physiological Zoology, 57, 590-597.

Zanotto F, Simpson S, Raubenheimer D (1993) The regulation of growth by locusts through post-ingestive compensation for variation in the levels of dietary protein and carbohydrate. Physiological Entomology, 18, 425-434.

Zanotto FP, Gouveia SM, Simpson SJ, Raubenheimer D, Calder PC (1997) Nutritional homeostasis in locusts: Is there a mechanism for increased energy expenditure during carbohydrate overfeeding? The Journal of Experimental Biology, 200, 2437-2448.

Zheng L, Qing L, Jibin Z, Ziniu Y (2012) Double the biodiesel yield: Rearing black soldier fly larvae, Hermetia illucens, on solid residual fraction of restaurant waste after grease extraction for biodiesel production. Renewable Energy, 41, 75-79.

Zudaire E, Simpson SJ, Montuenga LM (1998) Effects of food nutrient content, insect age and stage in the feeding cycle on the FMRFamide immunoreactivity of diffuse endocrine cells in the locust gut. Journal of Experimental Biology, 201, 2971-2979. 


\section{Chapter 7}

\section{General Discussion: unravelling BSF nutrition - the way forward}

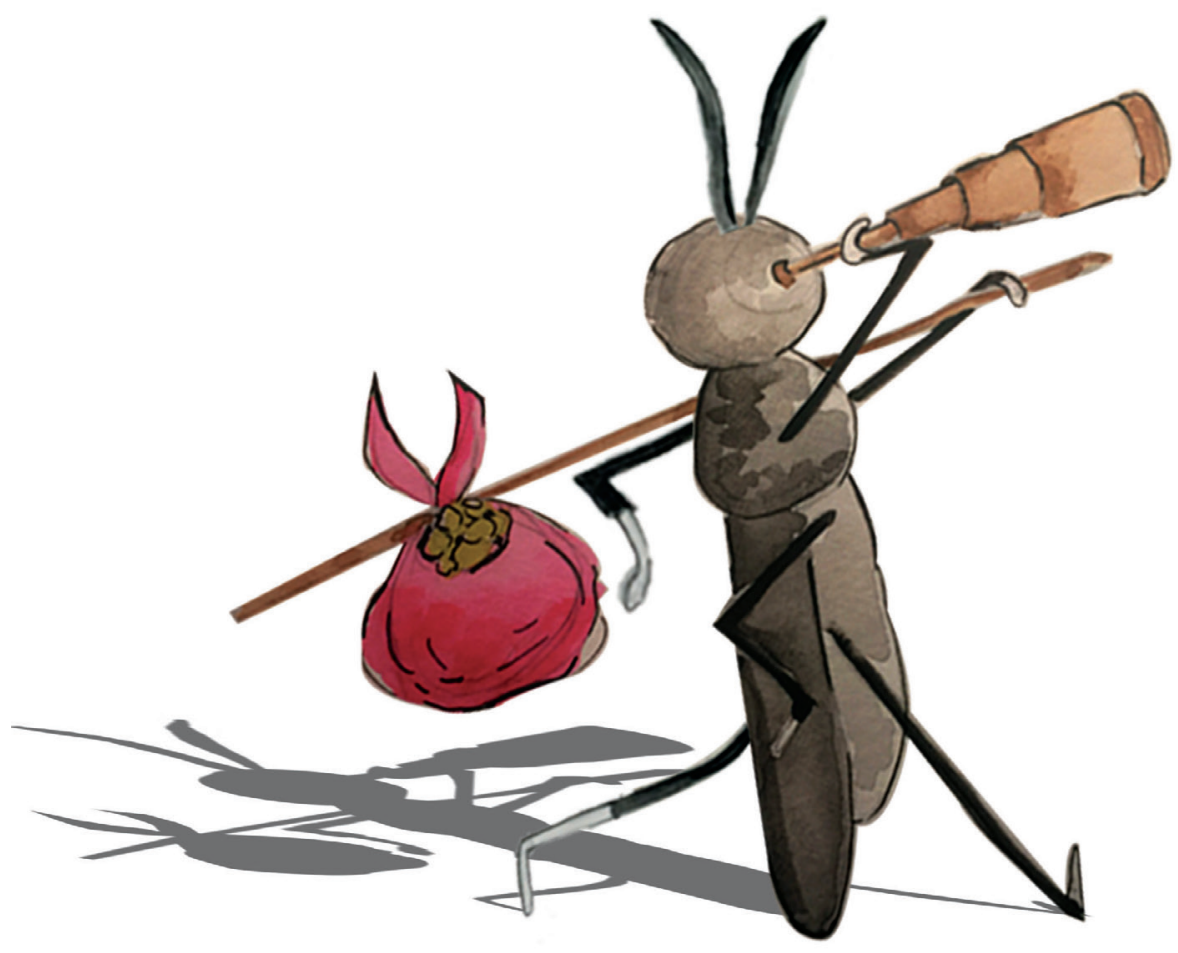




\section{Introduction}

Producing sufficient food of good quality for the growing human population requires a new approach, based on sustainability, protection of the environment, rational use of biodiversity that increases income for developing countries and new opportunities for the developed world (Godfray et al., 2010; Surendra et al., 2016). Current livestock production requires $70 \%$ of all agricultural area. Therefore, the development of sustainable production of other animal species than traditional livestock is of paramount importance. Because insects have both higher feed conversion efficiencies and growth rates (van Huis, 2013), have a high nutritional quality, are potentially profitable feedstuff for production animals (Bosch et al., 2014), and because some species can be reared on organic waste, they are good candidates to be used as so-called minilivestock.

Black Soldier Fly - BSF, Hermetia illucens L. (Diptera: Stratiomyidae) has been proposed as one of the most suitable insect species to be produced at large scale. Many advantages of using BSF have been studied: reducing organic waste (Nguyen et al., 2013), providing potential chemical precursors to produce biodiesel (Li et al., 2011a; Li et al., 2011b), and providing high quality animal-protein-rich feedstuff for a variety of animals, including swine, chickens, and fish (Veldkamp et al., 2012).

The challenges facing large-scale BSF production are the development of innovative and efficient methods that are suited to the social, environmental and economic needs of regional and local communities. In general, the application of insects for food and feed purposes is environmentally more beneficial than traditional sources of proteins. In this respect, the insect's diet is most critical for environmental sustainability of the final product and its usability for the feed or food purposes (Smetana et al., 2016). For instance, Life Cycle Impact Assessment (LCIA) shows that rearing of BSF has significant environmental benefits, mainly related to Land Use (LU) and its value as a source of animal proteins and fat (Salomone et al., 2017).

Taking into account that BSF as minilivestock is an environmentally sustainable production system, mainly because of its ability to feed on organic waste and to produce larvae of high nutritional quality (Salomone et al., 2017), the main objective of producing BSF as minilivestock is to maximize biological performance of this species in a sustainable large-scale system to enhance economic sustainability. The use of BSF as minilivestock is a challenge because despite ample research on various topics related to the effects of biotic (Tomberlin et al., 2002; Diener et al., 2009; Parra Paz et al., 2015) and abiotic (Furman et al., 1959; Alvarez, 2012) factors on BSF larval biology, limited information is available on how these factors affect performance of the adult stages of BSF, such as mating success, fecundity, egg size and fertility. The latter is particularly important because reproductive 
potential critically depends upon resource accumulation during the larval stage in BSF. Therefore, it is essential to study all fitness-related life-history traits to fully understand the effects of larval food quality on larval body content, and larval and adult biology.

Knowing how BSF deals with variable nutrient availability, and the impact on BSF life-history traits and larval body composition, is important for the development of mass production. The aim of this project was to focus on nutritional physiology of the BSF, and to address relevant knowledge gaps. My research explored how larval density, nutrient concentration of rearing substrates, dietary protein $(\mathrm{P})$ and carbohydrate $(\mathrm{C})$ contents affect life-history traits, biomass yield and body nutrient content of BSF larvae. Here, I discuss the significance of the findings on the nutrition of BSF for a sustainable minilivestock system, placing the findings of this thesis in a wider perspective. Figure 1 presents a graphical overview of the factors that affect BSF performance, highlighting the topics and factors covered in my thesis.

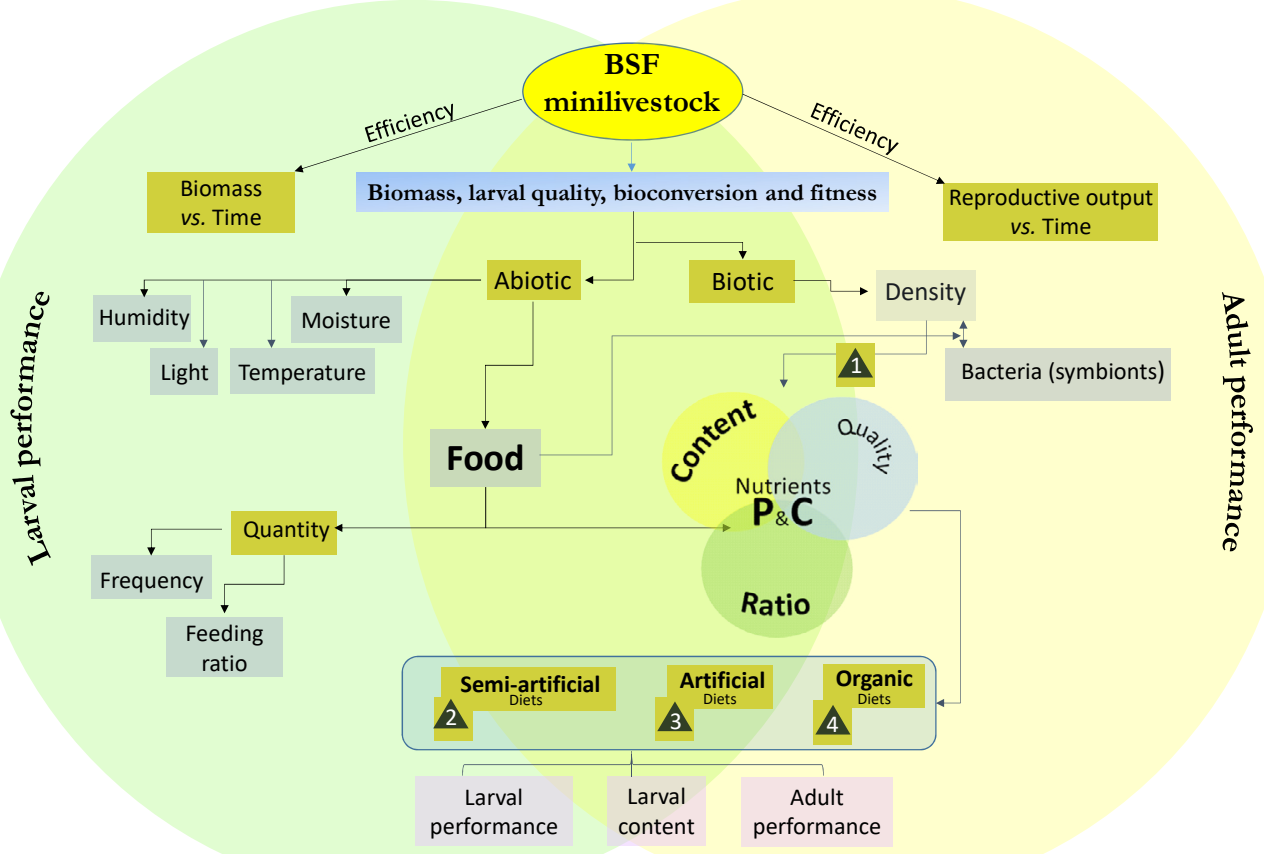

$=$ Experiments addressed in this thesis

$\mathbf{P}_{\&} \mathbf{C}=$ Protein and Carbohydrates

Figure 1. Overview of topics and factors relevant for Black Soldier Fly performance focusing on nutrition, as addressed in the thesis 


\section{Larval food as a major determinant of BSF performance and nutrient content}

Life-history parameters of BSF are influenced by a variety of abiotic and biotic factors such as temperature (Furman et al., 1959; May, 1961; Alvarez, 2012; Holmes et al., 2016), relative humidity (Holmes et al., 2012), food availability (Diener et al., 2009), and food composition (Gobbi et al., 2013), larval density (Tomberlin et al., 2002; Diener et al., 2009; Parra Paz et al., 2015), among others. The wide geographic distribution of BSF (Martínez-Sánchez et al., 2011; Gujarathi \& Pejaver, 2013) demonstrates its tolerance to a wide range of abiotic conditions. However, it is clear that there are optimal values for these conditions to increase BSF performance (Chapter 2).

Density is an important biotic factor for dipterans, because larval aggregation is characteristic for the biology of many dipteran species (Baldal et al., 2005; Rivers \& Dahlem, 2013; Jannat \& Roitberg, 2013). Larval aggregation has consequences such as heat accumulation and coprophagy and results in more exhaustive nutrient utilization and competition. In the case of BSF, larval density is a major factor affecting the rate of development (Tomberlin et al., 2002; Diener et al., 2009), bioconversion and larval yield (Parra Paz et al., 2015). Therefore, quality and quantity of food may interact with larval density, and together affect BSF production systems.

Thus, in Chapter 3, I addressed the effects of dietary nutrient concentration, larval rearing density, and the possible interaction between these two factors on growth characteristics and nutritional content of BSF larvae in terms of crude protein and fat. The results demonstrate that larval density and nutrient concentration affect BSF performance and body composition, nutrient concentration having a stronger effect. Low larval densities resulted in shorter development time. However, high larval densities increased larval yield probably because high larval densities are associated with higher bacterial densities which might allow larvae to have better access to nutrients resulting from bacterial metabolism, thereby resulting in more effective nutrient absorption (Liu et al., 2008).

On the other hand, I found that larval crude protein and fat are affected by nutrient concentration, larval density and their interaction. Crude protein was overall high and was regulated within narrow limits. It is interesting that high larval crude protein was found in larvae fed on diets containing lower nutrient levels. This is in line with the findings of Tschirner and Simon (2015) and Spranghers et al. (2016), and was also found in other experiments reported in this thesis (Chapters 4, 5 and 6).

\section{Food quantity}

With increasing amount of food available per BSF larva the duration of larval development is shorter and final larval weight increases (St-Hilaire et al., 2007; Liu et al., 2008; Diener et al., 2009; Banks et al., 2014), however, this negatively affects waste reduction 
efficiency (Diener et al., 2009). When the amount of diet added during the experiment was based on the visually estimated larval mass present, food limitation occurred (Chapter 3). Despite the strong feed limitation, survival was high, confirming that BSF larvae are resilient to unfavourable conditions.

Adaptive responses are activated in response to crowding and nutritional deficiencies. This study shows that BSF larvae are capable of physiological adjustments which allow them to survive in nearly equal proportions at low and high larval densities. The experiments reported in Chapter 3 on larval density and nutrient dilution, show that BSF larvae survived at high densities but had reduced body weight, as has been reported for others dipterans (Green et al., 2002; Yoshioka et al., 2012). Under extreme food limitation, BSF larvae had extended development time or could not complete larval development at all. Larvae that did not reach the prepupal stage had the lowest crude fat contents and the lowest larval weights, which points to starvation of the larvae; thus they had to mobilise their fat reserves (Tschirner \& Simon, 2015), did not grow and could not complete development.

BSF larvae fed on good quality diets might need lower feeding rations to achieve a good performance than larvae fed on low quality diets (Chapter 2). For chicken feed, we assumed an optimum feeding ration to lie between $0.8-1.2 \mathrm{~g}$ DM of food per larva. Our experimental data show that a feeding ration of between $0.6-1 \mathrm{~g}$ DM of food per larva was enough to obtain high larval weights; adding more did not increase larval weight (Chapter 3). On the other hand, BSF larval weight is also influenced by frequency of adding food (Banks et al., 2014). For instance, we found that adding food once at the beginning of the experiment led to an increase in larval weight (Chapter 3).

\section{Food quality}

Nutritional studies on BSF have addressed the effects of diets on BSF development and adult life-history traits focussing on oligidic or natural diets containing many undefined components such as organic waste or industrial by-products (Chapter 2). Based on these studies, it has been established that food quality is one of the most important factors that affect BSF growth rates. High food quality correlates positively with survival rate and negatively with duration of the larval phase (Newton et al., 2005; Gobbi et al., 2013), protein level being a limiting factor. Oonincx et al. (2015a) used vegetable by-products and observed that larvae fed a diet high in both protein and fat, displayed a shorter development time than larvae fed low-protein diets. High protein and fat diets also appear to increase BSF larval weight and size (Nguyen et al., 2013; Nguyen et al., 2015; Oonincx et al., 2015a). However there is an optimum relationship between dietary protein content and performance in BSF, as I report in Chapter 6. 
On the other hand, BSF larval body nutrient content varies among substrates, mainly in macronutrient content (Barragan-Fonseca et al., 2017) and to a lesser extent in micronutrient content (Tschirner \& Simon, 2015; Spranghers et al., 2016; Barragan-Fonseca et al., 2017). Although BSF larvae on average contain both a high protein and fat content (Zheng et al., 2012), body composition of the larvae also depends on the quality and quantity of ingested food (Nguyen et al., 2015, Oonincx et al., 2015b). Consequently larvae fed on different substrates varied in body protein content (ranging from 37.0 to $62.7 \% \mathrm{DM}$ ) and fat content, which showed more variation (ranging from 6.6 to $39.2 \%$ DM) than protein content (Barragan-Fonseca et al., 2017). In the experiments throughout this project larval protein content is high and largely independent of dietary protein content, although there are small differences. However, larval crude fat varies depending on dietary macronutrient content, protein content affecting to a large extent larval crude fat content.

In Chapter 5, I examined how vegetable by-products from the food industry that were formulated to obtain an average macronutrient content in terms of digestible protein and carbohydrates, and a C-biased P:C ratio influenced larval immature life-history traits of BSF. Compared with other studies on vegetable organic waste as feed, our study yielded a better performance in terms of survival rate, developmental time, and larval yield (Gamboa Rojas, 2008; Myers et al., 2008; Gobbi et al., 2013; Nguyen et al., 2013; Tschirner \& Simon, 2015). Compared with diets based on chicken/hen feed, larvae fed vegetable organic waste diets tend to have poorer performance. However, in our experiments a diet based on dried distiller's grains with solubles, cabbage leaves, and old bread gave results comparable to chicken/hen feed diets.

I conclude that carbohydrate-biased organic waste positively affects BSF performance. Nutritional value varies depending on the plant species and organ, even if they have a similar proportion of proteins and/or carbohydrates and these differences might explain performance differences. In terms of protein nutritional quality, a significant difference between seed protein and leaf protein has been demonstrated (Edelman \& Colt, 2016). Regarding carbohydrates, different carbohydrate sources on BSF larvae can produce differences in larval performance, a mix of carbohydrates resulting in the highest larval biomass (Gamboa Rojas, 2008). Regarding larval body content, we also found that larval crude protein was not different between tested diets, but crude fat content was significantly higher in larvae reared on high P-diet. Thus, higher dietary protein did not affect larval protein content, but did increase larval fat content, confirming the findings of Chapter 3.

\section{Protein and carbohydrates: their role in the nutrition of BSF}

Throughout this chapter, we have seen that food protein and carbohydrate quantity and quality affect larval and adult performance in BSF. Therefore, we wanted to analyse how 
the balance of macronutrients ingested affected performance and body nutrient content as this is important information to ensure dependable yields of BSF-mass rearing and high larval quality. We used the Geometric Framework (GF) developed by Simpson and Raubenheimer (1993) to study nutrient regulation in BSF. Since proteins (P) and carbohydrates $(\mathrm{C})$ are the most important nutrients for insect survival, growth and reproduction (Aguila et al., 2013), I used them as starting points to investigate the regulatory tradeoffs in macronutrient intake in BSF (Simpson \& Raubenheimer, 1993; Raubenheimer \& Simpson, 1999).

The saprophagous BSF exploits diverse diets, so larval stages are likely to encounter a wide range of dietary macronutrients contents and ratios. When analysing food sources on which this species is found in the wild, $\mathrm{P}: \mathrm{C}$ ratios tend to be $\mathrm{C}$-biased and present a wide range of $\mathrm{P}$ and digestible $\mathrm{C}$-contents $(\mathrm{P}+\mathrm{C} 40-80 \% \mathrm{DM})$. Several studies addressed the effects of (semi-)artificial diets and of different types of organic waste or industrial by-products on BSF development and adult life-history traits (Barragan-Fonseca et al., 2017), however, few of them explored the effect of both $\mathrm{P}$ and $\mathrm{C}$.

Thus, in Chapter $4 \mathrm{I}$ explored the influence of a range of chicken-feed-based diets with varying $\mathrm{P}: \mathrm{C}$ ratios and content close to its natural food sources on BSF performance, and larval body nutrient content. The data suggest that BSF performance was affected by $\mathrm{P}+\mathrm{C}$ contents rather than by $\mathrm{P}: \mathrm{C}$ ratio. Moreover, dietary $\mathrm{P}+\mathrm{C}$ contents during the larval phase significantly affected larval and adult performance, with P-content having a main effect. High $\mathrm{P}+\mathrm{C}$ contents resulted in high larval weights, large adults and higher egg production as has been recorded in other Diptera as well (Boggs \& Freeman, 2005). There was an optimum $\mathrm{P}: \mathrm{C}$ ratio $(1: 2-1: 3)$ and $\mathrm{P}+\mathrm{C}$ content $(70 \%)$ for chicken-feed based diets since these values supported the best larval and adult performance.

In Chapter 6, I investigated wider ranges of $\mathrm{P}$ and C-content in addition to $\mathrm{P}$ and C-biased ratios to explore the effect of nutritionally unbalanced diets on BSF fitness and the physiological mechanism this species uses to deal with such diets. Insects have pre-ingestive and post-ingestive mechanisms to compensate for an unbalanced diet (Raubenheimer \& Simpson, 1997; Zudaire et al., 1998; Raubenheimer \& Simpson, 2003; Behmer, 2009). My experiments were not suitable to investigate pre-ingestive mechanisms; however, we established that BSF has efficient post-ingestive mechanisms that probably evolved because adult females lay their eggs on patchy resources and early instar larvae are constrained to this specific resource.

We observed that BSF can tolerate a wide range of $\mathrm{P}$ and $\mathrm{C}$-contents, use protein as energy source on high P-content diets, and efficiently use low P-content diets. However, in the case of $\mathrm{P}$-content, there is a threshold, where $>37 \% \mathrm{P}$ seems to be toxic and reduces 
survival rate and adult emergence percentage. In the case of C-content, BSF larvae are able to use post-ingestive physiological mechanisms when carbohydrates are in excess as they performed well on high C-content diets (40-60\%), and we did not observe deleterious effects on these. We assume that BSF larvae can handle an excess of carbohydrates, either by respiring carbohydrates or by converting them into lipids and storing them, mainly in the fat body as has been reported for many insect species (Zanotto et al., 1993; Zanotto et al., 1997; Simpson \& Raubenheimer, 2001; Behmer \& Joern, 2012; Telang et al., 2003). In general BSF performance was improved at high $\mathrm{P}+\mathrm{C}$ content at low $\mathrm{P}: \mathrm{C}$ ratios. BSF might have a low requirement for $\mathrm{P}$, as endosymbiotic bacteria may contribute to nitrogen metabolism (Raubenheimer \& Simpson, 1997).

BSF moves the intake target and requirements depending on developmental time. For example, in Chapter 6 I observed that for larval performance (development time and survival rate) P-content had a stronger effect than C-content. Yet, for adult performance (egg mass number, egg yield, longevity, and weight) $\mathrm{C}$-content had a stronger effect than protein. However, adult as well as larval development is more affected by $\mathrm{P}$-content than by $\mathrm{C}$-content. Although BSF performance was affected by $\mathrm{P}+\mathrm{C}$ absolute content rather than by $\mathrm{P}: \mathrm{C}$ ratio, BSF performance can be reduced or enhanced as $\mathrm{P}: \mathrm{C}$ ratio change at low $\mathrm{P}+\mathrm{C}$ content. For example, high $\mathrm{P}$-content accelerates development time (larval and adult) at low $\mathrm{P}+\mathrm{C}$ content, probably because this species efficiently uses dietary protein. In the case of adult weight and egg production, high P:C ratio improved the performance at low $\mathrm{P}+\mathrm{C}$ content. Figure 2 presents a graphical overview of $\mathrm{P}$ - and $\mathrm{C}$-content effects on BSF performance and larval content. 


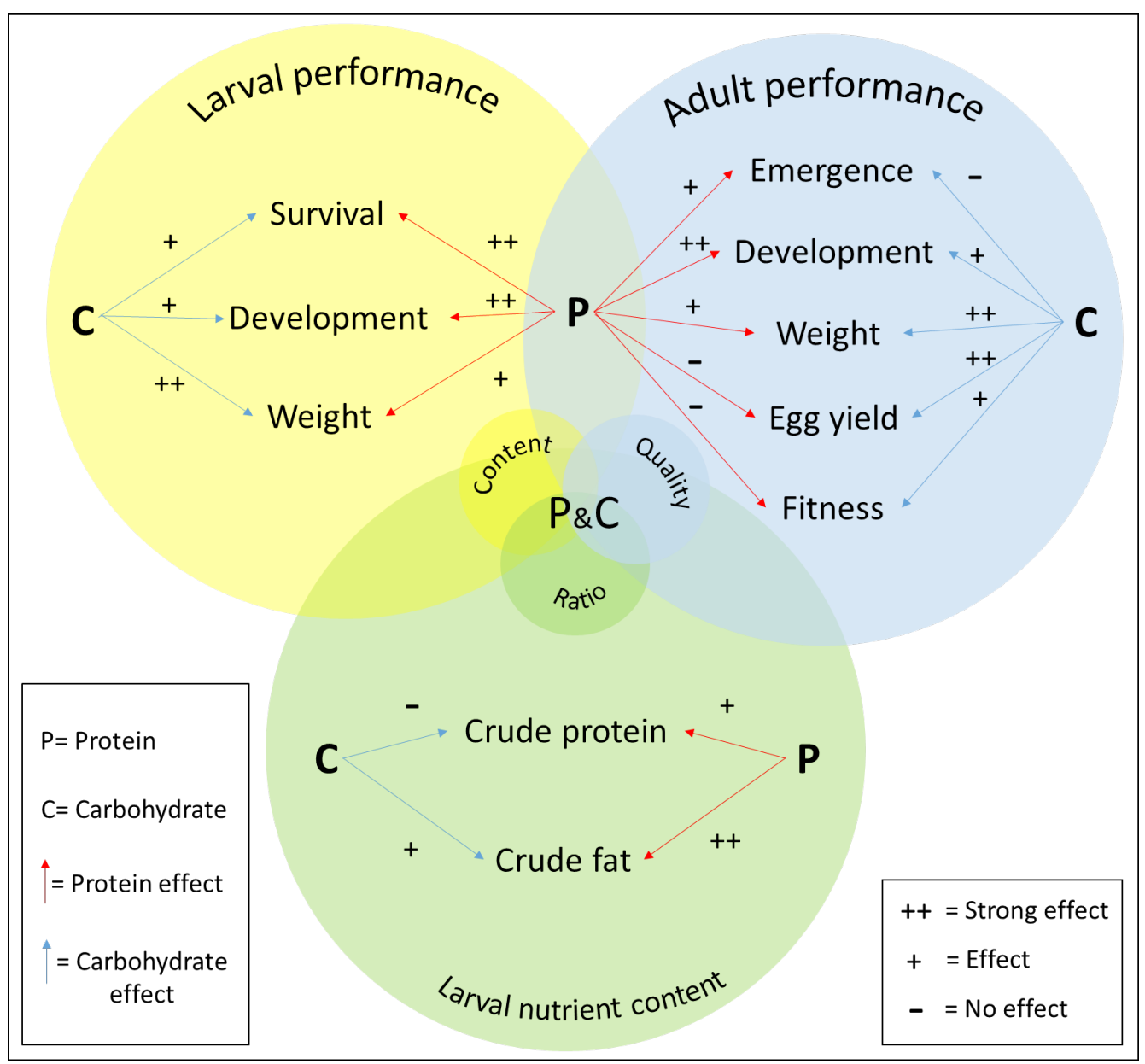

Figure 2. Effect of P- and C-content on BSF larval performance, adult performance and larval nutrient content.

\section{Optimizing BSF nutrition: the way forward}

Intake targets and requirements can vary depending on three time scales according to Raubenheimer and Simpson (1997): 1. physiological time in response to an animal's environment and recent nutritional and ecological history; 2. developmental time as the animal grows, reproduces, senesces and responds to its longer term nutritional history, and 3. evolutionary time as animals are selected (either naturally or artificially) to utilize different sources of nutriment and evolve differing life-history strategies. Taking into account that these three scales can affect nutritional requirements of BSF, these become even more important for BSF mass rearing that has several purposes: more dependable yields, high efficiency of bioconversion of organic waste to insect biomass, high quality of larval nutrient content, and stable colony health. 
In the case of the first time scale, several studies mentioned before show that environmental conditions have a big impact on BSF performance. In the case of the second time scale, we observed different performance among the different $\mathrm{P}+\mathrm{C}$ and $\mathrm{P}: \mathrm{C}$ diets according to the BSF developmental stage. In the third time scale, it seems there is variation among BSF populations as flies from different laboratories around the world are potentially different (Tomberlin \& Cammack, 2017) and specimens reared under laboratory conditions have reduced size, weight, longevity, and caloric content in comparison to specimens collected directly from the wild (Tomberlin et al., 2002; K.B. Barragan-Fonseca, personal observation).

Knowing that BSF nutritional requirements vary depending on the three time scales, we need to study them to find the optimum performance according to our objectives. For the physiological time scale there are already many studies that address abiotic environmental factors and the current BSF production systems use optimal abiotic conditions as reported in the literature for rearing BSF (Tomberlin \& Cammack, 2017). In future studies, we should focus on: 1 . How to increase biomass, bioconversion and population growth through organic-waste-derived diets, and 2. How to select BSF for a mass-rearing that has a high food utilization efficiency and growth performance. The ability of BSF to use a variety of organic resources together with the information on the effects of dietary protein and carbohydrate content and ratios on larval and adult performance may point the way forward.

Optimizing BSF nutrition still needs a lot of research. Applied studies are needed and experiments on organic waste- and/or agri-food by-products-derived diets will contribute to understanding BSF nutrition. Diet is the main factor affecting sustainability of BSF as minilivestock, as LCA evaluations show this production system is especially sustainable when it uses organic waste as rearing substrate. Therefore, selecting organic waste-derived ingredients of sufficient nutritional quality and having low environmental impact, is the first step to plan new experiments where we can explore how quality of $\mathrm{P}$ (amino acid profiles) and $\mathrm{C}, \mathrm{P}+\mathrm{C}$ contents and $\mathrm{P}: \mathrm{C}$ ratios affect BSF life-history traits, fitness and larval nutrient content to make BSF production systems more sustainable not only environmentally, but also economically.

\section{Formulating organic waste-derived mixed diets for BSF as minilivestock}

Based on my experiments advice can be derived to improve BSF larval performance, adult performance and larval content, regarding dietary protein and carbohydrate content. As generalist species, BSF can tolerate a wide range of sources because of post-ingestive adaptations to deal with different $\mathrm{P}$ - and $\mathrm{C}$-contents. However, we observed that this species performs better on diets of certain P-and C-contents and P:C ratios. This knowledge can be used to formulate organic waste-derived diets depending on its development time and/ or the purpose of the BSF as minilivestock. 
In general, from the experiments on organic waste-derived mixes, semi- and artificial diets on BSF performance, as described in this thesis, it can be concluded that quality, quantity and ratio are important for BSF performance. On the one hand, in Chapter 5 we observed that despite having the same $\mathrm{P}+\mathrm{C}$-content and $\mathrm{P}: \mathrm{C}$ ratio, protein and carbohydrate quality play an important role as some ingredients had a better effect on BSF larval performance probably due to amino acid and carbohydrate profiles. On the other hand, quantity and ratio can greatly affect BSF performance and larval content. In Chapters 4, 5 and 6 we observed the same trend: carbohydrate-biased P:C ratios positively affect BSF performance, independent from diet type. In addition, the optimum $\mathrm{P}$ - and $\mathrm{C}$-contents, $\mathrm{P}+\mathrm{C}$ contents and $\mathrm{P}: \mathrm{C}$ ratios for larval performance, e.g. biomass, adult performance, in particular fitness, or larval content (crude protein and fat) differ. Figure 3 presents a graphical overview of $\mathrm{P}+\mathrm{C}$ contents and $\mathrm{P}: \mathrm{C}$ ratios that improved BSF performance and larval nutrient content in our study, and some remarks to formulate a diet for BSF.

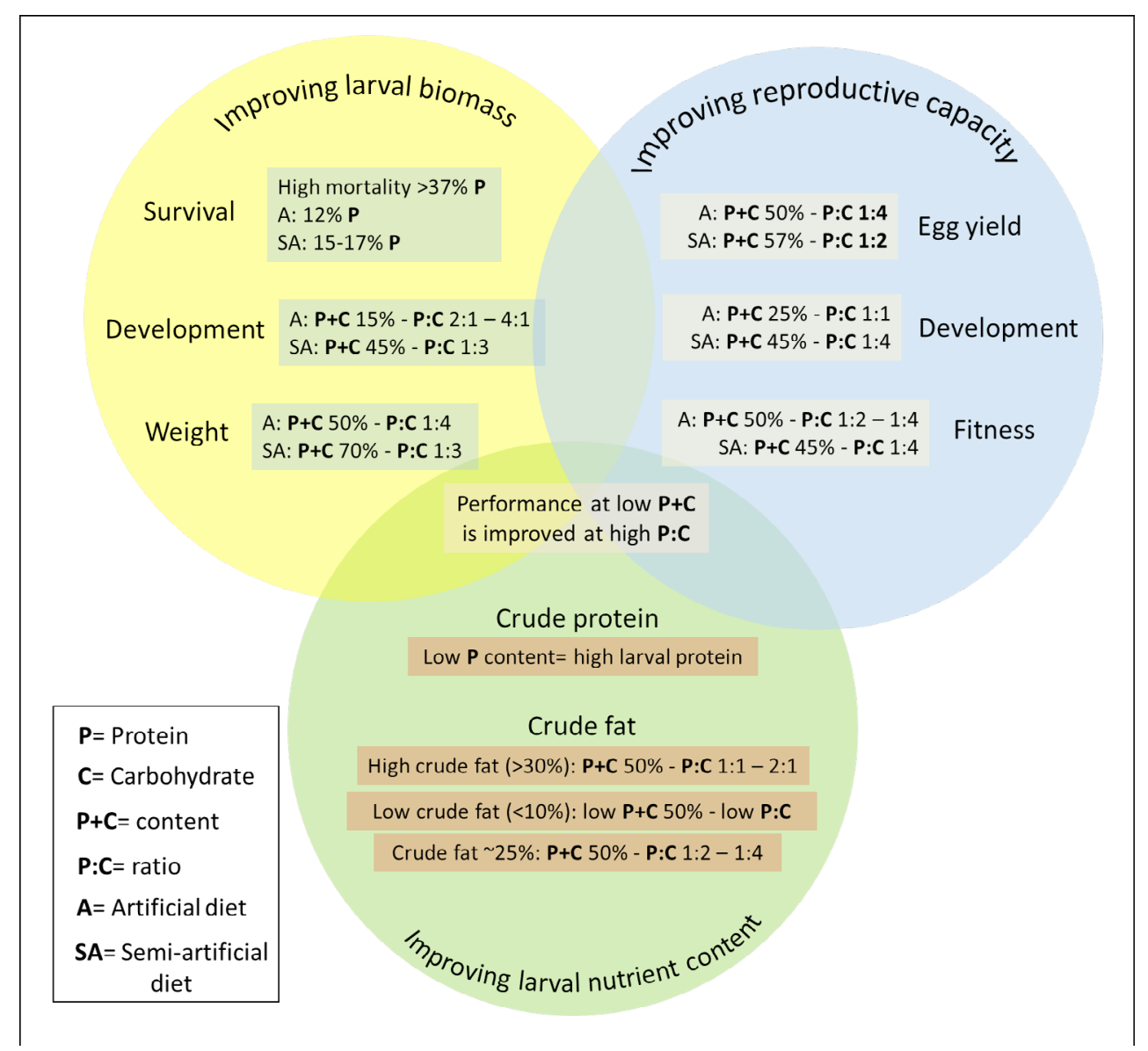

Figure 3. $\mathrm{P}+\mathrm{C}$ contents and $\mathrm{P}: \mathrm{C}$ ratios that improved $\mathrm{BSF}$ performance and larval nutrient content in our study, and some remarks to formulate a diet for BSF. 
In conclusion, this thesis provides insight into nutritional aspects of BSF production, both at the level of larval performance as well as adult performance. This knowledge can be used to develop mass rearings of this insect species that has rapidly become the major species to be used as a component of feed for livestock.

\section{Acknowledgements}

I thank Marcel Dicke and Joop J.A. van Loon for constructive comments on this chapter.

\section{References}

Aguila JR, Hoshizaki DK, Gibbs AG (2013) Contribution of larval nutrition to adult reproduction in Drosophila melanogaster. Journal of Experimental Biology, 216, 399-406.

Alvarez L (2012) The role of black soldier fly, Hermetia illucens (L.) (Diptera: Stratiomyidae) in sustainable waste management in northern climates. Electronic Theses and Dissertations. University of Windsor, Ontario, Canada.

Baldal E, Van Der Linde K, Van Alphen J, Brakefield P, Zwaan B (2005) The effects of larval density on adult life-history traits in three species of Drosophila. Mechanisms of Ageing and Development, 126, 407-416.

Banks IJ, Gibson WT, Cameron MM (2014) Growth rates of black soldier fly larvae fed on fresh human faeces and their implication for improving sanitation. Tropical Medicine \& International Health, 19, $14-22$.

Barragan-Fonseca KB, Dicke M, Van Loon JJA (2017) Nutritional value of the black soldier fly (Hermetia illucens L.) and its suitability as animal feed - a review. Journal of Insects as Food and Feed, 3, 105-120.

Behmer ST (2009) Insect herbivore nutrient regulation. Annual Review of Entomology, 54, 165-187.

Behmer ST, Joern A (2012) Insect herbivore outbreaks viewed through a physiological framework: insights from Orthoptera, Blackwell Publishing Ltd, Oxford, UK.

Boggs CL, Freeman KD (2005) Larval food limitation in butterflies: effects on adult resource allocation and fitness. Oecologia, 144, 353-361.

Bosch G, Zhang S, Oonincx DG, Hendriks WH (2014) Protein quality of insects as potential ingredients for dog and cat foods. Journal of Nutritional Science, 3, e29.

Diener S, Zurbrügg C, Tockner K (2009) Conversion of organic material by black soldier fly larvae: establishing optimal feeding rates. Waste Management \& Research, 27, 603-610.

Edelman M, Colt M (2016) Nutrient value of leaf vs. seed. Frontiers in Chemistry, 4, 1-5.

Furman DP, Young RD, Catts PE (1959) Hermetia illucens (Linnaeus) as a factor in the natural control of Musca domestica Linnaeus. Journal of Economic Entomology, 52, 917-921.

Gamboa Rojas EM (2008) Degradación de residuos de almidón y carnicos, mediante la producción de la larva soldada negra (Hermetia illucens L.). Ingeniería Ambiental y Sanitaria. Universidad de la Salle, Colombia.

Gobbi P, Martínez-Sánchez A, Rojo S (2013) The effects of larval diet on adult life-history traits of the black soldier fly, Hermetia illucens (Diptera: Stratiomyidae). European Journal of Entomology, 110, 461-468.

Godfray HCJ, Beddington JR, Crute IR, Haddad L, Lawrence D, Muir JF, et al. (2010) Food security: the challenge of feeding 9 billion people. Science, 327, 812-818.

Green PW, Simmonds MS, Blaney WM (2002) Does the size of larval groups influence the effect of metabolic inhibitors on the development of Phormia regina (Diptera: Calliphoridae) larvae? European Journal of Entomology, 99, 19-22. 
Gujarathi G, Pejaver M (2013) Occurrence of black soldier fly Hermetia illucens (Diptera: Stratiomyidae) in biocompost. Research Journal of Recent Sciences, 2, 65-66.

Holmes L, Vanlaerhoven S, Tomberlin J (2016) Lower temperature threshold of black soldier fly (Diptera: Stratiomyidae) development. Journal of Insects as Food and Feed, 2, 255 - 262.

Holmes LA, Vanlaerhoven SL, Tomberlin JK (2012) Relative humidity effects on the life history of Hermetia illucens (Diptera: Stratiomyidae). Environmental Entomology, 41, 971-978.

Jannat KNE, Roitberg BD (2013) Effects of larval density and feeding rates on larval life history traits in Anopheles gambiae ss (Diptera: Culicidae). Journal of Vector Ecology, 38, 120-126.

Li Q, Zheng L, Cai H, Garza E, Yu Z, Zhou S (2011a) From organic waste to biodiesel: Black soldier fly, Hermetia illucens, makes it feasible. Fuel, 90, 1545-1548.

Li Q, Zheng L, Qiu N, Cai H, Tomberlin JK, Yu Z (2011b) Bioconversion of dairy manure by black soldier fly (Diptera: Stratiomyidae) for biodiesel and sugar production. Waste Management, 31, 1316-1320.

Liu Q, Tomberlin JK, Brady JA, Sanford MR, Yu Z (2008) Black soldier fly (Diptera: Stratiomyidae) larvae reduce Escherichia coli in dairy manure. Environmental Entomology, 37, 1525-1530.

Martínez-Sánchez A, Magaña C, Saloña M, Rojo S (2011) First record of Hermetia illucens (Diptera: Stratiomyidae) on human corpses in Iberian Peninsula. Forensic Science International, 206, e76-e78.

May B (1961) The occurrence in New Zealand and the life-history of the soldier fly Hermetia illucens (L.) (Diptera: Stratiomyidae). The New Zealand Journal of Science and Technology, 4, 55-65.

Myers HM, Tomberlin JK, Lambert BD, Kattes D (2008) Development of black soldier fly (Diptera: Stratiomyidae) larvae fed dairy manure. Environmental Entomology, 59, 77-88.

Newton L, Sheppard C, Watson DW, Burtle G (2005) Using the black soldier fly, Hermetia illucens, as a value-added tool for the management of swine manure Smithfield Foods, and Premium Standard Farms, and Frontline Farmers. North Carolina State University, USA.

Nguyen TT, Tomberlin JK, Vanlaerhoven S (2013) Influence of resources on Hermetia illucens (Diptera: Stratiomyidae) larval development. Journal of Medical Entomology, 50, 898-906.

Nguyen TT, Tomberlin JK, Vanlaerhoven S (2015) Ability of black soldier fly (Diptera: Stratiomyidae) larvae to recycle food waste. Environmental Entomology, 44, 406-410.

Oonincx D, Van Broekhoven S, Van Huis A, Van Loon JJA (2015a) Feed conversion, survival and development, and composition of four insect species on diets composed of food by-products. PLOS ONE, 10, $\mathrm{e} 0144601$.

Oonincx D, Van Huis A, Van Loon JJA (2015b) Nutrient utilisation by black soldier flies fed with chicken, pig, or cow manure. Journal of Insects as Food and Feed, 1, 131-139.

Parra Paz AS, Carrejo NS, Gómez Rodríguez CH (2015) Effects of larval density and feeding rates on the bioconversion of vegetable waste using black soldier fly larvae Hermetia illucens (L.), (Diptera: Stratiomyidae). Waste and Biomass Valorization, 6, 1059-1065.

Raubenheimer D, Simpson SJ (1997) Integrative models of nutrient balancing: application to insects and vertebrates. Nutrition Research Reviews, 10, 151-179.

Raubenheimer D, Simpson SJ (1999) Integrating nutrition: A geometrical approach. Entomologia Experimentalis et Applicata, 91, 67-82.

Raubenheimer D, Simpson SJ (2003) Nutrient balancing in grasshoppers: Behavioural and physiological correlates of dietary breadth. Journal of Experimental Biology, 206, 1669-1681.

Rivers DB, Dahlem GA (2013) The Science of Forensic Entomology, Wiley-Blackwell, Chichester, UK.

Salomone R, Saija G, Mondello G, Giannetto A, Fasulo S, Savastano D (2017) Environmental impact of food waste bioconversion by insects: application of life cycle assessment to process using Hermetia illucens. Journal of Cleaner Production, 140, 890-905.

Simpson S, Raubenheimer D (1993) A multi-level analysis of feeding behaviour: the geometry of nutritional decisions. Philosophical Transactions of The Royal Society of London: Biological Sciences, 342, 381-402.

Simpson SJ, Raubenheimer D (2001) The geometric analysis of nutrient - Allelochemical interactions: A case study using locusts. Ecology, 82, 422-439.

Smetana S, Palanisamy M, Mathys A, Heinz V (2016) Sustainability of insect use for feed and food: life cycle assessment perspective. Journal of Cleaner Production, 137, 741-751. 
Spranghers T, Ottoboni M, Klootwijk C, Ovyn A, Deboosere S, De Meulenaer B, et al. (2016) Nutritional composition of black soldier fly (Hermetia illucens) prepupae reared on different organic waste substrates. Journal of the Science of Food and Agriculture, 97, 2594-2600.

St-Hilaire S, Sheppard C, Tomberlin JK, Irving S, Newton L, Mcguire MA, et al. (2007) Fly prepupae as a feedstuff for rainbow trout, Oncorhynchus mykiss. Journal of the World Aquaculture Society, 38, 59-67.

Surendra K, Olivier R, Tomberlin JK, Jha R, Khanal SK (2016) Bioconversion of organic wastes into biodiesel and animal feed via insect farming. Renewable Energy, 98, 197-202.

Telang A, Buck NA, Chapman RF, Wheeler DE (2003) Sexual differences in postingestive processing of dietary protein and carbohydrate in caterpillars of two species. Physiological and Biochemical Zoology, 76, 247-255.

Tomberlin JK, Cammack JA (2017) Black soldier fly: biology and mass production. In: Van Huis A, Tomberlin JK (eds.) Insects as food and feed - From production to consumption. Wageningen Academic Publishers, The Netherlands.

Tomberlin JK, Sheppard DC, Joyce JA (2002) Selected life-history traits of black soldier flies (Diptera: Stratiomyidae) reared on three artificial diets. Annals of the Entomological Society of America 95, 379-386.

Tschirner M, Simon A (2015) Influence of different growing substrates and processing on the nutrient composition of black soldier fly larvae destined for animal feed. Journal of Insects as Food and Feed, $\mathbf{1}$, 249-259.

Van Huis A (2013) Potential of insects as food and feed in assuring food security. Annual Review of Entomology, 58, 563-583.

Veldkamp T, Van Duinkerken G, Van Huis A, Lakemond CMM, Ottevanger E, Van Boekel MAJS (2012) Insects as a sustainable feed ingredient in pig and poultry diets - a feasibility study, Wageningen UR Livestock Research, Report 638, The Netherlands.

Yoshioka M, Couret J, Kim F, Mcmillan J, Burkot TR, Dotson EM, et al. (2012) Diet and density dependent competition affect larval performance and oviposition site selection in the mosquito species Aedes albopictus (Diptera: Culicidae). Parasites \& Vectors 5, 225.

Zanotto F, Simpson S, Raubenheimer D (1993) The regulation of growth by locusts through post-ingestive compensation for variation in the levels of dietary protein and carbohydrate. Physiological Entomology, 18, 425-434.

Zanotto FP, Gouveia SM, Simpson SJ, Raubenheimer D, Calder PC (1997) Nutritional homeostasis in locusts: Is there a mechanism for increased energy expenditure during carbohydrate overfeeding?. Journal of Experimental Biology, 200, 2437-2448.

Zheng L, Hou Y, Li W, Yang S, Li Q, Yu Z (2012) Biodiesel production from rice straw and restaurant waste employing black soldier fly assisted by microbes. Energy, 47, 225-229.

Zudaire E, Simpson SJ, Montuenga LM (1998) Effects of food nutrient content, insect age and stage in the feeding cycle on the FMRFamide immunoreactivity of diffuse endocrine cells in the locust gut. Journal of Experimental Biology, 201, 2971-2979. 
Acknowledgements 

I must confess that when I decided to do a PhD in The Netherlands I was very scared. Moving out from your comfort zone is not easy when you have a nice job position, little children, and don't speak the new language very well. However, when I decided to jump into this completely new experience, I never thought it would be one of the most wonderful experiences of my life. But why did I decide to do my $\mathrm{PhD}$ at Wageningen University? Well, it was a sunny day in Bogotá (Colombia) and I was talking with professor Germán Afanador (Animal Production Department - Universidad Nacional de Colombia) about the perspectives of insects as feed and food, and discussing some interesting papers. Two of these papers were written by Arnold van Huis and Dennis Oonincx, both from the Laboratory of Entomology at Wageningen University. At that time I was thinking doing my $\mathrm{PhD}$ in Brazil, but during that meeting professor Afanador suggested me to jump out my comfort zone by moving to a quite different country, and said: why don't you go to Wageningen University? So, I am here, thanks Germán, Arnold and Dennis for triggering my final decision! Arnold, thanks for being the first contact with Ento, for inspiring me to work on edible insects, and for your kindness and nice parties at your home with your lovely family. Dennis, thanks for being my first colleague in this field, our nice discussions about science and life, and your help with my English language.

I came to Wageningen on 1st April 2013 and had my first meeting at the Laboratory of Entomology. Finally, after hundreds of e-mails I met Arnold, Marcel and Joop in person. I think you can still remember my rudimentary English, as I can still feel your warm welcome. Since Arnold was about to retire, Joop and Marcel became my supervisors. Joop, you were my host in Wageningen that first week, and since the first day I could realize it would be a funny time with you as my supervisor. I must say I couldn't understand all the issues that we treated that time, but I can remember I laughed a lot, and I haven't stopped enjoying your jokes, stories and winks. Joop thank you so much for your time, wise advices and for helping me with every issue I had during my $\mathrm{PhD}$. Marcel, thanks for inspiring me, it is very clear why you are the "boss", your dedication and experience keep all the projects and people running forward; I cannot understand yet how you are so fast in replying with so many things you have to do. Joop and Marcel, thank you so much, it was a privilege to have you as supervisors.

There is something I realized when I talked with $\mathrm{PhD}$ students from other chair groups: the Laboratory of Entomology not only has a high scientific level, but also has the best team and atmosphere of all the chair groups in Wageningen. All the nice Ento-activities like YELREM, Labuitje, and others organized by the Party Committee make our PhD experience even better. You all are the Ento-family and I am very proud of being part of you. When finishing a $\mathrm{PhD}$ you are not the same person who you were when you started doing it. I am completely convinced that the most valuable result of a PhD is not knowledge itself, but personal growth which will allow the use of this knowledge in a wise way. 
The people, the experiences, the different and amazing cultures I had the opportunity to know during this journey made me the person I am now. With absolute certainty, The Netherlands and the Ento-family, became my second home!

There are so many people to thank that I don't know how to start! Well, I think my lovely paranymphs, Dani and Jeroen are a good beginning. Dani, my beautiful Brazilian friend, I met you the first day I visited Ento and since that day you have been my angel, thanks for all the advices, stories, chats, parties, dinners, and "secrets" we have shared. Jeroen, my guapo, I met you during my last $\mathrm{PhD}$ years, but our connection is so strong that I feel like if we've been friends for many years, even if we fight for toilet paper in our trips! $\odot$. Many thanks as well to my students, always willing and committed to the results: Lisa, Yue, Seppe and Julian, it was a pleasure to work with all of you. Keiko, many thanks for you lovely smiles and amazing Japanese dinners; Antonio, my Italian friend I enjoyed a lot our funny conversations about Hawaiian pizza and nice moments; Chantal, my first Dutch friend and hard worker, thanks for all our chats, dinners, and kizomba moves; Sandeep, my lovely Indian friend, I will miss our screams and games at the coffee corner, when I tried to catch you while the rest of the people were trying to focus on their work; Maite and Mile, my partners in crime, the last part of my $\mathrm{PhD}$ wouldn't have been so amazing without your jokes, happiness, company, funny moments, and our Latin parties, thanks for everything and always remember: "Contigo"; Kay and Lucille, thanks for all the delicious French food, smiles, chats, beers and wines, and of course: for your friendship; Gonzalo, my subtropical creature, it was a pleasure to share the last part of our $\mathrm{PhD}$, the music, parties and wines. Thibault, my sweet mountain man, always remember you freed "The maracas monster"!; Daan, thanks for "our Wednesdays", smiles and lovely chats; Tim, I really enjoyed our conversations and funny moments: "no drama, no life"; Yidong, thanks for your delicious Chinese candies and your smile all the time, you are a wonderful desk-mate; Helen, I really enjoyed dancing salsa with you and all our political discussions. A special thank you to the edible insect team: Stijn, Margot, Dennis, and Sarah, thanks for your help and nice discussions. Nurmi, Zanza, Cinzia, Ilka, Ana, Alexandre, Steve, John, Jitte, Yavanna, Quint, Cindy, Claudio, Shuhang, Peter, Julia, Jeltje, Tessa, Jessica, Emma, Tobias, Yehua, Foteini, Manus, Camille, Marjolein, Nelson, Enric, Jenny, Feng, Fran, Hans, Patrick, Peter, Rieta, Gerard, you are great ento-colleagues and, together with the rearing team: Frans, Léon, André, Pieter, make Ento a really nice place. Thanks Ento-Family, your good energy, kindness, hugs and smiles made me hyper-super-mega happy these PhD years. I would also like to apologize for all the screams and loud laughs in the coffee corner when it was not coffee break time. Anyway, I really think the "maracas tradition" should continue(-)!

I want to express my gratitude to Gerrit Gort, for his support and good energy. Thanks to Diana, Maite, Jose, Eurídice, Tijl, Inti, Christel, Martijn, Gerard, and Daniel for your 
friendship, the BBQs and for taking care of me during the hard times. Thanks to Rense, Floris and Daniele for making my life in The Netherlands even funnier. Bastiaan, thanks for the inspiring conversations, the support, the music and the hugs during the last part of my PhD. To la Universidad Nacional de Colombia, my home institution, thanks for granting me the possibility to do this $\mathrm{PhD}$. A mis colegas en la Universidad Nacional de Colombia por estar siempre apoyándome en este recorrido. A mis amigos en Colombia que pese a la distancia siempre están ahí: Luigui, Connie, Toño, Silvia, Eli, Astrid, Andrés, Lida, Claudia, Néstor, Oscar, gracias!. Fredy Julián, muchas gracias por el camino recorrido y el apoyo en parte de esta experiencia. Y no puede faltar mi maravillosa y amada familia: mi papito quién partió en este tiempo, pero que sembró en nosotros la semillita de perseguir los sueños sin importar qué tan difícil pudiera resultar, la empatía y la importancia de ponerse en los zapatos de los demás; mi mamita, una guía de amor que cuida y motiva, una guerrera que nos ha enseñado el arte de la lucha en la adversidad. Kari and Kathe, mis hermanitas, nada sería possible sin haber contado con su amor y apoyo en todo momento, sin sus consejos y sin la camaradería que siempre nos ha unido. Finalmente, quiero agradecer a mi lombriz y mi larva: Juliana y Juana, ellas son la luz en la oscuridad, la sonrisa en tiempos difíciles, el amor en su mas pura expresión.

Muchas gracias a todos, que la risa y los abrazos continúen! 

Summary 
Black Soldier Fly - BSF; Hermetia illucens L. (Diptera: Stratiomyidae) has been proposed as one of the most suitable insect species to be used as animal feed. Advantages of using BSF that have been identified are their capacity to convert organic waste, to reduce the numbers of certain harmful bacteria and insect pests, to provide potential chemical precursors to produce biodiesel, and to provide high quality protein to be used as feed for a variety of animals. Knowing the physiological mechanisms that BSF employs to deal with different nutrient concentrations, and their impacts on BSF life-history traits and larval body content, may yield helpful insights into the nutritional ecology of BSF. This knowledge will allow to increase body mass and/or size of individuals and consequently the continuous production of eggs needed for the mass-rearing. This will ensure more dependable yields of BSF-mass rearing and development of economically feasible methods to take advantage of this species as animal feed. Therefore, this thesis explores nutritional physiology of BSF, and addresses the following main questions: (1) How does larval density and nutrient concentration affect biomass production, larval performance and nutrient body content? (2) How do dietary protein and carbohydrate content and ratio affect life-history traits, nutrient body content and reproduction of BSF? (3) Can protein and carbohydrate contents and $\mathrm{P}: \mathrm{C}$ ratio be applied to optimize diets composed of different organic residues?

At the start of this project, we collected background information on the nutritional value of BSF larvae, its suitability as animal feed, biotic and abiotic conditions that affect its performance, and identified which knowledge is required to ensure more dependable yields of BSF-mass rearing and development of economically feasible methods to take advantage of this species as animal feed. In this literature review, it was identified that although BSF larvae contain high protein levels (from 37 to 63\% DM), and other macro- and micronutrients important for animal feed, the available studies on including BSF larvae in feed rations for poultry, pigs and fish suggest that it could only partially replace traditional feedstuff, because high or complete replacement resulted in reduced performance. This is due to factors such as high fat content (from 7 to $39 \%$ DM), ash (from 9 to $28 \%$ $\mathrm{DM}$ ), and consequences of processing. Therefore, further studies are needed on nutrient composition, digestibility and availability for target species and on improved methods to process larvae, among other aspects. Additionally, it was established that biotic and abiotic conditions affect BSF performance, food quality being one of the most important factors. However, studying the effect of food quality on BSF performance under the same biotic and abiotic conditions is needed to evaluate the effect of food quality as such, as well as its effect on the adult life-history traits of BSF.

Since performance and body composition of insect larvae depends on quality and quantity of their diet, and on biotic factors such as larval density, in Chapter 3, experiments were conducted on BSF to investigate the effect of dietary nutrient concentration and larval rearing density on larval survival, development, growth and larval protein and fat 
contents. Neonate larvae were fed with either a low (NC1), an intermediate (NC2) or a high nutrient concentration (NC3), at four rearing densities (50,100, 200 or 400 larvae per container). Two feeding regimes were tested: in feeding regime 1 (FR1), the amount of diet added during the experiment was based on the visually estimated larval mass present, whereas in feeding regime 2 (FR2), a fixed feeding ration of $0.6 \mathrm{~g}$ of food per larva was applied at the start. FR1 resulted in food limitation resulting in significantly lower body crude protein contents on diet NC1 than on NC2 at larval densities 100 and 200. Larval crude fat content was higher on diets with higher nutrient concentration and at lower larval densities. For FR2, development time was shorter on diets with higher nutrient concentration and at lower larval densities. Individual larval weight and total larval yield increased with higher nutrient concentration at all four larval densities. At lower nutrient concentrations, higher larval density resulted in higher individual larval weight and total larval yield, revealing an interaction between larval density and dietary quality. Larval crude protein content was higher at lower densities and lower nutrient concentration. Larval crude fat was higher at higher larval densities and nutrient concentrations. This study shows that larval protein content is regulated within narrow limits whereas larval crude fat content is strongly affected by nutrient concentration and also by larval density. Since nutrient content had an important effect on BSF larvae performance, in Chapters 4, 5 and 6, we explore physiological mechanisms that BSF employs to deal with different nutrient content, and their impacts on BSF life-history traits and larval body content.

In Chapter 4, we investigated the influence of dietary protein $(\mathrm{P})$ and digestible carbohydrate $(\mathrm{C})$ contents and protein to carbohydrate $(\mathrm{P}: \mathrm{C})$ ratio on both immature and adult life-history traits of BSF, and on larval body composition. Nine chicken-feed based diets varying in their $\mathrm{P}: \mathrm{C}$ ratio were formulated. We tested three protein concentrations $(10,17$, $24 \%)$ and three carbohydrate concentrations $(35,45,55 \%)$ and their combinations. All nine diets supported complete development and reproduction of BSF. Survival was high on all diets. Development time, larval yield, larval crude fat and egg clutch surface were more influenced by contents of macronutrients than by $\mathrm{P}: \mathrm{C}$ ratio. Low contents resulted in shorter development time. Larval yield was higher on diets with higher $\mathrm{C}$-contents. Pupal development was faster on low dietary P-content for all three C-contents. Egg clutch surface only increased when P-content increased but also varied with P:C ratio, and was found to be highest at P17:C55 (1:3) and P24:C35 (1:1.5). The highest egg clutch surface area, a proxy for egg number, was recorded on P17:C55, followed by the three P24-diets. Hatching percentage of F1-larvae was similar on all nine diets. Larval crude protein content was similar on all nine diets, but increased when C-content was low (10) in P10 and P17. Larval crude fat content was high at P24-diets irrespective of C-content. However, larval crude fat was higher when $\mathrm{C}$ increased at P10 and P17. We conclude that on the semi-artificial diets tested, BSF performance was not sensitive to dietary P:C ratio, but to carbohydrate and protein contents. High macronutrient content combined with a low P:C 
ratio positively affected BSF performance. The best diet was P17:C55 as it supported the highest larval and adult performance and resulted in high larval body protein content and an intermediate crude fat content, which are favourable from the perspective of quality of BSF as animal feed. However, studying a wider range of $\mathrm{P}+\mathrm{C}$ contents and $\mathrm{P}: \mathrm{C}$ ratios than reported thus far is warranted in order to identify effects on the performance and life history of BSF.

In Chapter 5, BSF larvae were fed on four diets consisting of vegetable by-products from the food industry. The diets were formulated based on an average summed protein and carbohydrate $(\mathrm{P}+\mathrm{C})$ concentration tested in the previous experiment (Chapter 4) and a 1:2 protein:carbohydrate $(\mathrm{P}: \mathrm{C})$ ratio. In a second experiment we took the ingredients from the best vegetable waste-based diet from the first experiment, and formulated diets having P:C ratios of $1: 2$ or 1:3 and 40 or $47 \% \mathrm{DM}$ of $\mathrm{P}+\mathrm{C}$ and we quantified both larval and adult performance. In the first experiment, although there were differences in larval performance among the diets, all diets supported a higher larval performance than reported previously, with the diet composed of cabbages leaves, old bread and dried distiller's grains with solubles (DDGS) $(47 \% \mathrm{P}+\mathrm{C})$ being the best diet. We infer that not only total macronutrient content but also nutritional quality of proteins and carbohydrates affected performance. In the second experiment, the two vegetable residue-based larval diets resulted in similar larval and adult performance. High dietary protein resulted in increases in larval crude fat content. Further research is needed to learn how different sources of protein and carbohydrates affect macronutrient intake and performance of BSF in terms of immature and adult life-history traits and larval body composition and how BSF regulates macronutrient intake.

In Chapter 6, we investigated the influence of P-and C-contents on both larval and adult life-history traits of BSF, and on larval body nutrient content. Twenty-five artificial diets varying in their $\mathrm{P}$ - and $\mathrm{C}$-content and ratio were formulated. We tested five macronutrient $(\mathrm{P}+\mathrm{C})$ concentrations $(5,15,25,50$ and $75 \%)$ and five $\mathrm{P}: \mathrm{C}$ ratios $(1: 1,1: 2,1: 4,2: 1$ and 4:1). BSF performance was affected by dietary content of carbohydrate and protein ( $\mathrm{P}+\mathrm{C}$-content) rather than by $\mathrm{P}: \mathrm{C}$ ratios. Since $\mathrm{BSF}$ tolerated a wide range of $\mathrm{P}$ - and $\mathrm{C}$-contents, we conclude that $\mathrm{BSF}$ has post-ingestive mechanisms to deal with imbalanced foods. A P-content between 10 and $15 \%$ and a C-content between 10 and 60\% supported high larval and adult performance. P-content is limiting for most of the performance variables and a P-content higher than 37\% was deleterious in terms of survival. C-content affected egg production more strongly than $\mathrm{P}$-content. In general, at $\mathrm{P}+\mathrm{C}$ values of 25 and 50\%, $1: 2$ and 1:4 ratios resulted in the highest values of most of the larval and adult performance variables we measured. Our results show that $\mathrm{P}$-content and C-content significantly affect adult performance, and high $\mathrm{P}+\mathrm{C}$-diets can increase adult weight and egg production. Follow-up experiments assessing the effects of other nutrient sources, e.g. vegetable organic 
waste or manure, are required to verify that the results we report here are also valid for sources that contain proteins and carbohydrates of different nutrient quality.

The data presented in this thesis contribute to our understanding of how nutrition affects life-history traits, nutrient body content and reproduction of BSF, mainly in terms of protein and carbohydrate content and ratio and how this knowledge can be applied to improve the productive performance and larval body composition in BSF production systems. I also emphasize that to ensure stable yields and high larval nutritional quality of BSF-mass rearing a better understanding is required of the complex interactions between quality and quantity of dietary nutrients. 

Résumé \& publications 


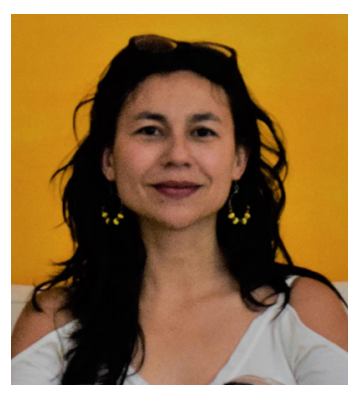

Karol B. Barragán-Fonseca was born and grew up in Bogotá, Colombia. Early on she developed a keen interest in animals, especially wild animals. In 2002 she got a bachelor degree in Veterinary Medicine and in 2005 a MSc degree in Biological Sciences: Wildlife Handling and Preservation; both degrees were obtained at the Universidad Nacional de Colombia. Karol has worked in situ and ex situ in wildlife teaching and research as well as in wildlife handling, conservation, production, and sustainable use programs, and has a background of interdisciplinary fieldwork, and wildlife consultancy for governmental institutions and non-governmental organizations. As director of the Edible Insects Production Unit (UN-Insectario) and Auxiliary Professor of wildlife management and conservation of the Universidad Nacional de Colombia (UNC), Karol developed a growing interest in insects as feed and food, as she is convinced that insects are high quality nutrient sources that can be produced with a low environmental impact thereby contributing to combat climate change, food crisis and rural poverty. For these reasons Karol came to Wageningen University in 2013 to work towards a PhD-degree in this field at the Laboratory of Entomology. You have the fruits of her research in your hands. 


\section{List of publications}

\section{In peer-reviewed journals}

Barragan-Fonseca KB, Dicke M, van Loon JJA (2017) Nutritional value of the Black Soldier Fly (Hermetia illucens L.) and its suitability as animal feed - a review. Journal of Insects as Food and Feed, 3: 105-120. (chapter 2 in this thesis)

Montoya V, Barragan-Fonseca KB (2011) Diagnóstico preliminar de la producción y comercialización del chigüiro (Hydrochoerus hydrochaeris) en Latinoamérica con énfasis en Colombia. Revista de la Facultad de Medicina Veterinaria y Zootecnia, 58: 20-33.

Barragan-Fonseca KB, Brieva C (2005) Tuberculosis y micobacteriosis en primates neotropicales: Un enfoque desde la conservación. Revista de la Facultad de Medicina Veterinaria y Zootecnia, 52: 128-143.

Barragan-Fonseca KB, Jiménez L, Sánchez C (2005) Estandarización del cultivo de linfocitos y técnicas de bandeo cromosómico para venado cola blanca (Odocoileus virginianus). Revista de la Facultad de Medicina Veterinaria y Zootecnia, 52: 44-55.

\section{In peer-reviewed books}

Álvarez O, Barragan-Fonseca KB (2014) Determinación de parámetros fisiológicos, hematológicos y de química sanguínea en chigüiros (Hydrochoerus hydrochaeris) en el departamento de Casanare. Pp. 185-195, in López-Arévalo HF, Sánchez-Palomino P, Montenegro OL (eds.). El chigüiro Hydrochoerus hydrochaeris en la Orinoquía colombiana: Ecología, manejo sostenible y conservación. Biblioteca José Jerónimo Triana No. 25. Instituto de Ciencias Naturales. Universidad Nacional de Colombia. 436 pp. Bogotá. ISBN: 978-958-761-922-5 (e-book).

Barragan-Fonseca KB, Álvarez O (2014) Estudios serológicos de Brucella abortus y Leptospira interrogans en poblaciones silvestres de chigüiros (Hydrochaeris hydrochaeris) en el departamento de Casanare. Pp. 197-209, in López-Arévalo HF, Sánchez-Palomino P, Montenegro OL (eds.). El chigüiro Hydrochoerus hydrochaeris en la Orinoquía colombiana: Ecología, manejo sostenible y conservación. Biblioteca José Jerónimo Triana No. 25. Instituto de Ciencias Naturales. Universidad Nacional de Colombia. 436 pp. Bogotá. ISBN: 978-958-761-922-5 (e-book).

Barragan-Fonseca KB, Álvarez O (2014) Estudios microbiológicos e histopatológicos en canales de chigüiros (Hydrochoerus hydrochaeris) en el departamento de Casanare. Pp. 211-223, in López-Arévalo HF, Sánchez-Palomino P, Montenegro OL (eds.). El chigüiro Hydrochoerus hydrochaeris en la Orinoquía colombiana: Ecología, manejo sostenible y 
conservación. Biblioteca José Jerónimo Triana No. 25. Instituto de Ciencias Naturales. Universidad Nacional de Colombia. 436 pp. Bogotá. ISBN: 978-958-761-922-5 (e-book).

Atuesta-Dimian N, Sarmiento C, Montenegro OL, Barragan-Fonseca KB (2014) Propuesta de reforzamiento de poblaciones afectadas por sobrecosecha en el municipio de Hato Corozal (Casanare). Pp. 257-271, in López-Arévalo HF, Sánchez-Palomino P, Montenegro OL (eds.). El chigüiro Hydrochoerus hydrochaeris en la Orinoquía colombiana: Ecología, manejo sostenible y conservación. Biblioteca José Jerónimo Triana No. 25. Instituto de Ciencias Naturales. Universidad Nacional de Colombia. 436 pp. Bogotá. ISBN: 978-958-761-922-5 (e-book).

Cristancho S, Barragan-Fonseca KB (2011) Análisis del sistema de aprovechamiento del gusano mojojoy (Rhynchophorus palmarum) (Coleoptera: Curculionidae) en el Municipio de Leticia - Amazonas, Colombia. Pp. 131-199, in Monroy R, García A, Pino J, Monroy-Ortiz R (eds.). Etnozoología: un enfoque binacional, México - Colombia. Universidad Autónoma del Estado de Morelos, Centro de Investigaciones Biológicas. 515 pp. Cuernavaca Morelos, México. ISBN: 978-607-7771-52-4.

\section{Submitted}

Barragan-Fonseca KB, Dicke M, van Loon JJA (2017). Influence of larval density and dietary nutrient concentration on performance, body protein and fat contents of Black Soldier Fly (Hermetia illucens L.). (chapter 3 in this thesis).

Barragan-Fonseca KB, Gort G, Dicke M, van Loon JJA (2017). Exploring the effect of dietary protein and carbohydrate on life-history traits and body protein and fat contents of the Black Soldier Fly (Hermetia illucens L.). (chapter 4 in this thesis).

Barragan-Fonseca KB, Pineda-Mejía J, Dicke M, van Loon JJA (2017). Performance of the Black Soldier Fly, Hermetia illucens L. (Diptera: Stratiomyidae) on vegetable residue-based diets formulated based on protein and carbohydrate contents. (chapter 5 in this thesis).

Barragan-Fonseca KB, Gort G, Dicke M, van Loon JJA (2017). Tipping the balance: effects of protein and carbohydrate contents on life-history traits and larval nutrient content of the Black Soldier Fly (Hermetia illucens L.). (chapter 6 in this thesis). 
Education statement 


\section{PE\&RC Training and Education statement}

With the training and education activities listed below the $\mathrm{PhD}$ candidate has complied with the requirements set by the C.T. de Wit Graduate School for Production Ecology and Resource Conservation (PE\&RC) which comprises of a minimum total of 32 ECTS (= 22 weeks of activities)

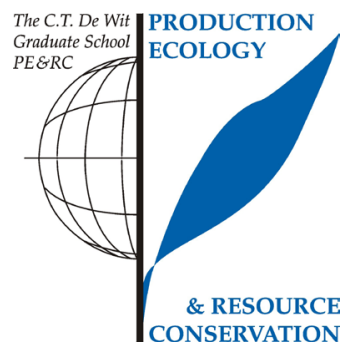

\section{Review of literature (6 ECTS)}

Nutritional value of the Black Soldier Fly (Hermetia illucens L.) and its suitability as animal feed

\section{Writing of project proposal (4.5 ECTS)}

- The potential of Black Soldier Fly as animal feed

\section{Post-graduate courses (3.6 ECTS)}

- $\quad$ Introduction to R for statistical analysis; PE\&RC (2014)

- $\quad$ Linear models; PE\&RC (2014)

- $\quad$ Mixed linear models; PE\&RC (2016)

- Writing proposal for project: Building a research partnership for the Comprehensive Rural Reform in a Post Conflict Colombia; SDC (SSG) $(2016,2017)$

\section{Deficiency, refresh, brush-up courses (2 ECTS)}

- $\quad$ Animal nutrition and physiology; Animal Nutrition Department (2015)

\section{Competence strengthening / skills courses (4.2 ECTS)}

- $\quad$ Techniques for writing and presenting a scientific paper; PE\&RC (2014)

- $\quad$ Scientific writing; Wageningen in'to Languages (2016)

- $\quad$ Writing grant proposals; Wageningen in'to Languages (2017)

PE\&RC Annual meetings, seminars and the PE\&RC weekend (2.1 ECTS)

PE\&RC Weekend (2013)

PE\&RC Day (2013-2016)

Discussion groups / local seminars / other scientific meetings (7.2 ECTS)

- $\quad$ Annual meeting of the Dutch Entomological Society (2013, 2014, 2016)

- Insect as food and feed meeting; chair group Food Quality and Design (2016- 2017)

Plant-Insect interactions meetings (2013-2018) 
- $\quad$ PhD Discussion meetings (2013-2018)

International symposia, workshops and conferences (7.6 ECTS)

- $\quad$ Insects to Feed the World; poster presentation; Ede, NL (2014)

- Annual meeting of the Dutch Entomological Society; oral presentation; Ede, NL (2016)

- Congreso 43 de la Asociación Colombiana de Entomología; oral presentation; Manizales, Colombia (2016)

- Alimentación Animal y Humana, un Reto de calidad desde la Producción”; oral presentation; oral presentation; Bogotá, Colombia (2017)

\section{Lecturing / Supervision of practicals / tutorials (1.2 ECTS)}

- $\quad$ Supervision study cases: insects as food and feed $(2015,2017)$

\section{Supervision of MSc students (9 ECTS)}

- Performance of Black Soldier Fly (Hermetia illucens) larvae fed organic waste diets based on a specific protein: digestible carbohydrate ratio

- Fitness of Black Soldier Fly feeding on organic waste of selected nutritional composition

- The influence of protein and carbohydrate inclusion levels in the diet of Black Soldier Fly larvae on growth and fecundity 
The research described in this thesis was financially supported by a grant from COLCIENCIAS - Departamento Administrativo de Ciencia, Tecnología e Innovación - Colombia.

Ilustrations by Mantícora

Cover design by the author

Layout by Antonio Márquez

Printed by GVO drukkers \& vormgevers, Ede, The Netherlands 


\section{Propositions}

1. The high degree of nutritional plasticity of the Black Soldier Fly makes it one of the most efficient insects for production of feed.

(this thesis)

2. Dietary manipulation can result in Black Soldier Fly larvae with high fat content while preserving protein content.

(this thesis)

3. Efforts to conserve endangered species should focus on creating protected areas that safeguard the future of the ecosystem in which they live rather than on conserving individual species.

4. Expanding investigations on non-pharmacological methods to raise brain serotonin would promote public health.

5. To achieve technological and societal advances in the Colombian countryside, challenges posed by the current post-conflict stage need to be taken into account.

6. Hugging is a simple, free and "super-hyper-mega" nice strategy to release stress during a $\mathrm{PhD}$.

Propositions belonging to the thesis, entitled:

"Flies are what they eat - Tailoring nutrition of Black Soldier Fly (Hermetia illucens L.) for larval biomass production and fitness".

Karol B. Barragán-Fonseca

Wageningen, 25 th of June 2018 